Stylistic Use of Phraseological Units in Discourse 



\section{Stylistic Use of Phraseological Units in Discourse}

Anita Naciscione

John Benjamins Publishing Company

Amsterdam/ Philadelphia 
The paper used in this publication meets the minimum requirements of American National Standard for Information Sciences - Permanence of Paper for Printed Library Materials, ANSI z39.48-1984.

\section{Library of Congress Cataloging-in-Publication Data}

Naciscione, Anita.

Stylistic use of phraseological units in discourse / Anita Naciscione.

p. cm.

Includes bibliographical references and index.

1. English language--Rhetoric. 2. English language--Style. 3. English language--Terms and phrases. 4. Discourse analysis. I. Title.

PE1442.N35 2010

$808^{\prime} .0014--\mathrm{dc} 22$

2010028218

ISBN 9789027211767 (HB; alk. paper)

ISBN 9789027287694 (ЕB)

(C) 2010 - John Benjamins B.V.

No part of this book may be reproduced in any form, by print, photoprint, microfilm, or any other means, without written permission from the publisher.

John Benjamins Publishing Co. P.O. Box 36224 1020 ME Amsterdam · The Netherlands John Benjamins North America · P.O. Box 27519 · Philadelphia PA 19118-0519 • USA 
To Judy, Reinis, \& Kārlis 



\section{Table of contents}

Acknowledgements $\quad$ XI

List of abbreviations $\quad$ XIII

Preface by Wolfgang Mieder $\quad 1$

Introduction $\quad 7$

Part I. Phraseological units in discourse

CHAPTER 1

Phraseology and cognitive stylistics

1.1 A discourse-based approach 15

1.2 The breakthrough of cognitive stylistics $\mathbf{1 6}$

1.3 The phraseological unit 17

1.4 Phraseology and stylistics 20

1.5 Attitudes to stylistic use of PUs 21

1.6 Stylistic use of PUs in dictionaries 24

CHAPTER 2

Identification of phraseological units in discourse

2.1 The phraseological unit and its base form $\quad 31$

2.2 Core use 35

2.3 The concept of instantial stylistic use $\quad 39$

2.4 Identification procedure 43

CHAPTER 3

Key concepts of instantial stylistic use in discourse

3.1 Stability of phraseological units in instantial use 57

3.2 Phraseological cohesion 60

3.2.1 Cohesion of the base form $\mathbf{6 1}$

3.2.2 Cohesion in discourse $\mathbf{6 2}$

3.2.2.1 Cohesion in core use $\mathbf{6 2}$

3.2.2.2 Cohesion in instantial stylistic use $\quad \mathbf{6 2}$ 
3.3 Patterns of instantial use: Continuity versus change 65

3.4 Discoursal character of instantial use: Sustainability of phraseological image 73

CHAPTER 4

The most common patterns of instantial stylistic use

4.1 Extended phraseological metaphor 79

4.2 Phraseological pun 91

4.3 Cleft use 102

4.4 Phraseological allusion 107

\section{CHAPTER 5}

Phraseological units in the web of discourse

5.1 Instantial aspects of phraseological reiteration in discourse $\mathbf{1 2 2}$

5.2 Instantial cumulative use: The potential of the diminutive in English phraseology $\quad 134$

5.2.1 Ways of expressing the diminutive in English phraseology 134

5.2.2 The diminutive in the semantic structure of phraseological units 138

5.2.3 Instantial use of the diminutive in English phraseology $\quad 140$

5.2.4 Cumulative use of the diminutive in Lewis Carroll's poem The Little Man that Had a Little Gun $\mathbf{1 4 2}$

5.3 Instantial concurrent use $\mathbf{1 4 5}$

5.4 Instantial phraseological saturation of discourse $\quad 151$

5.5 Comprehensive instantial use $\mathbf{1 6 2}$

5.5.1 Umbrella use: Use of phraseological units in titles and headlines

5.5.2 Use of phraseological units in codas 170

CHAPTER 6

Visual representation of phraseological image

6.1 Visual representation and phraseological units 175

6.2 Visual representation of instantial stylistic use $\mathbf{1 7 6}$

6.3 Visual representation in media discourse $\mathbf{1 8 1}$

6.4 Implicit visual messages $\mathbf{1 8 8}$

6.5 A discourse dimension 190

6.6 Visual literacy as a cognitive skill 197 
Part II. Towards applied stylistics

CHAPTER 7

Applied stylistics and instantial stylistic use

7.1 The rise of applied stylistics 205

7.2 Teaching and learning $\mathbf{2 0 8}$

7.2.1 A discourse-based approach to phraseology in teaching 209

7.2.2 Language skills, learning difficulties, and identification errors $\mathbf{2 2 0}$

7.3 Translation of phraseological units in discourse $\quad \mathbf{2 2 7}$

7.4 Lexicography, glossography, notes and comments $\mathbf{2 3 8}$

7.5 Advertising $\mathbf{2 4 5}$

Glossary 251

References

Appendixes

Index of phraseological units

Subject index 



\section{Acknowledgements}

I would like to thank John McRae and Ronald Carter for several valuable comments on and suggestions for terminology in English. I have been greatly influenced by their works; however, needless to say, the responsibility for theoretical conclusions and any faults is all mine. I am especially grateful to John McRae for his encouragement to pursue this project. I am also grateful to all linguists who gave constructive remarks, insights, and invaluable advice on the first edition of my book: Wolfgang Mieder, Pedro Chamizo-Dominguez, Raymond Gibbs, Gerard Steen, Tatiana Fedulenkova, Christopher Goddard.

It is my particular pleasure to convey my gratitude to the Latvian Academy of Culture for providing institutional support in my research.

Many thanks to my anonymous reviewers at John Benjamins for their insightful comments. Finally, special thanks due to Kees Vaes and the staff at John Benjamins Publishing Company for their support and expertise in the publication of this book.

Any book must draw on previously published ideas. I have tried to note due acknowledgements, at the same time trying not to interfere with the flow of the discussion in the interests of the reader who wants ideas, rather than a biographical survey. I will be happy to learn of, and apologise for, any omissions in this respect.

The author and publisher wish to thank:

1. Wright's Reprints for permission obtained from Time magazine to use the cover illustration "By a Thread" (Figure 6.16), Europe edition, 18 December, 1998.

2. NI syndication Ltd. for permission to use the photo of Queen Elisabeth II (Figure 6.7) and the cartoon "A New Pair of Shoes" (Figure 6.8).

The author and publisher are especially grateful to the following for permission to reproduce copyright material:

1. The Times for permission to use the illustration "A Black Eye" (Figure 6.14), published on 20 September, 2003, SL 4M. 
2. The Spectator for permission to use two figures: (1) The cover page of The Spectator (Figure 6.17), 10 January, 1998; (2) "Spinning out of Control" (Figure 6.18), The Spectator, 10 January, 1998, p. 8.

3. The Financial Times for permission to use the figure "The Art of Breaking a Sacrosanct Rule” (Figure 6.19), Financial Times, fm, 28 November, 2005, p. 3.

4. Petar Pismestrovic for permission to use his cartoon "A Black Sheep" (Figure 6.20), Kleine Zeitung, Austria, 20 June, 2008.

5. The painter Ivars Poikāns for permission to use his painting "A Pretty Kettle of Fish" (Appendix III) and his pen-and-ink drawing "To Let the Cat Out of the Bag" (Figure 6.1).

Every effort has been made to contact copyright holders of the works reproduced in this book. If any have inadvertently been overlooked they should contact the publisher who will be happy to remedy the situation. 


\section{List of abbreviations}

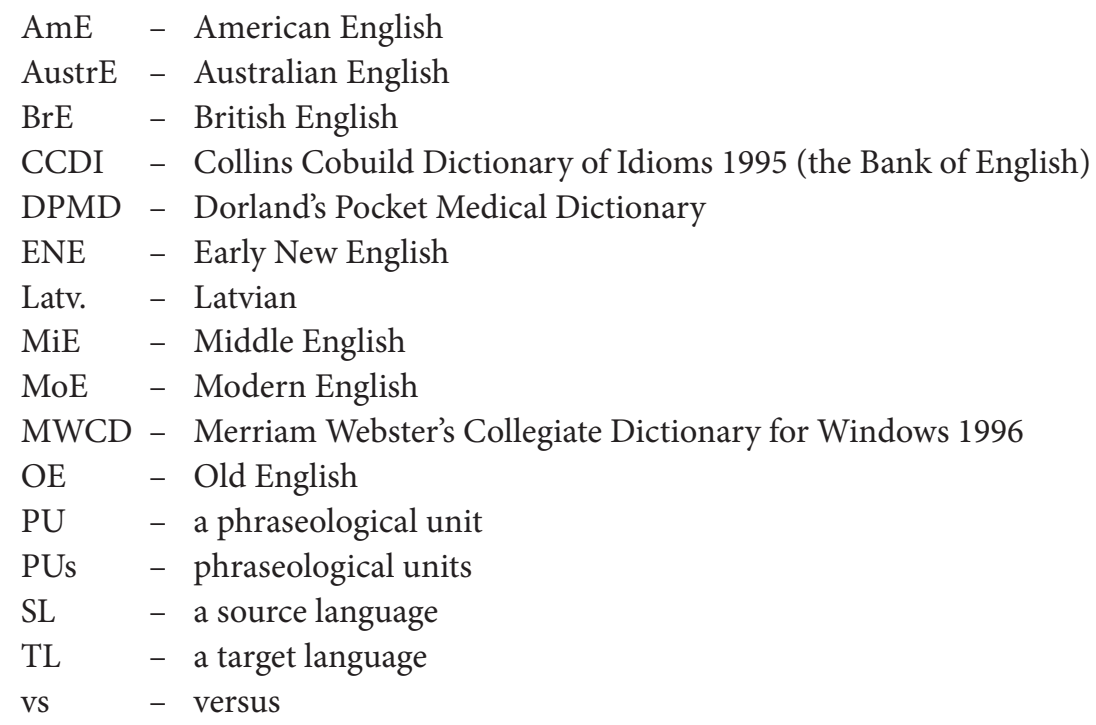





\section{Preface}

Actual texts show that phraseology is not a store of old fossils Anita Naciscione, Chapter 1

About ten years ago I had the good fortune to encounter Anita Naciscione's ground-breaking study Phraseological Units in Discourse: Towards Applied Stylistics (2001), and I remember well my scholarly excitement when I literally devoured page after page of this unique investigation into the stylistic aspects of phraseological units in actual discoursal contexts. Of course, much had been written by then about the multifaceted nature of phraseologisms, with the founding of the European Society of Phraseology in 1999. By now there exists a steady stream of publications on phraseology in the form of dissertations, bibliographies, monographs, handbooks, and articles, but it is fair to say that this plethora of studies has not really advanced the intriguing findings by Anita Naciscione in both their theoretical and applied aspects. Scholars and students of phraseology will and should therefore applaud Anita Naciscione's skilfully revised and extensively expanded new edition of her previous book with its new title Stylistic Use of Phraseological Units in Discourse (2011). It surveys and analyses recent scholarship and by adding various new sections and chapters goes far beyond the theoretical scope and the contextualised examples of the original volume. Written in clear, readable, and accessible English, it is thus a most welcome book that will without doubt be of major consequence in the future development of international phraseology. There is little jargon but rather precisely defined theoretical vocabulary, all important points are illustrated by appropriate textual examples, and the entire book is presented in a way that shows a scholar in solid command of her subject matter. It is truly a magisterial accomplishment and in many ways a new publication that should be added to libraries and be part of required reading in any course on phraseology.

There is no doubt that phraseological units of all types are basically "dead" in collections and dictionaries. In fact, most of them do not include any contexts and also ignore diachronic considerations. That is not to say that individual investigations of the contextualised use of proverbs, proverbial expressions, and other phraseologisms do not exist. There certainly are such studies on some of the 
major literary authors and historical figures, as for example on Geoffrey Chaucer, Charles Dickens, Abraham Lincoln, and Winston S. Churchill. But while they present the various phraseological units in context, they do not go into major detail concerning their actual stylistic use, including the variation, expansion, and augmentation of particular phrases. They could all benefit from the theoretical framework and the discussion of numerous examples that Anita Naciscione's book so appropriately provides. Anybody undertaking a stylistic and interpretive study of phraseological units in the context of literary works or the mass media would do well in making the methodology presented in her book the foundation for their work.

This is not the place to offer detailed definitions or descriptions, but it might be stated that Naciscione's special approach consists of looking at the stylistic discourse-level features of phraseological units from a cognitive perspective. And she is absolutely correct in stating that this presupposes an interdisciplinary analysis, since such fields as linguistics, psychology, folklore, literature, and iconography are necessarily part of it. Her distinction among the base form, core use, and instantial stylistic use serves very well as a theoretical basis in studying the naturally occurring phraseological units in all types of discourse. Above all, she is once and for all breaking with the traditional notion that phraseological units are characterised by fixedness, frozenness, or dead metaphors. Anybody who has studied such phrases in detail has long noticed that they are frequently varied, modified, parodied, or simply stated in a changed way in actual use. They are much more flexible and adaptable than previous scholarship has shown, and it is important to note that the author is adding the extremely important cognitive aspect to her study of the instantial use of phraseologisms. After all, when we are confronted with such texts, matters like access and recall, memory, identification, interpretation, perception, recognition, and comprehension enter into all of this. As a professor of English in Riga, Anita Naciscione is clearly aware of the fact that students of foreign languages are constantly confronted with these issues as they attempt to master the use and understanding of the phraseologisms of the target language. As a professor who is in the same boat with her, I applaud the fact that my friend has included important statements in her book on the applicability of her approach to foreign language teachers and students alike. I also want to emphasise the significant fact that she stresses the importance of historical considerations in the investigation of the stylistic use of phraseological units. After all, the use, function, and meaning of a given phrase might well change over time, as has been shown in comprehensive studies of such proverbs and proverbial expressions as "Big fish eat little fish", "Don't swap horses in the middle of the stream", "A house divided against itself cannot stand", and "To 
throw the baby out with the bath water". Again and again, as I read the manuscript of this new edition of Naciscione's book and as I am writing this preface, the thought reappears to me how much all of us can and must learn from her inclusive study.

The longer first part of the book is a highly informed theoretical presentation of what the author means by "instantial stylistic use" of phraseological units that is based on applied and cognitive stylistics dealing with discourse as it appears in literature and the mass media - obviously this approach is perfectly adaptable to the study of radio, film, television, and song, that is, to the oral contextualised use of phraseological units. While I have done some of this without Anita Naciscione's theoretical framework, I must admit that my future studies will now pay much more attention to her paradigm, notably the importance of cognitive matters. After all, psycholinguistics is of extreme importance in the study of the use and comprehension of metaphors, and by including cognitive considerations much can be learned about the psychological interpretation of phraseological units in human communication of all types. A small present-day example might be President Barack Obama's relatively frequent use of proverbial phrases in his books and speeches. As a politician on the national and international scene, he and his speech-writers must very much be aware of what phraseological units he uses, especially when he addresses audiences abroad for whom his English is a foreign language. He cannot and should not automatically expect his audiences to understand such common but culturally specific phrases as "to get to first base", "to play hardball", "to pinch-hit for someone", and "Three strikes and you are out", all of which stem from the game of baseball. Clearly, he would want to employ metaphorical phrases that have a rather international currency, as for example "to fight against windmills", "to be in the same boat", "to build castles in the air", and "All that glitters is not gold". But even then he would need to be careful to make certain that these phrases carry similar meanings abroad, that they are in fact still current and understood, and that they will be appreciated by his audiences as meaningful stylistic devices, especially if he shortens, expands, or merely alludes to them, as he is prone to do. This is especially important for President Obama, since he is in fact quite eager to employ phraseological units in his political rhetoric in the United States and abroad. As such, he is a perfect example for Naciscione's sound claim that phraseologisms in actual use are not dead fossils without any deeper meaning.

Of course, the author shows all of this by numerous contextualised examples ranging from authors like Geoffrey Chaucer, William Shakespeare, Mark Twain, George Bernard Shaw, D. H. Lawrence, Lewis Carroll, James Thurber, and many others. This is an impressive spread of literary talents over time by which she is 
able to show diachronically that this differentiated stylistic use of phraseological units is actually nothing new! It would be utter nonsense - as has been claimed at times - that phraseologisms in discourse are absolutely fixed. Nothing is further from the truth, as a large percentage of contextualised references show. But as expected, the author goes, of course, far beyond just stating the obvious. Instead she discusses in much detail such matters as phraseological cohesion, patterns of instantial use, extended phraseological metaphor, phraseological puns, phraseological allusion, diminutives in phraseology, phraseological titles, and even phraseological saturation of discourse. These are but a few aspects of particular interest to me that should also whet the reading appetite of others. Regarding the saturation of texts with phraseologisms, let me just mention that I have collected such textual amassments both in English and German. My International Proverb Archives hold dozens of examples from prose literature, poems, and songs that consist of proverbial collages that carry meaningful messages. To be sure, I have been able to show that the sub-genres of proverb poems and proverb songs exist, having found examples throughout history. I simply mention here François Villon's Ballade des proverbes from the 15th century and Bob Dylan's song Like a Rolling Stone (1965). In fact, there exists a definite tradition of such tour de force texts that also include the field of iconography, to wit the entire tradition of proverb illustrations from the late Middle Ages via Pieter Bruegel's famous oil painting The Netherlandish Proverbs (1559) on to comic strips.

Regarding this last point, the author has also included a completely new chapter on "Visual Representation of Phraseological Image" with which she once again charts a new way of interpreting the ubiquitous appearance of phraseologisms in various types of media. Claiming that "visualisation is part of metaphor recognition", she is especially concerned with the visual aspects that are part of metaphorical thought representation and of course also the creative employment of phraseological metaphors in visual discourse. While she does not comment in detail on the visual representation of phraseological units in woodcuts, misericords, tapestries, emblems, engravings, paintings, gold weights, coffee mugs, flags, cloths, quilts, and yes, T-shirts (a whole tradition by now!), she emphasises the appearance of phraseological illustrations in book illustrations of Mark Twain, James Thurber, Lewis Carroll, and others. Above all, the author zeroes in on how phraseologisms play a definite role in the visual aspects of the mass media, where they appear as texts with innovative and often literal pictoralisations of their metaphors. Once again her methodology could easily be transposed to the iconographic study of proverbs and proverbial expressions that has a considerable tradition among art and cultural historians, folklorists, and philologists. Her discussion of such matters as visual representation and instantial stylistic 
use, implicit visual messages, and above all visual literacy as a cognitive skill is absolutely superb, and once again I would add that I wish that I had her theoretical discoveries at my disposal when I have dealt with iconographical and phraseological issues. In any case, in a modern global world where visual emblems in the press and advertising play an ever more important role, it behoves us to include in the study of cultural literacy Anita Naciscione's innovative concept of visual literacy.

One could perhaps argue that this book could have been concluded at this point, but I do commend Anita Naciscione for adding a second part to her unique study by providing a long and extremely important chapter on "Applied Stylistics and Instantial Stylistic Use". Not that she has not done so throughout the first part of her book, she now, perhaps reminiscent of the proverb "The proof of the pudding is in the eating", practices what she preaches by presenting and analysing additional and carefully chosen examples. It is here where the educator in her comes to the forefront, and I am glad that she makes this engaged commitment to the importance of phraseological units for the teaching and learning of (foreign) languages. Again, the idea of stressing phraseologisms in language classes is nothing new, and there exists a considerable amount of international scholarship on the subject matter. But it is, of course, Anita Naciscione's innovative approach based on her insightful theoretical ideas that goes beyond previous work in this area. By way of convincing examples she illustrates new ways of a discourse-based approach to phraseology in teaching, explaining at the same time such matters as improved language skills, learning difficulties, and identification problems regarding phraseological units. And yet, as we all know, it is of utmost importance that our students learn to cope with this rich phraseological communication, that they learn to identify, understand, and interpret the metaphorical phrases in the discoursal context, that they know how to approach their translation, and that they are aware of their stylistic importance in advertising in particular but also in the mass media as such. Teachers and professors of foreign languages would do well in giving this particular chapter a careful reading, obviously also checking out the glossary, the comprehensive list of references, the appendix, and the index at the end of the book. All of this well written and clearly presented material is of excellent use, especially since it does include the cutting-edge state of theoretical and applied research in the ever fascinating field of phraseology.

There is an old Latin proverb "Opus artificem probat" (The work proves the craftsman) that is known in numerous languages and also in English as "The worker is known by his work". This is a most fitting piece of wisdom to bring this short and thus superficial preface to its conclusion. Anita Naciscione is to be congratulated on her superb scholarly accomplishment that will benefit 
generations of scholars and students of phraseology. It is not easy to write a comprehensive and at the same time truly innovative study of an entire research field and yet go far beyond the present state of scholarship. But the book Stylistic Use of Phraseological Units in Discourse accomplishes exactly that, and its author Anita Naciscione has every reason to be proud of her scholarly achievement in the service of phraseology.

Wolfgang Mieder

University of Vermont, 2010 


\section{Introduction}

The purpose of this book is to disclose stylistic discourse-level features of phraseological units from a cognitive perspective. A discourse-based view allows me to examine phraseological units in a broader context, not just in single phrases or sentences. This angle of vision is important, as discourse studies tend to overlook stylistic use of phraseological units. For instance, The Handbook of Discourse Analysis (Schiffrin et al. [2001] 2004) does not deal with phraseology in discourse at all.

A cognitive approach to stylistic use of phraseological units in discourse is a new research area. It is, of necessity, an interdisciplinary field, since these issues cannot be addressed through the knowledge resources of any single discipline. I rely on the findings of cognitive linguistics on figurative thought and language. Use of figurative language, including phraseological units, has been recognised as part and parcel of human cognition, a revealing cognitive mechanism.

Recent decades have witnessed increasing interest in various aspects of phraseology, especially after the foundation in 1999 of the European Society of Phraseology (EUROPHRAS), which has become a centre of phraseological research, organising regular conferences and other activities. Additionally, an increasing number of publications now exist on various aspects of phraseology. Here I should mention two weighty volumes on theoretical issues of phraseology that will certainly boost further studies in the area: Phraseology: An Interdisciplinary Perspective (Granger and Meunier [2008] 2009) and Phraseology in Foreign Language Learning and Teaching (Meunier and Granger [2008] 2009). In turn, research in phraseology has promoted studies in corpus linguistics and in compilation of corpus-based dictionaries.

This book attempts to explore the benefits of a cognitive approach to the stylistic aspects of phraseology both in the system of language and in actual texts. Use of phraseological image in verbal and visual discourse is of stylistic and cognitive interest for studies of both thought and language. 


\section{New findings}

- My major task has been to work on elaboration of key terminology and theoretical concepts in phraseology in general, and in stylistic use of phraseological units in discourse, in particular in the face of an abundance of various existing controversial terms. For the purposes of stylistic analysis, I introduce new basic terms in English: the base form, core use, and instantial stylistic use. To study phraseological units at the level of discourse, it is essential to draw a distinction between the stock of phraseological units and phraseological units in actual use, which fall into core use and instantial use. Hence the importance of the distinction between: the base form vs core use vs instantial use. The following are theory constitutive concepts in stylistic use of phraseological units.

- Definition of the phraseological unit as the most significant concept for phraseology. I argue that the phraseological unit is a stable, cohesive combination of words with a fully or partially figurative meaning.

- The base form of the phraseological unit is an archetypal conception. It is a decontextualised unit of language, stored in the dictionary or the longterm memory of the language user, accessed when a discourse situation calls for it. It is generic to all manifestations of a particular phraseological unit in discourse.

- Core use is use of a phraseological unit in its most common form and meaning. In core use the phraseological unit does not acquire additional stylistic features and does not exceed the boundaries of one sentence. Core use is largely predictable; it presents neither novelty nor surprise.

- By instantial stylistic use I understand a particular instance of a unique stylistic application of a phraseological unit in discourse resulting in significant changes in its form and meaning determined by the thought and the context. These are stylistic instances of naturally occurring phraseological units in discourse. Instantial stylistic use explores experiences far beyond the possibilities of core use, is more sophisticated and therefore requires a greater amount of processing and analysis than core use, especially for L2 learners. Both core use and instantial use are equally valid manifestations in discourse: they are language in use. The instantial form has been created for a particular purpose; however, the term instantial refers only to textual manifestation. It does not refer to the base form exploited in the given context or to pattern, which are language means applied to achieve a novel stylistic effect in discourse. Instantial use is a boundless resource for writer or speaker creativity. 
- Stability of phraseological units is an inherent, categorial feature not only in the system of language and but also in stylistic use. I argue against use of some terms which currently prevail in research on phraseology, such as fixedness, frozenness, dead metaphors. Stability in the system of language and flexibility in discourse do not contradict each other. Quite the contrary, they contribute to each other as a set of dialectic opposites.

- Phraseological cohesion derives from the figurative meaning of the PU and the structure of the unit. However, phraseological cohesion is not only part of the meaning of the base form, it is also the unity of phraseological meaning in instantial use; not only a semantic but also a stylistic relationship, realised in discourse by virtue of ties with the base constituents. Stylistic cohesion provides continuity and helps to create a narrative.

- I introduce the concept of the pattern of stylistic use as a reproducible mental technique. It is a set of common features and rules of instantial use of phraseological units. I have attempted to show that far more regularity exists in the instantial stylistic use of phraseological units than has been previously believed. In discourse, phraseological units secure cohesive ties to meet discourse needs by means of such patterns as extended metaphor, punning, allusion, or reiteration and their innumerable combinations. Patterns of instantial use are frequently achieved at the level of a certain length of text, larger structural units such as chapters, or at the level of a whole literary work. Texts show that instantial stylistic use of phraseological units has persisted since OE. The same basic stylistic patterns recur in discourse across centuries with varying degrees of frequency and density.

- Sustainability of phraseological image in discourse is the spread of a phraseological image over a length of text in sequential segments as part of the interrelated web of the discourse. Instantial use is sustainable and contributes to creation of coherence and cohesion in discourse. A phraseological unit may extend across sentence boundaries and even larger stretches of text, creating continuity, a network of unique interrelationships of figurative and direct meanings, and associative links. Sustained stylistic use reflects extended figurative thought and contributes to perception of the text as a cohesive and coherent entity.

- $\quad$ Cognitive insights. The study of phraseology cannot be separated from general cognitive processes. I challenge some prevailing assumptions about phraseological units in use. Clearly, instantial stylistic use cannot be discarded as a mere deviation, a distortion, a violation, or a strange exception. The reason is cognitive: instantial stylistic changes reflect the development of thought in 
discourse, which is closely linked with creativity in language use. The book also explores other cognitive aspects of instantial use, such as access and recall, the role of long-term memory and working memory, and the process of identification: perception, recognition, comprehension, and interpretation. The whole process of emergence of instantial use is a cognitive performance, a pathway leading from long-term memory, which provides a base form and an instantial pattern, to creativity, which yields instantial form and meaning. Phraseological metaphor exists not only in thought and language; it also exists in visual representation and its perception. Phraseology is a mode of figuration, and a cognitive linguistic approach to figurative language is a tool that helps to perceive, understand, and appreciate stylistic use of phraseological units, and draw inferences.

- A diachronic insight into stylistic use of phraseological units, going back to the OE, MiE, and ENE periods (Shakespeare) up to Modern English, discloses cross-century stability of patterns of figurative use. Diachronic development of patterns is a development in complexity and scope. The same basic stylistic patterns recur in discourse across centuries with varying degrees of frequency and density. Diachronic changes do not contradict stability. Texts show that instantial use of phraseological units has persisted since the OE period.

- Applied stylistics. In the book, I argue in favour of the need for applied stylistics as a field of special interest: use of stylistic competence of the language user in the fields of teaching language and literature, translation, lexicography, visual representation, and advertising. I see applied stylistics as an area which explores practical use of the principles, discoveries, and theories of language, literature, and stylistics. Training in stylistic awareness will lead to significant gains in stylistic literacy, including visual literacy, which will result in functional ability to use stylistic skills sufficiently well for applied purposes and activities.

\section{Scope of the book}

The book explores key issues in stylistic use of phraseological units and offers both theoretical and applied research; it falls into two main parts. Part I is devoted to theoretical research, which is concerned with elaboration of technical terms, key concepts, and key processes. Part I offers a new approach to key terminology and basic concepts, and provides a comprehensive discourse-based treatment of phraseological units from a cognitive perspective. The book examines patterns of stylistic use of phraseological units and the role of cohesion in the sustainability of a phraseological image in discourse. Exploration of phraseological meaning 
across sentence boundaries is based on ample textual illustrations of stylistic use ranging from the 8th century to Modern English, both from literary and media texts, and multimodal discourse.

Part II focuses on applied research, exploring challenges which instantial stylistic use of phraseological units cause in practical applications in various spheres of life. Applied stylistics is only an emerging trend. Indeed, phraseology is a wholly new area even as part of applied linguistics. For instance, The Oxford Handbook of Applied Linguistics (Kaplan 2002) does not explore the applied aspects of stylistic use of language in general or stylistic use of phraseological units in particular. However, the need for applied stylistics exists. One of the most important aspects is the pedagogical implications of teaching stylistic use of phraseological units. This is an essential strategy for raising stylistic awareness, which is a conscious perception and understanding of significant changes in base form and meaning, associative links and their networks, stylistic cohesive ties in text, and creation of new meaning in discourse. The importance of stylistic expertise in advertising is self-evident. Another area that calls for stylistic and cognitive competence is translation of phraseological terms. A cognitive approach is a tool that helps to comprehend the role of figurative use across languages and to recognise metaphor as a technique of abstract reasoning in the formation of terminology. Its translation is not merely part of cross-cultural communication; it is a cognitive operation of the mind. Translation of phraseological terms reveals the role of cognitive theory in translation practice. Hence it is crucial to gain full comprehension of the phenomenon and recognise the need for specialist training.

The book contains a List of Abbreviations, an Appendix, an Index of Phraseological Units discussed in the book, a Subject Index, an extensive Glossary with clear-cut definitions of key terms and concepts in stylistic use of phraseological units that support and reflect their analysis, and a comprehensive Bibliography that provides a basis for readers to pursue their further interest in the area.

This book is a revised edition of Phraseological Units in Discourse: Towards Applied Stylistics (Naciscione 2001b). I hope that it will contribute to further exploration of phraseological units and cognitive aspects of their use in verbal and visual discourse, which is crucial both in the theoretical and the applied sphere.

Anita Naciscione

Latvian Academy of Culture, 2010 

PART I

Phraseological units in discourse 



\section{CHAPTER 1}

\section{Phraseology and cognitive stylistics}

Awareness of style is essential for understanding and appreciation of language in use, including both literary and non-literary texts. By focusing on use of language and stylistic features, researchers have sought to combine the approaches of the linguist and the literary critic in a particular interpretation and consider both poetic function and poetic form (Jakobson 1960). A linguistic approach to literature has generated innumerable approaches and studies since Jacobson's outstanding contribution to this subject. One of the greatest gains has been the advancement of a discourse-based approach to language phenomena.

\subsection{A discourse-based approach}

In stylistics the discourse-based approach goes back to I. A. Richards, who broke the then-existing tradition in rhetoric; in The Philosophy of Rhetoric (1936) he presents the conception that the study of rhetoric should be a philosophical inquiry into the way words work in discourse. ${ }^{1}$

Discourse analysis, ${ }^{2}$ which has been fast developing over recent decades, encourages interpretation in discourse through exploration of meaning to integrate the study of language and literature (for example, Leech and Short [1981] 1994; Carter [1982] 1995a; Short [1988] 1992; Widdowson 1992; Cook [1992] 1994; Cook 1994; Carter and McRae 1996; Carter 1997; Emmott [1997] 1999). Drawing extensively on empirical research and theoretical work in linguistics, sociology, and psychology, discourse analysts explore key issues of both language use and language acquisition. Discourse analysis is a discipline that attempts to identify and describe linguistic regularities and irregularities in utterances which cannot be accounted for at sentence level; studies language in use across sentence boundaries; and explores the organisation of texts (Carter 1995:39-40). A discourse-based

1. For a detailed study of I. A. Richards' contribution to stylistics and his cognitive approach, see West (2005:327-336).

2. For a brief historical overview of discourse analysis see Cook ([1989] 1995:12-13); McCarthy ([1991] 1996: Ch. 1). 
view allows analysts to discern features occurring across a wide stretch of text and playing "a major role in realising the textual and interpersonal meanings of the unfolding discourse" (McCarthy and Carter [1994] 1995: 106). Recent decades in applied linguistics have witnessed a very considerable growth of interest in "discourse analysis - the study of how stretches of language take on meaning, purpose, and unity for their users" (Cook 1994: 1, 1995).

Although discourse analysis examines all types of discourse, a considerable growth of interest has arisen in the discourse of literature. This interest is also motivated by its practical implications. Study of literary discourse forms a substantial part of the curriculum of language education. McCarthy and Carter ([1994] 1995) describe the discoursal properties of language and demonstrate what insights this approach can offer to the student and the language teacher. Further exploration of the nature of discourse is thus crucial in both theoretical and applied spheres.

Discourse stylistics has emerged as a new discipline in its own right. It shows how discourse is constructed and what it conveys with the aim of proceeding to stylistic interpretation and evaluation of a text. Analysis of cohesion (Halliday and Hasan 1976: Ch. 8) is central to discourse stylistics because it reveals semantic and stylistic links. This approach is especially beneficial, as much of the research in the sixties and the seventies tended to disregard the stylistic features of language. The term discourse stylistics is now generally used to refer to the practice of using discourse analysis in the study of literary texts (op. cit.: Ch. 8; Carter and Simpson 1989: 11; McCarthy and Carter [1994] 1995: 135; Carter 1996: 5). Discourse stylistics deals with interpretation of semantic and stylistic relationships in text.

Style in discourse is a very complicated issue. As for phraseology, style is essential for analysis of phraseological units (PUs) in discourse to establish the role of PUs in creation of textual meanings. A context-oriented approach means that stylistic changes do not occur in isolation, but only as an integrated part of discourse.

\subsection{The breakthrough of cognitive stylistics}

My interest lies in figurative language in general and phraseology in particular. Cognitive science has demonstrated that figurative language is a tool of the human mind (Lakoff and Johnson [1980] 2003). Use of figurative language is a systematic and orderly part of human cognition processes (Gibbs [1994] 1999:450); phraseology forms part of this system.

In my research into stylistic use of PUs in verbal and visual discourse, I rely on the achievements of cognitive linguistics, which have made successive contributions to the understanding of metaphor and thought, and explorations of 
metaphor as a major mode of conceptual organisation. Studies by cognitive scholars over recent decades have established metaphor as a figure of both thought and language (for example, Lakoff and Johnson [1980] 2003; Paprotté and Dirven 1985; Lakoff 1986; Lakoff and Turner 1989; Gibbs 1990, [1994] 1999, 2003, 2007; Sweetser 1990; Steen 1992, 1994, 2006, [2007] 2009; Lakoff [1993] 1998; Katz 1998; Kövecses 2002, 2005, 2006).

Cognitive study has added a new dimension to discourse analysis and narrative comprehension (see Emmott [1997] 1999; Freeman 2000; Burke 2003). Use of metaphor has been recognised as part and parcel of cognition, a revealing cognitive mechanism. I fully agree with Steen that metaphors need to be investigated from the cognitive linguistic point of view, not only from that of literary criticism, as has been the case traditionally (Steen 1994:3, 2002a:386). The tenets of cognitive science have served as a basis for development of cognitive stylistics (for example, Lakoff and Turner 1989; Gibbs 1995, 1999b, 2002; Semino and Culpeper 2002; Steen 2002a, 2002b, 2006; Stockwell 2002; Gavins and Steen 2003).

My aim is to explore phraseological meaning and its stylistic aspects: the instantiation and development of meaning in discourse, the emergence of new associations and their chains, resulting in creation of successive sub-images, coupled with visual development of metaphorical meaning. Metaphor identification, comprehension, and appreciation become more challenging and also more interesting when metaphor is represented by a PU, not separate words.

Although discourse stylistics has proved the benefits of a discourse-based approach, much of contemporary research in both cognitive stylistics and phraseology is focused on sentence-level phenomena. Most of the examples to illustrate theory are limited to separate words, phrases, or sentences, which I see as an oversight in stylistic research. I would argue that the full stop in writing to mark the end of the sentence is not a full stop in the flow of thoughts. Many stylistic phenomena emerge in a shorter or longer stretch of text. These need to be addressed to provide a more comprehensive account of their use. That is why my concern is not just stylistic use of PUs but a cognitive approach to stylistic use of PUs in discourse. The PU is one of the modes of reflecting figurative thought.

\subsection{The phraseological unit}

It is a challenge to write on phraseology since it is an area with a confusing range of terminology and different approaches. ${ }^{3}$ I fully agree with Cowie that a lack of

3. It is not my aim to give a detailed survey of the terminology used in phraseology. For the most commonly used terms see Moon (1998:2-5). See also Cowie ([1998] 2001b:4-7). 
standardised terminology exists (1981:225). Three decades have passed and the situation is not much better. Idiom is the most common term among the terminology used. Other terms also exist, such as multiword lexical unit (Cowie 1992), fixed phrase (Verstraten 1992), fixed expression (Moon 1992; Svensson 2008) and many others. For instance, Makkai also includes compound words in the category of idioms (Makkai 1972). In his article The Possibilities of Paraphrase in the Teaching of Literary Idiom, Nash ([1986] 1991:70) uses the term idiom in a very broad sense meaning a separate word, a combination of words, or a proverb, while Strässler gives a long definition of the term idiom, though in a much narrower, phraseological sense, "An idiom is a concatenation of more than one lexeme whose meaning is not derived from the meaning of its constituents and which does not consist of a verb plus an adverbial particle or preposition" (Strässler 1982:79). The term phraseme is also common (Sabban 1999, [2008] 2009:227-241; Burger 2007). Kuiper uses the term phrasal lexical items when discussing linguistic creativity in formulaic genres (Kuiper 2009: 191-207).

Terminological uncertainty makes the work of lexicographers more demanding; linguists find it difficult to communicate their message for fear of being misunderstood. Reading a piece of research on phraseology starts with an attempt to establish use of terminology and basic definitions. "Phraseology is a field bedevilled by the proliferation of terms and by conflicting uses of the same term" (Cowie [1998] 2001c:210). First and foremost, this refers to the term idiom. The numerous uses of the term idiom only create terminological confusion. It is polysemous: it has several meanings in its semantic structure. Moreover, it has many theoretical interpretations. Hence, it is vague and confusing. As Moon points out, "idiom" is an ambiguous term, used in conflicting ways both in general English and as a specialist term (Moon 1988:108, 1998:3-6). I would agree with Moon that "the terminological situation cannot be easily resolved except by avoiding the term idiom altogether" (1998:4), however, use of idiom persists.

Moreover, terminology may change in the works of the same linguist over decades as research proceeds. For instance, Moon uses the term idiom as a blanket term to refer to "any sequence of two or more words that together function as a unit" (Moon 1988: 108). She uses the term fixed expressions in a later article in 1992, while in her book Fixed Expressions and Idioms in English, the term fixed expressions and idioms (FEIs) is used as one term to include both categories - idioms and fixed expressions (Moon 1998:2-5).

In parallel, the term phraseological unit has increasingly been used in phraseological research (for example, Gläser [1998] 2001; Fedulenkova 2003; Arsentyeva 2005; Mena Martínez 2006; Fiedler 2007; Szerszunowicz 2008). The term phraseologism is mostly used in research written in German (for example, Dobrovol'skij 
1980; Gläser 2000; Bass 2003). Both terms have been widely used by phraseologists in Eastern Europe for more than half a century.

I would argue for the term phraseological unit, and here I would like to make it clear that I do not consider that idioms form a subset of phraseological units. According to Kunin, "a phraseological unit is a stable combination of words with a fully or partially figurative meaning" (1970:210). This definition is best suited for purposes of both theoretical analysis and practical identification. ${ }^{4}$ Kunin was an outstanding researcher and lexicographer who followed his theoretical principles in his lexicographical work. His English-Russian Phraseological Dictionary (about 25000 units with textual illustrations) won high acclaim (Kunin 1967a). Cowie writes that it is "a meticulous work of scholarship and a model of theorydriven lexicography" (Cowie [1998] 2001c:220). Kunin's definition includes two inherent properties of PUs: stability and figurative meaning, which differentiate these units from free word combinations and also from set expressions which are stable but which have no figurative meaning. Therefore I follow Kunin in believing that two large groups exist: phraseological units and stable word combinations of non-phraseological character (Kunin 1964). The latter are non-figurative set phrases which fall beyond the scope of this book. They constitute a separate area of research in their own right with its own features and regularities. This explains why Moon's term FEIs does not work as an entity, as it includes two different categories.

Kunin's understanding of PUs also embraces proverbs (1970:313). I follow Kunin in including proverbs in the phraseological stock of language. Indeed, the study of proverbs has established itself into a separate discipline - paremiology. It is an area of inquiry in its own right as paremiologists "draw on such fields as anthropology, art, communication, culture, folklore, history, literature, philology, psychology, religion, and sociology" (Mieder 2004:13). As a scholarly subject, paremiology has a far longer tradition in comparison with phraseology; it has been extensively researched over the centuries (Taylor [1931] 1985; Mieder 2003: 9-16; Jamal 2006).

However, I would argue that from the linguistic point of view proverbs belong to phraseology for the following reasons. Semantically, they comply with the two main categorial requirements: stability and figuration. Syntactically, they feature sentence structure (simple or complex) and they never exceed sentence boundaries in their base form. Stylistically, the functioning of proverbs presents a great variety of patterns of stylistic use (see, for instance, Mieder 1989), the same as in other types of PUs.

4. I know this from my own experience as it has helped me to make a data base of all PUs in The Complete Works of Geoffrey Chaucer (1919) in MiE, Skeat's edition (see Naciscione 1976). 


\subsection{Phraseology and stylistics}

The idea that phraseology has the right to exist as a separate linguistic discipline was first put forward by Kunin. He also introduced the term phraseological stylistics to denote the study of stylistic properties of PUs (1969:71-75). Kunin viewed phraseological stylistics as part of both general stylistics and phraseology. He developed his ideas of stylistic use of PUs in his subsequent works (Kunin 1973, 1974, 1975, 1976, 1977, 1983). In Russia, stylistic studies of phraseology have flourished after Kunin (1964) (see, for example, Boldireva 1967; Sviridova 1968; Shadrin 1969; Naciscione 1976; Danchenko 1977; Zhantlesova 1978; Melerovich 1982; Moshiashvili 1982; Dubinsky 1985). This trend also continues today (see, for example, Ryzhkina 2003).

In Western Europe, scholarly interest in phraseology and in stylistic use of PUs in particular developed much later (Cowie [1998] 2001b). ${ }^{5}$ Following Kunin, Gläser (1986b) voices a plea for phraseo-stylistics as a subject of stylistic description in its own right to study the communicative effects of phraseological units and their occasional, individual modifications. Further studies are also devoted to the stylistic potential of phraseological units in text (Cowie [1998] 2001a; Gläser [1998] 2001). Research on stylistic changes of phraseological units in text has recently been on the increase; for instance, Sabban offers a thorough analysis of occasional variations of French and German phraseology in use, (1998b), and explores the text-building potential of PUs in discourse (2007). Various types and genres of texts have attracted much attention, including media texts and advertisements (for example, Sabban 1998b; Gläser [1998] 2001; Burger 1999, 2008).

In paremiology the term anti-proverb was introduced by Mieder (1982); it has been accepted by proverb scholars as a general term to denote innovative changes in traditional proverbs (for example, Mieder 1989; Mieder and Litovkina 1999; Walter and Mokienko 2005; Barta 2006; Litovkina and Mieder 2006). This approach works very well if the first part of the proverb has been fully or partly preserved in stylistic use, as in cases of extended metaphor, pun, replacement, zeugma, and others, while I believe it is not applicable in cases of phraseological allusion (see Ch. 4.4 of this work) and in cases of phraseological saturation when a number of stylistic changes are instantiated in one context in a stretch of discourse (see Ch. 5.4).

Whether phraseological stylistics should be singled out as a separate area is another issue. However, a need clearly exists to examine PUs in use and the rules

5. For an insight into the history of phraseology, see Kunin (1970: Ch. 1 and Ch. 7). For developments and trends in research on phraseology since the 1970s, see Cowie ([1998] 2001b: 120); Moon (1998: Ch. 1). 
and processes determining stylistic changes, many of which exceed the boundaries of one sentence. Cognitive stylistics is an appropriate discipline for these purposes as a cognitive approach to language use focuses on meaning and its development (Geeraerts 2006). Two essential avenues of exploration and observation are the relationship between phraseological meaning and thought in stylistic instantiations, and changes and developments in discourse, including visual discourse. One of the objectives of stylistics is to study and understand the general principles and procedures upon which stylistic changes are built and to account for the cognitive mechanisms underlying the functioning of PUs in discourse.

The growing interest in phraseology can be explained partly by the complicated processes which occur in this part of vocabulary, partly by a focus on lexicography as well as an increasing interest in discourse in general and its relevance to pedagogy. Our conception of discoursal use is bound to influence our way of teaching. Exploration of PUs in discourse is crucial not only in the theoretical sphere but also in applied aspects.

A cognitive approach to stylistic analysis of PUs in discourse is a transdisciplinary search. It calls for new ways of thinking about phraseology and stylistics, and their close links with fringe disciplines, such as psycholinguistics and cognitive linguistics, acknowledging the role of psychology in discourse comprehension, learning, and teaching, especially for complex language units like PUs.

Style is fundamental for analysis of PUs in discourse. Indeed, style is part of the meaning of PUs (see Ch. 2.2); it is one of the elements of the semantic structure of phraseological meaning (Melerovich 1982; Dobrovol'skij 1996, 1998, 2003). The cognitive dimension is particularly important in understanding the process of creating phraseological meaning in text. Cognitive psychology is the study of perceptual processes, especially the processing of a flow of words, as well as recognition, creativity, and imagery. Creativity in use of phraseology implies a capacity for random and non-traditional thinking, seeking to produce novel forms of PUs in discourse and introduce new features in their image. This approach calls for a greater awareness of changes in discourse and a readiness to accept new stylistic formations as facts of discourse.

\subsection{Attitudes to stylistic use of PUs}

Historically, attitudes towards unusual discoursal forms of PUs have differed greatly; they also differ today. One attitude has been that of open criticism. Stylistic changes to PUs have been seen as undesirable and therefore as something which need to be changed back to "normal". Some teachers still tend to mark stylistic changes to PUs as incorrect for both native learners and L2 learners or even 
label them as wrong. Interestingly, the famous English lexicographer Dr. Johnson is known to have been dead set against them as something undesirable (Baugh and Cable [1951] 2001:267). This certainly demonstrates an attitude.

Another practice is that of deliberate avoidance or non-acceptance of PUs or stylistic changes to them. For instance, the English writer George Orwell is known to have been against any stylistic "flourishes" of this type both in theory and in his own works. ${ }^{6}$

Moreover, covert criticism of this phenomenon is manifest in the terminology used by researchers. When stylistic use of PUs is discussed, it is often labelled with such pejorative terms as abnormality, abusage, anomaly, decomposition, defectiveness, deficiency, deformation, departure, deviation, dislocation, distortion, infringement, manipulation, misquotation, and violation, even an oxymoron: creative deformation. All these negative terms show disapproval and lend a negative aura. They also assume a prescriptive shade. For instance, Enkvist sees style as deviation from the norm, as a departure from a set of patterns which have been labelled as a norm; the norm is regarded as stylistically neutral, which is then surrounded "with a halo of style" by the speaker or writer (1973:15). This attitude implies non-acceptance of stylistic changes to PUs as a fact of discourse. In the cognitive linguistic view, stylistic use, metaphor included, "is not understood as a speaker's violation of rules of competence" (Taylor [1989] 1995: 132). A cognitive approach helps: (1) to disclose the processes of the mind in creative thinking; (2) to trace the role of associations; (3) to understand the process of perception and comprehension of the development of figurative meaning; and (4) to treat it as a natural discourse phenomenon.

Stylistically marked uses are even condemned as anarchic uses of language, showing its instability. This type of approach implies two concepts: a concept of normality which conforms to the standard, and a concept of abnormality which does not comply with the set rules of language use. This reasoning is encountered not only in cases of stylistic use of PUs, but also in cases of creative use of any lexical items when "regular (literal) interpretations are blocked by semantic violation" (Leech 1969:89). The terminology reflects the theoretical conception. Leech believes that an "obvious illustration of degrees of abnormality is provided by metaphor" (Leech [1969] 1993:31). Deviant use is apposed to normal use (op. cit.: 29-31), so that departure from the norm is seen as abnormality.

It is quite a commonplace to say that PUs are dead metaphors or clichés. This approach can be seen not only in many works of the 1970s and 1980s, but also in the following decades. The traditional view proceeds from the approach that

6. Orwell's negative attitude to 'stale metaphors' is clear in his essays, especially Politics and the English Language (Orwell 1946). 
phraseology is petrified language. The concepts of frozenness and anomaly still linger in phraseology. The old view persists in the face of achievements in cognitive linguistics and psycholinguistics, which reveal that figurative meanings are motivated by people's conceptual knowledge. Gibbs argues that traditional theories of idiomaticity have no way of accounting for the mental images of idioms, because they assume that the meanings of idioms arise from metaphors that are now dead and no longer a prominent part of our everyday conceptual system (Gibbs [1994] 1999:295). In his article Why Idioms Are Not Dead Metaphors he comes to the conclusion that "the dead metaphor view of idiomaticity is dead wrong" (1993:57). The empirical study of idioms and proverbs in cognitive linguistics and psycholinguistics provides considerable evidence against the idea that all idioms are dead metaphors (Gibbs [1994] 1999:318).

Gibbs believes that idioms are not simply frozen phrases but are excellent indicators of how people think metaphorically in their everyday lives. He exposes the myth that idioms are simple dead metaphors and challenges the traditional view that idioms have lost their metaphoricity over time and now exist in the mental lexicon as frozen semantic units or dead metaphors. On the contrary, they actually retain much of their metaphoricity and reflect metaphorical and metonymic schemes of thought, which exist independently as part of our conceptual system (Gibbs [1994] 1999:268-277).

The study of idioms is significant not only in terms of understanding how people learn and comprehend figurative language, but also because idiomaticity reveals some dramatic insights into the relationship between language and thought (Gibbs 1993: 75). Cognitive psychology advances the idea that the traditional view of the mind is mistaken because human cognition is fundamentally shaped by various processes of figuration. Idioms do not represent "the graveyard of metaphorical thought" (Gibbs 1993:75). Indeed, if we proceed from the approach that PUs are frozen clichés, then the whole dictionary may seem like a mortuary. I follow Gibbs in drawing a line of distinction between dead metaphors, which are no longer used and which are marked as obsolete in dictionaries, and conventional metaphors (Naciscione 2003a).

The dead-metaphor view follows from the premise that a PU was fresh at one time but is now dead. Indeed, the PU is lifeless when encased in a dictionary headphrase. Like any other inventory, it has no freshness about it. It is static, and what is more, it is not supposed to be dynamic in its dictionary form. In fact, it does not offer any freshness. However, in discourse this conventional metaphor is not doomed to remain in the same set form as found in a dictionary entry. Only in dictionary entries are PUs ready-made static word combinations. Phraseology is not merely a list of dictionary entries. 
Actual texts show that phraseology is not a store of old fossils. PUs come to life in actual use. Stylistic changes to PUs have been an accepted fact of language throughout the history of English; see, for instance, Shakespeare's works, which abound in creative use of PUs. Interestingly, Old English and Middle English writings already present ample evidence of this phenomenon (Whiting 1968). The Complete Works of Geoffrey Chaucer contains 3610 cases of use of PUs, of which 2446 constitute core use while 1164 (32.24\%) cases involve meaningful stylistic changes (Naciscione 1976: 180). The occurrence of stylistic changes in contemporary texts varies depending on author and type of discourse. What matters is not only the frequency of stylistic use, but also the scope of the text that one instance encompasses. For example, in the works of D. H. Lawrence about $25 \%$ of PUs undergo stylistic change. However, they differ in their stylistic significance; for example, in The Lost Girl (1920) a single metaphoric PU (an odd/strange fish) is sustained over a long stretch of text covering some 25 pages (see Ch. 7.3).

Thus, stylistic use of PUs is not a violation or an infringement, but a deliberate choice. It is a new perception, a different point of view, a novel vision calling for a change in the standard form. ${ }^{7}$ Stylistic use is a natural process, a textual channel for reflecting figurative thought.

\subsection{Stylistic use of PUs in dictionaries}

Another interesting indicator of the theoretical and practical approach is the treatment of stylistic use of PUs in dictionaries and various teaching materials, especially textbooks, as well as commentaries and glossaries that literary texts are supplied with. Are stylistic changes of PUs reflected at all, and if so, how fully and explicitly are they presented?

Traditionally, many lexicographers and textbook authors have tended fully or partly to ignore or overlook non-standard forms of PUs. This is not surprising in the face of insufficient development of the theory of both phraseology and stylistics, added to terminological obscurity and specific lexicographical or, if I may use the term, phraseographical difficulties, as PUs do not easily lend themselves to processing. ${ }^{8}$ Stylistic use is certainly hard for lexicographers to handle as a great

7. Style is a fact of language and hence is worth exploring. I beg to differ with Toolan that "stylisticians busy themselves with exploring the putative uniqueness of allegedly unique texts" (1997: 85).

8. See Cowie (1981:223-235) for analysis of lexicographical problems in work on dictionaries of idioms. Cowie does not deal with aspects of style. For "provision of occasional transformation use in the illustrations" see Veisbergs (1996:241-245). Veisbergs explores dictionaries 
diversity of forms exists in discourse. Each single case looks so frustratingly different, inconvenient to process, lengthy, and cumbersome.

A closer look at dictionaries of idioms, as they are commonly called, reveals a widely differing treatment of PUs. Several approaches seem to emerge. One is no reflection of the stylistic use of PUs of any type, that is, complete absence of any stylistic changes in the recorded examples. The illustrations supplied after the PU are perfectly standard with a one-to-one correspondence to the headphrase of the entry (except for minor grammatical changes necessary to introduce the PU into context and which are not stylistically relevant), for example, McMordie ([1905] 1971), Wykeham (1936), Hackenberg (1964), Longman Dictionary of English Idioms (1979), Chambers English Idioms ([1982] 1995), The Penguin Dictionary of English Idioms ([1986] 1994), Chambers Dictionary of Idioms and Catch Phrases (1995). These compilers seem to have been inspired by purism or a misguided striving for clarity. They choose only those illustrations that serve the purpose of attesting correspondence to the headphrase of the entry. The examples sound immaculately "perfect". They demonstrate, as it were, the correctness of the headphrase. The rest of the examples, which do not sound quite right, have obviously been quietly put aside. This approach is undoubtedly directly linked with the theoretical conception of phraseology.

In some cases this approach is manifest in the title, as is the case with Kirkpatrick's Dictionary of Clichés (1996a). In her ten-page introduction to the dictionary, Kirkpatrick points out that the cliché is "a pejorative term for an expression that has lost its first bloom and thus its potency" (Kirkpatrick 1996b: vi). She brands all familiar PUs as clichés which are stale, overused, and over-abused stereotypes, the old stock which cannot boast of actions or processes, lacking freshness. Kirkpatrick argues that the cliché has been convincingly established as "the bad guy of the English language. Furthermore it is the worst kind of bad guy - the bad guy that used to be a good guy before it suffered a fall from grace", that is, a fall from freshness (Kirkpatrick 1996b:vi). A similar attitude may be seen in Cresswell's The Penguin Dictionary of Clichés (2000b). The dictionary includes PUs, set phrases, and quotations, which are qualified as over-used and tired expressions. Moreover, as the author states in her theoretical introduction, she has tried "to find good, clear usages", which means - no stylistic use. Indeed, most citations given in the entries illustrate "straightforward uses" (Cresswell 2000a:ix). I would argue that the term cliché is inappropriate, as it presupposes lack of life, a certain stiffness, inability to change, and lack of potential to develop in discourse. It assumes that the unit is no longer alive.

published before 1994. See also Moon (1992: 16-17 and 1998: Ch. 3). A survey of phraseological dictionaries and some East-West comparisons appear in Cowie ([1998] 2001c:209-228). 
The basic reasons for the absence of stylistic changes to PUs in dictionary entries are, first, the theoretical premise and, second, lack of informed awareness of semantic and stylistic differences of PUs in various contexts. This confirms the direct link and interconnection between theory and its application and hence the importance of theory. Another reason is practical, that of choice of example. In all the dictionaries mentioned above, the illustrations are provided by the compilers themselves with the exception of Longman Dictionary of English Idioms where some examples come from fiction (1979:387).

Additionally, a number of dictionaries of idioms are text-oriented. A considerable amount of actual stylistic use is recorded in Kunin's two-volume EnglishRussian Dictionary of Phraseology (1967a); A Dictionary of English Proverbs in Modern Use (1985); the Oxford Dictionary of English Idioms by Cowie, Mackin and McCaig ([1993] 1994b). The latter draws examples from a wide range of contemporary sources, including modern fiction, newspapers and daily and weekly press, and radio and television broadcasts. Theoretically, though, the authors believe that occasionally idioms may be manipulated to achieve a variety of striking effects. They call this phenomenon nonce variation which, they believe, calls for a degree of cultural or literary awareness possessed only by mature native speakers of English (Cowie, Mackin and McCaig [1993] 1994a: xv-xvi).

The advent of computer technology brought about a revolution in lexicographical practice. The use of large computer-held corpora of English texts has yielded remarkable results. An outstanding achievement is Collins Cobuild Dictionary of Idioms (1995) (CCDI) which draws authentic examples from the Bank of English. The texts in the corpus include fiction, newspapers, magazines, and transcribed conversations. The dictionary provides coverage of the ways in which idioms and their contexts of use vary, so that it teems with illustrations of stylistic use. Not only does the live language material prompt recognition of the possibility of stylistic use of PUs in discourse. In addition, the theoretical approach of the analysts is discourse-based. They have extensively studied a large corpus of Modern English texts. Thus the dictionary is in a unique position to describe idioms in current English.

It may seem surprising that dictionaries exist that are based on a large corpus which do not register stylistic use. For instance, Chambers Dictionary of Idioms (1996) draws on the British National Corpus which has been recorded and gathered from books, magazines, newspapers, radio and TV, formal meetings, and everyday conversations between ordinary people. However, stylistic use is conspicuously absent in this edition. This absence indicates the attitude of the compilers and editors.

The same approach is seen in the corpus-based Cambridge International Dictionary of Idioms (1998). The last two dictionaries seem to have selected the ex- 
emplification to fit the "desirable" clear-cut headphrase of the entry. Evidently, a big difference exists between these three corpus-based dictionaries to reflect use of PUs in discourse (see Table 1.1). ${ }^{9}$

Collins Cobuild Dictionary of Idioms (1995) deserves special praise for the treatment of PUs. The compilers point out a distinctive feature on the jacket of their dictionary: a unique coverage of idiom variations and the ways in which people play with them. Although the authors do not exactly specify that they register stylistic use, they give the idea tentatively in a descriptive way, pointing out that the expression may be varied and exploited in a number of ways or saying that "people often vary this expression" (see, for example, page 300 in Collins Cobuild Dictionary of Idioms 1995). The merit of the dictionary lies in showing that stylistic changes are a fact of life and in line with the authors' objective "to reflect the range ${ }^{10}$ of forms occurring in The Bank of English" (op. cit.: xii). Without being aware of it, the compilers have actually reflected more stylistic use in their entries than they perhaps intended, as a number of cases show that the first part of the entry, designed to record only standard use, includes cases of stylistic use which the authors have termed "original variations". These are recorded after the symbol $\square$, for example, the following example of to slip on a banana skin/peel is a case of extended metaphor, although it is recorded as standard use, not "an original variation":

He was unaware of the banana skin on which his department's heel was about to skid (op. cit.: 18).

Another of the examples of stylistic use recorded in the first part of the entry:

Why are the 'stars' now jumping on the fashionable green bandwagon? Few people doubt their sincerity, although some people doubt their effectiveness (ibid.).

Chambers Dictionary of Idioms (1996) usually supplies one example, sometimes two, rarely three examples, but all of them in core use. An objection might be raised that it is only natural to show core use if giving only one example. However, the dictionary is not so small: it has 404 pages and, what is more important, is based on a corpus containing 100 million words, and yet each example is "correct", it "ideally" fits the headphrase. If no illustration is given of stylistic use, the

9. In this book, forms of PUs have been highlighted for emphasis: base forms are marked bold and underlined; $\underline{\text { instantial elements }}$ are spaced and underlined; $\underline{\text { replaced ele- }}$ $\underline{\underline{\text { ments }}}$ are underlined double and spaced; cuess are marked with an interrupted line.

10. The underlining is mine. 


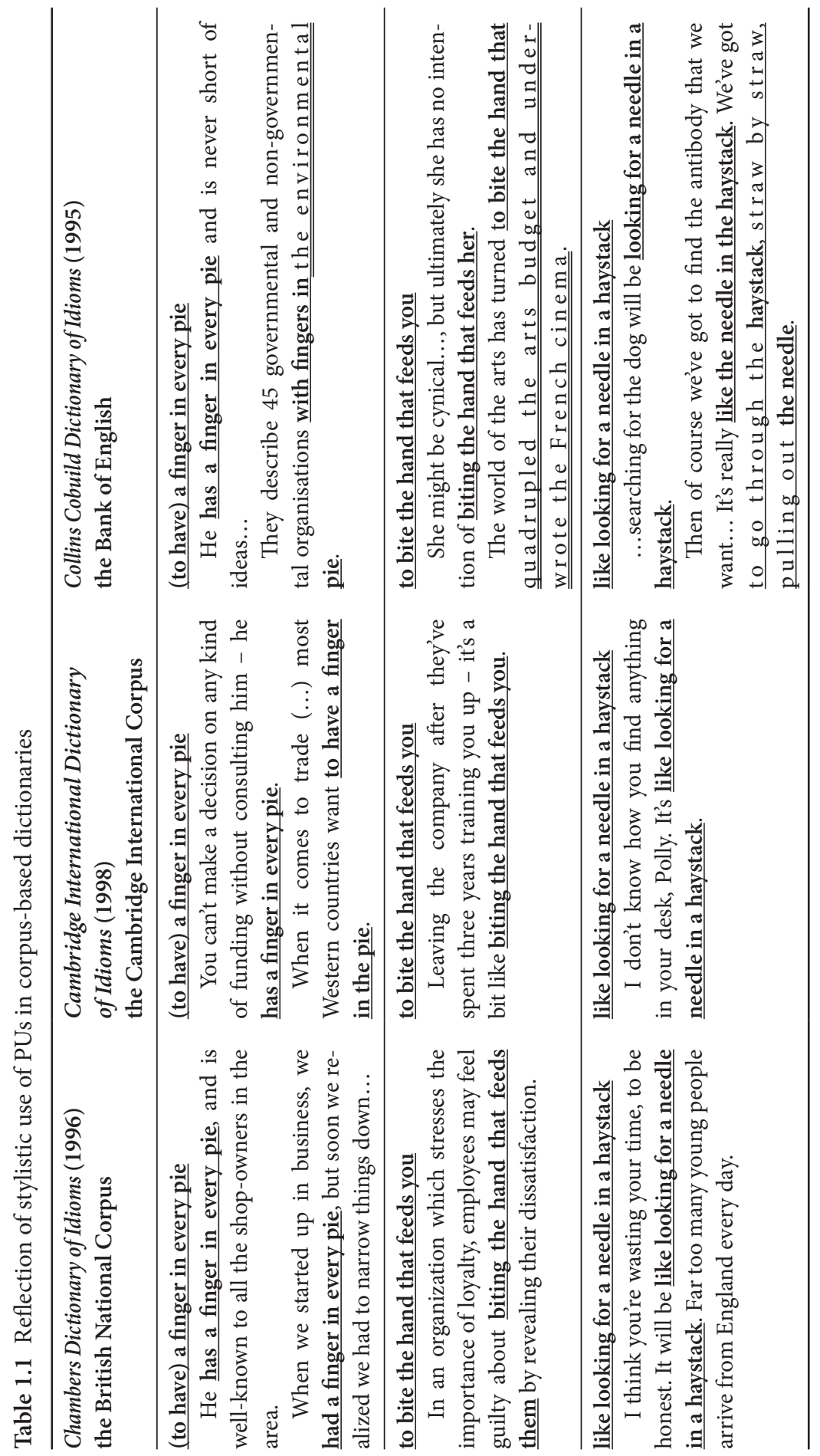


question arises: does it exist at all? In this way the user of the dictionary may jump to the wrong conclusion. The treatment of idioms proceeds from the objectives set by the authors: "to keep the examples clear" so that they "serve to support the definition" (Chambers Dictionary of Idioms 1996: viii). The problem is: should the examples support the definition or should they reflect actual use? A simplified attitude to choice of illustrations could only be justified in learners' dictionaries, which enable the learner to acquire meaning at a very basic level: see, for instance, Oxford Idioms: Dictionary for Learners of English ([2001] 2003).

Another modern dictionary of idioms in which the entries are completely lacking in illustrations of stylistic use is Cambridge International Dictionary of Idioms (1998) based on the Cambridge International Corpus. ${ }^{11}$ This explains the meaning and use of around 7,000 idioms in a very clear way; however, no cases of stylistic use are recorded, irrespective of whether one or two examples are provided. How can these three big corpus-based dictionaries differ so greatly in reflecting idioms in actual use? This must have something to do with the theoretical criteria for selection of examples.

One type of dictionary which seems to reflect actual discoursal use very accurately is the historical dictionary of idioms and proverbs, thanks to a diachronic approach and truthful quotation of the respective piece of text. Here I could mention Hazlitt's dictionary English Proverbs and Proverbial Phrases ([1869] 1882), Skeat's Early English Proverbs Chiefly of the Thirteenth and Fourteenth Centuries with Illustrative Quotations (1910), Whiting's Proverbs, Sentences and Proverbial Phrases from English Writings Mainly Before 1500 (1968), Apperson's Proverbs and Proverbial Phrases: A Historical Dictionary (1969), The Concise Oxford Dictionary of Proverbs ([1982] 1992, compiled by J. Simpson) and Pickering's Dictionary of Proverbs (1997). These historical dictionaries provide a good part of the context, though not all of it, yet give the analyst a wonderful opportunity to research into the use of PUs.

Thus, the view of phraseology as fossilized, petrified, or frozen language units is not conducive to discourse studies. More accurate and comprehensive reflection of PUs in use in dictionaries will undoubtedly be one of the future developments in lexicography. We see encouraging results in use of corpus linguistic techniques in retrieval of phraseological units (see, for instance, Pazos Bretaña and Pamies Bertrán [2008] 2009). Further development of electronic tools may prove fruitful for identification of stylistically changed PUs.

11. The authors of the dictionary specify in the Introduction that "every idiom is illustrated with examples based on sentences from the Cambridge International Corpus. This means that all of the examples reflect natural written and spoken English" (Cambridge International Dictionary of Idioms 1998: vi) (the underlining is mine). 
A corpus-based approach will improve dictionaries and promote both study of discoursal stylistic features of phraseology and acquisition of English vocabulary in use. The role of phraseological dictionaries is enormous in identifying and interpreting PUs in use in all their complexity. Focusing on discoursal use develops and improves student awareness and appreciative faculties. McRae and Boardman consider that intermediate and advanced foreign language learners should progress to reading literature while it is also true that studying literature irreplaceably contributes to development of communicative competence. Literature is generally believed to be language in use. The ability to understand and enjoy literary texts is "a fundamental constituent of that communicative competence of the educated native speaker which is the final goal of foreign students and their teachers" (McRae and Boardman [1984] 1989:1).

Reading and appreciation of literature (Steen 1994) is unthinkable without an understanding of the discoursal use of phraseology. The same is true of other types of texts, such as oral discourse and written media discourse. The role of phraseological dictionaries in comprehension of stylistic use of PUs and acquisition of a foreign language is enormous for L2 learners. Foreign language teachers and methodologists welcome dictionaries which are text-based as they suit teaching objectives best. Hence the reflection of stylistic use of PUs in dictionaries is an area which merits further investigation and development. In turn, this would be of assistance in studies of both phraseology and cognitive stylistics. 


\section{Identification of phraseological units in discourse}

PUs are known as complicated language units with endlessly varied manifestations in discourse. This calls for a systematic view of their actual use to gain a better insight into the discoursal dimension of text. The identification process needs, first and foremost, a profound understanding of the base form as an element of the system of language and its realisation in discourse in either its core use or its instantial use.

\subsection{The phraseological unit and its base form}

The phraseological unit as a stable combination of words with a fully or partially figurative meaning (see Ch. 1) is an extremely complex many-sided language unit. Stability and figurativeness are intrinsic features of any PU in all its innumerable varied representations in discourse. For purposes of analysis it is essential not only to have a clear idea of the concept of the PU as a separate entity, but also to establish terms for denoting various types of form of the PU and to reflect their meaning and function. I propose to introduce the term the base form ${ }^{1}$ in the English language to indicate the form of the phraseological unit to which other forms of the PU can be related and with which they can be compared. The base form is part of the system of a given language. It is certainly an archetypal conception. It is an abstraction ${ }^{2}$ which possesses all the most important characteristics of the given PU. In text it may be used with or without additional stylistic changes, depending on discourse needs and the thought expressed. In practice, the base form is the dictionary form and meaning, recorded as the headphrase. In its base form

1. No established term exists for this form in English, as it is not singled out as a separate entity in contrast to discoursal forms. The usual term used in Russian is ishodnaya forma, meaning "the initial form". It was introduced by Kunin (see 1964, 1970). Sabban uses the term Grundform (basic form) in German (see Sabban 1998b, 1999).

2. For the formation of phraseological meaning and types of phraseological abstraction, see Melerovich (1982); Dobrovol'skij (1998). 
the PU is a static out-of-context formation which does not depend on discourse. Of course, here I do not take into account diachronic development that may bring about changes in the form and meaning of PUs, which naturally develop as all language does.

According to Kunin's definition (1970:210) the PU is characterised by two categorial features: stability and figurative meaning (see Ch. 1). I believe the PU has a third distinguishing, categorial feature: that of cohesion. ${ }^{3}$ Cohesion and stability are not the same thing (see Ch. 3). Cohesion derives from phraseological meaning and the semantic, lexical, stylistic, and grammatical organisation of the PU. The PU is a cohesive formation, whether it operates in discourse or is viewed in isolation as the base form. When used in text, the intrinsic cohesive properties of the PU contribute to texture.

Cohesion also explains the intricate semantic structure of the PU. It was already noticed in very early phraseological investigations in the 50's that one constituent of a PU cannot be explained without the other(s) or, put in different terms, the meaning of the PU cannot be directly derived from its constituent parts. The 80's and the 90's have produced profound analysis of the meaning of PUs. Melerovich argues that the semantic structure of PUs includes their inner form, motivation of phraseological meaning, and phraseological abstraction (Melerovich 1982). The image-bearing component of phraseological meaning has been further researched from the point of view of cognitive linguistics (Dobrovol'skij 1996, 1998). However, the cohesive relationships within a PU are manifold, in that they are present not only in the meaning of the PU, but are also realised through grammatical, lexical, and stylistic ties. ${ }^{4}$ Cohesion of the PU depends on all these types of interrelationships. Cohesion secures and explains stability. Why is the PU stable? Because it is cohesive at the level of structure, constituential make-up, and meaning, including stylistic elements.

To sum up, the base form of the PU is cohesive in its own right. Hence I would reword the definition of the PU as follows: the phraseological unit is a stable, cohesive combination of words with a fully or partially figurative meaning. Cohesion is central to both an understanding of the base form of the PU and its use in discourse. This is in full compliance with the findings of cognitive science, as "human cognition is shaped fundamentally by processes of figuration" (Gibbs 1993: 75).

3. For the concept of cohesion see Halliday and Hasan (1976: Ch. 1). For semantic and stylistic cohesion in PUs, see Ch. 3.1 of this work.

4. According to Halliday and Hasan a tie is the occurrence of a pair of cohesively related items (1976:3). 
The base form has been established as a standard unit in the system of language due to customary use, for example, the white feather, to fall into the trap, to rock the boat, to foot the bill, a running battle. It is the most common and typical form, which serves as a base for creation of identical, similar, or more complicated and original forms in discourse. It represents all cases of use, including innumerable stylistic manifestations in discourse. Only if the base form and meaning are established is it possible to interpret and judge. This may require some conscious cognitive processes in the case of L2 users, depending on their level. However, native speakers usually process figurative use unconsciously without ever realising it, in an online manner: "figurative thought functions automatically in people's online use and understanding of linguistic meaning" (Gibbs [1994] 1999: 18).

As a base form, the PU is an integrated whole, a unit that is unbroken and intact. Syntactically the base form never exceeds the boundaries of one sentence. Some PUs constitute a full sentence, including compound or complex sentences, but they never go beyond the limits of a sentence in their base form or core use. Examples include the die is cast; what good wind brings you here?; well, I never (did)!; you can take a horse to the water but you cannot make him drink; the right hand does not know what the left hand is doing.

It is important to know not only how phraseology is organised but also how it is stored and retrieved. The base form as the invariable form and meaning of the PU is part of the mental lexicon, ${ }^{5}$ which is the storehouse of all the PUs that a person knows, integrated into one's general store of knowledge. PUs become stored knowledge once they have been acquired. They are located in long-term memory. ${ }^{6}$ Cognitive psychology gives an insight into the processes whereby language material is stored and recalled. The learner needs a certain level of ability and skills to acquire new PUs and draw on particular knowledge which is stored in the system of language.

Knowledge and understanding of the base form are essential for both research and practical applications, such as teaching and translation (see Ch. 7). Failure to identify the base form may lead to inaccuracy in theoretical conclusions. When discussing PUs in Shakespeare's plays, Sviridova (1968:7) comes to

5. To understand more about the mental lexicon and the processes in which human language is learned, produced, and processed, see Kess (1992: Ch. 3-4); Aitchison (2003). Moon reports some of the findings of psycholinguistic research in fixed expressions and idioms. Although some of the results are hypothetical and even contradictory, research in language acquisition suggests that language is learned, stored, retrieved, and produced in holophrases and other multi-word items, not just as individual words or terms (Moon 1998: Ch. 2).

6. See Eysenck for an account of the workings of long-term memory (1993: Ch. 4). For types of memory, see also Reber ([1985] 1995:446-449). 
the conclusion that to bite one's thumb at someone is an expression created by Shakespeare in Romeo and Juliet (see the analysis of this PU in Ch. 5.4). In order to establish the base form of a PU recorded in the 16th century, a diachronic study is essential. Historical material shows that this PU was used before Shakespeare wrote this play, for example:

I see Contempt marching forth, giving mee the fico with his thombe in his mouth.

Wits Miserie, Brewer's Dictionary of Phrase and Fable: 897

It is known that Shakespeare wrote his first sketch of Romeo and Juliet in 1597 (Buchan 1935: 119), that is, after Wits Miserie (1596). This clearly shows that the PU can by no means be attributed to Shakespeare. It is also important to avoid another mistake: to regard the first written record of a PU as its origin. It should be remembered that most PUs are created by the people who use the language, so that only a few PUs can be traced back to a specific author. For instance, although Chaucer's works contain rich phraseological material, none of these PUs can be attributed to Chaucer. He used the phraseology that was part of the language of his time.

As to the PU to bite one's thumb at someone, it is perfectly clear from both the examples - in Shakespeare ${ }^{7}$ and Wits Miserie - that these PUs were by no means new to readers or audiences of the 1590s, as both of them have been used with stylistic changes.

Taking into account the most typical features of the base form, its essential character could be summarised as follows:

the base form

- a form of the PU outside discourse;

- the form to which other forms of the PU can be related;

- used as a base when assessing PUs used in discourse;

- the form in which PUs are stored in the long-term memory of the language user as reproducible language units;

- accessed when a discourse situation calls for it.

In conclusion, the PU is an archetypal conception in its base form. As a decontextualised unit of language, it is generic to all manifestations of a particular PU in discourse or a totality of discourses. The base form is a cohesive entity per se which secures the existence, development, and sustainability of the PU in discourse. PUs are stored in base forms as part of stored language information. It is

7. See the analysis of Shakespeare's stylistic use of this PU in Ch. 5.4. 
possible to recall them because they are stable, cohesive, and figurative chunks of information.

\subsection{Core use}

In text, phraseological units often appear in their standard form and meaning. ${ }^{8}$ I introduce the term core use ${ }^{9}$ to denote the basic, most common, essential form and meaning which is the invariable of the $\mathrm{PU}$ available to a language user. The concept of core use implies the essential features of the entity. In their core form and meaning, PUs are used and understood by the majority of speakers. In many ways core use resembles the base form, and it never exceeds the boundaries of one sentence, just as the base form. Core use constitutes the "perfect" example.

Core use realises the cohesive relations inherent in the base form. Contextual changes are insignificant; they are grammatical changes in order to comply with the requirements of the sentence. The base form remains largely intact and no act of creation is involved in the case of core use, for example,

\section{to foul one's own nest}

"Well," she said, "I must say, your husband has caused a marvellous lot of mischief, Mrs. Bostock. He's fouled his own nest, indeed he has; done a lot of damage to others and no good to himself."

D. H. Lawrence, $M r$ Noon

Man has invented a hundred brilliant ways of fouling his own nest - the grime, the pollution, the heat, the poisons in the air, the metals in the water.

CCDI: 274

8. Numerous studies have investigated the standard form and meaning of PUs. See the study of idioms in, for example, Häusermann (1977); Makkai (1978); Fernando and Flavell (1981); Strässler (1982); Moon (1988, 1992); Fernando (1996); Moon (1998). Fernando and Flavell extensively study the formation and nature of idioms. Strässler offers a pragmatic analysis and views idiomaticity as a cross-cultural phenomenon of language in use. Phraseology received much attention and was investigated on a wide scale in the former Soviet Union; see, for example, the works of Kunin and his followers (Kunin 1970). Core use of idioms in spoken discourse has been examined by McCarthy (1998: Ch. 7). Many articles explore various aspects of standard form and use of PUs in Granger and Meunier ([2008] 2009b).

9. The term prescriptive use, which was suggested by Kunin in English, does not seem to meet the needs, as in traditional grammar the aim of prescription is to describe the language not as it is used, but as it is thought the language ought to be used, even condemning certain usages (Baugh and Cable [1951] 2001:273-275; Wales [1989] 1995:317-318). Prescription is also defined as an authoritarian statement about the correctness of a particular use of a language (Crystal [1987] 1995: 428). The term introduced by Kunin in Russian is uzual'noye upotrebleniye ("usual use"). 
The PU is marked per se; it is a stylistic item of language. Figurative meaning is an inherent feature of the base form of PUs, that is, the form and meaning stored in the long-term memory of the language user or in a dictionary, for example, to let the cat out of the bag. Figurativeness as one of the inherent features of the PU stipulates that at least one of the constituents must have a figurative meaning. ${ }^{10}$ Any figurative meaning is marked in contrast to the literal meaning. On the one hand, in its core use the PU operates without additional stylistic changes. It functions in a way that can be expected and predicted and has the same stylistic effect as the base form. On the other hand, in its base form a PU is not a stylistic void, as style ${ }^{11}$ is part of phraseological meaning. The stylistic features of the base form have a cohesive role; their main types are as follows: ${ }^{12}$

\section{types of figurative meaning:}

- metaphor, e.g., there's no smoke without fire; to break one's heart;

- metonymy, ${ }^{13}$ e.g., to wear the stripes; to lend a hand;

- hyperbole, e.g., to move heaven and earth; to feel like a million dollars;

- understatement, e.g., a bit of all right; to take a bit of doing;

- allusion, e.g., Hobson's choice; between Scylla and Charybdis;

- oxymoron, e.g., cold comfort; (as) clear as mud;

- euphemism, e.g., to be economical with the truth; to pay a call;

- periphrasis, e.g., when pigs fly; the eleventh hour;

- antonomasia, e.g., the Iron Lady; to meet one's Waterloo;

- antithesis, e.g., a big fish/frog in a little/small pond; for better for worse;

- transferred epithet, e.g., the Wailing Wall; the dark continent;

- irony, e.g., an eager beaver; like turkeys voting for Christmas;

phonetic features:

- alliteration, e.g., live and let live; chalk and cheese;

10. For instance, to have a bird's-eye view; a nine-day wonder.

11. By style of the base form I understand the set of distinctive stylistic features characteristic of the PU. See Wales ([1989] 1995:371).

12. It is not my aim to study the stylistic features of the base form and core use in more detail, as it is a special area of research in its own right.

13. For the intricate interaction of metaphor and metonymy, see, for example, Lakoff and Turner (1989: 100-106); Gibbs ([1994] 1999:319-358, 2007: 19-31); Barcelona (1998, 2000a:31-144); Steen (2005). Over the past decade metonymy has received sustained attention in cognitive research. "It is impossible to study metaphor without addressing metonymy" (Forceville and Urios-Aparisi 2009a: 12). 
- assonance, e.g., there's no fool like an old fool; a cat has nine lives;

- onomatopoeia, e.g., scratch my back and I'll scratch yours; to crash and burn;

prosodic features:

- rhythm:

iambus: ${ }^{14}$

e.g., $\quad$ to grin from ear to ear

$\cup \perp|\cup \perp| \cup \perp$

a game of cat and mouse

$\cup \perp|\cup \perp| \cup \perp$

dactyl:

e.g., $\quad$ none of your business

$\perp \cup \cup / \perp \cup$

nobody being the wiser

$\perp \cup \cup|\perp \cup \cup| \perp \cup$

trochee:

e.g., every little makes a mickle

$\perp \cup|\perp \cup| \perp \cup \mid \perp \cup$

neither fish nor flesh nor good red herring

$\perp \cup|\perp \cup| \perp \cup|\perp \cup| \perp \cup$

anapaest:

e.g., at the end of the day

$\cup \cup \perp / \cup \cup \perp$

on the knees of the gods

$\cup \cup \perp / \cup \cup \perp$

- internal rhyme, e.g., by hook or by crook; (as) snug as a bug in a rugg;

lexical features:

- repetition, e.g., handsome is as handsome does; to run neck and neck;

- archaic constituents, e.g., never the twain shall meet; hell hath no fury like a woman scorned; ${ }^{15}$

14. Iambus is the most typical rhythm in English. It broke the tradition of alliterative verse of Old English from the 8th up to the 11th century and also the accentuated verse of the 12th14th centuries. The formation of English iambus is best seen in the works of Chaucer, who uses both iambic tetrameter and iambic pentameter. Chaucer is considered to be not only the father of English literature, but also the father of iambus in English.

15. It is interesting to note that some PUs with archaic constituents survive beautifully; for example, these two PUs are classified as "regularly encountered" by CCDI (1995: xvii). The survival of archaic constituents in the structure of PUs reveals the force of cohesion. 
- word formation elements, for instance, diminutives, ${ }^{16}$ e.g., Johnny Newcome/ Johnny Raw; to take the mickey;

grammatical features:

- parallelism, e.g., easy come, easy go; an eye for an eye, a tooth for a tooth;

- interjections, e.g., hear, hear! bully for you!

- rhetorical questions, e.g., with friends like these, who needs enemies? what does the moon care if the dogs bark at her?

\section{register:}

- formal, e.g., an olive branch; a litmus test;

- informal, e.g., to hold one's own; to go easy on something;

- slang, e.g., shit and get off the pot; to get one's arse in gear.

These stylistic items may occur alone or in combination with other features. The semantic structure of phraseological meaning frequently includes a number of stylistic techniques. Innumerable PUs feature two or several stylistic properties that shape the stylistic potential of the PU:

two heads are better than one (metaphor + metonymy);

to have one's hand in the till (metaphor + metonymy + euphemism);

to make a mountain out of a molehill (metaphor + hyperbole + alliteration);

Adam and Eve's togs (allusion + euphemism);

the gentleman who pays the rent (periphrasis + euphemism + irony);

little love lost between (understatement + alliteration + irony);

out of sight, out of $\underline{\underline{\text { mind }}}$ (metaphor + parallelism + assonance + anapaest).

Core use realises and brings out the stylistic potential of the base form. This capacity operates as a means of cohesion and helps to understand and explain the stability of phraseological form and meaning.

Core use is predictable and readers or listeners know what it is likely to be once it is recognised. They already know the base form and meaning. Prior knowledge of the PU leads to anticipation of core use: it is taken for granted. In more familiar and longer PUs, recognition sets in with the first base constituents, for example to fiddle while ... (... Rome burns); never put off till ... (... tomorrow what you can do today; like looking for a needle ... (... in a haystack); much ado about ... (... nothing). All that is left to do is to grasp the minor contextual changes of the application. For the purposes of teaching phraseology at the initial stage, foreign language teachers often make use of the inherent cohesion of PUs and practice

16. For diminutives in phraseology see Ch. 5.2. 
cloze exercises, tick box exercises or other gap-filling exercises. ${ }^{17}$ In their core use, PUs lend themselves very well to filling in the gaps if one or several elements are deleted. This methodology does not work with stylistic use, which would be impossible to predict, cf.:

Lately there's been much ado about the ducks belonging to my poultry-farming neighbour.

CCDI: 3

This kind of stylistic realisation is not foreseeable and does not lend itself to any gap-filling exercise. For teaching stylistic use, more creative exercises and strategies need to be devised. This objective also calls for a cognitive insight into the mystery of creating novel form and meaning. Core use is not always best suited for the purpose of verbalising a person's feelings, thoughts, and experiences, nor does it adequately convey the meaning which the discourse situation requires. As a frequently recurrent item, core use sounds more common and conveys less information in comparison with the infrequent unusual stylistic instantiations.

In conclusion, core use brings out the essential cohesive qualities of PUs. The most important features of core use may be summed up as follows:

core use

- is use of the PU in its most common form and meaning;

- does not acquire additional stylistic features in discourse;

- does not exceed the boundaries of one sentence, just as the base form;

- is predictable once the PU has been identified.

In text, PUs often appear in their core use, that is, in their standard form and meaning. As core use is confined to a single sentence, it does not assume a discourse dimension. It never reaches out to embrace several sentences, let alone a paragraph or a chapter or a part of a book. Discoursal stylistic use is much more complicated and offers much more than meets the eye.

\subsection{The concept of instantial stylistic use}

In discourse, PUs may occur in their core use or they may appear in a creative instantiation, that is, in an enhanced light, and acquire a different discourse-related emphasis in a specific stylistic realisation. I would like to introduce the term

17. See, for instance, McCarthy and O’Dell ([1994] 1995: 148-169). 
instantial stylistic use $e^{18}$ to denote a particular instance of a unique stylistic application of a PU in discourse, which results in significant changes in its form and meaning determined by the thought and the context. This mental activity is "an instance of meaning construction" (Radden et al. 2007: 1). However, the concept of instantial stylistic use does not merely imply an instantiation of a stylistic change in a specific case in a particular discourse environment or even just a single case of a new discourse form which an author has created. In more general terms, instantial use $\mathrm{e}^{19}$ of PUs represents a broad linguistic category. For phraseology, it is a way of being. In cognitive linguistic terms, it is a mode of conceptualisation.

I would like to use the following figure (Figure 2.1) to illustrate realisation of PUs in discourse: ${ }^{20}$

Phraseological Units (PUs)

\begin{tabular}{|c|c|c|}
\hline$P U s$ in the system of language & base form & \\
\hline PUs in discourse & core use & instantial use \\
\hline
\end{tabular}

Figure 2.1 Phraseological units in language stock and in use

Instantial use is a process that creates new form and meaning in discourse. It is also a mechanism that secures stylistic use on each particular occasion and gives rise to a form and a text meaning unique to the specific instance. ${ }^{21}$ It is common

18. The term instantial stylistic use conveys some essential features of the phenomenon; the same refers to noun instantiation. Cf.: instantial premise (in logic) - a premise concerned with or arising from a particular case.

A great number of terms have been used to denote significant stylistic changes of PUs in use over recent decades. The oldest of these terms is occasional changes. The term is a loan translation from the Russian okkazionalniye izmeneniya introduced by Kunin $(1964,1969)$. It lays emphasis on the random occurrence of these changes; therefore, it fails to satisfy the theoretical requirements. However, it was the most commonly used term throughout the former Soviet Union and is still used today. The term transformations used by a number of linguists has unwelcome associations with transformational grammar.

19. From here on, the term instantial means instantial stylistic.

20. In Figure 2.1, the graphical presentation of the division between core use and instantial use does not reflect their actual proportion in use as it varies from author to author and from text to text. The frequency of instantial use also depends on the genre and the period. It may differ in the works of the same author.

21. Halliday and Hasan have noted that, without being aware of it, each occurrence of a lexical item carries with it its own textual history, a particular collocational environment that has been built up in the course of creation of the text and that will provide the context within which the item will be incarnated in this particular instance (Halliday and Hasan 1976:289). 
knowledge that form reflects meaning and is inextricably connected with it. Indeed, form is also the structure of meaning and one of its aspects. With a new discoursal form, the PU acquires a new meaning and stylistic effect. The effect of novelty is achieved by virtue of semantic and stylistic ties. The cohesive properties inherent in the base form secure instantial use. The concept of instantial use is a stylistic one.

Instantial use operates at the interface between the base form of the PU and the textual reality. It is a semantic and stylistic relationship linking the PU as a language unit to its instantial application. This relationship is similar to that of other language units (words, morphemes) and the contexts of their stylistic use.

Instantial use draws from the phraseological stock of the language. Hence it implies the juxtaposition: base constituents vs instantial constituents. The base form is the backdrop against which the instantial stylistic effect is perceived. It involves a contrast between tradition and novelty, the familiar and the unfamiliar: ${ }^{22}$ predictable core use vs the largely unpredictable instantial realisation of the PU. According to information theory, the item has less information content if it is highly predictable, but it carries more semantic information if it is less predictable.

What constitutes the variable aspect of the PU that distinguishes one stylistic realisation of a PU from another? What determines the range of possibilities that exist for realising a PU in order to create text? The differences lie not only in the stylistic choices of instantial constituents, but more importantly in the type of change, as well as in the effect of realisation and distribution. The same patterns ${ }^{23}$ may be found in oral and written discourse with a varying degree of frequency and density. The seemingly discontinuous and complex ways of phraseological use are actually a set of rules for turning the base form into an instantial application. Instantial use may be realised in one sentence or it may exceed sentence boundaries. It may also be carried over to subsequent paragraphs, chapters, parts of a book, or even cover a whole book.

Instantial use is a resource upon which language users draw in order to convey ideas and experiences which the base form of the PU is unable to express or for

22. The idea of the contrast between the familiar and the unfamiliar goes back to Aristotle's Poetics. It was developed by the Russian Formalists and further elaborated by the Prague School. For a systematic survey of the history of foregrounding, see van Peer (1986: Ch. 1). The concept of foregrounding proceeds from an analogy with a fundamental characteristic of human perception, that is, the necessity to distinguish a figure against a ground in the act of perceiving. This distinction functions aesthetically in the visual arts (van Peer 1986:21). For a study of foregrounding theory in the 21st century, see Language and Literature 16(2), 2007.

23. For understanding the concept of pattern of instantial use, see Ch. 3.2. 
which it turns out to be inadequate. It is one way to make language operational in certain contexts, as distinct from the base form, which is not functional or operational and which is reminiscent of an inventory or stock of PUs in the system of language. It is also distinct from core use, which is functional but which does not exhibit any relevant semantic or stylistic difference in comparison with the base form. Instantial use is a tool for stretching the imagination. Imagery and imagination have always been considered to be basic tools for discoveries in creative acts that enable people to arrive at new ideas, new views, and new relationships which initially were not obvious (Cornoldi and Logie 1996:3-17).

Instantial use is commonly exploited in cases when a need arises for greater cohesion in some part of the text. It is also used in emotionally tense situations or in discourses of conflict, producing a focal stylistic effect. Instantial use may set the tonality of the narrative or highlight the finality of the end of a paragraph or passage. Instantial use is both the process and the result of meeting the needs of a new discourse environment; thus it significantly contributes to the textual organisation of a narrative and enhances creation of text unity.

Instantial forms are stylistic instances of naturally occurring PUs in discourse. Although they carry distinctive structural, semantic, and stylistic features which distinguish them from the base form, the semantic relationships inherent in the base form may not be immediately apparent in their discourse manifestations. Instantial changes may seem nonsensical if taken out of context. It is the thought of the language user that shapes the meaning of PUs, and hence their form, in discourse. It is the context that helps to identify new semantic and stylistic relationships in discourse in each single instance of stylistic use.

The basic aim of the existence of instantial use is not to create neologisms, that is, new PUs in the system of language (although it may happen in exceptional cases, for example, in case of ellipsis in longer proverbs). Instantial use is a life form of PUs in discourse. Interestingly, data on instantial use in The Complete Works of Geoffrey Chaucer reveal that none of the 1164 instantial forms became part of the phraseological stock of the English language despite his popularity and despite universal acclaim of his status as the father of English literature (see Ch. 1.2).

How far can instantial use be stretched? To what lengths can it go? Actually it can be extended reasonably far, so long as ties with the PU are not severed, cohesion and coherence are not endangered, associations persist, and the stylistic effect endures.

What is needed to produce a novel instantial form of a PU? Three major elements serve as preconditions:

1. knowledge of phraseology and stylistic patterns,

2. stylistic discoursal skills, 
3. cognitive skills with a certain element of imagination and creativity and the ability to think outside the box.

Interestingly, creativity also results from a random element of thinking which contributes to the unique character of the novel formation. Cognitive psychology admits that creativity is hard to measure or access, and is by definition unpredictable. This relates to the famous Jakobsonian defeated expectancy effect which is also characteristic of instantial use of PUs. The particular manifestation differs from the base form as a result of random elements in thinking to meet the needs of the specific discourse situation.

What is common to all instantial use? It is the input of a base form of a PU and a pattern of instantial use, which are both stable, coupled with creative thinking, including a capacity for associative thinking and random observations. The mystery of the cognitive process of creation is of great interest for discourse analysis. The output is an instantial form of a PU, which is a non-stable, largely unique unpredictable formation that is beyond the ordinary way of expression. It conveys new shades of meaning and often works for greater cohesion of discourse.

The main features of instantial use can be singled out as follows:

\section{instantial use}

- is a single instance of a unique stylistic realisation of a PU in discourse,

- is semantically and stylistically related to the base form,

- creates significant changes in form and meaning determined by the thought and the context,

- draws upon the cohesive ties of the base form,

- is a boundless resource for writer or speaker creativity.

In conclusion, by instantial stylistic use I understand a particular instance of a unique stylistic application of a PU in discourse which results in significant changes in its form and meaning determined by the thought and the context. The inherent cohesive qualities of phraseology are best brought out by instantial use. It explores experiences far beyond the possibilities of mere core use, is more sophisticated and therefore requires a greater amount of processing and analysis than core use.

\subsection{Identification procedure}

It is known that reading involves interaction of the mind with the text and places certain demands on its readers in terms of inference-drawing (Emmott [1997] 1999). The cognitive approach to metaphor has contributed greatly to identifying, 
understanding, and appreciating lexical metaphor ${ }^{24}$ in language and in discourse processing (Steen 1994; Gibbs 1995:97-116, 2002; Steen 2002a, 2002b; Pragglejaz Group 2007). However, identification of phraseological metaphor presents additional challenges due to theoretical obscurity and increased textual complexity. Kunin's method of phraseological identification proves to be extremely useful in identifying PUs in core use to distinguish them from free word combinations, set phrases, and compound words (1964: 416-420, 1970:45-48, 1986:35-40). My aim is to offer a procedure for identifying instantial stylistic use of PUs in discourse.

For the purposes of linguistic analysis it is useful to devise an identification procedure. I follow Steen in believing that "methodology plays a fundamental part in reducing the role of personal bias and error as well as optimising the chances for reaching reliable and valid argument" ([2007] 2009:402-403). In this book, I deal with discourse analysis. ${ }^{25}$ Hence, to meet the challenges of instantial use in discourse it is necessary to establish a set of identification techniques, not based on intuitive understanding of a specific instantial form, but providing a tool to cope with the infinite variety of discoursal forms and meanings.

Discourse analysis has been greatly influenced by several areas of applied linguistics and cognitive psychology of language. These offer interesting findings on perception and cognition, indicating that "words with more than one meaning must be disambiguated according to their context" in a stream of speech (Tabossi and Johnson-Laird 1980:595).

As PUs are stable language units with a certain degree of figurative meaning (full or partial), they will always have to be disambiguated in this sense. Moreover, the PU is, by definition, a combination of words; it is always longer that one word and thus additional difficulties are created, involving changes in the structure of the PU and several meanings which may be at work in discourse. The PU needs to be identified and its base form resurrected to serve as a background against which instantial use stands out as a unique contextual formation. Only in contrast can the true discoursal effect be established.

In reading or listening, discourse is processed all the time whether consciously or not. The reader or the listener is concerned with an exceedingly complex inferential process in both written and oral discourse. Knowledge of the linguistic

24. I use the term lexical metaphor as opposed to phraseological metaphor, that is, a metaphor which is part of the image of the PU in its base form.

25. The term discourse analysis was introduced by Harris to denote analysis which goes beyond the limits of a single sentence (Harris 1952:1-30). Instead of working with isolated sentences and taking text to pieces, and analysing word use, sentence structure and metric features, discourse analysis has broadened the scope in observing stretches of text unified by meaning (Crystal [1987] 1995: 78; Cook 1994). 
features of PUs and their possible applications in discourse facilitates recognition and identification. It follows that inability to cope with ambiguities caused by a figurative interaction of language elements may inhibit comprehension and a faithful evaluation of the aesthetic or pragmatic implications of text. Semantic and stylistic identification fosters comprehension, leading to more accurate interpretation of the relevant stretch of text.

It is essential to establish a procedure for discovering instantial stylistic use in the flow of discourse and to set out a sequence of directions in order to avoid subjective judgement as far as possible. This is especially important for L2 learners, even at the advanced level. These difficulties are best seen when reading Shakespeare's plays. In teaching, we often see that our students are reluctant to read them. If they do, they find the texts baffling and difficult to interpret or analyse. The difficulty actually does not lie in the vocabulary, as obsolete and rare words can be looked up; the same applies to allusions to the Bible and historical facts. It is the stylistic complexity of the text and the figurative use of language that make reading difficult. Moreover, identification of the stylistic use of PUs is more difficult than analysis of separate lexical items. This is due to instantial stylistic use. That is why it is important to single out a number of discrete steps to aid the process of identification, which can be divided into several phases: recognition $>$ verification $>$ comprehension $>$ interpretation enabling the reader to cope with the complexities of discourse. Graphically, the stages of processing may be presented as follows (Figure 2.2):

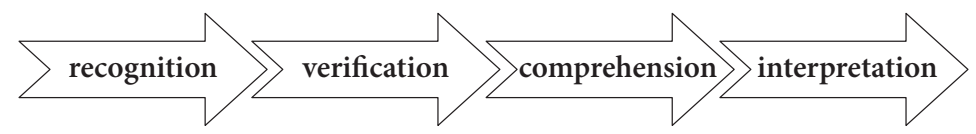

Figure 2.2 Procedure of identification of instantial use of PUs

\section{STAGE I: RECOGNITION}

The identification procedure is a multi-layered process, pursuing a number of aims. It starts with perception, which implies recognition and understanding of the item. This is an early cognitive stage. Recognition is awareness that the item has been previously seen, experienced, or learned.

Identification is at least in part a psychological cognitive phenomenon. PUs are recognisable, emerging in our perception, drawing on past experience and expectations of a novel form. Yet frequently these forms are still uncertain, unidentified items. Only on closer inspection is attention focused on them or their constituent parts. Readers or listeners train their eye or ear on instantial use of 
PUs, seeking to discern it in texts, and recognise that discourse is a coherent identifiable entity.

It is important to understand the complex mental processes in the brain that underlie cognitive performance. Many cognitive linguists believe that information processing in people resembles that in computers (Eysenck 1993:3). One of the first steps in processing for meaning is to search ${ }^{26}$ for the PU in the mental dictionary that we carry about in our heads (op. cit.: 11-12). This dictionary is used to comprehend written and spoken discourse. Storage and recall of PUs is an interesting area which to my knowledge has not been fully researched as yet. Obviously we consult the mental lexicon and scan through our memory to achieve recall, as PUs are located in our long-term memory, in the same way as words. During recall, reproductive memory helps to retrieve the stored base forms. In short, the reader or listener recalls the base form stored in long-term memory before interpreting the information or during the process of interpretation.

Associations play an essential role in recognition. They help to activate longterm memory and to recognise the figurativeness of phraseological meaning. Imagery ${ }^{27}$ evokes mental pictures and assists in reproducing the base form. The image-bearing constituents are crucial in semantic and stylistic processing leading to recognition and identification of the target PU. Failure of retrieval from the long-term memory store will result in failure to fully comprehend the text.

At present, software programmes do not permit complete automatic retrieval of stylistic changes in PUs. It is not possible to identify the whole context but only the closest instantial constituents, so that identification of the rest of the figurative network remains to be carried out by manual search. Cases of phraseological allusion do not lend themselves to electronic retrieval, especially if only one explicit constituent of the PU is left in the context. Hopefully, future development of linguistic techniques may create tools to retrieve stylistic use of PUs in discourse. For the time being, we must rely on human cognition and linguistic competence for recognition.

\section{STAGE II: VERIFICATION}

Verification necessitates accessing the base form and meaning of the PU in an effort to comprehend and interpret the discourse formation. Establishing a base

26. In cognitive psychology a memory search is a process where alternatives are considered until the target has been found or some piece of information has been located (Reber [1985] 1995: 695-696; Garman [1990] 1996:309).

27. In psycholinguistics it is generally believed that "the more imageable an item is", the better it is recalled in memory and the better such sentences are processed (Kess 1992:233). 
form is a fundamental requirement in any phraseological research. To establish the base form of the PU means to determine its stability and ascertain its accuracy. The base form possesses a considerable degree of stability of form and meaning at a particular stage of language development. ${ }^{28}$

Knowledge and understanding of the base form is central in discoursal studies of PUs, including advanced studies. The verification phase is a cognitive process designed to test the truth and accuracy of the form by careful investigation. This involves validating the base form as part of input data in an act of realisation of PUs in discourse and confirming the correctness of perceptions.

This procedure implies differentiating the old, previously seen material from the new elements - the old vs the novel - and singling out the base form of the PU as a decontextualised item of the stock of language. For foreign language learners, this means being on very friendly terms with their dictionary or preferably a number of dictionaries. Actually it may seem at first glance that establishing the base form is a compulsory requirement only for L2 learners. Basically this is true, but, as textual data show, it may not be easy to draw a line of distinction between a PU and a free word combination. This is very well seen in lexicographical practice. Beyond that, identification of the base form is of crucial importance in diachronic studies of phraseology, especially when going back not only to the Old English and Middle English periods, but also the Early New English period, for example, the works of Shakespeare. Are we dealing with a PU which has become obsolete or is it a free word combination? It is equally important, indeed increasingly difficult, when we deal with PUs which are new acquisitions in the language, whether native neologisms or loans from a foreign language.

In an attempt to avoid possible errors it is of vital importance:

- to establish the presence of figurative meaning,

- to prove the stability of the base form as an inherent feature of the PU at all levels: grammatical, lexical, and semantic versus non-stable figurative formations,

- $\quad$ to establish whether the PU has any variants ${ }^{29}$ and thus exclude the possibility of confusing core use and instantial use:

28. Stability of phraseological form and meaning certainly does not exclude diachronic changes over longer or shorter periods of time.

29. For types of phraseological variants, see Kunin (1965, 1970: 160-169). See also Moon (1996, 1998: Ch. 6) and Gläser ([1998] 2001: 129-130) for discussion and illustrations of the numerous kinds of variation. For variants of American proverbs, see Mieder (1992). 
a. two or several variants of the base form, e.g.,

to lead someone a merry dance/chase

a scarlet lady/whore/woman

to slip on a banana skin/peel

a big fish/frog in a little/small pond

to strike/touch a cord

not to lift/raise a finger

a pretty/fine kettle of fish

It is impossible to determine the type of discoursal use (core use or instantial use) in the following examples without establishing the base form to fight tooth and nail/claw, which is not a case of instantial replacement ${ }^{30}$ but one of lexical variants:

It was one of the hardest lessons Alvina had to learn - to bully these people in their own hovels, into some sort of obedience to her commands and some sort of respect for her presence. She had to fight tooth and nail for this end.

D. H. Lawrence, The Lost Girl

The pair had fought tooth and claw for four hours and eight minutes until John McEnroe emerged the victor.

CCDI: 396

As the base form serves to create both core use and instantial use, differentiation of variants and possible instantial constituents is important for discourse analysis.

b. variants in the varieties of BrE, AmE, and AustrE:

BrE vs AmE, e.g.,

like a child in a sweet shop $(\mathrm{BrE})$ vs like a kid in a candy store $(\mathrm{AmE})$

quote, unquote $(\mathrm{BrE})$ vs quote, end quote $(\mathrm{AmE})$

to beat about the bush (BrE) vs to beat around the bush (AmE)

to throw one's weight about $(\mathrm{BrE})$ vs to throw one's weight around $(\mathrm{AmE})$

not to see the wood for the trees $(\mathrm{BrE})$ vs not to see the forest for the trees (AmE)

to go red as a beetroot (BrE) vs to go red as a beet (AmE)

to chew the fat $(\mathrm{BrE})$ vs to chew the rag $(\mathrm{AmE})$

king of the castle $(\mathrm{BrE})$ vs king of the hill $(\mathrm{AmE})$

BrE vs AustrE, e.g.,

to be home and dry (BrE) vs to be home and hosed (AustrE)

30. Replacement is an instantial pattern involving substitution of a base constituent by one or several instantial constituents. For replacement in phraseology, see Sabban (1998b: 165-192). 
$\underline{B r E}$ vs AmE vs AustrE, e.g.,

to talk the hind leg off a donkey/a dog/a horse (BrE) vs to talk the bark off $\underline{\text { a }}$ tree (AmE) vs to talk the legs off an iron pot (AustrE)

c. variants existing in a particular dialect:

to set the heather on fire (Scots) vs to set the Thames on fire

d. variants as a result of phraseolgical derivation, ${ }^{31}$ that is, formation of new phraseological units from existing ones, for instance, by way of isolating a certain group of constituents:

- initial constituents, e.g.,

a new broom < a new broom sweeps clean

it's an ill wind < it's an ill wind that blows nobody any good

too many chiefs < too many chiefs and not enough Indians

- medial constituents, e.g.,

a black sheep $<$ there is a black sheep in every flock

doctors differ $<$ when doctors differ, who is to decide?

red herring < to draw/drag a red herring across the path/track/trail

- final constituents, e.g.,

to hang in the air < to be left hanging in the air

a silver lining < every cloud has a silver lining

to break the camel's back < it is the last straw that breaks the camel's back

e. identification of simultaneous use of two variants used in one context for the sake of intensification, including reiteration in an instantial form, e.g.,

(to have) a finger in the pie/a hand in the pie $^{32}$

"I didn't invent the problem," said Gilbert.

"Who did then?"

"Her father, society, and fools."

"You had no hand in it, then. You had no finger in the pie?"

"Be hanged to fingers," said Gilbert.

D. H. Lawrence, $M r$ Noon

Verification of phraseological meaning may also come up against the issue of polysemy, ${ }^{33}$ which exists in phraseology, although far less widespread than in words. See CCDI for examples, e.g., out of the box, off the boil, to skin someone alive, up the

31. For phraseological derivation, see Kunin (1980).

32. The PU to have a hand in the pie is obsolete in MoE.

33. For polysemy in phraseology, see Kunin (1967b:5-7); Moon (1998: 187-193). 
spout, over the top, to get to first base and others. For instance, the PU a basket case has two distinct meanings. If you describe a country or organisation as a basket case, you mean that its economy or finances are in a very bad state, e.g.,

The popular image about Latin America a few years ago was that it was a basket case.

CCDI: 20

Whereas, if you say that someone is a basket case, you mean that they are crazy or insane, e.g.,

Mary comes to work in tears every day, and you wouldn't believe the bags under her eyes. She's gained fifteen pounds as well. I tell you, she's turning into a basket case.

CCDI: 21

A language can normally tolerate such a semantic overload, because context aids selection of the appropriate meaning (Wales [1989] 1995:309). In some cases the polysemy of phraseological meaning may serve as a basis for instantial use (see Ch. 4.2 for punning on the PU good morning! in Tolkien's The Hobbit or There and Back Again). The existence of polysemy in PUs only reinforces the need for verification.

\section{STAGE III: COMPREHENSION}

By comprehension I mean a cognitive act which yields deep and thorough understanding of meaning construal and of interrelationships in a specific case of discoursal use. The comprehension stage ${ }^{34}$ precedes interpretation; it is a cognitive search that leads to analysis. Psycholinguistic evidence suggests that "the different senses of an ambiguous word are accessed ${ }^{35}$ during comprehension" (Tabossi and Johnson-Laird 1980:596). The text environment frequently provides a great deal of hidden information that is relevant to comprehension and interpretation of instantial use.

What information is required to secure comprehension? This poses a number of important questions which need to be resolved in the process of identification.

34. Cognitive psychologists often include interpretation in the comprehension stage. It is argued that the comprehension process has two distinct interlocking constituents: a construction process whereby an interpretation of the material is built up and a utilisation process whereby the interpretation is used for the specific aims in hand (Reber [1985] 1995: 144).

35. Access refers to retrieval of information from memory; it is used to denote the process and the actual fact of recall (Reber [1985] 1995:4-5). 
Is the given case core use or is it a stylistic instantial application of a PU? It goes without saying that instantial use cannot be understood and analysed without background knowledge of the base form. How do the two forms of the PU differ? How has the instantial form been created in contradistinction to the base form?

The act of understanding specific instantial use entails an insight gained by establishing the mechanisms and tools which have created the new instantial form and meaning, namely, by identifying the stylistic pattern or patterns used in the given context (see Ch. 3.2). Verification of the input data refers not only to the base form but also to the pattern employed in the given instance. It is fascinating to observe and examine the kinds of instantial patterns which PUs may assume in discourse, various sets of elements and their sequence, as well as presence of new instantial elements and absence of some elements recorded in the base form. It is also useful to note any eye-catching features or comments which may refer to the specific instantiation.

Identification of instantial use is facilitated by establishing cohesive links. Comprehension of phraseological cohesion and coherence forms part of cognitive performance. While identifying phraseological cohesion and making clear decisions about what constitutes a case of a single application of the PU is difficult, it is important to resolve each instance to avoid ambiguity. The cohesive effect is determined by the closeness of ties between constituents of the base form and the new instantial elements. Since the writer or speaker employs cohesion to establish intertextual links, the reader or listener is expected to recognise and identify this figurative network in order to interpret the textual qualities. If this process fails, coherence will be absent. In order to form judgements about written discourse, the reader needs to explore the cohesive structure of the details going back to preceding passages or chapters and examine subsequent ones. Hence the two basic reading techniques are as follows:

1. going back in the text, tracing backward associations, that is, ties between the PU and an item or a series of items that precede it, tracing any elements leading to instantial use, for example, separate constituents or words that anticipate the appearance of the PU and act as a cue, as a signal that prompts the way the PU should be perceived. This technique implies scrutinising the text in anticipation of instantial use;

2. following the text to observe and trace development of the PU and its image. Facilitating the process of comprehension involves establishing associative connections with the PU and its image, including immediate associations which can be identified in the particular sentence and beyond its boundaries, as well as remote associations with a non-adjacent item. It is equally important to note associative chains and the appearance of some complementary 
images, reiteration of the PU or its constituents, allusion to an image, use of several stylistic changes within one PU, the appearance of derivatives made on the basis of the figurative constituents of the PU. At the same time, it is crucial to develop an ability to retain the phraseological image at the back of the mind for a longer stretch in an attempt to uncover underlying meanings, and to specify the mechanisms of associative connections. For purposes of analysis, it is useful to highlight instantial use in some way to gain a better insight into the web of interrelationships (see Appendix I).

Special attention should be paid to cues within the text. Identifying appropriate recall cues ${ }^{36}$ may facilitate recall of the base form and evocation of the phraseological image alluded to. Failure in retrieving the base form that phraseological allusion is built upon will inhibit response and result in a semantic and stylistic loss in perception of the text.

Emerging cues help to identify phraseological cohesion in the discourse environment. Failure to perceive these ties will likely lead to a loss in understanding of the whole network. On the other hand, the intended instantial use may be ineffective if the context does not provide enough cues to help identify the phraseological image.

In the process of identification it is useful to look out for the author's comments. These may pursue a number of aims. Apart from providing cohesion in text, ${ }^{37}$ they may indicate that the formation is perceived as a stable word combination by explicitly stating that it is a proverb or using an inserted phrase such as as the proverb goes, as the saying goes. For example:

The course of their true-love was as plain as a pike-staff. It led to a little house in a new street, and an allotment garden not far off. And the way thither, with kisses and the little plannings, was as sweet as if it had led to some detached villa, or even to one of the stately homes of England. It is all the same in the end: safe as houses, as the saying goes.

D. H. Lawrence, $M r$ Noon

The author's comments may disclose the etymology and semantic structure of the PU. For instance, in The Canterbury Tales Chaucer creates a pun by making a jocular comment on the literal meanings of the constituents:

36. For recall cues see Tabossi and Johnson-Laird (1980:596).

37. For the author's comments on the phraseological nature of PUs, see Naciscione (1976:17, 58). For the speaker's/writer's comments signalling the idiomatic status of FEIs, see Moon (1998:305-307). 
Murmure eek is ofte amonges servaunts, that grucchen whan hir sovereyns bidden hem doon leveful thinges; (...) whiche wordes men clepen the develes Pater-noster ${ }^{38}$ though so be that the devel ne hadde nevere Pater-nosterer but that lewed folk yeven it swich a name.

G. Chaucer, The Canterbury Tales, I, 506-508

The author's comments may take the shape of revealing remarks pronounced by an interlocutor in a dialogue, resulting in an instantial development (see, for example, use of the PU you have made your bed and you must lie on it in Maugham's play The Circle in Ch. 5.1).

The comments may also indicate that the author is not fully certain whether the reader will be able to resolve the allusion and perceive the intended stylistic effect: see Shakespeare's use of adage in Ch. 4.4.

The comprehension stage of identification is complete only if all the semantic and stylistic information contained in the base form is fully retrieved, all the inclusive evidence has been obtained from the context, and obscure words and semantic and stylistic interrelationships have been disambiguated.

Instantial use is one way to attract attention. The appearance of an instantial phraseological item arouses the reader's or the listener's interest, which is immediately engaged and held in an attempt to find some interpretation which can be resolved by recognition and comprehension as a starting point. Comprehension of instantial use of the PU facilitates interpretation of the text. "Understanding and interpreting are fundamental processes of the human mind" (Gibbs 1999a: 15).

\section{STAGE IV: INTERPRETATION}

The aim of the final stage is to interpret the discoursal features of instantial use and its stylistic message. In discourse analysis the instantial constituents are not to be considered as individual lexical items, but as part of an instantial stylistic application of the PU. Interpretation and analysis of their stylistic use involves seeing beyond the manifest instantial form to identify the base form, and past the manifest content to understand the underlying and partly hidden meaning(s) in an act of creative synthesis. Garman argues that "recognition is used where the assumption of processing via stored forms in memory is strong", while in contrast "interpretation more usually carries with it the implication of creative processing, going beyond the strict properties of the signal" ([1990] 1996:305). Interpretation makes the reasons for enjoying the text, and returning to it, more transparent (van Peer 2000:47).

38. The PU the devil's Paternoster was common in the MiE period, but is obsolete today. 
It is essential to identify and interpret the whole network of interrelationships which the specific instantial use has brought about, especially in cases which are extended over longer stretches of text or some part of it, with an eye to discourse analysis. Specific interpretation of seemingly unambiguous words may help to locate the metaphoric web that is sustained, and raise awareness of the interplay of figurative and literal meanings. Instantial use becomes part of the analysis of the purport and message of the text.

To conclude, the aim of this exercise is unambiguous identification of PUs in discourse. Each stage of the procedure depends on successful completion of the previous one. At the same time, these stages invariably overlap or somewhat interlock and merge with the subsequent one in a natural way. The existence of these four interlocking phases does not imply that they are exclusive or wholly separate. They are integral parts of a united cognitive process, which is active and dynamic. The result largely depends on the awareness of the reader or the listener, their identification skills, experience, and prior knowledge of both the base form and the instantial pattern. The process of identification is a cognitive effort, involving both conscious and unconscious experience and mental inferencing.

As Gibbs puts it, "all language interpretation takes place in real time ranging from the first milliseconds of processing to long-term reflective analysis". This temporal continuum may be roughly divided into moments corresponding to linguistic comprehension, recognition, interpretation, and appreciation ([1979] 1998: 255). The process of identification is essential for L2 learners when they face analysis of PUs unknown to them or stylistic contexts that prove to be a challenge in disambiguation. Identification aspects are important as they permit a more subtle understanding of novel thought representations and linguistic formations, which may seem to be nonsense if taken in a literal sense.

The final goal of the identification process is enhanced interpretation skills, which ensure capacity to cope with a new discourse environment: to make judgements about figurative and literal meanings, resolve ambiguities, consider all the cues, and understand the message. The effect of this process is corroborated by multi-level discourse analysis. The desired end result is the ability to draw inferences about what is being overtly said and what is being implied in any text, to retrieve what has been concealed. The creative element is essential. Instantial use is a fertile way of creating new, imaginative formations in discourse. You need a degree of fantasy to create instantial use, as well as to comprehend and interpret it.

Identification skills are a precondition not only for reading and listening, but also for teaching and other aspects of applied stylistics. The available teaching materials often refer only to recognition and verification of the base form but do not deal with all aspects of identification. In translation it is also important to identify 
not only the base form and the stylistic pattern but also the complete web of stylistic links, which may at times stretch over considerable lengths of text, with the aim of creating an adequate translation. Stylistic awareness is equally important in lexicography and glossography, too (see Ch. 7).

In summary, the identification procedure is applied to a particular stretch of text or the whole text in order to establish the identity of the PU, exploring its instantial use and the web of figurative relationships with a view to discourse analysis of the instantiation. Identification starts as a memory exercise in recognition supported by verification of the base form from which the instantial form is devised. The base form serves as a yardstick against which it is possible to bring out the discoursal semantic and stylistic implications, comprehending and interpreting the new creation through cognitive search. Seemingly inexplicable associative links are resolved and tied to gain a complete picture by interpretation and analysis. A cognitive linguistic approach to figurative language is a tool that helps to perceive, understand, and appreciate stylistic use of PUs, and to draw inferences. 



\section{Key concepts of instantial stylistic use in discourse}

This chapter attempts to address some of the basic theoretical concepts in phraseology that determine and explain stylistic use of PUs in discourse. The concept of stability is a cornerstone of phraseological theory. Another key aspect of stylistic use is the involvement of phraseology in semantic and stylistic cohesion of discourse and the stability of these interrelationships as a manifestation of the inherent cohesion of the base form. The theory of stylistic pattern is also one of the fundamental concepts in instantial stylistic use. Pattern is a basic structural element, carrying semantic and stylistic information and serving as a framework for discoursal change and sustainability of phraseological image over longer stretches of text.

\subsection{Stability of phraseological units in instantial use}

My aim is to draw attention to the significance of stability of PUs as one of the basic concepts in phraseology, and give an insight into the background to the issue. Stability is a distinguishing, categorial property of PUs; therefore, Kunin gives it as the first feature in his definition of the PU (see Ch. 1). Kunin views stability (Russian: ustoichivost') as a totality of invariables of the PU (1970: 88). His theory of stability includes: stability of use, structural-semantic stability, lexical stability, morphological stability, and syntactical stability of PUs (Kunin 1964, 1970). Apart from these aspects of stability, I would also single out, firstly, stylistic stability, which is manifest in preservation of the same image and type of figurativeness in their meaning and other stylistic properties both in the system of language and in actual use, and, secondly, diachronic stability of PUs, that is, their stability across decades and centuries.

Let me examine the use of a diachronically recurring PU. A snake/serpent in/under the grass/flowers has been recorded in English texts since the end of the MiE period. Chaucer's works contain two instances of its use, both extended metaphors (see Ch. 5.4 and Ch. 7.4), which means that the PU was already in use 
before Chaucer, borrowed from Latin as a loan translation of latet anguis in herba (Apperson 1969:583).

Shakespeare used the PU twice in his plays, instances being cases of sophisticated allusion (see Ch. 4.4). The most common stylistic technique used in ENE and subsequent periods is extended metaphor, as we also see from the following examples:

His felle malys he gan to close and hide,

Lyche a snake that is wont to glyde

$\underline{W i t h} \mathrm{~h}$ is venym $\underline{\text { under fresche floures. }}$

1420 Troy I 18.209-211

But the serpent lurked vnder the grasse, and vnder sugered speache was hide pestiferous poyson.

1548 Hall, Chron., 236

In the course of development, the base form of the PU has had a number of lexical variants; it evolved in $\mathrm{MoE}$ as a snake in the grass. Recorded examples since Chaucer's day reveal cross-century stability of the PU in use, not fixedness, frozenness, or non-compositionality. The PU is inherently stable in the face of diachronic changes - the existence of lexical variants in its base form. Semantic and stylistic stability is due to the metaphorical image that reflects human experience; it is a figurative thought preserved through the centuries. The PU a snake in the grass is a reproducible language unit that can boast a great deal of flexibility in use depending on the context and thought expressed, which determine the given stylistic instantiation (see an example from D. H. Lawrence in Ch. 5.4).

Thus, PUs are stable figurative language units. Indeed, they have a permanent form and meaning at a given period of development. Semantic and stylistic cohesion of the base form and abstraction of phraseological meaning predetermine stability and constant shape. However, stability is not a sign of stagnation or lack of freshness. Stability means inherent semantic and structural permanency over the period during which the PU exists. If the unit is not stable, it is not a phraseological unit! If PUs are stable, it only follows that they are necessarily dead if they become obsolete. The stable, cohesive, and figurative structure of phraseological meaning secures change and development of the PU in discourse and enables creation of novel forms and meanings.

I believe that the appearance and development or disappearance of a variant does not interfere with the stability and stylistic use of a PU. Flexibility of PUs is determined by the key properties of the base form: stability, figurativeness, and cohesion, which enable their involvement in the web of semantic and stylistic relationships, and associative links. The intrinsic stability of the PU is part of the 
base form as a language unit; it is also preserved in discourse. Language stability does not contradict discoursal flexibility.

Most Western research deals with lexical or grammatical fixedness. ${ }^{1}$ Moon believes that "lexicogrammatical fixedness - or formal rigidity - implies some degree of lexicogrammatical defectiveness in units" (1998:7). Thus, fixedness implies rigidity and inflexibility. The term does not reveal the substance, and it misleads; it fails to convey the flexibility of phraseological units in instantial stylistic use.

The gap between Western and East European research - the great difference in approach and the time lag - can be explained by what I call the great divide: the great political divide between Western and Eastern Europe in the post-war period. Most Western phraseologists do not know Russian while in the Soviet Union linguists were not allowed to write and publish in English or leave the country for conferences. The language barrier has proved to be a major demarcation line in research, phraseology included. The point is that the theory of stability is not only Kunin's contribution. ${ }^{2}$ It is a whole school of thought (for example, Vinogradov 1947:364; Amosova 1961:55; Arhangel'skij 1964: 102-125). The theory has been successfully elaborated by many linguists over several decades on the basis of different languages. ${ }^{3}$ The great divide also explains why some ideas, for instance, non-compositionality, are presented as something new in research papers today. The idea that non-compositional meaning cannot be built up as the sum of its component parts was thoroughly discussed by Vinogradov and his contemporaries in the 1950s and 60s before the notion of stability gained prevalence. Moreover, the idea of non-compositionality as something unchangeable does not really work. Actual use shows that many PUs which are used as illustrations of non-compositionality (see, for example, Svensson 2008:88) may appear in discourse with stylistic changes. For instance, to spill the beans has been a common example to prove the non-compositional character of idioms. However, when reporting that an Italian mafioso had disclosed a secret, the BBC World Service resorted to stylistic use: he spilled the pa s ta (14 December, 2004).

1. It is not my aim to survey research on stability of PUs in the system of language over recent decades. For an insight, see Baranov and Dobrovol'skij, who view stability as a fixed surface structure (1999:64-65). See also Gläser, who includes syntactical and semantic stability in her definition of PUs (1986b:42). In German she uses two terms: Festigkeit and Stabilität (1986a:20). My aim is to ascertain stability of PUs in stylistic use.

2. The idea of stability goes back to Ferdinand de Saussure (1915) although he never used the term himself; see Cours de linguistique générale (de Saussure 1995).

3. For the history of exploration of the stability of PUs up to the 1970s and various aspects of stability as one of the fundamental concepts in the theory of phraseology, see Kunin (1964, 1970:74-137). 
It is also important to deal with the concept of variation, as this is intimately linked with stability. In phraseological research, variation is used to denote three different phenomena: parallel variants in the base form (indicated by an oblique stroke), grammatical changes in core use, and instantial stylistic changes (creative variation) in discourse. Moreover, as fixedness is understood as rigidity, lexical variants of PUs are often seen to be evidence of their instability. Cases of stylistic use are called anarchic uses (metaphors, puns), "where the instability of language is most evident" (Moon 1998:275).

To sum up, instantial stylistic use does not mean that stability of the base form is lost or violated. I would argue against the negative terms used to denote stylistic use in discourse (see Ch. 1), as the issue is cognitive: it is a question of creativity, which is life-asserting, not life-denying. The stable figurative meaning of a base form finds instantial expression as the figurative thought develops in discourse. More clarity and consistency in terminology would make it easier to communicate the message and follow developments in research.

\subsection{Phraseological cohesion}

Cohesion is one of the basic theoretical concepts in phraseology at all levels, whether it refers to the base form of the PU or its use in discourse. Thus cohesion is crucial not only to understanding the PU as a decontextualised unit but also to cohesive strategies for its instantial realisation in discourse.

Cohesion is a fundamental notion for discourse analysis and cognitive stylistics. It has been explored by a number of linguists over the last four decades. ${ }^{4}$ Leech (1966) develops the idea of cohesion across sentence boundaries. The theory of cohesion is elaborated by Halliday and Hasan (1976), revised by Hasan (1984) and further developed by Halliday (1985). See also Enkvist (1973:147); Fairley (1973); Leech and Short ([1981] 1994:79); Parsons (1991); Cook ([1992] 1994, 1994:29-35); McCarthy and Carter ([1994] 1995); Martin ([2001] 2004), among many others. The cohesive role of conceptual metaphor in discourse is discussed by Ponterotto (2000).

Cohesion occurs where interpretation of a particular element in discourse depends on that of another. Halliday and Hasan argue that "the one presupposes the other, in the sense that it cannot be effectively decoded except by recourse to it" (1976:4).

4. For a literature review of cohesion and coherence, see Parsons (1991: Ch. 2). 
Cohesion is usually understood at the phonological, grammatical, and lexical levels. Halliday and Hasan (1976) give a detailed account of grammatical and lexical cohesion. They describe cohesive links among the choices in grammar that directly relate to creation of text. Syntactic cohesion is also analysed by Fairley (1973). As to lexical cohesion, Halliday and Hasan point out that it is more subtle and difficult to estimate (Halliday and Hasan 1976:288). Every lexical item may enter into a cohesive relationship, but by itself it carries no indication of whether it functions cohesively or not. That can be established only by reference to the text, which provides a great deal of hidden information relevant to interpretation of the item concerned. Cohesion may also be viewed as one of the functions of the lexicon in text (Moon 1998:217-219). ${ }^{5}$

\subsubsection{Cohesion of the base form}

Further development of the theory of cohesion is based on the well-known idea expressed by Halliday and Hasan that "cohesion is a semantic relation" (1976:6) seen as a process in the text. Simpson understands cohesion in literary discourse as semantic links that operate within and across sentences (1997: 198). However, cohesion is not only a semantic means, providing ties in between and across sentences and linking sentences into larger units. Unlike Halliday and Hassan, who see cohesion as a lexical and semantic relation, I would argue that cohesion is also a stylistic relation. I believe that stylistic features play a role of their own in securing cohesion and coherence. Therefore, cohesion is also a stylistic category.

Cohesion is part of the meaning of the base form. Cohesion proceeds from the intricate semantic structure of the PU; it depends on these interrelationships, securing stability. At the same time, semantic cohesion does not contradict the possibilities of variation. Cohesion of the base form enables functioning of the PU in discourse, including both its core use and innumerable stylistic instantiations. Cohesion is one of the distinguishing, categorial features of the meaning of PUs alongside stability and figurativeness. Cohesion facilitates the cognitive process of identification: perception, recognition, comprehension, and interpretation.

5. For more on Moon's views on cohesion as one of the functions of FEIs alongside informational, evaluative, situational, modalising, organisational, interpersonal, and other functions, see Moon (1998: 217-219, 241-243, 278-286). 


\subsubsection{Cohesion in discourse}

It is fascinating to explore how phraseological constituents in discourse refer to each other and other elements of the discourse environment. Here, I am interested in the cohesive features of PUs, which have implications for creation of discourse. ${ }^{6}$ Linking is achieved through relations in phraseological meaning. Cohesion of the PU is a semantic and stylistic relation between one constituent of the PU and its other constituents, which is crucial to phraseological stability and style (see Ch. 2.1). In discourse, cohesion of the base form is retained and developed. Phraseological ties are carried over from the base form into discourse. The flexibility of PUs is determined by the key properties of the base form, which enable their involvement in the web of semantic and stylistic relationships, and associative links.

\subsubsection{Cohesion in core use}

Cohesive relations of the base form are manifest in core use when PUs appear in their most common, essential form and meaning, which is the invariable of the PU. Core use does not create any additional stylistic effect in discourse; changes (if any) are introduced merely to meet the grammatical requirements of the sentence, for example:

\section{the white feather}

The earlier attacks (on Britain) from the air were noticeable enough for a naval officer to be heard saying playfully to another. 'What! Going to sea, are you? So you're showing the white feather!

Cowie, Mackin and McCaig ([1993] 1994b: 588)

Phraseological cohesion is more challenging than lexical cohesion due to the semantic structure of the PU. As an inherent feature of any PU, cohesion of the base form includes all types of cohesion of a language unit: not only grammatical, lexical, and phonological but also stylistic (see Ch. 2.2). These relations are at work at higher levels of language organisation. This is not surprising as PUs are stable reproducible language units, hence they are intrinsically cohesive. Language resources are utilised with the aim of creating text.

\subsubsection{Cohesion in instantial stylistic use}

In discourse, the inherent cohesion of PUs is enhanced by specific semantic and stylistic ties created by instantial changes. The instantial constituents add to

6. For cohesive links of instantial stylistic use in discourse, see Naciscione (1976:56, 183); Zhantlesova (1978); Moshiashvili (1982); Naciscione (1982:67, 1996, 1997b, 1998, 2002). 
cohesion, as their meanings lie in the particular context. Hence, instantial use functions as a vehicle for stylistic and semantic cohesion, which secures unity of phraseological meaning in discourse.

The phraseological image frequently becomes sustainable, as cohesive stylistic links persist, developing the image and acquiring new associations and ties in discourse. Cohesion works: not only cohesion between the constituents of the PU in the new discourse situation but also between the PU and its instantial elements; thus cohesion changes in discourse, acquiring new contextual ties. The original base constituents and the instantial constituents are cohesively related items, all working for the same purpose. Cohesive ties can be overt or explicit; covert or implicit (Wales [1989] 1995:65). For instance, explicit ties are secured by extended phraseological metaphor, and reiteration of the PU or some of its constituents, while typical implicit patterns are allusion and aposiopesis.

The value of cohesion lies in its potential to relate one element in the text to another. It is a general text-forming relation or a set of such relations. Halliday and Hasan argue that cohesion, therefore, forms part of the system of language; it is also part of "the text-forming component in the linguistic system" (1976:27). The idea of the text-forming potential of PUs is not new in phraseological research; it has fascinated phraseologists for decades (Chernyshova 1974; Zhantlesova 1978; Dobrovol'skij 1980; Moshiashvili 1982; Naciscione 1997a, 1998; Sabban 2004, 2006, 2007; Trim 2007). In discourse, PUs play a text-forming role directly linked with the concept of cohesion. When used in discourse, the intrinsic cohesive properties of the PU contribute to text formation. Instantial use of PUs plays a special cohesive role in text creation.

The PU is operational; it functions as a semantic and stylistic entity in the context. Phraseological cohesion can extend over longer sequences, including paragraphs, chapters, even a whole book. In texts, phraseological elements occur in contexts which presuppose earlier passages on previous page(s). Writers and speakers exploit this phraseological potential by creating cohesive ties across considerable stretches of text. ${ }^{7}$

Style does not stop at the borders of sentences. This is due to inter-sentence cohesion devices, patterns of theme and dynamics, ways of opening texts or sections of text, and other features of inter-sentence grammar and text linguistics (Enkvist 1973:147). Sentences are linked coherently to each other, and lexical items relate to one another across textual boundaries. That explains why cohesion has become one of the elements seen as central to discourse analysis, applied

7. A stretch of text seems to have become a term as a unit of actual language in use (Cook [1989] 1995: 12; Carter 1997: xiv). A stretch of text is used to denote the part of the text which contains the discourse phenomenon to be observed and analysed. 
linguistics, and language teaching (see McRae [1987] 1990: 16-17; McCarthy and Carter [1994] 1995: 89-90). A profound understanding of cohesive ties is crucial for comprehension of language in use.

However, cohesion does not merely link sentences and utterances on the surface of the text; it also plays its part in creating genres and registers, and is one of the "discourse management" features that the lexico-grammatical system offers (op. cit.: 90). By "management" McCarthy and Carter mean speaker/writer decisions as to how entities may be made prominent or left as background and how parts of the discourse may be weighted against one another in terms of importance and textual hierarchy.

Phraseological cohesion is the degree to which all instantial elements belong together in a particular instantial application and cohere with the PU. Instantial constituents cohere with the base constituents of the PU, which is why the seemingly scattered appearance of instantiation makes sense even in sophisticated cases and secures unity of meaning.

Phraseological cohesion executes a link between phraseological constituents in discourse. These in their turn depend on the PU. Each instantial item in a string depends on the PU or another instantial element, and the context. Instantial elements may precede or follow the PU, or may be implied in the context (in the case of allusion). The totality of these dependencies results in cohesion. It is important to identify and interpret the relationships between the instantial form and the base form, as well as between the instantial elements in the web of text, that is, the stylistic and semantic signals of phraseological cohesion.

Instantial use presupposes knowledge of the base form and its phraseological links. Interpretation of instantial use depends on the base form of the PU for its full meaning and form. The link between the base form and discoursal forms is never severed. If this link is lost, instantial use becomes incomprehensible: it has failed to achieve its aim if the change does not cohere. Thus, instantial use is a notable feature of cohesion, contributing to texture.

In conclusion, the main aspects of phraseological cohesion may be summarised as follows:

\section{phraseological cohesion}

- part of the meaning of the base form;

- unity of phraseological meaning in instantial use;

- a semantic and stylistic relation, realised in discourse by virtue of ties with the base constituents.

In their base form, PUs are cohesive language units. Phraseological cohesion becomes an essential feature in the progressive development of text, as it secures 
continuity of phraseological links in discourse. Stylistic phraseological ties are one of the sources of cohesion in discourse. Cohesive effect is achieved by semantically and stylistically related items which are part of one instantiation of a PU, either in one sentence or in successive sentences or parts of text. Semantic and stylistic relations between phraseological items provide cohesion across discourse. The way the underlying base form sustains cohesion is enabled because PUs are stable word combinations with a figurative meaning. PUs are cohesive due to figurativeness, which is a semantic and stylistic category. Phraseology is a language resource for creating text.

\subsection{Patterns of instantial use: Continuity versus change}

It is generally known that creativity is pervasive in language use (Lakoff and Johnson [1980] 2003:248; Lakoff and Turner 1989; Carter 1996:1, 8-10; Pope 2005: xvi-xviii). An understanding of its mechanisms facilitates an insight into creativity. This also refers to the realm of phraseology.

It is important to recognise figurative pattern as a cognitive inference tool. Pattern, whether metaphor, metonymy, pun, hyperbole, oxymoron, allusion, or other figurative mode, is a cognitive mechanism and a mental stylistic technique, applicable in new figurative thought representations. Patterns are used to construct meaning.

The infinite variety of discoursal forms of PUs may turn out to be confusing and bewildering and may lead to a belief that instantial use is disordered or chaotic. However, texts display remarkably regular patterns of realisation of PUs in discourse.

Various types of instantial use catch the eye with obtrusive regularity and readers cannot help but notice them even if they do not need or want to explore them. It is important to see beyond the originality, beyond the unique form of expression and instantial meaning. Only when a large amount of text is explored and a great number of applications are contrasted and juxtaposed is it possible to establish their common features and the patterns of use they are based upon. Generalisations are drawn on the basis of empirical observation of regular processes across centuries and a detailed study of particular cases of use with a view to discovering regularities and determining recurring patterns. In order to establish the pattern amidst the variety, it is necessary to draw some inferences involving a certain measure of generalisation of countless instances. Thus, the concept of the instantial stylistic pattern is an abstraction which has no concrete identity but which is based upon observation, analysis, and generalisation of innumerable instantiations in discourse. 
Pattern is an archetypal conception and an integral part of mental cognitive structures. As "an abstract framework" (Gibbs 2003:32), pattern helps to understand and analyse language in use. In a way, stylistic patterns are like grammar rules, which are useful to make grammatical sense of the text. Both are abstract. Identifying pattern helps to perceive ties and establish cohesive semantic and stylistic links with the base meaning, which leads to a better understanding and appreciation of figurative language and the whole text.

A pattern is a set of common features and rules of use in discourse. It is a set of possibilities which exist in the system of language, a potential that the writer or the speaker has at their disposal. Although the instantial form has never been encountered before, the PU and the pattern are familiar. Recognition of mental pattern, which is used as the basic framework for actual instantial applications, facilitates perception and comprehension of instantiation.

Pattern forms part of the system of language. I would disagree that in the case of deviation the writer makes a choice outside the language system. ${ }^{8}$ I would argue that stylistic choice is not made outside the range of choices permitted by the language system but on the contrary it is the language system that offers this choice in discourse. Thus instantial stylistic patterns also form part of the system of language. The potential of instantial use lies in the language system itself. In discourse this use is inextricably tied up with the capacity of the given language system.

The base form is a resource. The stock of PUs in the system of language is a resource for expressing meaning in text. The base form is used to build contextual forms making use of patterns established in the history of the specific language and culture. Instantial use of PUs is a process that responds to meaning development in text, facilitating and enabling expression of individual creativity.

Patterns are also a resource. The theory of long-term memory helps to gain an insight into the way newly created forms and meanings are recognised and identified in the process of reading or listening (Eysenck 1993:33). A pattern is stored separately in long-term memory and retrieved in case of need, just as PUs. At a very general level, pattern identification also depends on matching textual information with pattern information stored in long-term memory.

Access to the base form is achieved from long-term memory or, in case memory fails to supply the base form or a need arises for verification, from dictionaries. However, stylistic pattern cannot be established by using a dictionary or a set of dictionaries as it is a mental representation. Pattern recognition is a cognitive skill which is enhanced in the process of reading and through special training in stylistic awareness. Access to pattern assists comprehension of a novel form and

8. Choice outside the language has been traditionally seen in contrast to choice within the language ('poetic' style of writing versus 'prosaic' style of writing) (Leech [1969] 1993:29-33). 
meaning that is constantly changing and progressing in a stretch of text, resulting in a creative representation of experience.

Writers and speakers have a wide range of options of instantial stylistic patterns which may be used in unique contexts creating cases of original contextual application. While original and unique, at the same time they rely on language resources and language tradition. Instantial use of PUs exploits the possibilities inherent in the English phraseological system.

Pattern recognition is an important function of perception (Field 2004: 18). The ability to recognise recurring patterns is one of the essential cognitive skills of perceiving "similarity in diversity" (Taylor [1989] 1995), of seeing that these are not chaotic discourse formations but a pattern of stylistic use with a meaning of its own behind it. Pattern recognition is essential for the process of identification. However, recognition of pattern is not sufficient in itself. Access to meaning calls for cognitive insight and procedural knowledge of how pattern works. Only knowledge of both the base form of the PU and the particular instantial pattern allows readers or listeners to perceive, comprehend, and interpret. Patterns participate in enabling the cohesive function. An assessment of stylistic phraseological cohesion stipulated by the base form and the pattern leads to a better understanding and evaluation of texts.

Both the PU and the pattern are stable language elements; they have the quality of relative permanency. A pattern is a tool that transforms the base form of a PU into instantial use. Each pattern has a set of its own features; it is characterised by a certain meaning, structure, and a set of realisation rules, all of which are compulsory for the given identity. Some patterns are more frequent and highly predictable, others may be rare. My aim is not to list $^{9}$ the types of these changes, but to ascertain that they are neither exceptions nor violations. The seemingly different manifestations are instantiations of the same PU or the same pattern. A pattern is the way stylistic use is structured.

Patterns exploited within the boundaries of one sentence do not cause great difficulties as they can be easily identified. In discourse, however, many patterns are exploited in a sophisticated way and they can be interpreted only against the background of a longer stretch of text or even the whole text. Hence, a need arises for enhanced systematic awareness of language.

The issue of continuity versus change is a challenging area in phraseology. Unfortunately, at present few new explorations of the earlier stages of language are occurring. Diachronic aspects do not fall within the focus of modern trends

9. Exploring separate stylistic devices seems to be an outdated occupation in a way. See, for instance, Leech who believes that "the practice of enumerating and naming figures of speech is an overrated pastime” ([1969] 1993:83). 
of discourse analysis. However, it should be remembered that the discourses of past centuries help us to understand the present and the future. In this sense it is a new past. As Chaucer puts it,

For out of olde feldes, as men seith,

Cometh al this newe corn fro yeer to yere,

And out of olde bokes, in good feith,

Cometh al this newe science that men lere.

G. Chaucer, The Parlement of Foules

A diachronic approach uncovers the development of English phraseology from its beginnings in the $\mathrm{OE}$ period up to MoE, focusing on stylistic use of PUs, both past and present, in an attempt to disclose what is new and what is old in their stylistic performance in context. It is revealing to discover the wealth of instantial use with a view to continuity and change across centuries. Diachronic studies also provide valuable insights into pattern evolution; they show that instantial use follows principles and guidelines, which have long been in existence in the English language tradition.

Instantial use of PUs is already recorded in writing in OE, starting with the 8th century. MiE reveals an increasing variety and frequency of recognisable recurrent instantial patterns. ENE shows a further increase in diversity, complexity, and sophistication of instantial patterns in discourse. This trend continues in MoE. Over the last century it is coupled with further developments: a broader range of operation, more frequent discourse-oriented instantiations, and the emergence of visual representations of phraseological image in multimodal discourse. Evidence of instantial use shows that the same basic instantial patterns recur in discourse across centuries. Even the few examples from earlier centuries, cited in this book, provide a diachronic dimension: an ongoing diachronic process of pattern evolution as a framework for representing figurative thought. The concept of pattern as a reproducible set of common features and rules of instantial use of PUs provides a key to understanding the great diversity of separate instantiations during the development of phraseology. ${ }^{10}$ Instantial stylistic use only seemingly consists of isolated instances. However, in each case the PU is a reproducible language unit, and pattern is a diachronically recurring technique; both are inherently stable, while each instantiation is creative. My aim is to show that these patterns are not an invention of recent centuries, but a logical diachronic development of thought and language.

10. The idea that the pattern of instantial stylistic use of PUs is a reproducible, dynamic element in the system of language and its use was first expressed by Naciscione (1973:45-47). For crosscentury stability of patterns of instantial stylistic use, see Naciscione (2004:177-189). 
Linguists have always been interested in language change. Explorations in the domain of historical phraseology bring out chronological changes, the origins and development of PUs, their structure and meanings. A diachronic study of the gradual alteration of PUs from Old English into modern times reveals the evolution of phraseology through time as a continuum. A closer look at the base form of the units registered in historical phraseological dictionaries (see, for instance, Whiting 1968) discloses that diachronic stability is an inherent characteristic of PUs versus all the changes. Diachronic instantial stylistic use of PUs presupposes diachronic stability of stylistic patterns across centuries.

When considering innumerable cases of instantial use of a PU in various text types and periods, it is important to practise a systematic approach to be able to discern regularities and realise that the potentially infinite variation of PUs in actual use can be explained by a set of structural and semantic principles and patterns which belong to the system of language. In place of isolated changes or examples, a set of patterns, a whole system of instantial changes of PUs in discourse underlies specific cases of use and may serve to generate new fresh instantial forms of PUs in future applications.

Thus, constancy and change are two facets of the operation of PUs in discourse. Constancy refers to the intrinsic stability of the form and meaning of PUs and patterns as stable elements of the language system, while instantial change, based on a language pattern, produces a new, unique realisation of the PU with a novel stylistic effect. This explains long-term stability versus changes in instantial use. ${ }^{11}$

Let me illustrate some of the varied instantiations of the same PU, e.g., when Adam delved and Eve span who was then the gentleman? recorded in English since the Middle English period:

(1) Whan adam delffid and eve span Who was than gentleman?

1381 Balliol

(2) For God and Mon wer fer a-twinne

Whon he made Monkuynde of See-flod.

I wolde wite, whon that Eve go n spinne,

Bi whom that youre gentrie stod?

11. I have chosen examples from a whole range of centuries and types of writing to show that the instantial use of PUs is not an acquisition of the twentieth century, as is some times believed. Instantial use in the $\mathrm{OE}$ and $\mathrm{MiE}$ periods remains an unknown and largely unsuspected area. 
Hou be-come ye godes kinne

But barelych thorw the wommones blod?

Of Women cometh this Worldes Weal, 1390 Brown, Lyrics XIV 177.97-102

(3) Whan Adam dolve and Eve span

Whowasin those golden daies, a gentleman?

1556 Heywood, Spider

When examining the actual discourse formations, it appears that the given PU functions in a different form in each case depending on the thought and the stylistic and semantic needs of the context. The first example is core use that practically coincides with the base form without any additional stylistic charge. The second is a striking case of instantial use based on the pattern of phraseological allusion. ${ }^{12}$ Use of some of the image-bearing constituents of the PU evokes the whole PU in the reader's mind by means of several explicit constituents preserving the semantic invariable without preservation of the language structure and the constituential make-up of the PU. The contextual link with the base form of the PU helps to disclose the implicit constituents of the PU and the semantic and stylistic information in the text. Use of the pattern of phraseological allusion results in creation of a new instantial meaning and form (see Ch. 4.4). In the third case, one element has been periphrastically replaced, resulting in an instantial effect.

Another way to explore developments is to follow up a pattern, for instance, extended phraseological metaphor, ${ }^{13}$ and trace the way the shift from language to discourse occurs. Let me have a look at some examples from earlier periods. Dictionary attestations reveal that written records of extended metaphor go back to the earliest stages of existence of written text in English, that is, to the 8th century. In OE, extended metaphor is common, though it usually does not exceed sentence boundaries, for instance, seo culfre is buton geallan is a common PU in the OE and MiE periods; ${ }^{14}$ see, for instance, illustrations of core use in Appendix II. Cf.:

12. See another example of allusion to this $\mathrm{PU}$ in Ch. 4.4 .

13. For extended phraseological metaphor, see Ch. 4.1.

14. The PU the dove is without gall has changed in the course of time (Whiting 1968:142). Compare the base forms:

$\mathrm{OE}$ - seo culfre is buton geallan;

$\mathrm{MiE}$ - the culuovre is withouten galle (hath no galle);

$\mathrm{MoE}$ - (obs.) the dove is without gall (has no gall). 
$\underline{\text { seo culfre is buton geallan }}$

Culfre is bilewiten nyten, and $\underline{\mathrm{fr} \text { a } \mathrm{m}}$

geallanbiternysse ælfremed.

c1000 Aelfric, Homilies I 584[34-35]

Extended metaphor is among the most widespread patterns in the MiE period:

the rote of alle harmes

Of the roote of thise sevene sinnes thanne is Pryde, the ge n e r a l rote of alle harmes; for of this rote springen certein braunches, as Ire, Envye, Accidie or Slewthe, Avarice or Covetise (to commune understondinge), Glotonye, and Lecherye. And everich of thise chief sinnes hath $\underline{\mathrm{h} \text { is e }}$ braunches and hise twigges, as shal be declared in hir chapitres folwinge.

De Superbia.

And thogh so be that no man can outrely telle the nombre of the twigge s and of the harmes that cometh of Pryde, yet wol I shewe a partie of hem, as ye shul understonde. Ther is Inobedience, Avauntinge, Despyt, Arrogance, Impudence, Swelling of herte, Insolence, Elacion, Impacience, Strif, Contumacie, Presumpcion, Irreverence, Pertinacie, Veyne Glorie; and many another $\mathrm{t} w \mathrm{ig}$ that I can nat declare.

G. Chaucer, The Canterbury Tales, I, 388-391

What is common to all the three instantiations is use of the pattern of extended metaphor which develops sub-images ${ }^{15}$ and associative ties, and sustains the image of the PU. Extended metaphor, like all the basic instantial patterns, is a figure of thought and language that has persisted and evolved across centuries.

Careful consideration of the similarities and differences between an instantial form of a PU and its base form brings out the changes in its semantic structure. Success of comprehension and interpretation will also depend on the outcome of the pattern recognition process. The change of a base form into a discourse formation proceeds according to certain regularities, which are not directly observable. They can be discerned only by detailed and systematic analogies constructed in order to help ascertain some aspects of the functioning of a PU which are not apparent in discourse.

Use of analogy is fundamental to language research. Aitchison calls it "the ability to reason from parallel cases" (Aitchison 1978: 155). Crystal points out the importance of setting up a working analogue of a phenomenon in order to visualise

15. For my definition of a sub-image, see Ch. 4.1. 
the structure or function of language and attain clarity and concreteness of the relationships the analogue proposes (Crystal 1971:114).

By means of systematic analogies it is possible to establish the structural, semantic, and stylistic features that account for all conceivable cases of a given pattern. The value of understanding the use of patterns lies in their specific applicability in diverse contexts. These patterns are elements of the system of language, like any other stylistic pattern. The stylistic effect of their application depends on their linguistic nature as a typified language means. In instantial use the pattern becomes part of the semantic structure of the PU.

Thus, as typified techniques, patterns of stylistic use are reproducible elements of the language system, the same as PUs in their base forms. The instantial character of the discourse form is created by language means: new inimitable instantial forms of PUs are constantly generated, exploiting existing PUs and language patterns. Hence, pattern is the key to understanding the metamorphosis of a base form into instantial use. Patterns provide infinite capacity with finite means. ${ }^{16}$ An infinite number of instantial cases are accounted for on the basis of a finite set of techniques.

To sum up, the instantial form has certainly been created for a particular purpose. However, the term instantial refers only to textual manifestation. It by no means applies to the base form that is realised in the given context or to the instantial pattern as applied to achieve a unique stylistic effect. The stability and reproducibility of the PU and the instantial pattern are basic concepts of instantial use in discourse.

Instantial patterns are a set of stylistic techniques which are drawn upon for the purpose of constructing meaning. Their key features are as follows:

\section{an instantial pattern}

- a set of common features and rules of instantial use in discourse;

- a tool which transforms the base form into instantial use;

- a cohesive device in discourse;

- a mental stylistic technique with innumerable manifestations in discourse;

- part of the mental lexicon, stored in the long-term memory of the language user;

- characterised by stability across centuries.

16. Cairns and Cairns argue that a finite number of linguistic rules exist for each language and are stored within the finite limits of the brain (1976:10). This explains the infinitude of language by finite means. This also accounts for production and perception of an infinite number of forms. 
Creation of new forms and meanings is a natural discourse process by which new stylistic instances emerge. The process of their identification involves knowledge of the base form and instantial patterns to see similarity in diversity, attain understanding, and facilitate analysis of the discoursal manifestations of PUs. Unfortunately, stylistic patterns have never been the concern of traditional teaching of phraseology. It is important to realise that pattern recognition is an essential cognitive skill.

\subsection{Discoursal character of instantial use: Sustainability of phraseological image}

It is a common expectation to encounter PUs in their usual base form. Readers are used to treating them as one unit that is easy to perceive, grasp, and survey. Learners are used to believing that in text PUs will be as compact as the form they find in dictionary entries. Core use is, indeed, largely predictable; it presents neither novelty nor surprise even in cases with a more complex syntactical structure, involving a subordinate clause, a participial phrase, or a sentence structure, as in proverbs.

Instantial use is dynamic; it expands the syntactic or semantic limits of the base form, going beyond the requirements of core use. Interestingly, not all instantial patterns are discourse-dependent. A number of them are realised at sentence level due to the inherent features of the pattern: insertion, replacement, addition, phraseological zeugma, inversion, periphrasis, blending, conversion, metathesis, instantial use of the diminutive, or some other special lexical or grammatical feature. This use does not exceed sentence boundaries. However, instantial use may be sustained over a stretch of text. ${ }^{17}$ It may also acquire a broader dimension in the web of discourse due to a special position in text, for instance, use in titles or codas (see Ch. 5.5) or as part of cumulative or concurrent use (see Ch. 5.2 and 5.3). That is one of the reasons why it is important to take a discourse-based view of phraseology and specifically take into account what McCarthy and Carter call "macro-level features" ([1994] 1995:90).

At discourse level the PU is often represented by an instantial form. Hence, a sentence-level approach to their stylistic use proves insufficient, as isolated sentences do not reveal the whole wealth and variety of instantial use. A discourse situation calls for cognitive stylistic awareness, a discourse-based approach to

17. The idea of sustainability in instantial use was first discussed by Naciscione (1996). See also Naciscione (2001c: 63-67, 2006b). 
PUs, and understanding of their stylistic properties and the techniques of their application, which is the realm of stylistic analysis.

Sustainability of PUs presents great interest. It is a largely unexplored phenomenon in phraseology. This is despite the fact that sustainability of phraseological image in discourse is one of the essential theoretical tenets for stylistic use of PUs alongside stability and cohesion of phraseological meaning, and patterns of instantial stylistic use. In discourse a PU may extend not only across sentence or paragraph boundaries but across larger stretches of text, constituting a continuum by establishing associative links. The sustainability of a PU is the spread of its image over a length of text in sequential segments as part of the interrelated web of discourse. As PUs are cohesive by definition, in discourse they contribute to the semantic and stylistic cohesion of text due both to the cohesive links of the base form and to the specific pattern, frequently accompanied by reiteration of the base form of the PU, its parts, its image or instantial elements. Moreover, in instantial use cohesion acquires new features, and new associations are established.

The discoursal flexibility of the PU is determined by the key properties of the base form: stability, cohesion, figurativeness and its multi-constituent structure. Instantial use affords an insight into the interplay of three layers of meaning: the figurative meaning of the PU with the literal meanings of the constituents, which remain covertly present, and the novel instantial stylistic meaning which has emerged in the new discourse situation. The language user exploits the stylistic potential of PUs as language units, choosing the pattern that best suits their thought and creative intention. Discourse stylistics describes the phenomenon in general terms and analyses a particular instance and features specific to the given discourse, while cognitive stylistics focuses on figurative aspects of language use and human cognitive processes, including the mystery of creation.

It is due to stability and cohesion at language level that the PU becomes sustainable, as the cohesive links persist, developing the image and acquiring new associations and ties in discourse. For purposes of analysis it is essential to treat each instantial case as a unique whole encompassing all discourse relationships as the ultimate output, at the same time keeping in mind the input of the instantiation: the base form and the instantial pattern with its inherent potential.

A thorough analysis of instantial use establishes a clear picture of the involvement of PUs in the interrelated web of discourse and reveals the subtle semantic and stylistic interrelationships between the instantial and base constituents, their ties, and interaction with other elements of the text. It also reveals the way instantial use creates coherent relationships between various parts of the text.

A commonly held view is that discourse is a process rather than a product (Cook 1994:46; McCarthy and Carter [1994] 1995: 179). It is crucial to see the development of a PU in context in terms of its interaction between the base form 
and the requirements of thought and context. Instantial use is a function central to the discourse view of phraseology.

It is equally important to see the role of instantial use of PUs in the cohesion of discourse. The discoursal properties of PUs stem from the very nature of PUs. The PU is an inherently cohesive structure due to the presence of figurative meaning and stability at all levels. In discourse the PU retains the cohesive ties of the base form, which makes it possible to retrieve it even in very complicated cases of use, such as phraseological allusion or concurrent use. These cohesive links secure recall of the base form in cases when the image is sustained over considerable stretches of text.

Interestingly, PUs may be relatively infrequent in actual use. ${ }^{18}$ They do not occur at regular intervals or as often as people tend to believe (Strässler 1982: 83). True, PUs do not occur frequently but when they do occur they occur "with a high degree of predictability, not randomly" (McCarthy and Carter [1994] 1995: 110). Their distribution in English texts is uneven and closely tied to discourse type (op. cit.: 114). Generally they are not regularly spread over the discourse or its parts.

Unfortunately, data are not usually available on the frequency of occurrence, density, or distribution of PUs in discourse. Even if data are available, as in the case of Chaucer's works (see Ch. 1.2), this does not solve the whole problem. Instantial use is hard to quantify, at least traditional methods of quantification do not work, as it is hard to quantify an instantiation in discourse. This calls for a greater degree of stylistic awareness, especially in the case of remote links. One PU may cover an extensive passage of text. See the example of the PU to smell a rat used by D. H. Lawrence (1984) in Mr Noon. To smell a rat appears as an extended metaphor on page 30 and the rat image, conveying the same message, is reiterated and sustained 60 pages later on page 90 (see Ch. 5.1). Sustainability is another reason why it is not possible to quantify the stylistic effect of instantial use.

PUs are common at focal points in the narrative. Normally, instantial use is not found in descriptive narratives but at key emotional moments and experiences that portray interpersonal relationships, as most of the examples indicate, especially when emotions run high. A closer look at D. H. Lawrence's novel $\mathrm{Mr}$ Noon (1984) reveals a striking difference in the distribution of PUs and instantial use: long stretches of descriptive narrative are devoid of PUs, both core use and instantial use (pp. 238-253, 261-282, 284-292), while emotionally tense pieces of narrative contain considerable sustained instantial use and clusters of phraseologically saturated text (see Ch. 5.3 and Ch. 5.4 of this book). The same regularity

18. For corpus-based evidence on the frequency of fixed expressions and idioms, see Moon (1998: 55-74). 
also emerges in other works by D. H. Lawrence. A good explanation exists for that. Suspense frequently lies at the basis of development towards a new stage. New forms and meanings are produced in discourse when a need arises to convey new thoughts and experiences. That is when language is used in a new and unconventional way. Language is alive; it finds new possibilities for expression.

In discourse PUs also tend to congregate at tense, crucial points and situations of conflict. The expression of conflict through style is an interesting area of research. A conflict situation involves mutually antagonistic or incompatible events, motives, purposes, behaviours, or impulses. How is a conflict (moral, emotional, spiritual) reflected in the use of PUs? It is revealing to explore how these thoughts and experiences achieve changes in the conventional form and meaning of PUs. The established way of expression no longer meets the needs of discourse. The syntactic integrity of the stable base form of the PU is broken as it is insufficient to convey the implications of the mounting effect of conflict or its resolution. A new instantial meaning is produced at a point of conflict, affording a cognitive insight into the linguistic creativity of the language user. A whole range of patterns of instantial change of PUs lend themselves very well to conveying meaning in discourses of conflict. The complexity of the conflict situation results in creation of complex modalities, producing a focal stylistic effect in discourse. That explains why more complex and powerful instantiations occur in environments of conflict, for instance, cleft use (see Ch 4.3), concurrent use (see Ch. 5.3), and saturation of discourse (see Ch. 5.4). This is another reason why distribution of PUs is usually uneven.

A phraseological image may also be sustained across a whole work, as occurs in D. H. Lawrence's short story Rawdon's Roof. As the story unfolds, the phraseological unit under one's roof appears sixteen times, undergoing creative changes and acquiring new associations and figurative ties in discourse. It first appears in core use (it is metonymic in its base form) while further in the text new patterns emerge - puns and extended metaphors, subtly interwoven with reiteration of the image-bearing constituent roof or the whole PU, which becomes the key image by force of sustained reference to it. It is also used in the title, lending an overtone and spanning the boundaries of the short story (see Ch. 5.1).

In conclusion, sustainability of phraseological image is one of the key concepts of instantial stylistic use of PUs. In discourse, instantial use exploits the potential of PUs beyond the requirements of core use. PUs may spread across sentence boundaries and over a considerable length of text. ${ }^{19}$ Fragmented contexts by which PUs are frequently illustrated are insufficient to reveal the interaction of

19. Sustained discoursal use of PUs will be illustrated in subsequent chapters. 
a PU and other elements over extended stretches of text and disclose the whole figurative network of semantic and stylistic interrelationships. PUs are sustainable in use, which is only natural as figurative meaning is one of their inherent properties. Figurative language reflects figurative thought. As thought is sustainable, so is figurative language. Its interpretation calls for linguistic and cognitive processing to reveal the whole wealth and variety of discourse. A sustained phraseological image provides for semantic and stylistic cohesion of the text. 



\section{The most common patterns of instantial stylistic use}

At discourse level the PU is often represented by an instantial form, exploiting the potential that a pattern offers in the discourse environment. Instantial stylistic use of PUs is one of the ways to reflect a novel turn of thought in discourse. Instantial use is dynamic; it expands the semantic or syntactic framework of the base form, exceeding the limits and requirements of core use. This is determined by the thought and the context. Instantial changes are possible due to semantic and stylistic cohesion of the base form, securing an associative continuity of phraseological links in discourse. This chapter will focus on some of the instantial patterns most common in discourse: extended metaphor, pun, cleft use, and phraseological allusion.

\subsection{Extended phraseological metaphor}

As a pattern, metaphor is one of the resources of conveying human experience. From the cognitive perspective metaphor is one of the modes of conceptualising experience and the external world in figurative terms (Gibbs [1994] 1999:1-23). Cognitive linguistics and psycholinguistics have most contributed to development of the theory of metaphor, highlighting the central role of metaphor in abstract thought and revealing the cognitive processes of the mind in metaphorical thinking, and their role in interpreting relations and associations (for example, Winter 1977; Lakoff and Johnson [1980] 2003; Johnson 1987; Lakoff and Turner 1989; Gibbs [1994] 1999, 1995, 1999b, 2007; Steen 1994, 1999, 2006, [2007] 2009; Gibbs and Steen 1999; Kövesces 2002, 2005, 2006; Semino 2008). Thus, the use of metaphor has been recognised as part and parcel of cognition, and a revealing cognitive mechanism.

Traditionally, as well as in many pieces of cognitive research, the focus has been single lexical metaphors, given out of context or contained within one sentence without an eye to discourse. It is Ricoeur who argued for the discursive character of metaphor ([1975] 1994). Over the recent decades more of the linguistic research on metaphor tends to probe beyond the confines of a single sentence. 
Werth provides a discursive account of the phenomenon of extended, or sustained, metaphor. He makes a notable contribution to the extended use of metaphor, pointing out that literary metaphor is frequently discursive. "There is an entire metaphorical 'undercurrent' running through a whole text, which may manifest itself in a large number and variety of 'single' metaphors" (Werth 1994: 79). Werth argues that it is important to deal with the "undercurrent" stratum rather than the superficial "single" metaphor stratum and represent "the double-layered conceptual structure of metaphors" (ibid.). He uses the concept of megametaphor and presents a new conceptual discourse model of text-worlds. ${ }^{1}$ This approach captures the conceptual layering generally inherent in language. Thus, the essential structural property of metaphor is that it represents a double-layered conceptualisation of the text. Metaphor is basically a "double vision" phenomenon (Ullmann 1957; Werth 1977:3-28).

Metaphor may be expressed on various levels of linguistic organisation (see Steen 2002b). Phraseological metaphor is one of the manifestations of metaphorical thought; it is the most widespread type of phraseological abstraction in $\mathrm{MoE}$ along with other types of figurative meaning (see Ch. 2.2).

Extended phraseological metaphor is among the most frequently used patterns of instantial use. The pattern is prototypically present in every case of use when the phraseological image is sustained. Extended metaphor is characterised by a spread of the phraseological image; thus, it is not a single metaphor but a string of $\underline{s u b \text {-images }}^{2}$ creating associative metaphors tied together, covering an entire area of experience. The pattern stipulates extension of the phraseological image, which is part of the base form, and creation of one sub-image (at least) or several sub-images, based on various associations. Sub-images cluster around the base metaphor ${ }^{3}$ of the PU, creating a cohesive network of various types of associative bonds, immediate or remote, forward or backward, linking things which occur together in space and time. Extension of phraseological image is achieved in the search for a more accurate representation of human thought and experience.

Several types of pattern exist, which are subsets of the instantiation of extended metaphorical thought. Metaphorical extension of one of the constituents

1. Italicised by Werth (1994: 79).

2. By a sub-image I understand an extension of the image of the PU, directly or through other sub-images. Sub-images become part of the associative metaphorical network created and sustained on the basis of the image of the PU.

3. The base metaphor is the metaphor which is part of the image of the PU in its base form. Thus it is not the word that is taken as the basic unit of metaphor but the PU, which is the carrier of metaphorical meaning (see Ch. 2.2). 


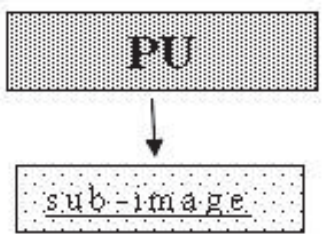

Figure 4.1 Extended phraseological metaphor Type 1

of the PU is the simplest type of extended metaphor, that is, use of one or several sub-images going back to the given constituent (Figure 4.1).

1. One or several sub-images go back to the same base constituent

\section{to wear one's heart upon one's sleeve}

Iago: For when my outward action doth demonstrate

The native act and figure of my heart

In compliment extern, 'tis not long after

But I will wear my heart upon my sleeve

For daws to peck at: I am not what I am.

W. Shakespeare, Othello, Act I, Sc. 1

In this example the PU has acquired one instantial image - that of a daw (Figure 4.2) with a metonymic link peck as part of the extension. Extended metaphor secures a continuum of figurative meaning by providing associations in ongoing discourse.

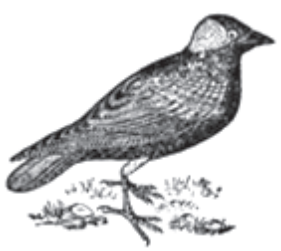

Figure 4.2 A daw

\section{A string of sub-images}

Another type of extended phraseological metaphor consists in successive use of sub-images. It is a linear development. A sequence of sub-images emerges, strung out in a line, offering a sustained mental picture of the image of the base form (Figure 4.3). Metaphorical development proceeds like a chain reaction mediated by the previous sub-image, with each instantial metaphorical item sparking off the subsequent one: 


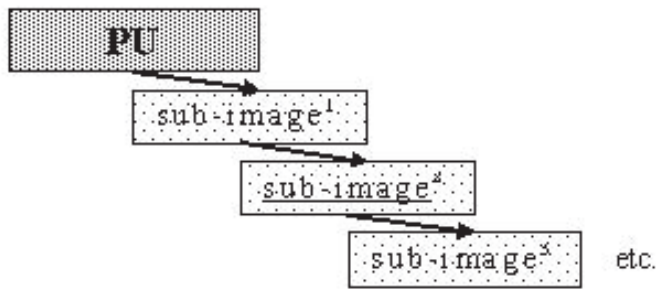

Figure 4.3 Extended phraseological metaphor Type 2

\section{a new broom/a new broom sweeps clean}

Wonderful what a lot of virtues she managed to have in a hurry. Though she wasn't at all a new broom, she swept the dust from pillar to post, and left everybody spitting, till some poor devil got the dust-pan and collected the dirt.

D. H. Lawrence, $M r$ Noon

Extension constitutes a process, resulting in a string, a whole semantic network of novel associative metaphors, which are sustained on the basis of the image of the PU, covering an entire area of experience. New associations and sub-images are facilitated by the previously established items of the metaphorical chain. So great is the intrinsic power of metaphor.

\section{Two or several notional base components extended}

The extension of several notional base components provides parallel lines of metaphorical thinking, creating a ramified semantic structure, which at the same time remains part of the image of the PU and its instantiation in the given context (Figure 4.4). In the following example from Chaucer, both an asse and the harpe are extended, securing a cohesive network of associative metaphorical ties:

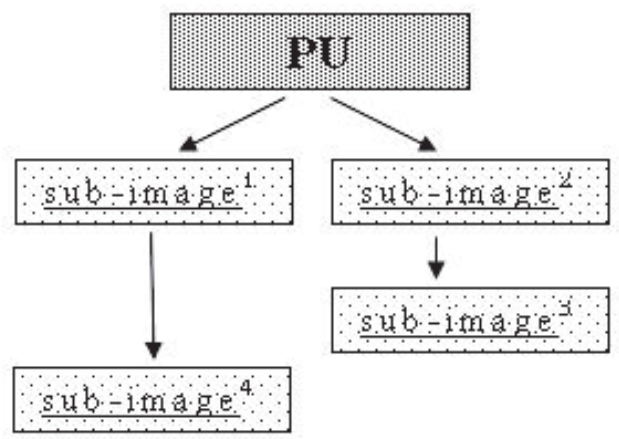

Figure 4.4 Extended phraseological metaphor Type 3 


\section{lyk an asse to the harpe ${ }^{4}$}

'What? slombrestow as in a lytargye?

Or artow lyk an asse to the harpe,

That hereth soun, whan men the strenges plye,

But in his minde of that no melodye

May sinken, him to glade, for that he

So dul is of his bestialitee?'

1380 Chaucer, Troilus and Criseyde, I, 730-735

Links between successive developments of phraseological image are secured by cohesion of the base form, which is an inherent feature of the PU. It is essential to look at the instantiation holistically and perceive the metaphorisation of the whole context.

As to the English language, extended phraseological metaphor is a centuriesold technique; as a figure of thought it has existed throughout the course of the history of the English language. ${ }^{5} \mathrm{OE}$ had many ways to construct meaning imaginatively and stylistic use of PUs was one of them:

\section{(swa) bittir swa wermod ${ }^{6}$}

\section{Swylce ic eom wrapre ponne wermod sy, \\ be her on hyrstum heasewe stondep.}

Year 750 Riddles in Exeter Book 202.60-61

MiE texts contain many diverse examples of extended metaphor, including elaborate instantiations (see the use of the PU lyk an asse to the harpe above). Sub-images are perceived and understood on the strength of their metaphorical ties, so that extended metaphor plays a role in the structural cohesion of discourse. The next example illustrates the role of extended metaphor in verse. Extended metaphor may go across lines and stanzas; it is the voice that sustains the melody. A stanza is characterised by semantic and stylistic unity as a prosodic unit of structure, and it is the metaphor that provides continuity:

4. See core use of this PU in Chaucer Boece i pr. 4.2-3, year 1380.

5. In Poetics, Aristotle writes that metaphor is as old as language and culture, as the earliest writings testify. He expresses the idea that metaphor consists in giving the thing a name that belongs to something else on the grounds of analogy (The Basic Works of Aristotle 1941: Ch. 3).

6. See the core use of (swa) bittir swa wermod in WBible, Proverbs v 4, year c1395 (Whiting 1968: 637). The PU was in regular use in OE and MiE. 


\section{$\underline{\text { loves daunce }}^{7}$}

"Now by your feyth, myn uncle," quod she, "dere,

What mener windes gydeth yow now here?

Tel us your joly wo and your penaunce,

How ferforth be ye put in loves daunce".

"By god," quod he, "I hoppe alwey bih inde !"

And she to-laugh, it thoughte hir herte breste.

G. Chaucer, Troilus and Criseyde, II, 1103-1108

Significantly, while the verbal manifestation of an extended phraseological metaphor does not repeat itself, the pattern does. What they share in common is that the development of metaphorical thought creates new extensions in real contexts, using the same language means. Extended metaphor, like all basic instantial patterns, has persisted and evolved over the centuries. The same mechanism has been in use for shaping extended phraseological metaphor: new instantiations have emerged using ancient patterns. Looking to the future, one might predict persistent creation of new inimitable instantial forms of PUs, exploiting existing PUs and language patterns.

Sustainable development of a PU is due to associative links between imagebearing constituents of the base form and newly-formed sub-images. Lengthy cohesive phraseological chains may be formed by gradual extension of semantic links, as the next example shows. In a discourse situation in D. H. Lawrence's novel Mr Noon, the PU a pretty kettle of fish evolves chain relationships on the basis of its figurative constituents; the extension is formed according to the general cognitive principle of metonymy; metonymic relations "lie in the contiguity or co-occurrence between them" (Steen [2007] 2009:64):

$$
\begin{aligned}
& \text { kettle } \rightarrow \text { smell ... stewed ... ready; } \\
& \text { fish } \rightarrow \text { the bottom of the sea ... lobsters ... the under-sea light. }
\end{aligned}
$$

The two sets of sub-images are related to each other by phraseological cohesion: their meaning depends on their cohesive relations with the PU and each other. The text becomes a figurative whole, unified by phraseological meaning. The PU first appears at the very beginning of Chapter VI (Lawrence 1984):

7. The MiE PU loves daunce has two variants: the new daunce and the olde daunce, meaning "the (new/old) game of love". All in all it appears four times in Chaucer's works: in instantial use in TC, II 1106-1108; the rest are core use: TC, III 965; CT, A, 475; CT, C, 79. 


\section{a pretty kettle of fish $^{8}$}

Meanwhile a pretty kettle of fish was preparing for Mr Noon. He s m elled nothing of it for some days.

\section{H. Lawrence, $M r$ Noon, Ch. VI, p. 51}

Extended phraseological metaphor is relatively easy to identify if it is a direct continuation of the PU. Identification may cause problems if the extension is at a considerable distance from the base form: across sentence and utterance boundaries. More than two pages later, Lawrence returns to the PU and gives the hint that Mr Noon "smelled the above-mentioned fish" which stretches the reader's imagination and sustains the image. It is curious to note that Lawrence gives the cue $^{9}$ "the above-mentioned" which plays a supporting role in the metaphorical network and acts as a guide in the process of recall in case the reader has failed to keep up the figurative thread:

When he arrived at the town hall, the porter told him the meeting was already sitting. He went to the waiting-room, and there sat cooling his heels. Doubtful if even now he smelled the above-mentioned fish, which were stewed and nearly ready for him in the next room.

D. H. Lawrence, Mr Noon, Ch. VI, p. 53

The extended metaphor reinforces the meaning of the PU "an awkward state of affairs" and conveys apprehension in a situation fraught with danger. In the next room is a long table around which various members of the committee are seated, "mostly fat fossils and important persons of complete insignificance" (Lawrence 1984: 53). Gilbert calls them lobsters:

Gilbert suddenly felt like a baby that has fallen to the bottom of the sea and finds all the lobsters staring at him in the undersea light. So they stared, like inquiring lobsters, and he felt like a baby, with his fresh face and pouting mouth.

D. H. Lawrence, Mr Noon, Ch. VI, p. 53

8. Interestingly, a kettle of fish is an old name for a picnic by the riverside in which freshly caught salmon provide the chief dish. The salmon is put into salty water and boiled. When it is ready it is eaten in gypsy fashion. The discomfort of this sort of picnic probably gave rise to $a$ pretty kettle of fish, meaning an awkward state of affairs, a mess, a muddle (Brewer's Dictionary of Phrase and Fable [1959] 1968:516).

9. $\underline{\text { A cue }}$ is a prompt that plays a supporting role in the metaphorical network, facilitates associative responses to the $\mathrm{PU}$, and acts as a guide in the process of recall. 
The network of sub-images creates metaphorical space. ${ }^{10}$ Instantial extension of the base metaphor provides semantic and stylistic enrichment of the flow of discourse and allows indirect information to generate. The underwater image, based on extended phraseological metaphor, is perpetuated over seven pages and carried over to the next chapter (Chapter VII), contributing to the metaphorical field of text: ${ }^{11}$

Gilbert's kettle of fish had been all lobsters but one: but that didn't make it any the sweeter.

D. H. Lawrence, Mr Noon, Ch. VII, p. 57

This PU has evolved a whole cluster of associated metaphors. All the sub-images need to be borne in mind to secure a complete semantic and stylistic analysis of the context. The interrelated elements of the textual web have an effect on the reader, who can feel and sense the image. The stylistic effect augments, as discourse unfolds with every successive part of the metaphorical chain, never losing a link with the image of the base form (see Appendix III for a painter's vision of this extended image). Metaphors are inherently dynamic in discourse. As Forceville and Urios-Aparisi put it, "many metaphors are mini-narratives" (2009a: 11). Extended phraseological metaphor is a mini-narrative in its own right.

Extended metaphor may go together with reiteration ${ }^{12}$ of some base constituents, instantial elements, or even the whole of the PU. In the next example the PU is repeated twice. The antonymic replacement (smooth turns into jagged) creates associations of contrast: things, differing from one another in compelling ways, tend to be associated with each other. The reiteration of jagged takes the image over to the next paragraph where it is further extended:

10. Werth speaks about a metaphorical field which extends through a discourse. By this he means not only use of extended metaphor, but also irony, pun, metonymy, and personification (Werth 1994: 83-84).

11. Cf.: Gilbert's vision of members of the School Committee as lobsters in the underwater world: "Gilbert wondered if they really did never bark, or if, un der-water, they ru shed out of their rock-kennels and snapped and yapped at the heels of the passing fishes. This fancy caused him to hear only a wave-lapping sound for a few moments, which was actually Mrs Britten's going on. He came to himself when she flapped a paper to attract his rather vacant-looking attention" (Lawrence 1984:54).

12. For phraseological reiteration as a stylistic means, see Ch. 5.1. 


\section{the course of true love never did run smooth}

The course of true love is said never to run true. But never did the course of any love run so jagged as that of Joanna and Mr Noon. The wonder is, it ever got there at all.

And yet, perhaps, a jagged twisty, waterfally, harassed stream is the most fascinating to follow.

D. H. Lawrence, $M r$ Noon

Instantial metaphorical use is a natural consequence of using PUs creatively. The thread of phraseological meaning persists from one segment of discourse to another as the semantic process continues and the discourse unfolds:

to keep the wolf from the door

But though one may keep the wolves from one's door, they still howl out there in the darkness.

J. Fowles, The French Lieutenant's Woman

The PU is taken up one paragraph later:

Having quelled the wolves Ernestina went to her dressing-table, unlocked a drawer and there pulled out her diary ...

J. Fowles, The French Lieutenant's Woman

Associations (wolves $\rightarrow$ howl ... darkness) are important elements in creating successive associative chains. Phraseological links provide cohesion between sentences and each part of instantial use relies upon its relation with the PU.

Extension of the base metaphor lends itself easily to dialogical discourse when the interlocutors create several associative elements sustaining the image. In the following example, sharp rejoinders, quick and witty replies are flung across turn boundaries:

don't swap the horses when crossing a/the stream

Proteus: I resign.

Crassus: Not at such a moment as this. Don't let us swap the horses when crossing a stream.

Nicobar: Whynot, if the horse you have got is subjected to hysterics?

Boanerges: Not to mention that you may have more than one horse at your disposal.

Proteus: Right you are. Perfectly true. Take my job, Nick. It's vacant, for you, Bill. I wish you joy of it.

G. B. Shaw, The Apple Cart 
The PU gives a clear warning of the danger of introducing a decisive change at an ill-chosen moment. In this case it concerns replacement of the Prime Minister. Members of the Cabinet do not see any sense in his resigning in a critical situation like this, even though "the horse" has been subjected to hysterics, metaphorically speaking.

Sub-images are critical for creation of texture; they can be interpreted only by reference to the base image of the PU. Each sub-image promotes and develops metaphorical links, which constitute a network of related figurative items, all going back to the PU. In the following example from The White Monkey (Galsworthy [1928] 1978), the metaphorical continuum is secured by recourse to the PU over a number of successive pages in which the PU first appears in its core use. Two pages later it is followed by an instantial extension of the image at a moment of mounting tension which is resolved by core use, constituting a frame construction:

\section{to skate on thin ice}

It was a really remarkable tribute to her powers of skating on thin ice that the word "good" should still have significance.

J. Galsworthy, The White Monkey, p. 128

Desert said suddenly: "Stop! Don't move! He is down there in the street." (...)

Fleur sat down; she felt weak in the legs. The ice seemed suddenly of an appalling thinness - the water appallingly cold.

J. Galsworthy, The White Monkey, p. 129-130

Get home before Michael! She felt relieved, almost exhilarated. So much for skating on thin ice.

J. Galsworthy, The White Monkey, p. 131

The cohesive effect is achieved by an instantial extension of phraseological meaning. The longer the span covered by an extended image, the greater the awareness the reader is expected to possess. Perception of the whole span requires a considerable effort due to the semantic distance. Successful retention calls for a need to store the sustained image in the working memory.

Extension involves instantial widening of the metaphorical meaning of the PU; it is also a process of expansion of the context in which the PU occurs. If we have a look at the next instantiation from G. B. Shaw's Preface to the Black Girl in Search of God ([1934] 1954), which is an extended metaphor of a proverb, we see how important it is not to lose the metaphorical continuum. It is "exactly the metaphor of the proverb which enables us to employ proverbs in so many different contexts" and which explains why they are flexible and adaptable to ever new contexts and interpretations (Mieder 1989:21, 1993: x): 
It forgets the prudent_old precept " you get in your clean" which is the very devil unless completed by, "This also I say unto you, that when you get your fresh water you must throw out the dirty and be particularly careful not to let the two get mixed.

Now this is what we never do. We persist in pouring the clean water into the dirty and our minds are always muddled in consequence.

G. B. Shaw, Preface to the Black Girl in Search of God, p. 4

Shaw's scathing irony about human shortsightedness and foolishness turns into a sustained ironic commentary, which appears nine pages later as part of further extension of the phraseological metaphor:

But we spoil it all by that lazy and sluttish practice of not throwing out the dirty water when we get in the clean.

G. B. Shaw, Preface to the Black Girl in Search of God, p. 13

A repartee takes up the image again in a philosophical way on the next page:

When we come to Micah we find him throwing out the dirty water fearlessly.

G. B. Shaw, Preface to the Black Girl in Search of God, p. 14

The overall semantic and stylistic continuity of the PU forms a metaphorical undercurrent running through four pages or, as Trim puts it, a metaphor network (2007). Readers or members of the audience are expected to recall and keep the image at the back of their minds. Reiteration permeates the text, charged with associative links. It is possible to capture the metaphorical flow and arrive at subtle reading only if the whole stretch is taken into account, interpreting the relations between metaphorical items going back to the PU and establishing the whole network of instantial use.

Extended phraseological metaphor is not a mere extension of the base image of the PU and is much more than the totality of its sub-images. It is a new discoursal quality, born in instantiation, and a dynamic meaning development. Discoursal use is enabled by the very nature of the PU - cohesion of the base form. The PU and extension of its image remain focal in the context, which cannot be understood and interpreted without the complete extent of the instantial metaphor:

\section{like a thousand of bricks}

Young George Washington was actuated in all things by the highest and purest principles of morality, justice and right. (...) Young George was always 
prompt and faithful in the discharge of every duty. It has been said of him, by the historian that he was always on hand, like a thousand of brick. And well deserved was this compliment. The aggregate of the building material specified might have been largely increased might have been doubled (...). Indeed, it would hardly be possible to express in bricks the exceeding promptness and fidelity of young George Washington. His was a soul whose manifold excellencies were beyond the ken and computational mathematics, and bricks are, at the least, but an inadequate vehicle for the conveyance of a comprehension of the moral sublimity of a nature so pure as his.

Mark Twain, Brief Biographical Sketch of George Washington

These examples demonstrate a continuum of phraseological meaning and the process of linking elements together by placing them in a sequence of associative strings, constituting part of the same instantial application. A whole set of metaphorical items related to the PU sustains the phraseological image, which becomes the focus of the stretch of text.

Thus, the pattern of extended phraseological metaphor is a way to instantiate a new meaning in discourse which is different from base metaphor, that is, the established metaphor of the base form. The network of strings of metaphorical instantial elements brings out the cohesive strength of the pattern. The force of the metaphorical ties and associations with the base image provides semantic and stylistic cohesion and coherence in discourse. Creation of an extended metaphor is a cognitive skill, part of the human ability for continued abstraction. Interpretation and analysis of the metaphorical network call for associative thinking and a cognitive approach to use of metaphorical language.

To sum up, extended phraseological metaphor defines as an entrenched figurative pattern that can be characterised by the following features:

- it is a cognitive process that reflects extended metaphorical thought;

- it involves a string of sub-images sustained and tied together by the base metaphor of the PU;

- it creates a cohesive network of associative metaphorical bonds;

- it is an extension of the abstraction of the phraseological image;

- $\quad$ it forms a pattern of both thought and language.

Extended phraseological metaphor is one of the figures of thought whereby people conceptualise their experience. It provides for the development and sustainability of metaphorical thought and language in discourse. My conclusion is: as thought develops, phraseological metaphor develops too. Extended phraseological metaphor reflects extended figurative thought. 


\subsection{Phraseological pun}

This chapter will consider phraseological pun as part of the process of change and development of phraseological units in discourse.

In general stylistics, a pun or wordplay is broadly characterised as an ambiguity. It involves use of a polysemous word to suggest two or more meanings, or use of homonyms. Leech (1969:209) calls pun a foregrounded lexical ambiguity. Much interest has been focused on lexical puns (for example, Nowottny 1962; Redfern 1984; Nash 1987; Chiaro [1992] 1996; Fill 1992; Alexander 1997; Goodman 1997).

In phraseology, pun has received much attention and is well-known. The stylistic effect of phraseological pun does not lie in the presence of the PU, but in the relationship between the PU and the corresponding free combination of words with their literal meanings. This use emerges as another type of cohesion as it can be explained only by the relevant interrelationship. Phraseological puns are frequently sustained beyond sentence level. For instance:

\section{to take one's leave of someone}

Polonius: My lord, I will take my leave from you.

Hamlet: Youcannot, sir,take anything from me that I will more willingly part withal - except my life, except my life, except my life.

W. Shakespeare, Hamlet, Act II, Sc. 2

This is a classic type of phraseological pun where the PU is followed by an abrupt return to the literal meaning of the constituent(s). One use of the PU instantiates two different meanings. Another example:

\section{to pull someone's leg}

But I laughed and said, “Don't worry, Professor, I am not pulling her ladyship's leg. I wouldn't do such a thing. I have too much respect for that charming limb".

J. Cary, The Horse's Mouth

Naturally, different theoretical approaches and terms are used. In phraseological research this stylistic pattern has been variously dubbed: pun, dual actualisation, ${ }^{13}$ wordplay, literalisation, and others. The term dual actualisation seems to be appropriate from the semantic point of view, as it is the duality, the two-dimensional quality of the narrative that characterises this instantial use.

13. The term dual actualisation was first introduced by Boldireva (1967). See also Dubinsky (1985). 
My interest lies in the involvement of phraseological pun in discourse as a particular case of instantial stylistic use where two interpretations can be assigned to it: literal and figurative. The salient feature of this pattern is the juxtaposition and contradistinction of the figurative meaning of the PU and the literal meaning of a constituent or constituents. As PUs are figurative, cohesive combinations of words, they easily lend themselves to wordplay, for every figurative constituent invariably has a literal meaning at the same time. This is the technique of double exposure, to use a photographic term, which seems to convey the essence of this pattern where two pictures appear on top of each other without coinciding. Thus, figurative items contrast with literal, non-figurative language. The dual perception results in a dual reading of the lines. Punning creates an abrupt semantic shift as the PU is also simultaneously perceived as a non-figurative combination of words which reveals the secret of image creation.

Another example. David has asked about the apparent paradox of the old man's pacifism in 1916 and his serving as a medical orderly with the International Brigades during the Spanish Civil War. The old man replies:

\section{the white feather}

'White feather, dear boy. Qu ite lite ral, you know. Had a collection of the damn' things. Didn't care, all a joke. Russell, he converted me...' J. Fowles, The Ebony Tower

The pattern of phraseological pun may take on varied forms in discourse. It may be only one phraseological constituent which is used in its literal meaning and repeated in the subsequent or preceding sentence(s) at least once. The literalised constituent assumes dual significance and is loaded with meaning.

\section{birds in their little nests agree}

"Birds in their little nests agree," she said, smiling ...

She knew nothing at all about birds.

L. I. Wilder, Little Town on the Prairie

Or the whole PU may undergo literalisation, creating an analogue, a parallel construction which is an identical non-figurative structure recalling the PU in form but having no figurative meaning.

\section{a skeleton in the cupboard}

Bernard: What guilty secret?

Jack: Some skeleton in the cupboard.

Jenny: (handing him back his glass): No, no, a body in the garden. 
Phraseological pun offers a cognitive insight into the process of creation of a phraseological image and the secret of dual interpretation. The juxtaposition of figurative use vs literal use lays bare the semantic structure of the PU; it uncovers the image. Identification of dual actualisation is the perceptual process of demetaphorisation, a linguistic procedure that is reverse to image creation which PUs undergo in their formation stage. The process of demetaphorisation reveals the mechanism of figurative language. The PU is turned into an image-free nonfigurative combination of words which entails an abrupt shift in topic. In the following example, the use of cuffs brings out the literal meaning of sleeve which is in a logically contiguous relationship with cuffs:

\section{to have something up one's sleeve}

Again that indefinable mockery, as if he had something up his sleeve. Soames looked mechanically at the fellow's cuffs - beautifully laundered, with a blue stripe, at his holland waistcoat, and his bird's-eye tie - a regular dandy.

J. Galsworthy, The White Monkey

It is of practical and theoretical interest to distinguish between phraseological pun and extended metaphor. Both create a double vision. Redfern argues that wordplay incites us to think, see, and hear on more than one level, or at least with only a slight time-lag, the time needed to see the connection (Redfern 1984:97). In the case of extended metaphor, the figurative meaning is sustained, and it remains figurative by acquiring new sub-images, all pertaining to the main image upon which the PU is based, while pun involves a sudden return to literal meaning in one or several constituents of the base form. In discourse, these semantic shifts may meander and waver in between the two semantic levels. The previous example is a clear-cut case of pun while the following example illustrates use of both techniques - extended metaphor and phraseological pun - in one instantial application:

\section{to kill two birds with one stone}

Beryl: Oh, good, $\underline{I}$ can kill two birds with one stone and you're one of the m, Jenny.

Bill: Lenny a bird?

G. Cooper, Everything in the Garden

In most cases, literalisation comes as a cataphoric exercise (as in the two previous examples). However, the relevant item bearing literal meaning may also be anaphoric to the PU: 


\section{without rhyme or reason/neither rhyme or reason}

Rosalind: But are you so much in love as your rhy mes speak?

Orlando: Neither rhyme nor reason can express how much.

W. Shakespeare, As You Like It, Act III, Sc. 2

As we see from these examples, it is essential to explore phraseological pun in dialogue. For one thing, this pattern is typical of dialogues, including prose and drama dialogue, as well as oral discourse. The study of dialogue is also ofconsiderable value as it enables us to follow the access ${ }^{14}$ and perception of pun over turn boundaries and longer stretches of text. In dialogical discourse, the remark containing a pun may be a witticism (see the first example), which shows the ability of the interlocutor to perceive the two levels of meaning and create a pun or, on the contrary, a failure to access, which means a failure to recognise, and see beyond the literal meaning of a string of words. Recall failure may also mean that the right phraseological item cannot be identified, as it does not exist in the mental diction$\operatorname{ary}^{15}$ of the character:

\section{on the rocks}

Lanny: On the rocks? Or as it comes?

Ruth: Rocks? What do you know about rocks?

Lanny: We've got rocks. But they are frozen stiff in the fridge.

H. Pinter, The Homecoming

The traditional pattern of taking turns in dialogue lends itself very well to punning. In the next dialogue, the interjectional PU "hear, hear!" is an unattended verbal stimulus, and recall failure emerges as the leading element. When asked to say it again, Bilbo himself gets confused and flustered trying to save the situation. He echoes the word "hear" as a transitive verb in its literal meaning. Flustered acts as a cue signalling a shift in the semantic level:

14. Psycholinguistic research on lexical ambiguity is uncertain whether only one meaning of an ambiguous word is accessed, first determined by the context, or whether in word recognition the more common meaning is accessed first and discarded if inappropriate (Kess 1992:224225). Hirst argues that all meanings of an ambiguous lexical item are accessed during the first 200 milliseconds of the search, after which the appropriate meaning is chosen and the other meanings are discarded (Hirst 1987:93).

15. On the mental lexicon, see Kess (1992: Ch. 4). 


\section{hear, hear!}

"Hear, hear!" said Bilbo, and accidentally said it aloud.

"He ar wh at?" they asked turning suddenly towards him and he wa was _so flustered that he answered,

"Hear what I have got to say!"

J. R. R. Tolkien, The Hobbit or There and Back Again

In longer dialogues the context infrequently wavers between literal and figurative levels of meaning, shifting focus and creating a pervasive parallelism of metaphorical and literal meanings. In the next example, the interactive dimension of the dialogue is based on a clash, an ambiguity arising from using the same combination of words in a way that is pregnant with meaning:

\section{blood is thicker than water}

Gentleman: We are of the same stock, you and I. Blood is thicker than water, we are cousins.

Woman: I am afraid I am as much in the dark as before. You said also that blood is thicker than water. No doubt it is; but what of it?

Gentleman: The meaning is quite obvious.

Woman: Perfectly. But I assure you I am quite aware that blood is thickerthan water.

Gentleman: (sniffing: almost in tears again) We will leave it at that, madam. G. B. Shaw, Back to Methuselah

The dialogue also includes the cue: The meaning is quite obvious, as well as the author's disambiguating comment in the stage directions sniffing: almost in tears which give instructions to the actor to enact the pun. These cues help to bring out the dual function to reader or audience. Absence of recollection obviously indicates absence of the PU in the long-term memory ${ }^{16}$ of the character. The words we will leave it at that signal a painful dismissal of the hope of getting the thought across.

Puns may also be based on paronymic or homophonic relationships creating a double level of meaning:

$\underline{\text { to carry coals }}^{17}$

Sampson: Gregory, o'my word, we'll not carry coals.

Gregory: No, for then we should be colliers.

16. On storage in long-term and short-term memory, see Eysenck (1993: Ch.4).

17. The PU to carry coals is obsolete; the allusion is to the dirty, laborious occupation of charcoal carriers (Brewer's Dictionary of Phrase and Fable [1959] 1968:114). 
Sampson: I mean, an we be in choler, we'll draw.

Gregory: Ay, while you live, draw your neck out o' the coll a r.

W. Shakespeare, Romeo and Juliet, Act I, Sc. 1

In dialogue, pun may not only provide a cohesive link across turn boundaries, but also encompass some of the author's narrative. The duality of the semantic structure of the text is extended:

\section{a scarlet woman}

"No gentleman who cares for his good name can be seen with the scarlet woman of Lyme."

And that too was a step; for there was a bitterness in her voice. He smiled at her averted face.

"I think the only true scarlet things about you are your cheeks."

J. Fowles, The French Lieutenant's Woman

Identification of a pun calls for an insight into both semantic levels and their interrelationship. The meaning of a phraseological constituent is identified, as some unambiguous words are rendered salient in the context. In this case it is the word cheeks, which has a metonymic link with the second non-figurative constituent woman.

A continual implication of figurative and literal meanings (both anaphorically and cataphorically) creates a phraseological web which sustains the parallel levels of meaning and reinforces the overall dual perception:

to go West ${ }^{18}$

Desert said slowly:

"The moment I believe that I shall go East."

"East?"

"Not so stale as going West, but much the same - you don't come b a ck."

J. Galsworthy, The White Monkey, Ch. II

In the next chapter the pun is picked up again nine pages later, continuing the web of alternating phraseological and non-phraseological meanings. The same semantic pattern persists over a page:

A voice behind her said:

"Well, Fleur, a m I going East?" (...)

"You're very silly, Wilfrid!"

18. The PU to go West has become old-fashioned today (CCDI 1995:417). 


\section{"Anything you like, a m I going East?" \\ "No, Sunday morning - eleven o'clock at the Tate. We'll talk it out." (...) \\ If she were going to keep Wilfrid, she must be nice to Michael (...) Yes, he (Wilfred) was dear! But would she break her heart if he went E a st or West tomorrow? \\ J. Galsworthy, The White Monkey, Ch. III}

The discoursal properties of phraseology secure an environment in which a pun may be based not only on figurative and literal meanings, but also on the polysemy of one PU (see Ch. 2.4). As a synchronic fact, polysemy is a relatively rare phenomenon in phraseology, but when it is exploited in discourse, it may achieve a striking effect. Let me have a closer look at the use of the PU good morning! ${ }^{19}$ which is a very common PU (too common to achieve notice in core use). In this context it is highlighted and carried to stylistic lengths, including instantial conversion which is infrequent in the discoursal use of phraseology. ${ }^{20}$ The technique of punning brings out not only the literal meanings of the phraseological constituents, but also the polysemy of the PU itself, providing cohesion in discourse:

\section{good morning!}

“Good morning!" said Bilbo, and he m e a n t it. The sun sun was shining, the grass

"What do you mean?" he (Gandalf) said. "Do you wish me a good morning or mean that it is good morning whether I want it or not, or that you feel good this morning, or that it a good morning to be good on?"

... Bilbo got quite uncomfortable and even a little cross.

"Good morning!" he said at last. "We don't want any adventures here, thank you!" (...) By this he meant that the conversation was at an end. "What a lot of things do you use 'good morning!' for", said Gandalf. "Now you mean that you want to get rid of me, and that it won't be good till I move off... to think that I should have lived to be good-morninged by Belladonna Took's son as if I was selling buttons at the door!"

J. R. R. Tolkien, The Hobbit or There and Back Again

19. This pun is addressed in Straume's paper on stylistic use in English Children's Nonsense Literature. She suggests the term multiactualisation to denote punning on a polysemous PU (1989:96).

20. Although instantial conversion is rare in English PUs, it is not a new phenomenon, as it had already been used by Chaucer (Naciscione 1976: 122-126). 
Gandalf's failure to perceive and recognise the PU results in a misunderstanding and brings about a humorous effect. The pun is one of the instantial stylistic devices that integrates PUs in dialogical discourse.

The term dual actualisation seems to be appropriate when dealing with cases of simultaneous dual-purpose realisation of both phraseological and literal meaning in discourse where the PU is not reiterated, nor are its constituents. Semantic cohesion of text is attained by a dual vision backed by a network of cues as in the following example from Chaucer's The Canterbury Tales:

\section{to blere somebodys yë $\ddot{e}^{21}$}

With this chanoun I dwelt have seven yeer,

And of his science am I never the neer.

Al that I hadde, I have y-lost ther-by;

And got wot, so hath many mo than I.

Ther I was wont to be right fresh and gay

Of clothing and of other good array,

Now may I were an hose upon myn heed;

And wher my colour was bothe fresh and reed,

Now is it wan and of a leden hewe;

Who-so it useth, sore shal he rewe.

And of my swink yet blered is myn yë,

Lo! which avantage is to multiplye!

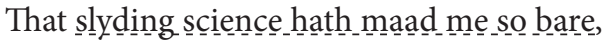

That I have no good, wher that ever I fare;

And yet I am endetted so ther-by

Of gold that I have borwed, trewely,

That whyl I live, I shal it quyte never.

Lat every man be war by me for ever!

What maner man that casteth him ther-to,

If he continue, I hodle his thrift y-do.

So helpe me god, ther-by shal he nat winne,

But empte his purss, and make his wittes thinne-

G. Chaucer, The Canterbury Tales, G, 720-741

21. The PU to blear someone's eyes is obsolete in Modern English. For the MiE form to blere somebodys yë, meaning "to deceive somebody", see the glossary to Skeat's edition of The Complete Works of Geoffrey Chaucer (1919: 15). The earliest registered example of this PU in Whiting (1968: 167) goes back to a1300. 
The PU to blere somebodys yë is recurrent in Chaucer's works; it occurs four times, presenting both core use and instantial use. ${ }^{22}$ This example is from The Canon's Yeoman's Tale. Here two meanings are packed into one PU: a simultaneous actualisation of both the figurative meaning of the PU and the literal meaning of its counterpart. The cohesive relationship between the two meanings is secured by the proximity of words which sustain both semantic levels:

1. the literal meaning of the phrase, set off by the contrast of the words of my swink $k_{2}$ my colour was bothe fresh and reed and now is it wan and of a le leden hewe and the description of the trade of alchemists in the preceding The Canon's Yeoman's Prologue to the tale in which we find out that blowing into the fire has discoloured his face (CT, G, 664-667);

2. the figurative meaning of deceit, set off by slyding science hath maad me so bare, have no good, endetted ... of gold, empte his purs, and make his wittes thinne, as well as the insinuations of delusion and failure in the prologue to

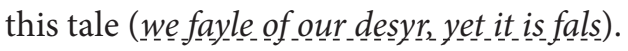

The dual perception is clearly signalled by all the cues, which make access possible. However, the burden of disambiguation rests with the reader. For instance, the PU to die with one's boots on means "to die while still actively involved in one's work". The cue the legendary cowboy and the instantial insertion ${ }^{23}$ in the saddle help to bring out the two meanings of the pun, encased in with his boots on which is the figurative part of the PU:

\section{to die with one's boots on}

Like the legendary cowboy who proudly professes he wants to die in the saddle with his boots on, he says when his turn comes 'I always pray that I'll die at work, gardening'.

CCDI 1995: 43

The following example is notable not only for its discoursal features but also because it reveals the cognitive complexity of some of the processes of thought and reason. As Count Dionys is a non-native speaker, Lady Daphne tries to give him a literal interpretation of the PU by commenting on its meaning. His facial expression, acting as a cue, clearly shows that this PU is not part of his mental lexicon. Comprehension is also encumbered by the fact that the PU does not first appear

22. Core use - CT, H, 252; CT, A, 4049; instantial use - CT, A, 3865; CT, G, 720-741.

23. Insertion is an instantial pattern where one or several instantial constituents are introduced into the base form of the PU. Insertion affects both structure and meaning of the PU in discourse. 
in core use but in a zeugmatic construction. ${ }^{24}$ However, after her literalised explanation he is capable of taking up the thread and extending the wordplay by replacing bee by ladybird - the insect of his family crest:

\section{to have a bee in one's bonnet}

"I suppose", she mused, "it is as bad to have your bee in your shirt as in your bonnet".

He looked at her with round eyes.

"Don't you know what it is to have a bee in your bonnet?" she said.

"No".

"To have a bee buzzing among your hair! To be out of your wits.," she smiled at him.

"So!" he said. "Ah, the Psaneks have had a la dybird in their bonnets for many hundred years".

"Quite- , quite mad”-, she said.

“...But with my wife I was quite sane for ten years. Now give me the madnof the ladybird. The world I was sane about has gone raving. The ladybird I was mad with is wise still...”

"But surely you are funny, with your family in sect."

"My family insect? Now you want to be rude to me".

D. H. Lawrence, The Ladybird

It is revealing to follow how the lady reacts in an attempt to explain the base meaning of the metaphorical PU by comparing the stinging effect of such an idea on one's mind with that of a bee trapped under one's hat. This instantiation is cognitively insightful as it uncovers the anatomy of the phraseological pun and discloses its semantic make-up. It is, as it were, dissected to allow the reader to gain a close-up of the process of demetaphorisation; this enables the reader to understand and interpret change of PUs in discourse. Interestingly, the pun is picked up again some 50 pages later towards the end of the story in an explanation of the silly obsession with the family crest. Moreover, the extension of the pun goes hand in hand with the metaphorical umbrella use of The Ladybird in the title of the short story, thus acquiring a discourse dimension.

Intradiscoursal ${ }^{25}$ preference of an instantial pattern is an interesting phenomenon and cognitively a challenging area for discourse stylistics. Its interpretation

24. Phraseological zeugma is an instantial pattern relying on a phraseological constituent to function simultaneously as part of the structure of a PU and a free word combination.

25. I use the term intradiscoursal to denote reiteration of a pattern within the framework of one text and transdiscoursal to mean pattern connections across a number of works by one author or one genre. For semiotic understanding of intertextuality, see Orr (1986). 
calls for a thorough consideration of the discoursal aspects of the whole work. A good example is a story from the collection The Thurber Carnival, featuring the world of Thurber's childhood:

\section{to cry out one's heart}

I came into the house one rainy dusk and asked where Frances was. "She is," said our cook, "up in the front room crying her heart out." The fact that a personcould cry so hard that his heart would come out of his body, as perfectly-shaped and glossy as a red velvet pin-cushion, was news to me. For some reason I had never heard the expression, so common in American families whose hopes and dreams run so often counter to attainment. I went upstairs and...

My search for her heart took some fifteen minutes. I tore the bed apart and kicked up the rugs and even looked in the bureau drawers...

\section{J. Thurber, The Secret Life of James Thurber}

Punning on the common image of a heart shaped as a red pin-cushion offers a glimpse of the enchanted world of idiom of Thurber's early boyhood. Reiteration of this pattern creates a surrealistic landscape of his secret vision and comprehension of the world. Many wonderful and grotesque figures are brought to life by his imagination: one lady who was all ears, another one who was always up in the air, a husband who was not able to put his foot down, a man who lost his head during a fire, but was still able to run out of the house yelling, a man who left town under a cloud all wrapped in it and invisible, and many others. The imaginative world of his childhood is conjured up through a sustained literal perception of phraseological images building up a surrealistic realm of their own.

Phraseological pun permeates not only The Secret Life of James Thurber but also Thurber's other works, especially his fables, contributing to their coherence and cohesion, and linking them transtextually through instantial use. The recurrence of phraseological pun and the continual return to it throughout Thurber's writing acquire a transdiscoursal quality by reaching beyond the level of one discourse. The pervasive presence of a PU-based pun as the dominant stylistic pattern is a striking feature of his works, also appearing visually in his own illustrations (see Ch. 6). Both intradiscoursal and transdiscoursal realisation of an instantial pattern clearly reveals the role of phraseology in the web of discourse.

To sum up, phraseological pun is one of the techniques of figurative use, a way to reflect experience beyond the possibilities offered by a PU in its core use. Discourse analysis sheds light on double exposure and the cohesive links achieved by use of the phraseological pun. 


\subsection{Cleft use}

In its base form the PU is a syntactical and semantic continuum in its own right; it is perceived as one whole. The integrity of the PU is due to cohesion at language level. This wholeness is retained in core use, which reflects the cohesion and fluency of the base form: the structure of the PU remains intact; it is syntactically and semantically unbroken. However, in discourse PUs may undergo an instantial cleft, which creates a discontinuity. This indicates a transition from core use to instantial use, signalling the beginning of a new stylistic application. The continuum seems to be intentionally broken. It is not only the syntactical flow of the PU that is interrupted; it is a cleft with strong semantic and stylistic implications in discourse.

Cleft structures have certain functions in discourse; they belong to discourse management features (Jones and Jones 1985; McCarthy and Carter [1994] 1995: 93). The discourse functions of cleft structures are varied. They are influenced by textual mechanisms, securing a flow across sentence boundaries, as well as interpersonal aspects of turn-taking, interruptions, and transitions from one speaker to another, that is, involvement of a PU over a stretch of dialogical discourse. Clefts are important.

In a way, a cleft PU is a paradox, as by its nature the PU is a stable, figurative unity and thus cohesive. Cleft use splits up the PU, at the same time retaining a set of stylistic and semantic resources for linking it into an entity, ensuring cohesion in text. ${ }^{26} \mathrm{Cleft}$ use stipulates that the first part of the PU must be semantically and stylistically adequate in itself. It must be sufficient to generate a link to cross the gap. Hereby the first part of the PU acquires an instantial metonymic function: a part stands for the whole, which facilitates retrieval of the phraseological image in the mind's eye of the reader or interlocutor.

The contrast between continuous and cleft forms lends new information, while a semantic and stylistic link with the base form persists, hence the significance of discontinuity versus continuity.

An instantial cleft may occur in a PU within the limits of one sentence, deliberately breaking the principle of wholeness. The cleft may result in retardation, as the processes of perception and comprehension are slowed down. The cognitive complexity of speech output involves a number of psychological and phonological features, especially pausing and hesitation phenomena (Crystal and Davy [1969] 1995: 104-107; Kess 1992: 57). For example:

26. Cleft use as an instantial stylistic pattern in phraseology was first described by Naciscione (1976: 112-122). 


\section{to go out like a candle}

"If that there King was to wake," added Tweedledum,

"you'd go out - bang! - just like a candle!"

Lewis Carroll, Through the Looking-glass

The structure of the PU to go out like a candle is broken in striking fashion, without causing it to fall apart. The discontinuity is constituted by an unexpected separation of phraseological constituents by an exclamation, which does not become part of the image of the PU in the given context. ${ }^{27}$ Both break and pause are manifest graphically and phonologically. Both punctuation and intonation are of semantic and stylistic significance.

One of the most common ways of creating a cleft in a PU in the author's narrative or monological discourse is by using parenthesis. In the next example the parenthesis what she called appears in the middle of the PU, modifying the meaning. Cleft use often goes hand in hand with other patterns to create a stronger effect. For example:

\section{to give someone a bit/a piece of one's mind}

Knox: ... I told her she'd only just come out to China and didn't know what she was talking about, and then she gave me what she called a bit of her mind. I was obliged to remark that if that was a bit I didn't much care about knowing the rest.

W. S. Maugham, East of Suez

Cleft use is frequently carried over into the next sentence or sentences. The instantial split severs the PU into two parts; the stable structural and semantic continuity of the base form is broken. However, semantic and stylistic ties stretch beyond the limits of one sentence, as phraseological cleft performs a cohesive function. For example:

\section{to rise to the occasion}

Michael saw Soames, pale and deliberate, take a piece of paper from his breast-pocket, and rise. Was it to the occasion?

J. Galsworthy, The White Monkey

27. A major difference exists between a cleft and the pattern of insertion; insertion does not create discontinuity as the flow of the PU is retained semantically and also phonologically: the PU remains in the same sense group or breath group as they are also called. The phonological aspect helps to differentiate. Some examples of insertion: Thy old groans yet ring in my a n cient ears (W. Shakespeare, Romeo and Juliet, Act II, Sc. 3); (...) an early victim of male chauvinism, sent to Shaftesbury to mend her wicked ways (J. Fowles, A Personal Note). 
Cleft use is one way in which a PU is integrated in discourse. The novelty of this instantiation is that the PU is split into two parts as part of an indirect interior monologue. The PU may also appear in a reversed order across sentence boundaries, creating a pause to ponder and reflecting the character's innermost thoughts:

\section{to turn over a new leaf}

The old boy! He was a darling to have kept that list! A new leaf! She would go at once to Bertie Curfew and get him to turn it over for her! The expression in his eye last night!

J. Galsworthy, The Silver Spoon

Cleft use of PUs is mostly realised in dialogical context where it acquires a discourse dimension, involving pauses and hesitations. Cognitively, cleft use is associated with decrease in speech fluency. Psycholinguistic research shows that hesitation phenomena in speech production often appear at such important cognitive points of transition when new or vital pieces of information appear in the output (Kess 1992: 56-58). Psychologically, interruptions are natural discourse strategies, especially in dialogue. Cleft use is one of the mechanisms to secure these effects; hence it is one of the ways in which PUs are integrated to create discourse.

How is a dialogical gap bridged using a PU? Turn-taking is known to be one of the overt transactional skills in spoken discourse (McCarthy and Carter [1994] 1995: 175). Use of cleft PUs is one of these skills; it forms part of the interaction of talk and silence. ${ }^{28}$ It is well-known that silence may be meaningful. The split-up sustains a link between speakers, who use parts of a PU to create interpersonal involvement. Cleft use is essential in cohesion and coherence of dialogue. At the same time it allows the addressee to draw inferences about the meaning of hesitation (Kurzon 1997: 19). The following example of cleft use illustrates communicative competence in the way the interlocutor handles a breakdown in communication, emphasising his own message: ${ }^{29}$

28. Jaworski views silence as a linguistic resource; he shows how talk and silence are part of the metamessage of interaction, that is, how they frame utterances and how they are used to establish the footing between interactants (Jaworski 1998:99).

29. Communicative competence is said to be composed of four areas of knowledge and skills: grammatical, sociolinguistic, discourse, and strategic competences. Strategic competence is composed of strategies which enable speakers to handle breakdowns in communication and their own lexico-grammatical inadequacies to enhance the effectiveness of their message (Coulthard [1977] 1991: 147). 


\section{to be born in the gutter}

Magnus: I have not won my position by my merits. If I had been born as you were in the $-\underline{\text { in the }}$

Boanerges: In the gutter. Out with it.

G. B. Shaw, Apple Cart

A break of this type usually occurs in a conflict situation. The cleft is marked by reiteration and punctuation, which characteristically signal a certain tension or hesitation. Punctuation lends the phrase a distinct pause value, implying that more remains to be learned. A euphemistic touch exists about this pause, as the speaker is reluctant to proceed. It is a pregnant pause, marked graphically. The interlocutor uses the second part of the PU as a retort, conveying annoyance. Breaking the PU into pieces immediately affects intonation. The intonation changes, carrying along with it the sphere of content, for it is an inseparable part of content. Pauses and intonation reveal the subtext of the statement.

Cleft use is a creative way to form dialogical discourse. The second part of the PU may be used as repartee to bridge the gap in dialogue and show a desire to be on the same wavelength. The riposte acts as a sentence connective:

\section{art is long and life is short}

"Art is long," Sloan heard himself saying aloud...

"And life is short. I know that." Dr. Bressingham completed the quotation brusquely.

C. Aird, Dead Liberty

One of the most common cases of cleft use occurs by coupling it with other types of instantial use (see concurrent use in Ch. 5.3), especially extended metaphor and pun. The instantiation is split between two interlocutors:

you have made your bed, now lie on it/you have made your bed and you must lie on it

The garden at Vale View was a patch of tender colour which the miners often stopped to admire on their way back from their shift. Chiefly these colours came from flowering shrubs which Christine had planted the previous autumn, for now Andrew would allow her to do no heavy work at all.

"You've made the place!" he told her, with authority.

"Now sit on it."

Her favourite seat was at the end of the little glen where, beside a tiny watersplash, she could hear the soothing converse of the stream. An overhanging willow offered protection from the rows of houses above. The difficulty with the rest of the garden of Vale View was that they had only to sit outside the porch for all the front windows of the rows to be tenanted... 
By choosing instantial use, the speaker signals willingness to negotiate in the same terms, picking up the figurative thread: the same PU is continued.

PUs occupy an important role in maintaining interactions. If the figurative phraseological link is not established, the result may be miscomprehension. Failure to perceive and recognise the PU on the part of interlocutor may be used as a special stylistic tool with a specific aim in mind:

\section{to go West}

He said absent-mindedly,

"That dago secretary of the boss has gone."

"Where?"

"West." He could feel her arm go g-_tiff: she strained away from him towards the wall. He had touched the taboo - the bond was broken, he couldn't tell why.

G. Greene, The Power and the Glory

The second speaker perceives the words merely in their literal meaning, failing to identify the PU. The cleft is accompanied by the author's comment He could feel her arm go stiff, which is a cue indicating that the meaning of the PU is understood. Has gone also has a euphemistic meaning to die, which is the meaning the speaker has in mind. This is a case of a lexical euphemism. As the interlocutor does not perceive the euphemistic meaning, she tries to clarify the situation. The answer West resolves the ambiguity, as it brings to mind the PU to go West which means to die. The cleft occurs in the middle of the euphemistic pun. The pause is a non-verbal cue, indicating unwillingness to speak. The context gives cues that confirm the pun. The wife's reaction shows that death has entered their conversation, and this subject is considered taboo.

The image of the PU may be split over two utterances as an interactional feature, lending liveliness to dialogue. The process of reading (or watching) is more strenuous and more rewarding as the reader comes to grips with this discoursal technique, which usually develops into an allusion to the PU (see Ch. 4.4). Actually, most of the complicated cases of allusion appear in dialogue as cleft constructions. For instance, in the next example the conversation consists of witty comments and sharp rejoinders, which are so typical of Shakespeare:

\section{can the leopard change its spots?}

King Richard: $\quad$ Rage must be withstood: Give me his gage: lions make leopards tame.

Thomas Mowbray: Yea, but not change his spots: take but my shame, And I resign my gage. 
As it is a conflict situation, the focus is on discontinuity. Knowledge of the PU is crucial to understanding the interconnection between utterances by the characters. Cleft use underlines a sense of psychological tension, which is semantically significant.

The pattern of cleft use may be exploited for comic effect in dialogical context:

\section{to go out of one's senses}

Bardolph: Why, sir, for my part, I say the gentleman had drunk himself out of his five sentences.

Evans: $\quad$ It is his five senses: fie, what the ignorance is !

W. Shakespeare, The Merry Wives of Windsor, Act I, Sc. 1

This instantiation involves several types of stylistic patterns, changing both the syntactical structure and the constituent make-up of the PU (which is metaphorical in its base form): cleft use, replacement (the verbal constituent of the base form go has been replaced by drunk himself while senses have turned into sentences), and insertion ( $f i v e$ ), resulting in a malapropism, based on logical incongruity. This is a logical mistake in choice of the right word, due to a fallacy in thinking; thus, cognitively it is not a slip of the tongue, it is a slip of the mind, as language reflects thought. The cue fie, what the ignorance is! is a prompt that plays a supporting role in the metaphorical network and facilitates tracing of associative links. This example is proof that malapropisms were already in use before Sheridan, for instance, by Shakespeare (see Oncins Martínez 2000).

In conclusion, in its base form the PU is a stable figurative continuum which is retained in core use, while discourse provides for cases when the PU is severed for stylistic purposes Instantial cleft use is enabled due to cohesion of the PU at language level. The pattern of cleft use implies discontinuity: a sudden change, an abrupt break, or a hesitation, which precedes the second part of the PU and its instantial extension. Cleft use is one of the patterns of instantial use.

\subsection{Phraseological allusion}

It is crucial to distinguish allusion as a pattern of instantial use in discourse from allusion as a stylistic technique in the abstraction of phraseological meaning, that is, allusion enshrined in the base form, e.g., to meet one's Waterloo, an/the apple of discord, Job's news, Judas kiss, the Trojan horse, to fight like Kilkenny cats (see Ch. 2.2).

This chapter will explore the meaning of phraseological allusion as a pattern of instantial stylistic use, its implications for discourse analysis, and its role in 
conveying the message of a text. It is one of the most sophisticated patterns of instantial use of PUs. The identification procedure requires considerable insights from cognitive psychology, which is fundamental to understanding the pattern of allusion and its complexities.

It is important to verify intuitions about the PU and make an effort to identify it. As the PU never appears in its full base form in the case of allusion, it is crucial to extract this phraseological information from memory and conjure it up in the mind's eye. Information contained in the context combines with relevant knowledge of the PU stored in long-term memory. ${ }^{30}$ This secures conscious awareness and allows the reader or listener to respond to written or spoken text with full comprehension. Non-native speakers and L2 learners frequently have to resort to dictionaries to aid the process of recall.

In order to access the base form, it is necessary to identify both the visible and the invisible: the explicit image-bearing constituents, as they play the key role in bringing to mind the meaning of the PU, and the implicit constituents, supported by a wider context. The explicit constituents remain in the focus; they create a symbolic representation of the PU. In complicated cases, the reader has to go through the whole procedure of identification to reinstate the missing pieces in order to obtain a full picture of the base form and identify the semantic and stylistic links.

It is common knowledge that inferences are constantly drawn not only from what is overtly said but also from what is implied (Kess 1992:6). Consciously or unconsciously, the reader seeks to make explicit the missing constituents and retrieve the base form exploited in the given instantiation. The persistence of ties between explicit constituents and the base form provides cohesion, an important element in interpreting text. Allusion best illustrates the force of phraseological cohesion. "It is the continuity provided by cohesion which enables the reader or listener to supply all the missing pieces" (Halliday and Hasan 1976: 299). Retrieval of implicit constituents and phraseological meaning is enabled by the inherent cohesion of the base form of the PU, which explains the cognitive mystery of recall. Thus the complete form of the PU is recoverable. The reader seeks cues to establish a link between the explicit and implicit constituents.

Understanding phraseological allusion relies on building a mental model of the PU, which is hinted at on the basis of the meanings of explicit image-bearing

30. Memory is crucial to language use in all aspects and at all levels, that is, from perception to semantics (Garman [1990] 1996:309). The classic distinction between a central, long-term vs peripheral, short-term memory is criticised by Garman. He divides memory into current memory and encyclopaedic knowledge ([1990] 1996:308). According to this division, the base forms of PUs are obviously stored in encyclopaedic memory. 
constituents, which are semantically and stylistically loaded. Identification and interpretation of associative links largely depends on the stylistic skills of the reader, listener, or translator who has to deal with the interrelationships of figurative and literal meanings, single out the explicit and implicit constituents of a PU, and mentally embrace the spread of the phraseological image.

If online recognition of instantial use does not set in, identification becomes compulsory. The identification steps (see Ch. 2.4) are a prerequisite to facilitate recognition and comprehension of the instantial form. Unresolved allusion exerts an inhibitory effect. Allusion is achieved if one or more constituents bring to mind the complete semantic and stylistic information of the PU. For purposes of identification, it is important to keep the base form at the back of one's mind throughout the stretch of phraseological allusion. This facilitates perception of the stylistic and semantic impact of allusion and sustains the associative vision. Allusion as a stylistic pattern in use of PUs has existed throughout the history of the English language:

\section{a burnt child dreads the fire $^{31}$}

$\mathrm{O}$ ! fy, for shame! they that han been brent,

Allas! can they nat flee the fires heete?

G. Chaucer, The Canterbury Tales, VIII, G, 1407-1408

Phraseological allusion is one of the ways to generate compelling associations in discourse and focus on a significant point at issue. Shakespeare is a great master of the pattern of allusion, among many other stylistic techniques:

\section{a serpent under flowers $^{32}$}

Lady Macbeth: To beguile the time,

Look like the time; bear welcome in your eye,

Your hand, your tongue; look like the in nocent flower,

But be the serpent under't.

W. Shakespeare, Macbeth, Act I, Sc. 5

The PU a serpent under flowers appears in Shakespeare's plays only twice (see ShakespearePlaysPlus 1996), and the pattern of allusion is exploited in both

31. Cf. This PU was first recorded in core use in the 13th century: Brend child fuir fordredeth (1250 Hendyng O 199.43), see Whiting for more examples (1968:81).

32. The PU a snake/serpent in the grass has had many variants in the history of English: (1) MiE the serpent under floures/in the gras; (2) in ENE two other variants appeared in parallel: a snake under flowers/in the grass; (3) MoE a snake/serpent in the grass (Whiting 1968:508-509). It was used twice by Chaucer as extended metaphor (see Ch. 5.4, Ch. 7.4). 
instances. In Romeo and Juliet, the news that Romeo has killed Tybalt creates an outburst of strong emotions - disbelief and pain in the face of deceit and betrayal:

\section{a serpent under flowers $^{33}$}

Juliet: O God! did Romeo's hand shed Tybalt's blood?

Nurse: It did, it did; alas the day! it did.

Juliet: $O$ serpent heart, hid with a flowering face!

Did ever dragon keep so fair a cave?

Beautiful tyrant! fiend angelical!

Dove-feather'd raven! wolvish-ravening lamb!

Despised substance of divinest show!

Just opposite to what thou justly seem'st;

A damned saint, an honourable villain!

W. Shakespeare, Romeo and Juliet, Act III, Sc. 2

Allusion usually concentrates on the most important piece of information. In stylistic use of PUs it conveys the meaning of the PU in a more focused way. The implicit constituents are understood by the reader or listener, as they are brought to mind by the context. Phraseological allusion has a holistic effect as the explicit constituents convey the meaning of the whole PU. However, it is not only the semantic message of the base form that is conveyed. The instantial change achieves a novel stylistic effect of its own due to creative effort in discourse. It is important to assess the new instantiation both from the linguistic and literary points of view.

Thus, phraseological allusion is a mental implicit verbal or visual reference to the image of a phraseological unit which is represented in discourse by one or several explicit image-bearing constituents, and their instantial ties, hinting at the image. ${ }^{34}$

Allusion frequently emerges in stylistic use of proverbs. When speaking about proverbs in the modern age, Mieder calls it "old wisdom in new clothing" (Mieder 1993:58). A mere allusion often suffices to bring to mind the whole proverb and complete the communication process (Mieder 1989:148). This technique is common not only in the instantiation of long proverbs with a more complicated syntactical structure but also in short proverbs. The pattern of allusion acts as a mental reference to the image of the PU in discourse, securing an associative vision:

33. This example has been kindly lent by José Luis Oncins Martínez.

34. In visual representation, allusion to a PU may function without the presence of a single explicit constituent in the verbal part of the discourse (see Ch. 6). 


\section{two heads are better than one}

He said, "It's just a worry I have to think out for myself. Something I hadn't considered."

"Tell me, dear. Two brain s..."

G. Greene, The Heart of the Matter

As to its meaning, two heads are better than one belongs to "metonymy-based metaphors" (see Barcelona 2000b:52). It is a metaphorical proverb with a metonymic constituent head (where head stands for a person). ${ }^{35}$ In this case of instantial use, a new metonymic association is shaped head $\rightarrow$ brains, which is a further instantial metonymic shift as brains stands for a head; it is a metonymic mapping PART FOR WHOLE. It is only the initial constituent two that has been preserved in the text. We see the way associations work in the human mind, enabling retrieval of an item from storage with one base constituent left explicitly in the text. The implicit constituents are graphically represented by aposiopesis, signalling a sudden breaking off in the midst of the sentence. Moreover, aposiopesis lends a meaningful touch to the phrase by leaving the thought incomplete and indicating that there is more to it than meets the eye.

The reader immediately infers, and implicitly recognises and identifies, the overtly missing constituents, and hence the base form. This is enabled as the explicit part of the PU performs the function of recall, retrieving the base form from long-term memory. Interpreting a piece of text calls for creative processing, as the meaning of the PU has been developed: it is no longer the same as the figurative meaning of the base form.

Allusion is a pattern where much is asserted by implication. Identifying allusion calls for cognitive effort. In the case of L2 learners, it requires some additional endeavour and training in stylistic use and awareness. Let me turn to some more examples of instantiated allusions to PUs in which only a few explicit constituents have remained scattered in the text, for example:

\section{to choose the lesser of two evils}

"Ach! Ach! Only pantoffeln! Well - what do you say?" and the professor turned boisterously to Gilbert, changing into English. "It is a choice of evils. Which do you choose? Boots or slippers with no heels? Hein? Say the word, say the word."

D. H. Lawrence, $M r$ Noon

35. The metonymic character of the proverb two heads are better than one is clearly seen when we consider its meaning, e.g. "some problems may be solved more easily by two people working together than by one working alone" (The American Heritage New Dictionary of Cultural Literacy 2009); "if one meets a difficulty it is better to accept help or advice than to try and face the difficulty alone" (Longman Dictionary of English Idioms 1979). 
The implicit constituents are as much part of the text as those which are explicitly present. When reading the passage, we realise that the isolated constituents refer to the $\mathrm{PU}$, as the text contains indications leading to establishment of the full base form in the mind. The following example is illustrative of the many cases where the relevant part of the text would be unintelligible without awareness of phraseological allusion. Without associative ties, the text would remain uninterpretable. A sequence of associations emerges and phraseological cohesion becomes an important fact of discourse:

\section{when the cat's away, the mice will play}

West.: But there's a saying very old and true,

'If that you will France win,

Then with Scotland first begin:'

For once the eagle England being in prey,

To her unguarded nest the weasel Scot

Comes sneaking, and so sucks her princely eggs,

Playing the mouse in absence of the cat.

To tear and havoc more than she can eat.

Exeter: It follows then the cat must stay at home:

Yet that is but a crush'd necessity,

Since we have locks to safeguard necessities,

And pretty traps to catch the petty thieves.

W. Shakespeare, Henry V, Act I. Sc. 2.

When the cat's away, the mice will play is an old proverb, recorded in MiE: in the absence of a controlling entity, subordinates will take advantage of circumstances. This instantiation is a case of concurrent use (see Ch. 5.3), going across utterance boundaries, involving allusion and extended metaphor as part of the dense figurative network. The cat must stay at home is an extended metaphor with a metonymic base, developing the inherent metaphor of the proverb. Traps is a sub-image, a metonymic link going back to both the mouse and the weasel. In cognitive psychology this kind of link is qualified as an association by contiguity enabling development of meaning (Reber [1985] 1995: 159). Associations representing contiguity are not merely connections between items; they constitute a semantic network (Harley 1995: 179-180).

The PU is seemingly disjointed and remains incoherent if these items are viewed in isolation. Alone, they do not cohere. Taken together, the separate elements serve as explicit signals of allusion. In fact cohesion is provided by what is left out and by semantic links with the whole PU. A coherent mental picture is established only if the absent constituents are, consciously or unconsciously, recalled in the mind of the reader or listener as the base form of this particular 
PU. Thus allusion shows the strength of cohesion inherent in the PU: one or two constituents evoke associations with the whole unit.

When going through OE to MiE texts, we discern a noticeable similarity in the metaphorical process and a sense of constancy as to method. Allusion is a creative technique, evolving from the base metaphor and developing a novel meaning in discourse. In use of the following proverb from Chaucer, only one metaphorical constituent of the base form is retained and extended:

\section{curses, like chickens, come home to roost}

And ofte tyme swich cursinge wrongfully retorneth agayn to him that curseth, as a bryd that retorneth agayn to his owene nest.

\section{G. Chaucer, The Canterbury Tales, I, The Parson's Tale, 620}

The proverb curses, like chickens, come home to roost is metaphorical or, as Gibbs puts it, "overtly metaphorical" (Gibbs 2003:118). It is alluded to and extended, resulting in parabolic thinking, a type of thinking typical of the Middle English period. The proverb represents a moral attitude. Its stylistic instantiation illustrates an extension of the figurative thought enshrined in the proverb; it goes on being didactic, preaching and teaching a moral lesson.

The missing constituents of the base form lie at the back of the reader's or listener's mind. We see the way association works in the human mind, which has the ability to retrieve an item from storage with one base constituent left explicitly in the text. Visible absence is compensated by an invisible implicit presence. Cognitive access to the base form of the PU and knowledge of the pattern of allusion are central to perceiving, identifying, and interpreting the semantic and stylistic subtleties of allusion, as can also be seen from the following MoE example:

\section{people who live in glass houses shouldn't throw stones/those who live in glass houses} should not throw stones

"And my sweet, silly Tina, why should we deny to others what has made us both so happy? What if this wicked maid and my rascal Sam should fall in love? Are we to throw stones?"

J. Fowles, The French Lieutenant's Woman

In this instantiation, the explicit image-bearing constituents of the PU throw stones perform a metonymic function in discourse: they act like a recall cue alluding to the PU, providing a web of associative links, enabling the reader or listener to see beyond words. Recall is also facilitated by throw stones as they epiphorically present the final constituents of the PU.

The next illustration is a long PU (a proverb with the structure of a complex sentence). Quite commonly, longer PUs undergo instantial changes in discourse. 
In this example, quite a number of phraseological constituents do not surface into explicit form in discourse. The remaining notional constituents function as an explicit signal that allusion has been exploited.

he should have a long spoon that sups with the devil

Trinculo: I should know that voice: it should be - but he is drowned; and these are devils: O defend me!...

Stephano: This is a devil, and no monster: I will leave him; I have no long spoon.

W. Shakespeare, The Tempest, Act II, Sc. 2

Separate items of the PU have been retained in the context. The constituents are not presented in the regular logical sequence and are difficult to understand due to the disjointed order. Some explicit elements may be located elsewhere in an earlier sentence or in a subsequent one, while some constituents may not be found in the text at all, but all are necessary for comprehension of the text.

It may be quite surprising that a PU can be retrieved from a few isolated constituents or even a single constituent. In an extreme case of phraseological allusion, only one base constituent is retained in discourse. In order to assign and interpret meaning, it is essential to comprehend the interaction of the PU with the context, and the process that the PU has undergone in a certain segment of discourse.

\section{a cat has nine lives}

Burge-Lubin: But damn it, man - I beg your pardon, Archbishop, but really, really -

Archbishop: Don't mention it. What were you going to say?

Burge-Lubin: Well, you were drowned four times over. You are not a cat, you know.

\section{G. B. Shaw, Back to Methuselah}

The presence of the image-bearing constituent cat acts as a recall cue in the face of absence of the full form. The missing constituents can be retrieved due to cohesion of the base form, discoursal cohesion rooted in the phraseological meaning, and the anaphoric tie you were drowned four times over together with the negation you are not a cat. The implicit constituents are invisibly present in the text. This shows once again that hidden meanings may play a significant role in literary texts and that it is essential to treat them as interpretative problems (van Peer 2000:39).

Cases of phraseological allusion differ in their degree of subtlety and complexity. Cohesive ties are a source of information for the reader. Coherence is created by contiguous associative links and tenuous relationships, which at times 
are so slight and subtle or even next to imperceptible that they could easily be lost. Phraseological cohesion is the primary factor that makes the text intelligible:

\section{hunger is the best sauce}

\section{to cut one's coat according to one's cloth}

A povre widwe somdel stape in age,

Was whylom dwelling in a narwe cotage, ...

Ful sooty was hir bour, and eek hir halle,

In which she eet ful many a sclendre meel.

Of poynant sauce hir needed never a deel.

No_deyntee morsel passed through hir throte.

Hir dyete was accordant to hir cote.

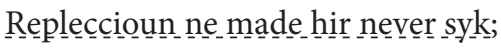

Attempree dyete was al hir physik,

And exercyse, and hertes suffisaunce.

G. Chaucer, The Canterbury Tales, B, 4022-4025

The implicit constituents present information retrievable from both preceding and subsequent lines thanks to cues that provide the semantic background, such as a povre widwe, a sclendre meel, no deyntee morsel, dyete, repleccioun ne made hir never syk. These anaphoric and cataphoric ties (Halliday and Hasan 1976: 1719) hint and prompt the mind, thus improving recall. They support associative semantic information that is present in the text. Accordant to hir cote is instantial elliptical use of the second PU. Ellipsis is another cohesive device in discourse.

While allusion is a subtle reference, it is also a powerful strategy; it can be highly concise and economical, using very little language. Sometimes the allusion is accompanied by the author's comments, which reveal that the author is aware that instantial meaning may be hard to perceive and grasp. The comment gives a lead which may help to prompt and identify the PU:

the cat would eat fish, but would not wet its feet ${ }^{36}$

Lady Macbeth: Art thou afeard

To be the same in thine own act and valour

As thou_art in des desire? Wouldst thou have that

Which thou esteem'st the ornament of life,

And live a coward in thine own esteem,

Letting "I dare not" wait upon "I would",

Like the p o or cat i' the adage?

W. Shakespeare, Macbeth, Act I, Sc. 7

36. $\mathrm{MiE}$ - the cat wolde ete fish, but wolde not wete his feet, MoE - the cat would eat fish, but would not wet his feet. 
In order to understand and interpret discoursal changes, it is important to attempt to find some element of the meaning of the PU suggested by the rest of the context. Analysis is needed to confirm predicted differences between the base form and the instantial elements presented in discourse. It may be helpful to set down identification moves in the cognitive process in greater detail:

1. The adage is a prompt; it leads us to think that the text involves a proverb containing the constituent cat. This cue may be helpful in the cognitive process of identification. As this is an ENE text, the reader must undoubtedly rely on the evidence of the printed word. The Concise Oxford Dictionary of Proverbs ([1982] 1992:37-39) has registered 11 proverbs containing the constituent cat, while Whiting's dictionary (Whiting 1968:72-74) has recorded 17 proverbs with cat in MiE. Clearly, this clue alone does not identify the PU in question, but it surely alerts the reader to the issue and raises awareness not only of the figurative meaning but also of a certain degree of stability and cohesion of the language unit.

2. The instantial epithet poor indicates a negative shade of meaning and excludes all PUs with a happy connotation.

3. It is crucial to scrutinise the following and preceding text in search of an anaphoric or a cataphoric cue, a connection between the cat and the context, seeking to abstract a figurative network and establish the meaning entailed by the cat. In many cases of allusion, retrieval of the base form is cue-dependent. A sequence of associations emerges in search of hidden cues, which would prompt associative links. A backward association takes the reader to a semantic cue which summarises the meaning of the PU:

To be the same in thine own act and valour

As thou art in desire?

This helps to establish the semantic and stylistic link between the poor cat in the adage and unfulfilled desires. Although a backward association is assumed to be weaker than a forward association (Reber [1985] 1995:59), it facilitates emergence of the PU the cat would eat fish, but would not wet its feet in one's mind's eye. The allusion is thus resolved. The entity of the PU is referred to by mention of a single constituent. This example clearly brings out the metonymic function of the explicit image-bearing constituent/s.

It is useful to remember that, in the case of allusion, implicit constituents are as much part of instantiation as explicit constituents: 


\section{fools rush in where angels fear to tread}

The peace-keeping forces in Liberia are the only ones in areas where ot hers fear to tread.

BBC World Service, 12 August, 2003

The final explicit constituents fear to tread perform the reminiscent function (Shadrin 1969) in disambiguation, supported by the syntactical structure of the second part of the PU and enhanced by epiphoric prosodic features.

The following examples will illustrate phraseological allusion in dialogical context. Comprehension requires specific understanding of the pattern in the instantiation of a new dialogical form. Punning interaction between the two characters sustains the allusion. Missing constituents are retrieved in the mind of the reader or listener.

when Adam delved and Eve span, who was then the gentleman?

\section{to bear arms}

Clown: There is no ancient gentleman but gardeners, ditchers and gravemakers. They hold up Adam's profession.

Other: Was he a gentleman?

Clown: He was the first that ever bore arms.

Clown: Why, he had none.

Other: What, art a heathen? How dost thou understand the Scripture? The Scripture say Adam digged. Could he dig without $\underline{\operatorname{arms}}$ ?

W. Shakespeare, Hamlet, Act V, Sc. 1

The base form when Adam delved and Eve span, who was then the gentleman? has been recorded since the Middle English period (see Whiting 1968: 4; The Concise Oxford Dictionary of Proverbs [1982] 1992:2; Apperson 1993:2). Thus, dig is a case of instantial synonymic replacement as the person is a gravedigger. The first meaning of to delve is to dig, esp. with a spade (Chambers 20th Century Dictionary [1983] 1987:330). This punning line is intertwined with punning on the PU to bear arms, creating a metaphorical network that encompasses the whole instantiation. The pattern of allusion involves several stylistic techniques to make the associations work.

The persistence of relationships between explicit and implicit constituents is an important element in the interpretation of text. The cues perform a semantic function, helping to establish a network of associative links and disambiguate the instance. The continuity of links between the explicit constituents and the base form provides cohesion and achieves sustained associative vision. Verbal absence becomes textual presence. 
The complete impact of a phraseological allusion comes to the reader who is fully aware of the origin of the allusion, i.e., the PU that is alluded to. Failure to perceive a message of phraseological allusion may be exploited as a special technique:

the road to hell is paved with good intentions

"To speak truth, sir, I don't understand you at all: I cannot keep up the conversation, because it has got out of my depth. ..."

"Justly thought; rightly said, Miss Eyre; and at this moment, I a m paving hell with e n ergy."

"Siir??"

"I am laying down good intentions, which I believe durable as flint. Certainly, my associates and pursuits shall be other than they have been."

C. Bronte, Jane Eyre

Jane's question "Sir?" is a cue. It suggests a semantic difficulty in comprehending the allusion. She fails to catch it immediately, as Mr. Rochester's idiomatic speech makes it hard for Jane to keep up the conversation. This is a case of unresolved allusion from the point of view of the second interlocutor.

Shakespeare has been subtle in handling the issue of comprehension. The next example is a good illustration of the pervasive power of allusion: it is sustained, embracing a whole stretch of text. The king does not perceive the allusion. Therefore he asks "What doest thou mean by it?" Failing to comprehend the figurative meaning, he repeats his question, "Where is Polonius?" The second notional constituent, food, does not appear in the text at all, compensated by an intricate network of sub-images and cues. The comprehension of allusion is largely cuedependent:

\section{to be food for worms ${ }^{37}$}

King: Now, Hamlet, where's Polonius?

Hamlet: At supper.

King: At supper? Where?

Hamlet: Not where he eats, but where he is eaten. A certain convocation of politic worms are eaten at him. Your worm is your only emperor for diet: we $\underline{\mathrm{fat}}$ all creatures else to fat us, and we fat ourselves for maggots. Your fat king and your lean beggar is but variable service - $\underline{\mathrm{two}} \mathrm{dishes}$ but to same table. That's the end.

37. Interestingly, Shakespeare exploited allusion to the PU food for worms in a number of his works: As you Like It, Act IV, Sc. 1; Sonnet 6 and Sonnet 74. It is also widespread in the texts of the MiE period (wormes fode), mostly in instantial form (Whiting 1968:675). 
King: Alas, alas!

Hamlet: A man may fish with the worm that hath eat a king and eat of the fish that hath fed of that worm.

King: What doest thou mean by it?

Hamlet: Nothing, but to show you how a king may go a progress through the guts of a beggar.

King: Where is Polonius?

Hamlet: In heaven.

W. Shakespeare, Hamlet, Act IV, Sc. 3

All this stretch of text is built on one PU: related elements form chains in which the metaphorical network is intertwined with associations of contiguity, bringing out the cohesive force of phraseological allusion. In this way, allusion acquires a discourse dimension. Both overt and covert intentions need to be recognised in interpretation of meaning (Gibbs 1999a: 39). Identification of the base form of the PU and its instantial meaning help to transform a series of seemingly unrelated isolated figurative items into a unified, coherent whole: an associative web signifying a complex network of metaphorical and metonymic links. Interpretation and analysis need to take into account the interrelationships between and coherence of all the stylistic elements involved in one instantiation.

An example from media texts. This is a serious financial article, dealing with the exchange rate tie to the US dollar which has held firm in Hong Kong. The headline is an allusion to the PU a square peg in a round hole/a round peg in a square hole:

The pegstill fits the hole

Financial Times, 30 June, 1998, p. 11

In this instantiation, allusion involves punning on another metaphorical meaning of the word peg: the rate to which one currency is pegged to (secured by) another. Moreover, as the headline it performs an umbrella function (see Ch. 5.5.1). The allusion to the phraseological image embraces the whole article.

In conclusion, phraseological allusion is an implicit mental verbal or visual reference to the image of a phraseological unit which is represented in discourse by one or more explicit image-bearing constituents. Allusion shows the strength of cohesion inherent in the PU: one or more constituents act to evoke associations with the whole PU. Cognitive access to the base form of the PU and knowledge of the pattern of allusion are central to perceiving, identifying, and interpreting the semantic and stylistic subtleties of allusion. This pattern calls for informed stylistic awareness of use of language. The explicit image-bearing constituents of the 
PU perform a metonymic function in discourse, acting like a recall cue alluding to the PU, providing a web of associative links and securing sustained associative vision which enables the reader or listener to see beyond words. Failure to retrieve the image of the PU will result in failure to capture the semantic and stylistic message of the allusion. Unresolved allusion operates to the detriment of inference and results in semantic and stylistic loss in reading and interpreting a given text. 


\section{CHAPTER 5}

\section{Phraseological units in the web of discourse}

The aim of this chapter is to have a closer look at the potential of phraseological resources in weaving a seamless web of discourse. When looking at the structure of vocabulary from a semantic point of view, Lyons maintains that discourse is best regarded as a large and intricate network with interconnected relationships of meaning, as "a huge, multidimensional, spider's web”, in which each strand is one relation in the network (Lyons 1981:75). By taking into account the essential discourse processes, it is possible to discover "the discourse world" (Werth 1994: 90). In the case of instantial stylistic use of PUs, it is necessary to establish how the PU interacts with other elements over extended stretches of text in order to bring out the involvement of phraseology in the interrelated web of semantic and stylistic interrelationships in discourse.

The concept of textual or text-forming function (Halliday and Hasan 1976:299) is directly applicable to phraseology and is inextricably linked with the concept of cohesion (see Ch. 3.2). The instantial constituent adds to cohesion as its meaning lies in the context. Instantial use plays a special role in creation of text, providing continuity across various parts of discourse. The PU becomes a pivotal factor, affecting development of the part of discourse it is involved in. The thread of phraseological meaning persists from one segment of discourse to another as the semantic process continues and the discourse unfolds.

The discoursal web is enabled by the very nature of the PU: cohesion of its base form. Signals of phraseological presence work like a cohesive framework. Instantial use may provide cohesion across not only sentences and paragraphs, but also larger stretches of text. The PU, some part or separate constituents of it, cannot be interpreted without the complete extent of instantial use. The structure of discourse depends on a balance between all base and instantial elements interlinked by phraseological ties. Any change in the PU, for instance, replacement of one instantial pattern by another, let alone replacement of instantial use by core use, would change the entire network of relationships and hence meaning. Phraseological cohesion is central to interpretation of a stretch of discourse.

Apart from extended use of single patterns, sustainability of PUs in the web of discourse may also be achieved in other ways: by reiteration, cumulative use, concurrent use, saturation, and comprehensive use. 


\subsection{Instantial aspects of phraseological reiteration in discourse}

One of the most common patterns that easily becomes incorporated in the web of discourse is phraseological reiteration. This creates an intricate linking of features, contributing to textual cohesion and coherence. The "cross-sentential repetition" (Carter 1997:135) of elements which are discoursally interconnected produces the unifying effect of these interrelationships.

In traditional rhetoric, repetition is generally seen as a fundamental if primitive device of intensification, especially in affective situations, states of extreme emotional tension, or for the sake of emphasis. In the history of stylistics these devices have received an elaborate classification; thus rhetorical tradition has handed down a large number of technical names for various kinds of verbal repetition and repetitive effects (Leech [1969] 1993:73-83). Figures of repetition were, for instance, particularly common in sixteenth- and seventeenth-century literature, when the vogue for the art of rhetoric was at its height (Wales [1989] 1995: 342). Interestingly, in each period the role of repetition varies depending on the purport of the message and the style of the work. Likewise, each school of analysis has brought out some other valuable feature or aspect of repetition.

In psychology, repetition is one of the laws of association: it secures links and adds coherernce by enabling associations. In discourse analysis, another role of repetition is revealed: that of creating relationships and new meanings in a discourse world. Tannen, for instance, views repetition as "a limitless resource for individual creativity and interpersonal involvement" (Tannen 1989:37) and hence as a key aspect of discourse. She believes that repetition is a central resource in language use. In contrast to the conventional approach, when repetition is often seen as inefficient or inappropriate and is often deliberately avoided or replaced by synonymy, discourse analysis treats repetition as a phenomenon that performs certain functions in discourse. It explores the nature of repetition and its role in creating deeper levels of meaning and reinforcing particular meanings in various types of texts (McCarthy and Carter [1994] 1995: 145-149). Verdonk offers a pragmatic and socio-cognitive view of lexical repetition as an element of meaning production in literary discourse which may contribute to a highly emphatic or emotionally charged style (Verdonk 1995:7-31).

Leech believes that repetition of a lexical item or a whole phrase may be considered a variety of cohesion (Leech 1966:142). This idea is further developed by Halliday and Hasan, who see repetition as a broader phenomenon, which they term reiteration. A reiterated item may be a repetition, a synonym or near-synonym, a 
superordinate, or a general word commonly used with cohesive force. ${ }^{1}$ However, it is not only reiterated phonological and lexical items that reinforce particular meanings across sentence boundaries. PUs are also involved in creating discourse meanings through reiteration, performing a cohesive function.

Phraseological reiteration is a form of cohesion. ${ }^{2}$ It may involve repetition of the whole PU, its parts, or isolated constituents that refer back to it. It may be coupled with any of the techniques of instantial stylistic use of PUs such as extended metaphor, pun, or allusion. The closeness of the semantic and stylistic relationship between the isolated phraseological constituents and the PU determines the cohesive effect of the PU in discourse. The greater the distance, the more difficult it is for the reader, listener, or translator to recognise and identify phraseological links, so that increased awareness would be needed to meet the challenge.

Both literary and non-literary discourse offer ample illustration of cases when a PU pervades the text, when it is reiterated fully or in parts, or when separate constituents are used in isolation over larger stretches of text, sustaining a continuum of reiterative cohesive elements. All these cases call for an enhanced level of identification and interpretation skills. They do not, however, constitute insurmountable difficulties if students are adequately trained. A higher degree of discourse awareness is needed to analyse the stylistic discoursal use of PUs. It is helpful to be aware of the effect of reiterated items on perception and memory. According to the psychological law of repetition, the more often a response is made, the more resistant to extinction it becomes (Reber [1985] 1995:299). Realising the cognitive value of reiteration will help identify its cohesive function and recognise its role in the sustainability of phraseological image, which reflects figurative thought.

In texts, reiteration may take on varied forms when the whole of the PU or one part of it is repeated at different points in the linear organisation of discourse. The pattern of phraseological reiteration is commonly used with cohesive force. "Reiteration is itself cohesive in its own right" (Halliday and Hasan 1976:319). In the case of partial reiteration, the reiterated constituents are usually located in relative proximity to the PU; the distance separating a constituent from the PU

1. "Reiteration is a form of lexical cohesion which involves the repetition of a lexical item, at one end of the scale; the use of a general word to refer back to a lexical item, at the other end of the scale; and a number of things in between - the use of a synonym, near-synonym or superordinate" (Halliday and Hasan 1976:278).

2. For phraseological reiteration as a form of cohesion and its translation, see Naciscione (1997a). 
is not too big. ${ }^{3}$ In the following example, the isolated phraseological constituent refers back to the PU in dialogical discourse:

\section{to leave no stone unturned}

"We mustn't leave a stone unturned and there's a st on e for you."

“A stone, Mr. Dombey!" falterered Walter.

C. Dickens, Dombey and Son

Use of phraseological constituents as cohesive elements is common in dialogues. Partial reiteration of PUs is also frequently exploited by playwrights in turn-taking. Reiteration is one of the different interactive tactics during a sequence of talk in drama dialogue (Simpson 2004: 86). The interlocutor seems to echo the words of the first speaker, creating an elliptical form by immediate reiteration:

\section{to hear the last of someone}

The Executioner: Her heart would not burn, my lord, but everything that was left is at the bottom of the river. You have heard the last of her.

Warwick: (with a wry smile, thinking of what Ladvenu said) The last of her? Hm! I wonder!

G. B. Shaw, Saint Joan

Another type of partial reiteration is anaphoric reiteration of a separate notional constituent, usually closely followed by the PU. In the next example it is a simile, which is a more powerful tool than an adjective alone. Thus the elements appear "in an ascending order of importance" (Wales [1989] 1995:58) with each next reiterated item sounding more powerful and creating a kind of climax as a dramatic means of persuasion:

\section{(as) fit as a fiddle}

How could it have happened? He seemed sof $\mathrm{fit}$. He was $\underline{\mathrm{fit}}$. As fit as a fiddle.

\section{H. Pinter, The Basement}

Bare reiteration of the whole of the PU in core use may produce a powerful effect. The PU has a cohesive function because it is reiterated. In the following case the PU to come to pass is repeated three times in one sentence, each time without instantial changes. However, even verbatim repetition may create an effect in an emotionally meaningful passage, conveying distress and misery:

3. Halliday and Hasan introduce two terms: tight texture and loose texture. If two items occur in adjacent sentences, they exert a very strong cohesive force: this would be progressively weaker the greater the textual distance between them. The fewer the cohesive ties and the further they are located from each other, the looser cohesion will be (Halliday and Hasan 1976:290-296). 


\section{to come to pass}

He did not talk about love and tears: only that this was something which had come to pass, and which, given Johanna's state of mind, was bound to come to pass, and which coming to pass might have taken a more painful form, bringing far more nastiness and misery than at present.

D. H. Lawrence, $M r$ Noon

Repetition across turn boundaries involving idioms is explored by McCarthy and Carter. Repetition signals rapport between speakers who use repetition actively to create interpersonal involvement ([1994] 1995: 146). My observations show that in dialogues phraseological reiteration is frequently practised in core use to hold information in memory, drive a message home, or make a point. Abundance of reiteration serves the purpose very well. This approach is typical of Shaw's manner of writing:

\section{to have the last word}

Ellie: This gentleman wants to know is he never to have the last word?

Hushebye: I should let him have it, my dear. The important thing is not to have the last word, but to have your own way.

Mangan: She wants both.

Hushebye: She won't get them, Mr. Mangan. Providence always has the last word.

G. B. Shaw, Heartbreak House

In discourse analysis, reiteration is seen as a central linguistic meaning-making strategy (Tannen 1989: Ch. 3). Reiteration is motivated; it reinforces the role of the PU in discourse, creating a web of semantic and stylistic interrelationships. Thus, reiteration creates a semantic parallelism, which is relevant to cohesion. This is a common feature in many types of discourse. It offers unbounded scope for creativity even with commonplace PUs. Discoursal links are strengthened by a continuum of persistently reiterative cohesive elements in adjacent sentences:

\section{to keep one's head}

I do not know whether anyone really kept his head completely except those who had to keep it, because they had to conduct the war at first hand. I should not have kept my own (as far as I d id keep it) if I had not at once understood that as a scribe and speaker...

\section{G. B. Shaw, Heartbreak House}

Phraseological reiteration across turn boundaries may go together with use of an antonymic PU, creating antithesis. This brings out contrast associations: things that differ from each other compellingly yet tend to be associated with each other: 
$\underline{\text { top dog }}$

\section{bottom dog}

"When you are tied to a person, as I am tied to you, Soames. Or as we French are tied to Germans, it is necessary to be top dog, or to be bottom dog."

"Do you suppose yourself top dog in this house?"

J. Galsworthy, The White Monkey

In discourse, reiteration is frequently coupled with instantial changes. The subsequent reiterated part is stronger than core use, which it follows:

\section{to cut no ice with someone}

Mr. Paradock: He wanted me to be taken in - I could see that.

Mrs. Paradock: So I suppose you obliged?

Mr. Paradock: That sort of thing cuts no ice with me ... It was all of a sudden with his asking me to form a government.

Mrs. Paradock: I hope you didn't start saying: My mission is to pacify Ireland?

Mr. Paradock: It cut no more ice with me than Gladstone would have done if I'd been Queen Victoria.

N. F. Simpson, A Resounding Tinkle

The sequential links go across the speakers' turns, reinforcing the message. In the next example the reiterated form is more emphatic due to the comparative degree:

\section{a pretty kettle of fish}

Maurice: It's what they call a nerve storm. It's lucky it was only you there. It would have been a pretty kettle of fish if Nurse Wayland had seen me like that.

Stella: (Trying to laugh with him) It would have been a $\mathrm{much}$ prettie kettle of fish if I'd seen you clinging to her capacious bosom.

W. S. Maugham, The Sacred Flame

Reiteration is an essential unifying element in nearly all types of discourse. A fact influencing the cohesive force between reiterative items in the text is their overall density in a stretch of text (Halliday and Hasan 1976:290). In the next example, reiteration goes together with a pun: the duality of exposure reveals the figurative and literal levels of meaning:

\section{you have made your bed and you must lie on it}

Arnold: But you weren't obliged to marry me. You've made your bed, and I'm afraid you must lie on it. 
Elizabeth: That's one of the falsest proverbs in the English language. Why should you lie on the bed you've made if you don't want to.? There's always the floor.

Arnold: For goodness' sake, don't be funnny, Elizabeth.

Elizabeth: I've quite made up my mind to leave you, Arnold.

W. S. Maugham, The Circle

By using the cleft I am afraid Arnold tries to soften the negative message. Elizabeth, however, refuses to accept the unpleasant idea of the eternal bonds of her marriage by commenting on the falsehood of the English proverb.

Through reiteration the PU becomes a noticeable feature in the text. On the other hand, the instantial change enhances the effect of reiteration. In the following dialogue, reiteration brings out the two meanings of a polysemous PU, resulting in a pun. The frequency of reiterated elements achieves a kind of insistent crescendo:

\section{to take care $^{4}$}

Malone: Now, you take care what you're saying, Hector. Take care, I tell you.

Hector: I have taken care. I am taking care. I am taking care of my honour and my position in English society.

G. B. Shaw, Man and Superman

Reiteration may go hand in hand with extended metaphor, which pervades the stretch of text, creating an effect of density:

all is fair in love and war

"Mildred, there are limits!"

"Are there? All's fair in love and war, they say. And you a re a sold ier."

"Quite," said Felix. "All is not fair in war, thank God, and when it is I shall resign. Nor in love either."

I. Murdoch, An Official Rose

The complexity of instantial use reflects the complexity of the conflict situation. Reiteration strengthens motivation and sustains the discoursal meaning. The next PU to smell a rat means "to become suspicious that something is wrong with the situation". Reiteration of the same PU and the same pattern of extended metaphor reinforce the message, i.e., suspicion that trouble is looming for Mr. Noon. Intense emotion is revealed by creating a new discourse form:

4. The PU to take care is polysemous: (1) to see that something suffers no harm; (2) to take the responsibility for something (Longman Dictionary of English Idioms 1979: 47). Cf.: Kunin's dictionary records four meanings of this PU (Kunin 1967a: 142-143). 


\section{to smell a rat}

He (Alf Bostock) had heard her voice speaking to Mr Noon, though he had not caught what she said. But he had smelled a rat. And he was a ve ry ke en rat-catcher these days.

Therefore he did nothing that could betray his suspicions, and he set off to work a few minutes earlier than he needed in order that he might turn back and do a bit of spying. When he passed the more-than-doubtful figure of Mr Noon in the field the smell of the rat was very hot in his n o strils. Like the wicked, he exulted, and said Ha-Ha! He let Gilbert return towards the cottage.

D. H. Lawrence, Mr Noon, Ch. III, p. 30

It is not only the PU that is reiterated after a lengthy stretch of 60 pages; the same sub-image nostrils is also used in the extended metaphor, acquiring a discourse dimension:

He (Gilbert) resented the intrusion deeply. Not only was he forced to smell a rat, but even he must have the rat thrust under his nostrils. He sat rather stiff on the bed, and turned the side of his rosy cheek unrelentingly towards the bothered Emmie.

D. H. Lawrence, $M r$ Noon, Ch. XII, p. 90-91

Recourse to the PU is motivated: it conveys intense emotion and refers to another precarious situation when trouble is imminent for Mr. Noon. Cohesion is shaped by persistent reference to the phraseological image.

The longer the stretch, the bigger the challenge for the reader to follow up cohesive phraseological links and the greater the degree of awareness needed to infer and interpret. Cohesive force between these phraseological items in a passage of discourse is determined by their semantic closeness: the items are phraseologically related. A greater distance is possible because PUs are cohesive by their very nature.

Sustained reiteration of a phraseological image is a striking pattern of instantial use, testifying to the narrative skills of the author. Let me illustrate this by D. H. Lawrence's short story Rawdon's Roof (1978:69-80), whose leading image is based on the PU under one's roof. The PU appears in core use in the opening paragraph, followed by stretches of phraseologically saturated text across the short story. 
The PU under one's roof is metonymic in its base form, as under one's roof stands for "in one's home". ${ }^{5}$ It is based on the contiguous relation PART FOR WHOLE. When reading the short story, the PU under one's roof catches the eye with obtrusive regularity. As the story unfolds, it appears sixteen times, undergoing creative changes, acquiring new associations and figurative ties in discourse, resulting in shifts in meaning seeking to create a psychological insight into human emotions and experience, which is an integral part of D. H. Lawrence's writing.

Human ability to think metonymically ${ }^{6}$ may be reflected in separate words, in free word combinations, or in PUs. Reflection of metonymic modes of thought in idioms in their core use has been discussed by Gibbs, who indicates that metonymy helps motivate idiomatic meaning, for metonymy forms a fundamental part of our conceptual system whereby people take one well-understood or easily perceived aspect of something to represent or stand for the thing as a whole (Gibbs 1995: 111). However, to my knowledge no special research has been carried out on metonymic reasoning in instantial stylistic use of PUs. Discoursal instantiations frequently seem to follow the rule "Expect the unexpected!" Moreover, novel metonymic expressions can be more difficult, as Gibbs notes (Gibbs [1994] 1999:320).

As we continue reading the first page of D. H. Lawrence's short story, we come across the first case of instantial stylistic use ten lines below. The metonymic potential of the base form under one's roof has been expanded in instantial use, turning it into a metonymic pun:

\section{under one's roof}

'No, I've come to the determination that no woman shall ever sleep under my roof again - not even a female cat!'

One looked at the roof and wondered what it had done amiss. Besides, it wasn't his roof. He only rented the house. What does a man mean, anyhow, when he says 'my roof'? My roof! The only roof I am conscious of having, myself, is the top of my head. However, he hardly can have meant that no wo man should sleep under the elegant dome of his skull.

D. H. Lawrence, Rawdon's Roof, p. 69

5. Kunin gives the following meaning of the PU under someone's roof: in someone's home, making use of someone's hospitality (Kunin 1967a:771).

6. For the workings of metonymic conceptualisation, see Gibbs' The Poetics of Mind, which contains an interesting chapter on lexical metonymy: Gibbs ([1994] 1999:313-358). See also Dirven 1993; Barcelona 2000a; Steen ([2007] 2009:57-61). 
Metonymy is not merely a referential device. It also serves the function of enabling understanding and organising our thoughts and actions (Lakoff and Johnson [1980] 2003:36-39). From the cognitive psychological point of view, the endlessly shifting flow of thoughts, which we experience in our mind, determines language in use: all textual changes and developments, including novel metonymic shifts. Thus, the point is "the representation of meaning in human thought" (Gibbs 2002: 83) and in this instance - reflection of a metonymic mode of thinking.

What is striking in this instantiation is how a metonymic PU turns into extended pun: the meaning is no longer abstract but concrete. This is an interesting feature - turning from abstract phraseological meaning, which is a figurative perception, to the sense of sight, which is a physical perception. The shift from the figurative to the literal, resulting in a pun, activates visual perception. This example is an interesting case, as the pun is based on metonymy. Usually, metaphorical PUs are punned upon. Sustained use of pun facilitates presentation of a visualised narrative. "Explaining in detail is drawing a picture" (Lakoff and Johnson 1999). D. H. Lawrence continues elaborating on the visualised picture in our mind's eye. ${ }^{7}$ The pun is further extended, based on the polysemy of the word "roof". "The roof of the skull" has a metaphorical meaning, while "the elegant dome of his skull" is an ironic periphrasis and a synonym for "the roof" as the top of his head.

This example shows how the reiteration of "roof" provides cohesion. Stylistically, this is manifest in a number of ways. One wonders what the roof has done amiss (metonymic personification), and after all it is not his roof as he only rents the house (extended metonymic pun). When the phrase "My roof" is reiterated, " $M y$ " is given in italics to lend emphasis. Italics function not only as what is called an attention-controlling device. Emphasis, indicated typographically by the use of italics, is "part of the phonological effect" of the text (McRae [1897] 1990: 17). It is a way of expressing intonation and emotions, as language reflects emotional thoughts.

The text offers an intricate semantic and stylistic network, which reflects associative thinking - metonymy, pun, personification, reiteration of the image, acquiring new associations and ties in discourse. "Authors combine tropes and narratives in subtle ways, often shifting between tropes as they shift points of view" (Gibbs [1994] 1999:452). The combination and interaction of two or several tropes gives rise to new instantiations of PUs in the unfolding discourse.

Cohesion is provided by further sustained reiteration of the PU. We read on that Rawdon keeps paying a daily visit or even a twice daily visit to a lonely and very attractive woman, and he goes on insisting, "I've taken a vow that no women

7. On visualisation in literature and film, see Arnheim ([1969] 1997); Spiegel (1976). 
shall sleep under my roof again!” (p. 72). The PU under one's roof is reiterated as the story develops, enhancing the emotional tension and creating a mounting feeling of affective suspense. ${ }^{8}$ It is also a tool for sustaining an image: the reiteration brings out Rawdon's obsession with his determination that no woman shall ever sleep under his roof. His compelling emotions are conveyed by semantic and stylistic reiteration of the phraseological image, reasserting the thought, as it were, to himself. Indeed, it remains at the back of his mind all the time and it keeps emerging at stressful moments. Lawrence is a good psychologist and a master of portraying human emotions.

Development of phraseological image lends a narrative perspective. Use of PU gains a cumulative effect, affording a psychological insight into the emotional tension of the main character, and covering the whole of the short story. The narrative turns into "an overt manifestation of the mind in action" (Chafe 1990:79). The PU pervades the text. As the image roof is reiterated, various instantial patterns are used:

\section{under one's roof}

\section{not for love or money}

Poor Janet! But he wouldn't have her sleep under his roof, no, not for a ny money. And apparently he never slept under hers - if she could be said to have one. So what the deuce?

D. H. Lawrence, Rawdon's Roof, p. 73

"Not for any money" is an elliptical form of the PU not for love or money, meaning "not for anything, not for any price". "Not for love" is conspicuously missing. The pattern of instantial ellipsis is combined with replacement followed by a metaphorical extension of a metonymic PU. It is another instance where PUs and tropes interact in discourse.

The mystery of manifestations of human emotions is accentuated by reiteration of the words mysterious, mystery, and mystification (pp. 70-73). And, of course, the pure mystification of not having a woman sleep under his roof, which is reiterated in the next paragraph:

under one's roof

\section{to let the cat out of the bag}

Of course, if they were friends, just friends, all right! But then in that case, why start talking about not having a woman sleep under your roof? Pure mystifification.

8. For affective use of PUs, see Gréciano (1988). 
The cat never ca me out of the bag. But one evening I d ist inctly heard it mewing inside its sack, and I even believe I saw a claw through the canvas.

D. H. Lawrence, Rawdon's Roof, p. 73

Thus, the mystery was never disclosed, but some information came out. The extended metaphor creates a number of instantial associations and sub-images: mewing, sack, claw, canvas, which retain a metonymic link with the base metaphor. Incidentally, the claw turns out to be a woman's foot (p. 79). This is a revelation, especially after the firm assertion that "no woman shall ever sleep under my roof again - not even a female cat!” (p. 69). In this short story, instantial use has evolved to acquire a broader dimension in the web of discourse. I follow linguists who believe that language should not be viewed as static but rather as development in discourse. Language in action is better captured by the metaphor of a flowing river, in which a stream of thoughts enjoys a priority (Chafe [2001] 2004:673).

The leading motif of the story is further sustained by reiteration. The phraseological image functions as an integral strand in the web of emotional tensions, becoming a salient aspect of text. It aids exploration of psychological depths and secures the flow of figurative sequences, maintaining the feeling of suspense. It is Janet who has come to ask Rawdon to stay under his roof in an emotional crisis. Rawdon is desperately trying to extricate himself from the situation:

\section{under one's roof}

'You couldn't stay and protect me yourself?' she said quietly.

'I! I! Why, I've made a vow - haven't I, Joe?' - he turned to me - 'not to have any women sleep under my roof again'. - He got the mixed sour smile on his face.

She looked up at the ceiling for a moment, then lapsed into silence. Then she said:

'Sort of monastery, so to speak!'

D. H. Lawrence, Rawdon's Roof, p. 77

The pun evokes a change from the abstraction of phraseological meaning to the literal meaning of its constituents, appealing to the sense of sight. Instantial metonymy "gives realistic detail" (Pankhurst 1997: 124) to the metonymic base form. Reiteration of a PU, if emotionally charged, is a way of creating suspense, especially in instantial use. In the text new figurative shifts have emerged - puns and extended metaphors, subtly interwoven with full and partial reiteration of the whole PU or the image-bearing constituent roof. In this way the PU becomes the key image of the short story, and development of the image turns into what I 
would call an extended metonymy, drawing on the sense of sight and enhancing emotional suspense. The text presents a generously sustained image: the stable boundaries of the base form of the PU have been extended and the image covers the whole stretch of the short story.

The roof appears again at the end of the short story as an innuendo:

\section{under one's roof}

That day, Rawdon left for London, on his way to Tunis, and Hawken was to follow him. The roof of his house looked just the same.

D. H. Lawrence, Rawdon's Roof, p. 80

Both figurative and literal meanings are instantiated at the same time. The roof has not changed, nor has Rawdon's attitude. A sustained visualisation has been secured in the mind's eye. A parallel vision has been maintained: the abstract metonymic thought of roof as one's home and the literal meaning of a roof. The two domains have been metonymically linked. This example reveals the role of PUs in metonymic conceptualisation.

The analysis illustrates one of the types of interaction between metonymy and metaphor: instantial metaphorical and metonymic development of a PU, which is metonymic in its base form. Sustained use of a combination of metonymy and metaphor gives rise to new instantiations in discourse. The phraseological image has been sustained across the whole short story, acquiring a sense of continuity. In a way it is also a means of stretching the imagination and the boundaries of the phraseological image: use of this PU coincides with the boundaries of the short story. Moreover, the same phraseological image also appears in the title of the short story, providing an overtone and spanning its scope: "Rawdon's R o of". This is umbrella use (see Ch. 5.5.1), which occupies a special position in the text. Sustainability is enabled due to semantic and stylistic cohesion, which proceeds from the base form and is developed throughout the story. The whole text becomes the context of the instantiation, and sustained use of the PU turns into a narrative technique by force of constant reference to it. Understanding of the sustained phraseological image becomes cognitively salient.

Discoursal use of under one's roof shows that not only phraseological metaphor can be sustained in discourse, as commonly assumed, but also other stylistic techniques, which the base form of the PU is built on, as is so in this case - metonymy. This encourages exploration of the role of other tropes in securing a sustained image in discourse and forming a figurative chain that cuts across modalities and experience.

In conclusion, the pattern of phraseological reiteration creates semantic and stylistic ties that promote cohesion and sustainability in discourse. Phraseological reiteration is a form of cohesion. The cases analysed give an idea of the varied 
nature of reiteration, its potential involvement in instantial use, and the amount of phraseological cohesion it can create. When involved in reiteration, the PU lends additional cohesive force across a stretch of discourse. It is the closeness of semantic and stylistic relationships between the PU and isolated phraseological constituents, including instantial constituents, that determines the cohesive effect of the PU. Reiteration reinforces the meaning and cohesive role of PUs. It is also another resource for creativity in the web of discourse.

Sustained reiteration of phraseological image is a narrative technique that calls for a holistic approach. My conclusion is that phraseological image is a way to sustain a narrative, and reiteration is a stylistic means of achieving it; phraseological image may serve as a leitmotif in a paragraph, a chapter, or even an entire literary work. A sustained image helps to convey the psychological message of the text - the thoughts and emotions of the character, and the workings of their mind. Sustainability reveals a process of emotions and experience, a continuous interaction of metonymic and metaphorical reasoning. However, at the same time it serves the author as a narrative structure, genuine continuity, sustaining the message by reiteration.

\subsection{Instantial cumulative use: The potential of the diminutive in English phraseology}

Reiteration of a PU or its parts organised consecutively is not the only technique of cohesion and enhancement. A cumulative concatenation of instantial items in linear sequence may also achieve a cumulative effect by successive reiterations of the same single pattern of instantial use over a larger stretch of discourse. The stylistic effect keeps increasing steadily in quantity, degree, or rate of development, augmenting by successive additions. Incremental use of one stylistic element gains a cumulative momentum of its own.

Let me explore the cumulative potential of one instantial element on the basis of the diminutive in English phraseology. In order to be able to draw inferences or make judgements about instantial use of the diminutive in phraseology, it is essential to have a clear understanding of the linguistic character of this phenomenon.

\subsubsection{Ways of expressing the diminutive in English phraseology}

Usually the diminutive is seen as a morphological category (Taylor [1989] 1995: 144-147). I would argue that the diminutive in phraseology is a semantic 
stylistic category that has diverse forms and means of expression. ${ }^{9}$ Its semantic and stylistic load is of great interest both in language and discourse: in the system of language as an inherent part of the stable language form of a PU and part of its semantic structure, in discourse emerging as a natural stylistic functional break of phraseological stability. In order to understand discoursal use of the diminutive in phraseology, it may be helpful first to discuss formation of the diminutive as part of the structure of phraseological meaning in the system of language.

The diminutive constituent(s) of PUs may be formed by morphological means, lexical means, or in a combined lexical morphological way. Each of these is characterised by a varying degree of frequency, productivity, and diversity.

The morphological way of expressing the diminutive in phraseology is untypical of English. The occurrence of diminutive suffixes in phraseological constituents is extremely rare, a fact which can be explained by the scarcity of live diminutive suffixes in the lexical system of MoE, -y (-ie, -ey) being the most common of all of them all;

to watch a birdie; an ugly duckling; a silly billy; a charley horse (AmE); a sugar daddy (AmE); the daddy of them all; little Rhody (AmE); Johnny Newcome/ Johnny Raw; coal-oil Johnny (AmE)

Though rare, these examples are relevant, as they demonstrate the possibility of use of a suffix to express the diminutive in PUs in MoE. In English the diminutivisation of phraseological constituents affects only nouns. Variants containing a diminutive constituent are very rare, e.g., to shoe a goose/to shoe a gosling. They are certainly not identical from the stylistic and semantic point of view, as the diminutive constituent brings about a change in the formation of phraseological meaning, and hence, a change in the semantic structure of the PU.

The lexical way of conveying the category of the diminutive in English is comparatively much more common. ${ }^{10}$ The scarcity and low productivity of diminutive

9. Cf.: the Latvian language can boast a wealth of diminutive suffixes in the lexical system of language (Endzelīns 1951; Rūḳe-Draviņa 1959; Rozenbergs 1983; Veisbergs 1997a: 135-137), and the morphological way of forming diminutive constituents is widespread in Latvian phraseology, too. For a comparison of diminutive formation in English and Latvian phraseology, see Naciscione (1995). Some examples of Latvian PUs with diminutive constituents are: kerties

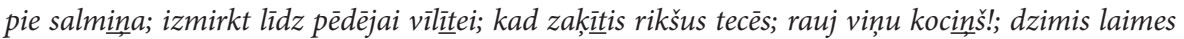

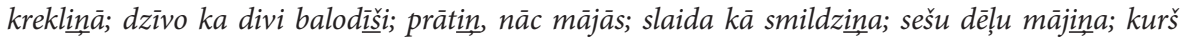

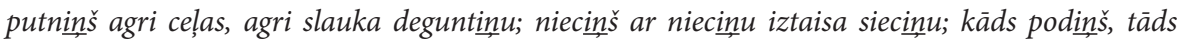
$v \bar{a} c \underline{i n} \underline{s}$. The diminutive is also productive in some other languages, e.g., Italian and Spanish. See Taylor ([1989] 1995: 144-148) for diminutivised forms in Italian.

10. For use of diminutives in lexical endearments in English, see Mills (1995:116-117). 
suffixes in Modern English are compensated lexically. The lexical way has ousted the morphological means of formation of diminutives in phraseology as part of the general trend of English turning into an analytical language. ${ }^{11}$ It is another means of expressing the same semantic category. The following constituents are used to express diminutivity in English PUs: little, small, thin, petty, wee, slight, a bit (of), by the skin of and others.

a little bird told me; little pot is soon hot; little knows the fat sow; small fry;

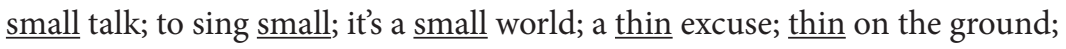

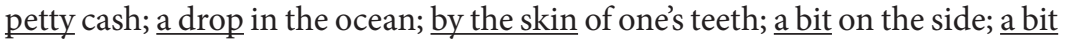
of blue sky; a/someone's bit of skirt/stuff/fluff/crumpet/tail; a bit of all right

Some PUs contain a repetition of the diminutive constituent:

little by $\underline{\text { little; }}$ bit by bit; by small and $\underline{\text { small }}$ (obs.)

A few PUs possess lexical diminutive variants of the diminutive constituent in English:

the thin/little/small edge of the wedge

little/small pitchers have great/long/wide ears

with a little/small A, B, C, etc.

the small hours/the wee hours

more than a bit/a little

Only very few English non-diminutive PUs possess a diminutive lexical variant, e.g., a rift within the lutel a little rift within the lute.

Proverbs are an interesting part of phraseology, offering considerable insight into some of the ways that diminutivity is achieved and sustained. The diminutive contributes to conciseness and cohesion of the proverb along with parallelism and rhyme that create "structural balance" (Mieder 1989:322). The stylistic effect is often intensified by contrast of the diminutive vs the augmentative resulting in antithesis in which the two parts of the proverb are measured against each other:

little strokes fell great oaks

little chips light great fires

small rain lays great dust

a little/small frog in a big pond

11. As a synthetic language, Old English had a whole list of diminutive suffixes. Chambers Etymological Dictionary of the English Language (1882:576-578) registers 13 diminutive suffixes; Nesfield (1924: 136) gives 14. 
Contrast is known to be one of the universal elements of style. Juxtaposition of the two contrasting phraseological constituents emphasises the phraseological meaning. The semantic contrast is set off by syntactical parallelism which is the organising axis of antithesis and the structure of the PU. The syntactical pattern creates a peculiar cadence. Rhythmical organisation yields special emphasis to the PU. In this contrast the diminutive constituent usually occupies the focal initial place in the proverb, thus gaining prominence. A reversed pattern in which the augmentative takes up the initial position is comparatively less frequent:

a big fish/frog in a little pond

a big head and little wit

In some cases the diminutive and the augmentative constituents are interchangeable as to their place in the PU, constituting positional variants:

$\underline{\text { small and great }}$

great and small

It is only in a few proverbs that the diminutive and the augmentative constituent do not occupy the initial, but the medial or the final position.

to venture a small fish to catch a big one

every little makes a mickle

In separate cases we come across use of two diminutives in proverbs with two juxtaposed parts. Repetition of the diminutive constituent enhances the diminutive effect; however, it does not create a contrast due to absence of the augmentative element.

little things please little minds

little mead, little need

a small heart has small desires

To summarise: diminutivity is a rare but a significant stylistic element of phraseological meaning in the system of language in English. This study reveals a whole range of ways of expressing the category of diminutivity in English phraseology that differ in their manifestation and degree of productivity. It discovers that more PUs with diminutive constituents in English and of greater variety exist than has been traditionally considered. 


\subsubsection{The diminutive in the semantic structure of phraseological units}

Before discussing the role of the diminutive in discoursal use of PUs, I would like to have a closer look at the semantic and stylistic significance of the diminutive in the base form of English PUs. My aim is also to review the traditional division of all diminutives into hypocoristic and pejorative, which merely shows that evaluative meaning is either of a positive or negative kind. This does not cover the broad range of evaluative meaning that the language system has to offer, nor does it specify the stylistic function of the diminutive in the semantic structure of the language unit.

Analysis of the diminutive constituents of PUs brings out the complexity of their semantic structure and shows that the diminutive forms part of their stylistic potential. It is a powerful stylistic means with a variety of semantic and stylistic functions.

1. As PUs are figurative representations, diminutives may be central to the formation of phraseological meaning ${ }^{12}$ and play the leading role in the semantic structure of PUs in the process of metaphorisation, image formation, and phraseological cohesion (see Table 5.1).

2. The diminutive may perform a euphemistic function. Euphemistic PUs are ameliorated secondary nominations of notions that are morally or socially unacceptable. The stylistic effect of euphemism in a PU may be created by a diminutive:
a bit on the side - a sexual relationship outside marriage
a sugar daddy - an elderly man who supports a girl or young woman in return for sexual favours
to have/get the drop on - to aim or be ready to shoot a gun at an antagonist before he can draw his gun

3. The diminutive constituent plays a decisive semantic role in creating the stylistic effect of meiosis (understatement) in PUs. The implication conveyed by the diminutive serves as a specific mode of intensification:

12. Cf.: the role of diminutives as a derivational tool in the lexical system. Diminutive suffixes may be used to create new lexical items. This process is fairly common in Latvian, e.g., zìle (an acorn) - (acu) zìlîte (the pupil of an eye); läpsta (a spade) - (plecu) läpstina (a shoulder blade). This process is a rare phenomenon in English, e.g., an eye - an eyelet, a bird - a birdie (in golf), a vein - a veinlet, or a plate - a (blood) platelet which is not a small plate, but a medical term, meaning a thrombocyte (see MWCD 1996). It also has further derivation by compounding, e.g., plateletpheresis. Interestingly, derivation of new words by a diminutive suffix usually occurs in terms. Semantic specialisation may be considerable, e.g., a tumourlet has a different meaning from a tumour, although both are medical terms (DPMD 1995). 
Table 5.1 The role of diminutives in formation of phraseological meaning

\begin{tabular}{|c|c|c|}
\hline \multicolumn{2}{|c|}{ Free word combination } & \multirow{2}{*}{$\begin{array}{l}\text { Phraseological unit } \\
\text { an ugly duckling - } \\
\text { a dull ordinary child, plan, and so on, that becomes interesting and } \\
\text { successful }\end{array}$} \\
\hline an ugly duck & $\rightarrow$ & \\
\hline watch the bird! & $\rightarrow$ & $\begin{array}{l}\text { watch the birdie! - } \\
\text { used to attract attention while taking snapshots, especially of } \\
\text { children }\end{array}$ \\
\hline someone's joke & $\rightarrow$ & $\begin{array}{l}\text { someone's little joke- } \\
\text { something that irritates or offends }\end{array}$ \\
\hline green men & $\rightarrow$ & $\begin{array}{l}\text { little green men - } \\
\text { facetious extra-terrestrial beings }\end{array}$ \\
\hline a bird told me & $\rightarrow$ & $\begin{array}{l}\text { a little bird told me- } \\
\text { used about someone whose name the speaker prefers not to reveal }\end{array}$ \\
\hline love lost between & $\rightarrow$ & $\begin{array}{l}\text { little love lost between - } \\
\text { there is a great dislike }\end{array}$ \\
\hline the end of the wed & $\rightarrow$ & $\begin{array}{l}\text { the thin end of the wedge - } \\
\text { the beginning of something that seems harmless is likely to become } \\
\text { important or harmful in the future }\end{array}$ \\
\hline
\end{tabular}

to take a bit of doing - to call for a considerable effort

a bit thick - (1) unfair, unreasonable; (2) stupid, near-moronic

4. The diminutive may also create litotes, a particular kind of understatement where affirmation is achieved by negation of the contrary:

no small feat - a considerable achievement

to do oneself a bit of no good - to incur loss or harm through misjudgement, folly, carelessness

5. Paradoxically, the diminutive in PUs may function to create or enhance the stylistic effect of hyperbole, consisting in a deliberate, incredible, exaggerated claim of smallness for the sake of emphasis:

a drop in the ocean - a very small amount

Hyperbolisation through smallness may perhaps be very well illustrated by the PU a drowning man will clutch at a straw, used to denote a person who will resort to the slightest possible means in extreme difficulties.

6. In PUs the diminutive may function as a signal of irony or sarcasm:

the goodies and the baddies - the positive and negative characters in a story. Johnny Newcome/Johnny Raw (sl.) - a stripling; a milksop; a recruit 
a tail-end Charlie - someone who is habitually late, slow, or ineffective (originally a phrase in World War II for the last aircraft in a mission)

The role of the diminutive in creating the stylistic effect of sarcasm consists in challenging or saying the opposite of what is intended, with the aim of moral criticism:

a proper/right Charlie/Charley - a stupid, inept, or freakish person or one who appears to be so

7. Words that are not diminutives when used outside PUs may acquire a diminutive meaning when they enter the structure of PUs:

the/a ghost of a chance - the smallest possible chance

a thin excuse - an inadequate reason

by the skin of one's teeth - with very little time, space, or other margin left over

8. PUs possess a complicated semantic structure resulting from the interaction of several semantic processes and stylistic devices in secondary nomination. The diminutive may perform several stylistic functions in the semantic structure of one PU, for instance, euphemistic meiosis:

a bit off - crazy, out of one's mind

to have/take a drop too much - to get drunk

In conclusion: the diminutive in phraseology is semantically and stylistically polyfunctional.

\subsubsection{Instantial use of the diminutive in English phraseology}

Stylistic use of the diminutive is not only a rare phenomenon, but also highly unexpected. As the probability of occurrence is low, attention is drawn to this unexpected element:

\section{a little bird told me}

How did I come to know

Which way the wind would blow?

A little birdi e told me so!

L. $\operatorname{Hart}^{13}$

13. The example is taken from Bryan (2001:36). 
In practice it may be very difficult to differentiate between instantial use and core use in the case of diminutives. Whether it is a unique discoursal formation and a stylistically significant change or part of the base form of the PU can only be answered by identification and analysis of specific cases of use. Instantial diminutivisation is a stylistically significant appearance of a morphological or lexical diminutive in the base form of the PU in the given instantiation in discourse:

what's sauce for the goose is sauce for the gander

Obviously he didn't like the idea, any more than she'd liked the idea of their checking up on her social life. What's sauce for the goose is sauce for the gosling, she thought.

CCDI: 334

Instantial use of the diminutive in PUs may take several forms:

the black dog on one's shoulder

I can see that little black doggie on your shoulder.

M. Dickens, The Angel in the Corner

Intensification of a diminutive constituent of the base form of a PU creates an additional instantial diminutive effect, resulting in double diminutivity. This may be achieved by insertion, replacement, use of the comparative or superlative degree of the diminutive adjectival constituent, or by other intensifiers of the diminutive constituent of the base form. In the next example the instantial diminutive dicky enhances the base constituent little: ${ }^{14}$

a little bird told me

\section{A little dicky bird must have told me.}

G. W. Target, The Teachers

Not only is the unexpected presence of the diminutive in a PU striking, but it may also be the sudden loss of the diminutive of the base form that may result from omission of a diminutive constituent or replacement of a diminutive constituent by a non-diminutive or an augmentative. Likewise, the diminutive effect may be intensified by use of several instantial diminutives in one PU to create inimitable discourse forms. Like any other stylistic element, the diminutive may also be used cumulatively, with the diminutive effect increasing with every successive addition. Instantial diminutivisation of the whole text or part of it testifies to the discourse potential of the diminutive. It is sustained, permeating a longer stretch of

14. Dicky bird/dickybird/dicky - a small bird (used esp. by or to children) (Longman Dictionary of Contemporary English 1978:302). 
text. Let me analyse cumulative use of the diminutive in Lewis Carroll's nonsense genre poem The Little Man that Had a Little Gun in which it becomes the leading stylistic pattern, including phraseology.

\subsubsection{Cumulative use of the diminutive in Lewis Carroll's poem The Little Man that Had a Little Gun}

The aim of this study is to look at the stylistic discoursal significance of the cumulative effect of one instantial element by exploring the diminutive in Lewis Carroll's poem The Little Man that Had a Little Gun. ${ }^{15}$ In this poem Lewis Carroll uses the form and imagery of an English folk ballad. He imitates and parodies the folk ballad by keeping to its conventions - its rhythmic and narrative elements, frequent repetitions, rapid action, abrupt effects, and stark characterisation. In contradistinction to the rigid economy of narrative in a folk ballad, Lewis Carroll's poem is more stylistically charged and more saturated with stylistic elements. Another feature is Lewis Carroll's disregard of the conventions of common sense. We are led to believe impossible things, as the poet takes delight in the imaginary, the inexplicable, and the nonsensical.

At first sight, the reader of the poem is carried away by the unexpected vision, while closer rereading reveals an abundance of stylistic features. One useful way to approach stylistic techniques in discourse is to thoroughly study their basic elements or characteristics, so as to appreciate their full significance. What catches the attention of both eye and ear is Lewis Carroll's preoccupation with the diminutive, which occurs both in words and in PUs.

Although the diminutive is a rare linguistic phenomenon in English, its significance should not be underestimated when it is brought into prominence in discourse. In this poem the diminutive permeates the texture of the narrative and is thus made conspicuous. First, the reader notices its frequency and sheer presence. Lewis Carroll has coined a whole range of nonce words with the diminutive suffix -let for the present purpose: Wifelet, runlet, bunlet, wordlet, birdlet, Lobsterlet, Crablet, Dablet, Grublet, Froglet, Doglet, and others. The novelty of strings of instantial diminutives heightens the emotional impact.

It is noteworthy that several ways of diminutive nomination are used to name the main character of the poem: (1) the Little Man appearing in the title, (2) the Manlet in Verse I, Line 1 and (3) the Manikin in Verse V, Line 6. Similarly, the weapon which the Little Man uses appears as (1) the little gun in the title (in this way the title has two diminutives), (2) gunlet in Verse I, Line 5, and (3) minikin

15. From Sylvie and Bruno Concluded. 
gunlet in Verse II, Line 1, thus creating textual variation for emphasis. Interestingly, the Little Man addresses his Wifelet as sweet Atom (Verse I, Line 5), an uncommon metaphor in which the minutest particle stands for the Little One, thus acquiring a diminutive sense and creating a nonce endearment.

These examples clearly show why the diminutive should not be treated as merely pertaining to derivational morphology. It should be viewed as a semantic and stylistic category. Ultimately it is not the suffix that is a diminutive but the lexical item that contains a diminutive marker as part of its semantic structure. In a single poem, one and the same word undergoes all three ways of diminutive formation: morphological means (e.g., gunlet), lexical means (e.g., little gun), or a combined lexical-morphological way (e.g., minikin gunlet).

The diminutive is an arresting device. Lewis Carroll not only uses it to create improbable lexical forms but also exploits poetic license to produce novel turns of PUs. He is often called "an innovator of nonsense poetry" (Hudson 1958:27). In Verse I the dwarfish Manlet asks his Wifelet:

"Now reach me, sweet Atom, my gunlet, And hurl the old shoelet for luck: Let me hie to the bank of the runlet, And shoot thee a Duck!"

The discourse form hurl the old shoelet is all the more striking against the base form of the PU to cast/fling an old shoe after someone. This PU is repeated in Verse II in the same instantial form. Use of reiteration imparts the quality of an incantation. This PU, however, is not the only one that is subjected to instantial diminutivisation in Verse II:

She has reached him his minikin gunlet:

She has hurled the old shoelet for luck:

She is busily baking a bunlet,

To welcome him home with his Duck.

On he speeds, never wasting a wordlet,

Though thoughtlets cling, closely as wax,

To the spot where the beautiful birdlet

So quietly quacks.

In this verse, the diminutive suffix -let is a recurrent element, which repeats itself six times at close intervals. The presence of the diminutive builds cumulatively as the poem progresses. The PU to waste words gains a diminutive meaning, as the Little Man speeds without wasting a wordlet. The diminutivised constituent of the PU becomes part of the rhyme pattern, which creates the effect of epiphoric assonance. Another striking feature is the gentle irony of the Little Man's thoughtlets. 
Diminutive tonality is built gradually by successive additions. Incremental reiteration achieves suspense moving towards a climax. The stylistic effect is cumulative. The Little Man speeds to the runlet,

Where the Grublet is sought by the Froglet:

Where the Frog is pursued by the Duck:

Where the Ducklet is chased by the Doglet -

So runs the world's luck!

Diminutive quality is sustained by rhyming. The suffix -let not only serves to create multiple rhyme (Lines 1 and 3 also rhyme in - $\underline{\text { let }}$ ) but also produces internal rhyme, adding to the heavy amount of repetition. Density of rhyme, like density of alliteration, may sound boring or extremely comic (Nash 1987:158). Here the effect has a playful, jocular quality.

In Verse IV the assonance of the diminutive merges into a single onomatopoeic effect with the overwhelming hullabaloo of the threatened Voices by the runlet as they cry out for revenge on their Foelet. Note the coinage "avengement" which is contrasted with the diminutives:

"Avengement," they cry, "on our Foelet!

Let the Manikin weep for our wrongs!

Let us drench him, from toplet to toelet,

With Nursery-Songs!

Here another widespread PU from top to toe has been subjected to instantial recreation to keep the reader in the world of nonsense. The base form has acquired two diminutive suffixes resulting in internal rhyme within the PU, thus focusing attention on its unique discourse form.

The second part of the poem changes its tonality. The presence of the diminutive abruptly subsides. It signals a shift of emphasis. The absence of a stylistic element may be as relevant as its presence. Thus, the abrupt change from use of the diminutive to its absence lends a certain flavour to the whole poem and provides a turning point away from cohesive diminutive ties to diminutive-free verse. This change makes a shift in the focus of attention. The first part of the poem is characterised by a dense cluster of cohesive ties provided by reiteration of the diminutive across stanza boundaries. The cumulative use achieves a remarkable stylistic effect. The Voices have shrieked out their curse to drench the Little Man with Nursery Songs. Now he must muse upon the popular images of English nonsense poetry and talk wildly of them as a punishment for all their wrongs. The Ducklet's dark doom is decided and the doleful Voices have ceased their strife. Only at the very end does the diminutive appear again, as the Little Man, cheerfully chewing 
the bunlet, hurries once more to the runlet to fetch his wifelet the Drake. So the world goes round. In this way instantial diminutivisation "exhibits the sense in nonsense necessary for true humour" (Norrick 1986: 51).

All the elements of the poem work in harmony towards one end: to contribute to the aesthetic and stylistic values of the poem. Use of the diminutive in this poem provides an interesting example of the amount of phraseological cohesion which may be achieved in a very short text. Appearing both at the lexical and phraseological levels, the instantial diminutive saturates the poem, thus playing a key part in its style. The cohesive effect is achieved by recurrence of the diminutive, which creates a semantic and stylistic link across the poem, providing continuity and creating sustained diminutiveness. Persistence of the diminutive is an interesting feature of cohesion, which is crucial for interpretation of the text, as interpretation depends on recognition and identification of continuity. Lewis Carroll is fascinated with the diminutive. Strings of instantial diminutives serve creation of what might be called a minikin worldlet in which the fantasy narrative unravels and the reader believes the imaginary picture so created.

Discourse analysis of cumulative use of one instantial pattern brings out its cumulative power and helps to grasp the tenor of the poem, appreciate the aesthetic, evolve inferences, and develop a feel for the language and the application of its poetic tools in discourse. Thus, cumulative use is incremental use of an instantial element gaining momentum, achieved by successive reiterations of the same single pattern over a stretch of discourse, augmenting and increasing steadily in quantity, degree, or rate of development. It works consecutively as a technique of cohesion and enhancement.

To conclude, the concatenation of a number of instantial diminutives tied together in one overall stylistic effect of instantial diminutivisation results in a cumulative effect. Both reiteration and cumulative use are based on the sequential principle when each successive item appears as part of a series, a longer sequence of utterances, providing phraseological sustainability in discourse.

\subsection{Instantial concurrent use}

Cognitive linguistics has established that figures of thought do not exist in isolation from one another; they are functionally related to each other to provide figurative coherence to the text (Gibbs [1994] 1999:449-454). In phraseology, stylistic use of PUs presents innumerable instances which contain simultaneous application of several instantial patterns in realisation of one PU, creating a focal point and reinforcing the message. I propose the term concurrent use to 
denote simultaneous occurrence of several instantial changes within the framework of one PU. ${ }^{16}$

Concurrent use differs from reiteration and cumulative use, which are linear in character, just as most single instantial changes: they are string-like and operate in a consecutive fashion and hence are less striking. However, texts abound in cases of concurrent use when a PU undergoes a number of instantial changes simultaneously, coinciding in time and contextual space. The natural propensity of language to change and create new ways of expression secures its ability to convey new thoughts and experiences in this way. Cognitively, it also testifies to the linguistic creativity of the language user in shaping new discoursal forms.

How to deal with several patterns of instantial use exploited concurrently in one and the same PU? Such a piling up of stylistic features is called convergence by Riffaterre. He speaks of stylistic clusters and accumulation of several independent stylistic devices (SDs) at a given point. Alone, each would be expressive in its own right. "Together, each SD adds its expressivity to that of the others. In general, the effects of these SDs converge into one especially striking emphasis" (Riffaterre 1959: 172).

In concurrent use, all the separate changes work simultaneously towards unity of stylistic effect. They all point in the same direction, thus creating a powerful stylistic effect. Concurrent use is a merger when several changes blend into one in an instantial application, which conveys intensity of emotion or experience. As concurrent use combines several instantial changes in one PU, it tends to occur in a heightened, complicated stretch of text, focusing on a particularly significant point in the development of discourse. The intersection of several instantial changes explains "the creation of composite modalities of discourse" (Ricoeur [1975] 1994:279). It is important to see each change in relation to the other elements, remembering that "a change in any one element usually entails a change in the whole" (Cook 1994:3).

While recognising the importance of prior knowledge of phraseology, the stylistic processes involved, and cognitive interpretation skills, it is essential to develop a holistic approach to complicated instantiations, such as concurrent use, which require treatment of the particular case as a coherent and indivisible entity, perceiving the whole PU, involving a broader understanding of the context rather than just analysing separate types or aspects of changes. Let me consider an example of co-occurrence of several types of instantial changes achieved in one PU:

16. For concurrent use of stylistic techniques in phraseological instantiations, see Naciscione (1976: 160-172). 


\section{to turn over a new leaf}

"I turn over a new leaf every day," I said.

"But the blots show through the page!"

"Well," said Liz. "Perhaps a new leaf is n't good e n o ugh. Perhaps you

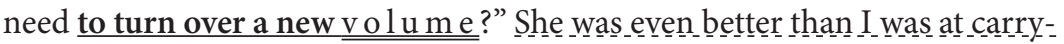

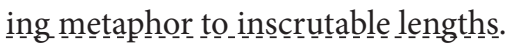

K. Waterhouse, Billy Liar

First the PU to turn over a new leaf appears in core use, followed by an extended metaphor and partial reiteration. It is extended metaphor that most frequently emerges together with other patterns of instantial use. Patterns are mobile in actual use. Later the PU is reiterated with replacement of the main notional constituent leaf within the framework of the same PU. The text also includes the author's comment on the stylistic application. Several instantial changes of one PU exploited in the context blend into a single whole and reinforce the stylistic effect. The metaphorical web is woven by two interlocutors who reiterate and carry the metaphor to further lengths each in their turn. The author's comment contains the word metaphor, thus indicating instantial use and his awareness of the stylistic application. In written discourse such cues are vital as they help readers to identify the PU and the new meaning.

When two or more changes are incorporated in one instantiation, it is, as a rule, impossible to establish the leading change. In the following example, aposiopesis and extended metaphor act together, concurring within the context of one PU. The extended metaphor sustains the image, while aposiopesis creates a discontinuity: hesitation is conveyed by a sudden breaking off before the PU is completed at an emotional moment. Aposiopesis is marked by graphic means: a dash and an explanation mark signifying a pause, reflected in the intonation:

when the cat's away, the mice will play

When the cat's away, the mice - ! People were all alike - take what they could get, and give as little as they could for it. (...) Well, there it was, and he wished he had a cat to talk to !

J. Galsworthy, The White Monkey

Concurrent use affords an enormous scope of flexibility, turning instantial use into a focal point in discourse. It may involve an intricate blend of several patterns, all meeting at the same point, as in the following example: extended metaphor, cleft use, inversion of the standard word order of the base form and the insertion ful bitterly which are all merged into one instantially modified image. Concurrent use acquires a synergic quality, with the changes working together and cooperating in a joint action. It is a new way of expression, created to meet 
the needs of the discourse situation: the Wife of Bath is telling about her fourth husband whom she has made extremely jealous by flirting. She says, “... in his owene grece I made him frye For angre, and for verray jalousye" (CT, D 487-488). She tortured him and she was actually his purgatory on earth:

\section{to witen best wher ones shoo one wringeth ${ }^{17}$}

For got it woot, he sat ful ofte and song

Whan that his shooful bitterly him wrong.

Ther was no wight, save god and he, that wiste,

In many wyse, how sore I him twiste.

G. Chaucer, The Canterbury Tales, D, 491-494

This instantiation brings out the striking difference between a dictionary entry (conventional base meaning) and a piece of live text (unconventional instantial meaning). The focused nature of concurrent changes meeting and acting together is represented in Figure 5.1:

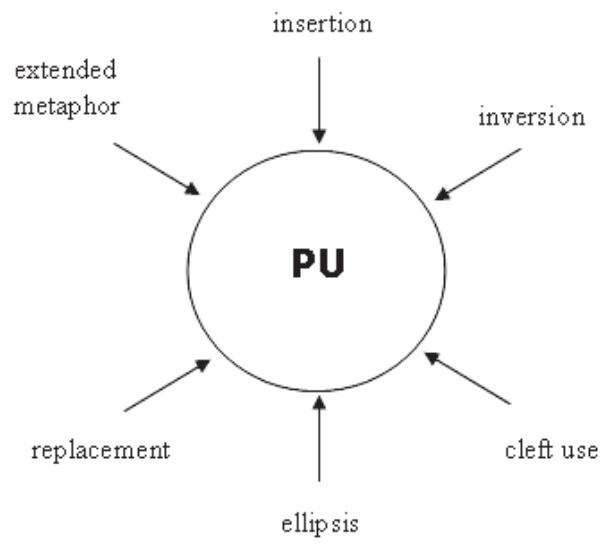

Figure 5.1 Concurrent use of several stylistic techniques within the framework of one PU

The PU has undergone a number of instantial changes of various types, all happening concurrently. As a result of concurrent use, PUs are frequently changed almost beyond recognition; however, they still remain identifiable. Concurrent use clearly shows the interdependence of elements, each coming into existence through the interaction of the others, while none of them is the leading pattern.

17. MiE - to witen best wher ones shoo one wringeth, MoE - to know best where one's shoe pinches. Chaucer uses this PU in CT, E, 1544-1553 in core use (see the full text of the example in Appendix IV for comparison). 
Concurrent use gains in impact due to density and cohesion of changes which all work in the same direction. As concurrent use is a focused pattern, it conveys powerful and colourful emotions and experiences.

In the following example the instantiation covers four utterances, reinforcing the message over turn boundaries in a joint stylistic effect, which blends all the instantial elements, including the author's comment "jest on", which clearly indicates his awareness of creative use of language. At the same time, it cues the actors as to how to recite the lines:

\section{a nine days' wonder}

King Edward: You'd think it strange if I should marry her.

Clarence: To whom, my lord?

King Edward: Why, Clarence, to myself.

Gloucester: That would bet e n days' wonder at the least.

Clarence: That's a day longer than a wonder lasts.

Gloucester: By so much is the wonder in extremes.

King Edward: Well, jest on, brothers: I can tell you both

Her suit is granted for her husband's lands.

W. Shakespeare, King Henry VI, Part III, Act III, Sc. 2

This stretch of text illustrates reinforcement of the message by means of concurrent use of instantial changes. As the base form is frequently unable to convey all the complexity of human experience, development of emotional conflict is reflected in a new instantial formation. In the following example it embraces anaphoric reiteration, replacement, and reiteration in an indirect rhetorical question, all together securing a high density stylistic environment:

\section{Caesar's wife must be above suspicion}

Lady: The Letter! About Caesar's wife!

Napoleon: Caesar's wife is above suspicion.

Lady: I wonder would Caesar's wife be above suspicion if she saw us here together.

G. B. Shaw, A Man of Destiny

To disentangle and understand a particular case of instantial use, it is important to go back to the base form and analyse the stylistic mechanisms involved in the given instantiation and establish the cohesive ties. For the sake of clarity, analysis should always single out the base form.

Concurrent use provides an excellent illustration of phraseological cohesion. The lines display a high degree of cohesion with dense clusters of cohesive ties meeting at the same point, which signifies that items and meanings are interdependent to a great extent and that the whole forms a single unity. In the following 
instance, the syntactic integrity of the base form is broken; rupture of the uninterrupted wholeness of the base form brings with it a new instantial meaning, as the image-bearing constituents have entered into new discourse relationships. It is a dynamic synthesis of many elements and comes into being through them. Here concurrent use conveys a new instantial meaning across poetic lines:

the cat wolde ete fish, but wolde not wete his feet

For ye be lyk the sweynte cat

That wolde have fish; but wostow what?

He woldeno-thing wete his clowes,

Yvel thrift come on your jowes.

G. Chaucer, The Hous of Fame, 1783-1786

This is a complicated subtle case of concurrent use: all the basic notional constituents have been preserved and the changes have been exploited within the framework of one PU, all merged into a coherent synthesis. It is essential to assess the significance of the entire effect of concurrent use. Each pattern involved in the instantiation contributes to the stylistic effect of the whole: (1) cleft use: the second part of the PU is used in a subsequent sentence and the syntactical structure has been changed; (2) insertion of the instantial epithet sweynte before the main notional constituent; (3) replacement of the base constituent feet by clowes, for the sake of rhyme: clowes - jowes, which is an essential prosodic device. ${ }^{18}$ The synergy of all these changes produces a novel discourse form. Concurrent use also accommodates the lengthy and cumbersome structure of the base form to the needs of the playful rhythm of the iambic tetrameter.

To conclude, the concurrence of several types of instantial changes in one PU forms a single entity, reinforcing the message. Each instantial change exploited in concurrent use contributes to the combined stylistic effect of the whole instantiation. It is the effective density that makes the process of inference more difficult and presents additional challenges in identification. The complex and sophisticated discoursal formations represent the complexity of human communication and cognitive processes. Concurrent use is characterised by a high degree of phraseological cohesion. These changes are interdependent, creating dense clusters of cohesive ties. The cohesive unifying effect creates a single powerful impact. Thus, in phraseology, concurrent use is the simultaneous occurrence of several instantial changes reinforcing the message and creating a focal point within the framework of one PU.

18. For the role of the instantial use of PUs in creating rhyme and rhythm, see Naciscione $(1984,1986)$. Tarlinskaya demonstrates that the last foot is the strongest in Chaucer's iambus (1975: 157). 


\subsection{Instantial phraseological saturation of discourse}

Instantial phraseological saturation is one of the ways PUs operate in the web of discourse, creating instantial networks and a considerable concentration of instantial features. ${ }^{19}$ Instantial meaning becomes the leading type of figurative meaning. The dominant characteristic is the interfusion of several PUs which are exploited in one stretch of text, blending and intermingling. The PUs and their instantial constituents pervade the text, resulting in a subtle network of phraseological ties. The particular instantiation is outside the experience of the reader or speaker, as it has not been encountered before. It becomes the centre of interest, a focal point where two or several phraseological images meet and a number of instantial changes occur, thus attracting attention and increasing emotional suspense.

The simplest form of phraseological saturation is use of two PUs running close to each other, complementing the image and creating phraseological space:

in the soup

up to the neck

Charles: I have one or two things to say that a good deal concern you.

Patrick: But if you're hammered we're in the soup, Daddy.

Charles: Up to the neck, my boy.

W. S. Maugham, The Bread-winner

The interlocutor is quick to pick up the thread and continue the metaphorical line: the two PUs constitute one united image of being engulfed by trouble. In the next example the PUs are smoothly blended on the basis of a common constituent shut. In this way, two PUs may form an uninterrupted figurative flow across turn boundaries:

to keep one's mouth shut

to shut up like a clam

“Can you keep your mouth shut?" He asks me.

"Like a clam," says I.

W. S. Maugham, The Narrow Corner

Two PUs may be used in parallel over a certain part of text, as in the following example. Both are exploited to produce a new instantiation, saturating the context by involving an extended metaphor and replacement set off by reiteration:

19. Instantial phraseological saturation was first identified by Naciscione (1976: 173-179). 


\section{a fly in the ointment}

\section{a snake in the grass}

But alas, there is a fly in the ointment. There is a snake in the grass. It is in Gilbert's mood. Alas, poor Emmie. She is mistaken about his soft, sweet, sinful coming-on. Instead of being in the melting stage, just ready to melt right down with her, the final fuse within the spoon, he is horrid. Ah, in the last coming on, how gentle is the Galahad of kisses, how subtle his encroachment to the goal! But Gilbert was a snake in the grass. He was irritable, in a temper, and would not let her go though he did not really want her. Why he was in a temper, and why he hated her he did not know. Doubtful if he ever knew his own state of feeling. B ew a re, gentle reader!

D. H. Lawrence, Mr Noon, p. 27

A conflict is gathering that poor Emmie is not aware of, that of strong emotions and conflicting attitudes. Suspense is kept up through instantial use, which helps to convey the state of anxiety about what is going to happen. Instantial use meets the needs of the conflicting context and finalises the instantiation by replacing the ointment by $\underline{\text { oil }}$ on the following page (note the alliteration):

Alas, he would be a womaniser. Yet he kicked with fury against the universal spoon. He fought like a fly in oil.

D. H. Lawrence, $M r$ Noon, p. 28

Saturation is truly a pattern of cohesion; it brings out the interactive dimension of discourse:

\section{to throw oneself on someone's mercy}

to break one's neck

Gentleman: I throw myself upon your ind ulgence...

Zoo:

Don't throw yourself on anything belonging to her or youwill go right through her and break your neck. She isn't solid, like you.

\section{G. B. Shaw, Back to Methuselah}

A tie exists between to throw myself upon your indulgence and the lines of the second speaker, who develops the PU by punning on the verbal constituent throw. A metaphorical tie also exists with the second PU break your neck. The instantiations of these two PUs create a common metaphorical area, conveying a burst of irony. This example deals with an imaginary situation in Ireland in the year $3000 \mathrm{AD}$, where two representatives of different civilisations meet, but fail to come to terms. The eloquence and rhetoric of the Victorian age clash with the rationalism of $3000 \mathrm{AD}$. 
For purposes of comprehension and interpretation, it is essential to identify which PUs have been involved and what the semantic and stylistic mechanism is that this case of instantial use is based on, and what the semantic and stylistic implications are. The next example contains a blending of two PUs with synonymous meaning in one instantiation: to promise to give people things that in fact are impossible to give. The two PUs are alluded to and the images are extended by a joint sub-image the Universe. The images are fused into a single finally textured image that captures more information and affords greater flexibility:

\section{to promise the earth}

\section{to promise the moon}

Violet: I saw Christina drive away, what did she want?

Arthur: The earth.

Violet: I hope you gave it to her.

Arthur: No, I' m trying to get the moon for you just now, darling, and I thought if I gave her the earth it really would upset the Universe a little too much.

W. S. Maugham, Caesar's Wife

The following example is an instance of phraseological saturation, which reveals a close interaction of stylistic patterns, combining individual but harmonising figurative threads, at the same time maintaining semantic and stylistic unity. Extended metaphor is often the leading instantial change in a phraseologically saturated stretch of text:

\section{to go to the devil}

\section{to change horses (in midstream)}

Englishmen start galloping to the devil, but as they grow older, they nearly always change horses and a mble along gently to respectability, a wife and seventeen children.

W. S. Maugham, Mrs Craddock

The instantiation is an interesting case of extended metaphor, saturating the context. The metaphorical replacement in the first PU is part of the extended metaphor of the subsequent PU. The link between the two PUs is achieved by associations of contiguity (horses may gallop or amble). Galloping to the devil is opposed to ambling along gently to respectability, creating antithesis while ambling to respectability, a wife and seventeen children creates a zeugma. The number of children has ironically been exaggerated to seventeen, resulting in a hyperbole. Thus, use of two PUs in one context, united by a common extended metaphorical image and set off by replacement, antithesis, zeugma, and hyperbole, creates 
a striking instance of saturation. Phraseological saturation illustrates the mobile and interactive aspects of the semantic and stylistic network of text.

Phraseological saturation is typical of tense situations. Instantial use involving two or several PUs draws attention to itself; it is creative and is designed to be noticed. The result is a disruption of expectations and regular patterns. The two PUs blend and saturate the context:

to smell a rat

without rhyme or reason

The P.P.R.S. was so imposing a concern, and he had been connected with it so short a time, that it seemed presumptuous to smell a rat; especially as he would have to leave the Board and the thousand a year he earned on it if he raised smell of rat without rat or reason. But what if there were a rat? That was the trouble!

J. Galsworthy, The White Monkey

The reiteration discloses emotional unrest, apprehension, and anxiety. A rat appears again as part of an indirect interior monologue of the character, bringing out inner hesitation and wavering before making a decision. The interfusive effect is enhanced by the instantial replacement of rhyme by rat and set off by the onomatopoeic effect of alliteration: $[\mathrm{r}]$ is common to the base forms of both the PUs.

The next example is a case of two PUs intertwined in one context. The notional key component the serpent appears only once, serving as a basis for sustaining metaphorical thought. The two instantiations have been blended together in a longer stretch of verse (cf. use of this PU in Ch. 4.4 and 7.4):

\section{a serpent in one's bosom}

\section{a serpent under gras/floures}

And Thomas, yet eft-sones I charge thee,

Be war from hir that in thy bosom sle pe th;

War from the serpent that so slyly crepeth

Under the gras, and stingeth subtilly.

Be war, my sone, and herkne paciently (...)

Ther nis, y-wis, no serpent so cruel,

Whan man tret on his tayl, ne half so fel,

As woman is, whan she hath caught an ire.

G. Chaucer, The Canterbury Tales, D, 1992-1996; 2001-2003

Phraseological saturation is frequently difficult to grasp and identify. Stylistic awareness needs training to ensure an understanding of the effects and the message of saturated stretches of text and an ability to interpret instantial networks. 
In the following example, instantial use is sustained and carried over to the next paragraph, and the stretch of text is permeated with phraseological meaning:

\section{in one's element}

\section{a drowning man will clutch at a straw}

Kate felt a bit like a mermaid trying to swim in a w rong element. She

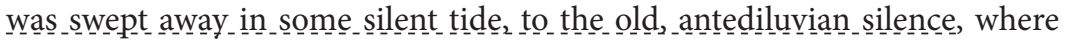
things moved without contact. She moved and existed without contact. Even the striking of the hours had ceased. As a drowning person sees nothing but the waters, so Kate saw nothing but the face of the timeless waters.

So, of course, she clutch ed at her straw.

D. H. Lawrence, The Plumed Serpent

Kate is disastrously struggling to survive in an emotional conflict. The inevitable desperate drift in which she is caught is reflected by the development of the image. The tragic expression of despair is conveyed by allusion to the PU a drowning man will clutch at a straw. The anaphoric cue like a mermaid trying to swim links up with the subsequent PU at the end of the paragraph and becomes part of the silent underwater image that D.H. Lawrence resorts to in a number of novels (see also The Lost Girl and Mr Noon). The instantial form and meaning is the product of the emotionally strenuous situation.

Saturation is particularly effective if the PUs involved are close in meaning or if they share some constituents in common. The following stretch of text is from the very beginning of Shakespeare's play Romeo and Juliet. We know that Shakespeare's plays are built on figurative language. Instantial use of PUs is one of the figurative modes in his plays. The instantiation is interfused by several PUs, containing a common notional constituent wall, permeating the dialogue. This example shows the capacity of language to express a conflict situation: a conflict is raging between two houses with mutually incompatible goals. The complexity of language reflects the complexity of the conflict situation. A sudden and strong outburst of hatred and scathing irony occurs as the two houses are further drawn into another conflict:

to take the wall of someone

the weakest goes to the wall

to push/thrust someone to the wall

Sampson: A dog of that house shall move me to stand: I will take the wall of any man or maid of Montague's.

Gregory: That shows you a weak slave, for the weakest goes to the wall. 
Sampson: True, and therefore women, being the weaker vessels, are ever thrust to the wall. Therefore I will push Montague's men from the wall, and thrust his maids to the wall.

W. Shakespeare, Romeo and Juliet, Act I, Sc. 1

Phraseological saturation occurs at a point of high tension. Reiteration of the image-bearing constituent wall in a number of PUs is in line with the growing conflict, and the tension is enhanced. All three PUs share one element in common: the main notional constituent wall. Semantically they are very close; they all convey various aspects of defeat:

to take the wall of someone - not to give in, not to be defeated;

the weakest goes to the wall - the defeated succumbs in a conflict, suffers ruin or is pushed aside as worthless or hopeless;

to push/thrust someone to the wall - to force someone into a hopeless condition, to cause someone to suffer defeat.

In Shakespeare's day a maid whose honour went to the wall was disgraced and dishonoured, so that the last PU hints of a bawdy joke.

This example reveals the force of phraseological saturation, which secures essential links in the text structure, and the role of phraseological image in construction of meaning. Reiteration and modification of meanings build up the web of discourse. The art of establishing richly saturated contexts is a significant element in the complexity of Shakespeare's creation.

The texts of Shakespeare's plays show that saturation is by no means new to the English language. They also show that this technique is favoured by Shakespeare. The first page and a half of Romeo and Juliet is charged with phraseological meaning and instantial use. This short section contains three cases of sophisticated instantial use: to carry coals (paronymic punning, see Ch. 4.2), to take the wall of someone, the weakest goes to the wall and to push/thrust someone to the wall in one saturated context (see above) and to bite one's thumb at someone - all at the very beginning of the play (see Appendix V). Let me have a closer look at the third PU of this short saturated stretch of text:

\section{to bite one's thumb at someone ${ }^{20}$}

Sampson: Nay, as they dare. I will bite my thumb at them, which is a disgrace to them if they bear it.

Enter Abraham and Balthasar.

Abraham: Do you bite your thumb at us, sir?

20. The PU to bite one's thumb at someone is obsolete in MoE (Kunin 1967a:928). 
Sampson: I do bite my thumb, sir.

Abraham: Do you bite your thumb at us, sir?

Sampson: (aside to Gregory) Is the law on our side if I say "Ay"?

Gregory: No.

Sampson: No, sir. I do not bite my thumb at you, sir, but I bite my thu mb, sir.

W. Shakespeare, Romeo and Juliet, Act I, Sc. 1

The reiteration goes hand in hand with visual punning, which is to be perceived by sight. Comprehension is made possible only if the gesture of biting one's thumb goes together with the meaning of the PU to bite one's thumb at someone: to make a sign threatening revenge (Chambers 20th Century Dictionary [1983] 1987: 1349). The image of the PU is recreated by acting. The pun is visual. Let us keep it in mind that Shakespeare wrote his plays to be watched, not to be read. Alternating reiteration of both the PU and its literal meaning produces a network of punning supported by visual representation (see Ch. 6). It is of critical importance to understand the elements of non-verbal enactment alongside the lines of the play.

Thus, the play Romeo and Juliet starts with a tense conflict situation in Verona. Phraseological saturation is an integral part of this discourse. An old quarrel between the Capulets and the Montagues has grown to such enmity that it is extended even to remote relatives, followers, and servants who cannot meet each other without fierce words and sometimes bloodshed. When L2 learners explore Shakespeare's texts it is mandatory to recognise and identify PUs in order to infer and analyse. His works contain innumerable sophisticated and diversified forms of phraseological interaction with the text, providing cohesion and textual continuity.

Use of saturated passages of text at the very beginning of a piece of work is also characteristic of 20 th century writing. The first page of D. H. Lawrence's short story Rawdon's Roof ends with a cluster of three PUs in close proximity, entwining metaphorical, metonymic, and literal meanings, demonstrating that much cognitive development is based on emotions and motivation:

\section{under one's/someone's roof}

walls have ears

what's sauce for the goose is sauce for the gander

The point, however, is that Rawdon said so emphatically - no, not emphatically, succinctly: 'No woman shall ever again sleep under my roof.' It was a case of futurity. No doubt he had had his ceilings whitew ashed, and their memories put out. Or rather repainted, for it was a handsome wooden ceiling. Anyhow, if ceilings have eyes, as walls have ears, then $\underline{\mathrm{R} a w d o n} \mathrm{had}$ given his ceilings a 
new outlook, with a new coat of paint, and all memory of any woman's having slept under them - for after all, in decent circumstances we sleep under ceilings, not under roofs - was wiped out for ever.

'And will you neither sleep under any woman's roof?'

That pulled him up rather short. He was not prepared to sauce his gander as he had sauced his goose.

D. H. Lawrence, Rawdon's Roof

Sustained phraseological image is a natural reflection of a way a thought tends to develop: the figurative meaning of the PU persists, then gives rise to a literal interpretation, followed by a return to the figurative level. A metonymic PU turns into an extended metaphor, sustained by a pun. The parallel construction "ceilings have eyes" is cataphorically pointing forward to walls have ears, providing a cohesive tie. "Ceilings have eyes" is an instantial metaphor, based on contiguous associations. Moreover, the subtle irony of the comment brings out the literal meaning again by way of a pun: “...in decent circumstances we sleep under ceilings, not under roofs", and with the ceilings repainted the memory of a woman having slept under them is metaphorically wiped out for ever. This perception considerably extends "our field of vision" (Lakoff and Johnson [1980] 2003:30). The shift from metaphor to pun ("a repainted, handsome wooden ceiling") creates a vivid visual representation - extended pun in a phraseologically saturated stretch of text.

In this context, instantial use has been carried to considerable lengths; it is striking in more ways than one. The proverb what's sauce for the goose is sauce for the gander has acquired an instantial form: "was not prepared to sauce his gander as he had sauced his goose". This is a case not only of allusion, but also of instantial conversion, which is extremely rare in the use of PUs in English. There is another rare pattern, that of metathesis, which involves a swap of notional constituents, changing the regular sequence in the base form. In sum, this instantiation has incorporated three PUs; the techniques of metonymy, metaphor, and punning have created a web of figurative and literal meanings, providing cohesion and coherence in discourse. Phraseological saturation is one of the ways in which PUs function in the web of discourse, creating instantial chains, fusing and intermingling both base and instantial features.

The next example is a phraseologically saturated stretch of text, a complex weave of novel turns, covering a whole page. The instantiation involves both core use and instantial use, a striking case of cleft use, an instantial metaphorical extension of two constituents, bag and cat, reiteration, and instantial analogues, all saturating the context. Phraseological saturation is polyphonic by its very nature. 
It is used to imply multiple voices in text. Several thoughts are unravelled at the same time, involving several instantial patterns, fitting in with each other and shaping a semantic and stylistic unity. It is like a polyphonic composition, consisting of several voices, playing several parts, each with an independent melody, capable of producing more than one line of thought at a time. It reflects the author's intuitive feeling for the "emotional density" of a particular moment (Spiegel 1976: 44):

to let the cat out of the bag

to buy a pig in a poke

tit for tat

an eye for an eye (and a tooth for a tooth)

Gentle reader, I am going to let the cat out of the bag. I am going to do so, because I never ask anyone, even the most desirous, to buy a pig in a poke. After this very nice little peace-like-a-river touch, I am going to let the cat out of the bag. (...)

Out of this very promising-looking bag of story, which Ihave this minute shown youtied with a pretty blue ribbon of peace, I am going to let out, - what? - the cat! I am going to let the cat out of the bag. Or even two whirling, fur-flying cats, all claws and sparks. (...)

But whether he knew it or not isn't the point. I know it, and I'm telling this history. And I like to let my cat out of the bag right off, so that nobody shall think it's a chaste unicorn or a pair of doves in a cage.

Dear Gilbert, he had found his mate and his match. He had found one who would give him tit for tat, and $\underline{\underline{\text { ittle }}}$ for tattle. He had found his soul's affinity, and his body's mate: a she-cat who would give him claw for $\underline{\underline{\mathrm{claw}}}$, a bitch who would give him $\underline{\underline{\mathrm{snarl}}}$ for $\underline{\text { snarl}}$, a falcon who would demand an eye for an eye. Here's to them!

D. H. Lawrence, $M r$ Noon

In the following example, saturation is achieved by bringing together several voices: uniting the phraseological images in a context which combines the use of three PUs, out of which two PUs contain the same image-bearing constituent rose. Coupling of images is a means of cohesion (as in the above example from Shakespeare's Romeo and Juliet). The image-bearing constituent acts as a tie; its reiteration is cohesive, hence it contributes to the texture. The cohesive effect is achieved by the continuity of the figurative level: the level of phraseological meaning. Use of the constituent rose as part of the two PUs creates cohesive semantic and stylistic ties between the textual elements in this part of the text. Thus, phraseology 
is a rich resource for linking elements in discourse. This case of phraseological saturation involves three PUs in one paragraph: the first PU to skate on thin ice constitutes a regular case of instantial replacement; the second PU under the rose is reiterated two sentences later while the third PU a bed of roses/life is not a bed of roses is a case of concurrent use involving elements of allusion, extended metaphor, and pun, echoing the image-bearing constituent of the second PU:

to skate on thin ice

under the rose

a bed of roses/life is not a bed of roses

... His daughter was ruining the family honour. Marriage was a social institution, and whoever attacked the social fabric deserved to be treated as a criminal and coerced into submission. A private excursion in in the fields of ad_ultery was perhaps to be condoned.

The Baron knew he w a s on thin ice, on the marriage question. Had he not his own illegitimate ménage, under the rose? But he kept this position. The institution was to be supported, the individual might do as he liked - under the rose. "Ach yea!" said Lotte. "If the bed isn't roses the bedcover is." $\underline{\text { So she went in and out among the rose-bushes, and hid, }}$ not behind the fig-leaf, but behind this same immortal rose.

D. H. Lawrence, Mr Noon

This stretch of text is phraseologically charged to the point of being oversaturated. It is characterised by a high degree of semantic density. The PU is supplemented by a wealth of other rhetorical and dramatic techniques, providing a dense and rich metaphorical web.

Another example referring to the essential mysteries of modern love reveals the potential of PUs to create new composite ways of expression. Several phraseological voices are developed in parallel. Two allusions are blended in one context, reinforced by alliterative replacement and extended metaphor, resulting in a focal effect of phraseological saturation:

an old wives' tale/old wives' tales

to call a spade a spade

when Adam delved and Eve span who was then the gentleman?

It does not matter what you do - only how you do it. - Isn't that the sincerest of modern maxims? - And don't we all do it nicely and con molto espressione? We know we do. So little grossness nowadays, and so much dear reciprocal old-beaniness! How can there be any real wrong in it? Old wives tales! There is no wrong in it. We are all so perfectly sweet about it all, and on such a sympathetic plane. 
Why bother about spades be ing spades any more? It isn't a point. $\underline{\text { Adam }}$ no more delves than Eve spins, in our day. Nous avons changé tout cela. Call a spoon a spoon if you like. ${ }^{21}$ But don't drag in garden implements.

D. H. Lawrence, $M r$ Noon

As the concluding example, I would like to offer Thurber's fable The Hunter and the Elephant, which is a web of phraseologically saturated discourse:

\section{a white elephant}

a purple cow $^{22}$

\section{a bird in the hand is worth two in the bush}

Once upon a time there was a hunter who spent the best years of his life looking for a p in k elephant. He looked in Cathay and he looked in Africa; he looked in Zanzibar and he looked in India; but he couldn't find one. The longer he looked, the more he wanted a pin k elephant. He would trample black orchids and he would walk right past purple cows, so intent was he on his quest. Then one day in a far corner of the world he came upon a pink elephant and he spent ten days digging a trap for it and he hired forty natives to help him drive the elephant into the trap. The pin k elephant was finally captured and tied up and taken back to America.

When the hunter got home, he found that his farm was really no place for an elephant. It trampled his wife's dahlias and peonies, it broke his children's toys, it crushed the smaller animals around the place, and it smashed pianos and kitchen cabinets as if they were berry boxes. One day, when the hunter had had the elephant for about two years, he woke up to find that his wife had left his bed and his children had left his board and all the animals on the estate were dead except the elephant. The elephant was the same as ever except that it had faded. It wasn't pink any more. It was white. Moral: $\mathrm{A} \mathrm{burden}$ in the bush is worth two on your hands.

J. Thurber, The Hunter and the Elephant, Fables for Our Time

Resolution of the exasperating situation comes in one word: white, which appears in a simple unextended sentence, revealing the tragedy, and makes sense of the anaphoric portrayal of the surrealistic pink elephant. The full base form a white elephant never appears in the text, but it is there at the back of the reader's mind all the time. And still at the end of the fable it was white comes as a revelation, as

21. Spoon/spooning (obs.) - making love by caressing, kissing and talking amorously, being sentimentally in love (MWCD 1996).

22. A purple cow - something remarkable, something out of the ordinary. 
an anticlimax which resolves the ambiguity. This example is interesting from the cognitive point of view, as the process is that of gradual development of meaning, laying bare the semantic structure of the PU and developing instantial meaning. The whole fable is an instantiation of the PU a white elephant: all the fable is pink until the pink elephant fades and turns white. The pun is facilitated by Thurber's own ingenious pictorial representation of an enraged wild elephant, signifying the author's awareness and creativity. ${ }^{23}$ The gradual unfolding of the story is set off by a terse piece of wisdom in the coda, expressed by a PU with two instantial replacements to meet the new discourse situation. ${ }^{24}$

In conclusion, phraseological saturation implies a dense phraseological presence in the web of discourse. The striking result of saturation is due not only to its high stylistic density, but also to the impact it creates. Even when PUs undergo many instantial changes, permeating the texture of a paragraph or a longer stretch of text, they still preserve the stability of phraseological meaning and their identity. They become part of a phraseologically saturated segment of discourse: an instantial network in which a number of figurative strands are intertwined. Saturated stretches reveal how several PUs may be realised in interaction as a polyphony of phraseological voices.

\subsection{Comprehensive instantial use}

Comprehensive use is a type of instantial use which encompasses a text, either appearing in titles and headlines or in codas. Comprehensive use applies simultaneously to the whole text. Due to its prominent position and the inherent quality of cohesive figurative meaning, the PU is in a position to comprise the scope of all the text. Use of PUs both in titles and headlines and in codas lends a comprehensive unity to the text. ${ }^{25}$

23. For the fable together with Thurber's illustration, see Appendix VI.

24. For the use of PUs in codas, see Ch. 5.5.2.

25. For a study of titles, see Carter and Nash ([1990] 1995: 78-86). The function of headlining is complex: headlines have to contain a clear, succinct and if possible intriguing message, to kindle a spark of interest in the potential reader (Crystal and Davy [1969] 1995:174). For cohesive ties of headlines with the text involving FEIs, see Moon (1998:290-293). For examples of proverbs in titles of songs and dramas (both core use and instantial use), see Bryan $(2001,2002)$. 


\subsubsection{Umbrella use: Use of phraseological units in titles and headlines}

By umbrella use I understand use of PUs in titles and headlines performing a sustainable cohesive text-embracing function. Umbrella use is a comprehensive term. It refers to and covers the whole of the text, which comes under the general unifying influence of the PU.

The title or the headline is certainly language of a particular type not only grammatically and typographically (such as size and style of printing, layout, use of colour) but also stylistically. It catches the eye and commands attention. Moreover, a PU appearing in a title or a headline attracts by its figurative meaning and image. It brings the idea of the text to the fore, making it more prominent. The reader is offered a conclusion or is invited to draw one. An interesting area of research is the striking and innovative use of proverbs in the headlines of texts of advertisements, where much emphasis is achieved by "creative headlines which act as major attention-getters" (Mieder 1989:293).

In umbrella use the PU is a general cover, lending an overtone which runs throughout the text. At the same time it is like an undercurrent that helps to determine its overall stylistic quality. Different techniques in umbrella use reflect a variety of phraseological cohesion and sustainability. The main types of umbrella use are as follows: ${ }^{26}$

1. The title/headline is core or instantial use of a PU, which is not reiterated in the text. Although the PU does not appear in the text, its umbrella use is text-inclusive, pertaining to the whole chapter, book, or article.

Innumerable cases of umbrella use exist in the texts of news media. The following two headlines illustrate core use:

\section{Entrepreneurs catch the eye}

Financial Times, 2 December, 1999, p. IX

Eyeball to eyeball in the furnace of war

The Sunday Times, 21 June, 1998, p. 16

Many authors choose PUs as the best way to represent the gist of their work. For instance, the title of Joyce Cary's novel The Horse's Mouth serves to convey the message of the book. On the back cover critics have sustained the image of the $\mathrm{PU}$ (straight) from the horse's mouth saying that Mr Cary is the right hor se and that his book has the kick of ten stallions.

26. For a graphical presentation of the main types of phraseological cohesion and sustainability in umbrella use, see Appendix VI. 
2. The title/headline is core or instantial use of a PU, which is reiterated at the beginning of the text. ${ }^{27}$ Reiteration works as a kind of reference to the PU in the title or headline.

The PU may certainly appear at any point of the text, though usually it is reiterated at the beginning of the text in the first paragraphs, or one of the first, working for figurative links in discourse. For instance, the headline Slow to join the bandwagon is core use, and the PU is repeated in the first sentence of the first paragraph with insertion of two instantial constituents. Reiteration of the PU in an instantial form echoes the PU, modifying and specifying the thought expressed in the headline:

Switzerland, one of Europe's richest countries, has been rather slow to join the private equity bandwagon.

Financial Times, 2 December, 1999, p. IX

Instantial use in headlines is a favourite pattern for media journalists. It lends a subtle additional meaning to the whole of the text. In the following example the PU the Wild West has undergone instantial replacement coupled with extended metaphor to meet the needs of an article headlined Taming the Wild East:

As the best westerns all make perfectly clear, the real drama in the Wild West was not about guns, or whiskey, or courage, but money, and the making of it. Today in the Russian Wild E a s t, little has changed. Boris Yeltsin is Burt Lancaster, though more corpulent, the brutal but admirable cattle baron, determined to carve an empire from the wilderness.

The Spectator, 22 August, 1998, p. 7

Let me turn to another headline Can the stiff upper lip survive? The article focuses on new attitudes and a new corporate British identity. The instantial form is a metonymic personification of the PU to keep/show a stiff upper lip, which is a metonymy-based metaphor in its base form. The insight the instantial use affords is supported by a photo of two English ladies of the Victorian era in profile, having tea and keeping a stiff upper lip (a visual pun) and by reiteration of the PU in an elliptical form further in the text:

\section{to keep/show a stiff upper lip}

The English language is full of phrases attesting to the British sense of reserve and decorum - stiff upper lip, fair play, it's not cricket. And the response to a crisis, in this mythology, is to go away and have a nice cup of tea.

The Times, 7 July, 1998, p. 17

27. Moon points out the significance of idioms in the text-initial or paragraph-initial, as well as the text-final or paragraph-final positions (1998:297-300). 
3. The title/headline is core or instantial use of a $\mathrm{PU}$, which is reiterated in the final paragraph or sentence.

For instance, in the article Square pegs, round holes both the headline and the last two paragraphs are instantial use, each of a different type. The idea of the Tate's collaboration in mass-producing art is to create a work of art which would slip effortlessly into everyday life. At the end of the article the literal meaning is brought up by the phrase "dowel-like coat pegs", and the image is extended by the onomatopoeic to bang in the closing sentence:

\section{a square peg in a round hole/a round peg in a square hole}

However, it poses the question why, when we have such a vast pool of creative design talent in this country, we are trying to bang a square peg $\underline{\underline{i n t o}}$ a round hole.

The Independent, 13 November, 1999, p. 18

Another example: the headline White lies turn red (Sunday Independent, 24 October, 1999, p. 8L) is a case of instantial use; it contains a pun, embracing the whole article. The PU is alluded to towards the end of the last column when an imaginary truth machine with rows of green, yellow, and red lights analyses voice stress in real time.

Use of a PU in closing paragraphs of chapters or parts of a book may acquire the significance of epiphoric use. For instance, in John Galsworthy's novel The Silver Spoon the PU to be born with a silver spoon in one's mouth gains prominence not only by elliptical use in the title, but also by its use at the end of Part I, Part II, and Part III. The title embraces the whole book, while recurrence of the PU or its image works for emphasis of the main thought. First the PU appears in Part I on p. 57 (core use), followed by an elliptical reiteration in the next paragraph. The PU occurs again in Part I, p. 68 (concurrent use) and p. 84 (allusion). It is also alluded to in Part II, p. 124. What is noteworthy is that the PU is used in an instantial form epiphorically in the concluding paragraphs of all three Parts of the book (p. 87, p. 167, and p. 242). For instance, Part II ends in instantial use, reiterating the thought of the spoiled English sucking their silver spoon (already expressed at the end of Part I on p. 87):

\section{to be born with a silver spoon in one's mouth}

Self-conscious national efforts were just pomposity. Pompous! He? The thought was terribly disturbing. (...) How many dreams spoiled, with his measured resonance! Line up with the top-dressers, and leave the Country

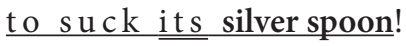


Thus, reiteration of the PU over the whole book, including the end of all three parts, sustains the image alluded to in the title The Silver Spoon, which is an umbrella phrase, going beyond the limits of its separate parts and encompassing the whole novel.

4. The title/headline is core or instantial use of a PU, which is reiterated both in the openings and closings of discourses. Use of the PU in the initial and final paragraph or sentence embraces the text, creating a frame effect.

Sitting on the fence can harm your health is the headline of an article in Travel Weekly (22 March, 1999, p. 14). The main idea of the article is that independents need to re-evaluate their position in the travel industry. While the title is in core use, the summary, coming straight after the headline, is instantial use. It repeats the PU sustaining the metaphor: "So get off that fence and show the agents who support us exactly how much we appreciate them". The article discuses the urgency of the issue and the PU is repeated in the last sentence: "You can no longer sit on the fence because you'll die". The frame construction is a compositional technique that emphasises the theme, shaping a context.

5. The title/headline is a PU in core or instantial use, the whole text becomes the context of the instantiation, and the PU turns into a narrative technique by force of constant reference to it.

Texts present an enormous variety of cohesive ties, which provide sustainability of the phraseological image throughout the stretch of text, supported by umbrella use of the PU in the title or headline, which is comprehensive of all the text. One of the patterns is extended metaphor. This can be very well illustrated by John Fowles' story The Ebony Tower ${ }^{28}$ To convey the artist's ideas on abstract art, Fowles uses the PU an ivory tower. ${ }^{29}$ Fowles is known for working and reworking his images. He tends to return to them by reiteration, and the same applies to phraseological images.

\section{an ivory tower}

"Art is a form of speech. Speech must be based on human needs, not on abstract theories of grammar. Or anything but the spoken word. The real word."

J. Fowles, The Ebony Tower, p. 50

28. For discourse analysis of J. Fowles' short story The Ebony Tower, see Short (1995:45-62).

29. An ivory tower - studies, interests (esp. academic or artistic) that cut one off from the realities and struggles of life; observation and imagination in place of direct experience (Cowie, Mackin and McCaig [1993] 1994b:323). 
Then the old man spoke, with a strange lucidity, as if he had only been pretending to be drunk, and now summarized with one final inconsequence. "Ebony tower. That's what I call it".

J. Fowles, The Ebony Tower, p. 51

Certainly, replacement of the epithet in itself would not constitute discoursal use; however, the whole work is a context for this application, so that instantial use in the title fulfils an umbrella function, sustained by reiteration of the image. Interestingly, in A Personal Note to Eliduc Fowles refers to The Ebony Tower as a variation on a theme, dealing with "black proof of an ultimate shirking of creative responsibility" (Fowles [1974] 1975:119). ${ }^{30}$ In its core use the PU appears a few pages later, establishing an explicit metaphorical link with the instantial form and what it stands for:

She drew back to go, but he stopped her. "What on earth did that last thing he said mean? The ebony tower?"

"Oh." She smiled. "Nothing. Just one of the bats in his belfr_y". She tilted her head. "What he thinks has taken the place of the ivory tower?"

"Abstraction?"

She shook her head. "Anything he doesn't like about modern art. That he thinks is obscure because the artist is scared to be clear...".

J. Fowles, The Ebony Tower, p. 54

Abstraction is seen not only as "the ivory tower", isolation, a condition of seclusion or separation from the world and the harsh realities of life. Abstraction is seen as betrayal, as "the ebony tower", representing a flight from human and social responsibility. Fowles returns to the PU towards the end of the story, where it appears as a one-member sentence forming a paragraph of its own, acting as a coda and summarising the previous paragraph on abstraction:

It was not just his own brand of abstraction that was a fault, but the whole headlong post-war chain, abstract expressionism, neo-primitivism, op art and pop art, conceptualism, photo-realism ... il faut couper la racine, all right. But such rootlessness, orbiting in frozen outer space, cannot have been meant. They were like lemmings, at the mercy of a suicidal drive, seeking Lebensraum in an arctic sea; in a bottomless night, blind to everything but their own illusion.

The ebony tower.

J. Fowles, The Ebony Tower, p. 112

30. The underlining is mine. 
The novel formation the ebony tower would be incomprehensible without an understanding of instantial use which directly relates to the message of the story. Instantial use of the PU in the title turns into a comprehensive line of thought spanning the whole of the text and testifying to Fowles' narrative skills. Thus, umbrella use is part of his method of narrative presentation.

Another pattern that frequently goes together with umbrella use is pun. In this case the title or headline comprises a PU in core or instantial use while the text is a pun on the PU with one or several of the literal meanings of the constituents sustained throughout the work. For example, the headline Melanie lets cat out of the bag contains a PU which is repeated in core use in the first paragraph:

\section{Melanie Johnson let the cat out of the bag on Monday night.}

The Times, 27 October, 1999, p. 35

However, the text of the article works like a pun referring to efforts to promote Catmarking for mortgages and apply Cat standards to home loans. ${ }^{31}$ In parallel with the figurative meaning of the PU, the whole of the article sustains one of the literal meanings of the image-bearing constituent cat: Cat (CAT) - computeraided trading (Encarta World English Dictionary 1999).

Another example of pun: Real food for thought (Weekend Financial Times, $26 / 27$ June, 1999, p. VI). The whole of the article is an illustration of the metaphor contained in the base form of the PU and the literal meaning of the corresponding word combination. The article is saturated with interesting associations and thoughts concerning food. The PU in the headline has integrated the whole text, performing the umbrella function.

In umbrella use, the effect of a saturated context may also be reached through insistent reiteration of the PU, its base or instantial constituents, permeating the text. For example, the headline The scream of consciousness (The Guardian, 4 May, 1996, p. 27) is instantial use of the PU the stream of consciousness. ${ }^{32}$ The sub-headline reads: Francis Bacon's Popes Reveal Childhood Anguish.

As the PU occurs in the headline, it acquires significance for the whole text. The instantial form with the replacement "scream" recurs seven times in this short feature as a leitmotif, becoming prominent and evoking a thought of constant pain. We perceive this image not only in our minds, but also through our ears

31. Interestingly, it is quite common to find instantial use in serious financial articles in English while in Latvian it would be extremely rare or almost unthinkable. The cultural traditions differ.

32. Cowie, Mackin and McCaig ([1993] 1994b: 523) explain the PU the stream of consciousness as follows: the events and circumstances (including one's own reaction to them) of one's life as continuously experienced and interpreted by oneself. 
owing to onomatopoeia. Reiteration of the instantial element becomes audible. It describes Bacon's intense suffering in childhood, subconsciously expressed in the screaming mouths of the Screaming Popes in his paintings. Incidentally, Bacon never succeeded in painting a smile.

This example illustrates involvement of phraseology in the sounds of discourse: evocation of a new sound image with the help of instantial use. The onomatopoeic aspect of instantial use affects the reader. The aural effect creates a sensory experience. The representation of anguish is attained by a sound falling into the consciousness.

Thus, reiteration of the instantial form creates an audible effect of sound and sense. The instantial image the scream of consciousness runs through the feature from the title to the very end as a continuous thought, acting as a narrative technique.

6. Multimodal-use: the title/headline is core or instantial use, the whole text becomes the context of the instantiation, which is reinforced by visual representation (often with the PU in the caption).

The multimodal approach involving the whole text is representative of newspaper language. In general "texts in English are becoming increasingly multimodal: they use devices from more than one semiotic mode" of representation at the same time (Goodman 1996:39). Creating meaning in a multimodal text involves a complex interaction of visual elements and verbal English presented to the eye, as well as contextual and background knowledge (op. cit.: 69).

For instance, the headline Home Truths (Weekend Financial Times, 23/24 October, 1999, p. XI) is a PU in core use. The PU is polysemous, and in this text it is used in its second meaning which is less common: a statement of undisputed fact. ${ }^{33}$ The article, which is devoted to an exhibition, contains interior design drawings for a home. This use is multimodal. The PU in the headline fulfils an umbrella function: the whole article turns into a pun dealing with the design of home products, supported by the visual effect.

Take another example: the article Bee in a bonnet (The Guardian, 27 October, 1999, pp. 12-13) refers to new measures to disguise GM food and the issue of a drop in sales for bee farmers if the public suspects that nectar is contaminated with GM pollen. The proposed legislation aims to legitimise the $1 \%$ threshold for GM material contamination in food which is seen as an idea one cannot stop talking about and which is not shared by others. The whole article is the context for instantiation of the PU to have a bee in one's bonnet (CCDI 1995: 25) working

33. MWCD 1996 gives two meanings of the PU home truth: (1) an unpleasant fact that jars the sensibilities; (2) a statement of undisputed fact. 
as a pun. The visual representation of a bee gathering nectar brings up the literal meaning of the constituent. The photo is placed in the second half of the article, making the reader return to the PU in the headline and reinterpret its message. The headline would have been incomprehensible without an understanding of the pun both visually and verbally.

Thus, in case of multimodal use the PU in the headline performs an umbrella function, reinforcing cohesion. This is a meaningful relationship, an explicit tie with the text. The whole article reveals the literal meaning of the phraseological constituent with visual representation as part of the direct line of the narrative. All these elements combine in one stylistic effect, each contributing to the cohesion of the structure of discourse. Together they bring out both the meaning of the base form and the instantial meaning of application of the PU.

In conclusion, umbrella use forms various types of phraseological cohesion and sustainability, embracing the whole range of the text and preserving semantic and stylistic ties with the PU in the title or headline. Umbrella use is a particular instance of use of PUs at focal points in discourse.

\subsubsection{Use of phraseological units in codas}

Another focal point is the coda, which serves to conclude a text or part of a text. In narratology, the coda is the final unit of a narrative, following resolution of an action (Wales [1989] 1995:61). As a rule, the coda is a separate item structurally, designed as an additional section. It not only rounds off a stretch of text to a satisfactory conclusion, but also gives additional information. In this way, it offers an interest of its own.

Use of PUs in codas is discoursal. Although the coda is usually expressed within the limits of one sentence and is the final element of the text, it refers to the whole of the narrative and becomes a distinctive part of it. The coda conveys the quintessence and represents the gist of the central idea in a concentrated form. It is human nature and desire to summarise through a generalisation. Evaluation is also discernible, so that the coda is a factor which influences the way a situation is understood and inferences are drawn; it is part of the cognitive processes by which judgement is made. ${ }^{34}$

Stylistic use of PUs is well suited for the coda. A coda expressed through instantial use frequently helps to elicit a moral lesson or message, or offers a moral

34. PUs often occur in segments where the teller evaluates the events of the narrative, including codas (McCarthy and Carter [1994] 1995: 111). For use of PUs in summaries and evaluations, see Moon (1998:298-304). 
base for particular events. The moral that can be evoked from the text is given in a nutshell in a PU, especially in a proverb, usually a generalised piece of folk wisdom. "Proverbs are 'monumenta humana' and as such they mirror life in all its expressions" (Mieder 1989: 148). Moreover, as a wrap-up of narration, the proverb lends organisational completeness to the text.

I would like to illustrate the effect of PUs in codas on the basis of J. Thurber's fables ([1939] 1983). ${ }^{35}$ Thurber is known as one of the great comic artists and American humourists who makes the reader laugh and instructs at the same time. He has a tremendously original angle of vision. Whether he writes on discarded sorrows, immediate joys, stale dreams, or thoughts of good cheer, the technique of coda reveals the subtlety of his thinking and the intensity of his interest. Thurber resorts to a number of instantial techniques in codas: extended metaphor, pun, insertion, instantial replacement, or some other technique. The merging of the real and the figurative is revealing and effective, for example:

don't count your chickens before they are hatched

Title: The Unicorn in the Garden

the text of the fable

Moral: Don't count your bo obies until they are hatched.

J. Thurber, Fables for Our Time

The coda moves away from the specific peripeties and summarises the events. Another example:

a new broom sweeps clean

Title: The Tortoise and the Hare

the text of the fable

Moral: A new broom may sweep clean, but never trust an old s aw.

J. Thurber, Fables for Our Time

The function of the coda is to encapsulate the gist and make it easier to remember. The coda represents all the most important aspects of an idea, a fact, or an event in a very small space. Instantial use gives scope for further generalisation.

35. For a deeper insight into Thurber's use of codas in fables, see Carnes (1991). 
A striking feature of Thurber's codas is his repeated use of metathesis, a transposition resulting in an exchange of places of two constituents of the PU, for example:

early to bed, early to rise makes a man healthy, wealthy and wise

Title: The Shrike and the Chipmunks

the text of the fable

Moral: Early to rise and early to bed makes a male healthy and wealthy and de ad.

J. Thurber, Fables for Our Time

This is a highly effective coda. The proverb serves as the final structural and thematic unit of the fable after the action is resolved. A man is replaced by a male, retaining an alliterative and semantic link with the base constituent. The second replacement dead creates an anticlimax, frequently exploited in humorous pieces of writing. ${ }^{36}$

Metathetic replacement of the notional constituents in the coda is an instantial technique favoured by Thurber in a number of fables. For instance, The Hunter and the Elephant is based on a pun which grows into a kind of paradox. ${ }^{37}$ "The reader must probe beyond the literal meaning to find a deeper, usually more philosophical meaning which will reconcile the apparent absurdity" (Wales [1989] 1995:282). The coda embodies the quintessence. The instantial twist in the coda is achieved by metathetic replacement, adding alliteration but preserving the syntactical parallelism of the two parts of the proverb, which certainly facilitates identification:

a bird in the hand is worth two in the bush

Title: The Hunter and the Elephant

the text of the fable

Moral: A burden in the bush is worth two on your hands.

J. Thurber, Fables for Our Time

36. An anticlimax (or bathos) is a sudden lowering from a heightened tone for ironic effect, sometimes even reaching the absurd (Cuddon [1976] 1982: 42; Wales [1989] 1995:39-40).

37. See Appendix VII for the full unhighlighted text of the fable The Hunter and the Elephant and Thurber's illustration. See Ch. 5.4 for analysis of the fable. 
In the fable The Sheep in Wolf's Clothing both the title and the coda contain instantial use, embracing the text. The fable affords a psychoanalytical insight showing what humans are like. The text of the fable is supplemented by Thurber's own pictorial interpretations, featuring a sheep typing on a typewriter and a wolf looming from behind. ${ }^{38}$ Although a visual representation of instantial use seems to convey Thurber's message best, it is the combination of a subtle stylistic turn and a visual back-up which puts it in focus and enhances the effect:

\section{a wolf in sheep's clothing}

to get something right ${ }^{39}$

\section{The Sheep in Wolf's Clothing}

Not very long ago there were two sheep who put on wolf's clothing and went among the wolves as spies, to see what was going on. They arrived on a fete day, when all the wolves were singing in the taverns or dancing in the street. The first she e p said to his companion, "Wolve s are just like us, for they gambol and frisk. Every day is fete day in Wolfla n d." He made some notes on a piece of paper (which a spy should never do) and he headed them "My Twenty-Four Hours in Wolfla nd," for he had decided not to be a spy any longer but to write a book on Wolfland and also some articles for the Sheep's Home Companion. The other sheep guessed what he was planning to do, so he wired a book to his publishers called "My Five Hours in Wolfland," and it was announced for publication first. The other she e p immediately sold his manuscript to a newspaper syndicate for serialization. Both sheep gave the same message to their fellows: wolves were just like sheep, for they gambolled and frisked, and every day was fete day in Wolfla nd. The citizens of $\underline{S}$ h e e pland were convinced by all this, so they drew in their sentinels and they let down their barriers. When the wolves descended on them one night, howling and slavering, the sh e e p were as easy to kill as flies on a windowpane.

Moral: Don't get it right, just get it written.

J. Thurber, Fables for Our Time

This fable is a saturated text involving instantial metathesis in the title and use of a paronymic pun in the coda: "right" is realised not only in the meaning of "correct", but also implicitly evokes the first form of "written", which is necessary to disambiguate the pun. The effect is enhanced by the pictorial representation,

38. See the unhighlighted text of the fable The Sheep in Wolf's Clothing and Thurber's illustration in Appendix VIII.

39. To get something right - to carry out a task, answer a question, solve a problem (Cowie, Mackin and McCaig [1993] 1994b:219). 
adding a visual dimension and illustrating the pun carried by the main PU. The fable is completed by a fitting coda, bringing out the irony of the situation. All the fables discussed reveal Thurber's original vision as well as his choice of compositional and stylistic techniques. It is evident that Thurber favours use of PUs both in titles and codas, performing the comprehensive function.

It is worth noting that in newspaper articles PUs may appear in the captions of photos functioning as codas. I would like to consider an article with the headline "I'm only a poor little sparrow" (The Independent, The Weekend Review, 13 November, 1999, p. 14). The whole article is about sparrows and the fact that they might disappear completely from rural areas. The article contains a photo of a sparrow sitting on the palm of a hand. The caption reads: $\underline{A}$ bird in the hand: suburbia has become the sparrow's last stronghold. In thiscontext the PU a bird in the hand acquires the effect of a coda: the photo of the bird brings out the literal meaning while the PU in the caption turns into a visual pun, providing the conclusion. This example reveals the role of visual representation in instantial use. It also shows that visual literacy is becoming more important in spheres traditionally associated with verbal forms of English, such as reading a newspaper or a magazine.

Thus, when a PU is used in a coda at the end of a text or a stretch of text, it gives a summary, following resolution of an action and conveying a quintessential generalisation or moral message. Use of PUs in codas offers a cognitive insight into the play of literal and figurative meanings and the process of meaning construction.

To conclude, comprehensive use is instantial use which encompasses a text, either appearing in titles and headlines or in codas. Comprehensive use applies simultaneously to the whole text. Whether in umbrella use or in codas, PUs convey an overtone and take on a prominence in relation to the entire text. Comprehensive use often goes together with visual representation, which is a multimodal way of expression. This means that a need exists to train students to comprehend and interpret the visual representation of instantial use and its significance for the text. 


\section{CHAPTER 6}

\section{Visual representation of phraseological image}

Visual representation is a non-verbal mode of expression perceivable by sight. A visual instantiation of a phraseological image is of stylistic and cognitive interest because it brings out the potential of phraseological meaning, and the creative aspects of the verbal and the visual in multimodal discourse. Visual expression of text usually goes together with the verbal. In visual representation, the process of creating a mental picture in one's mind relies on close ties between the visual and the verbal, and knowledge of the political, socio-cultural, and semiotic implications. Visual representation creates new meaning, stretches our imagination, and sustains figurative thought. Thus, phraseological metaphor exists not only in thought and language; it also exists in visual representation and its perception.

\subsection{Visual representation and phraseological units}

Visualisation is part of metaphor recognition. Aristotle pointed out that metaphor can bring an image before our very eyes (Aristotle 1991:247). In other words, metaphor makes the image visible in our mind. Perception of an image, whether lexical or phraseological, is a cognitive process that creates a mental picture in the imagination, a kind of visualisation in the mind's eye, which is subjective. For instance, we would each visualise the base metaphor of the PU to let the cat out of the bag in our own way (Figure 6.1). However, this picture presents an artist's angle of vision. ${ }^{1}$ Visual representation of an image serves to create a new guided mode of perception which we are led to accept: seeing is persuasive. Cognitive science seeks to understand "the internal mental representations responsible for higher-order mental functions", among them vision and language (Harrington 2002: 125). Cognitive psychologists argue against the traditional split between vision and thinking, emphasising that the sense of sight is the most efficient organ of human cognition (Arnheim [1969] 1997:14). In this chapter I am concerned with visual aspects of metaphorical thought representation and with creative use

1. I am grateful to Ivars Poikāns for permission to use this drawing. 


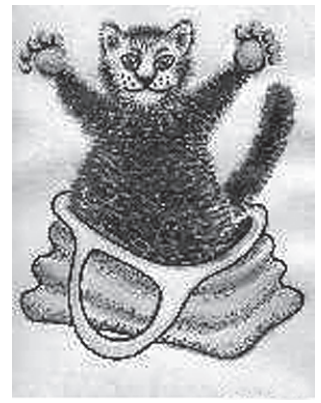

Figure 6.1 The cat is out of the bag

of phraseological metaphor in verbal and visual discourse. ${ }^{2}$ My aim is to have a closer look at the benefits of a cognitive approach to visual representation of instantial use and to focus on perception and comprehension of the verbal and the visual in use of PUs.

\subsection{Visual representation of instantial stylistic use}

Stylistic changes of PUs in pictures is an issue that has long fascinated researchers (for example, Mieder 1989, 1993; Forceville 1991, 1994, 1996, 2008; Naciscione 2001a; Lundmark 2003, 2005; Fiedler 2007; Burger 2008). ${ }^{3}$

Visual instantiation of phraseological meaning is not merely a feature of traditional illustrations. In instantial stylistic use, visual representation of phraseological units performs a different semantic and stylistic function from core use: it enhances and interprets the image, bringing the literal meaning to the fore. Illustrations open up the possibility to make human thought visible, to create a visual effect; they provide food for thought or, as Arnheim puts it, they form visual thinking ([1969] 1997). The picture (Figure 6.2) from Thurber's book The Beast in Me and Other Animals ([1928] 1973:269) is an apt drawing about the nature

2. Visual discourse is a coherent visual representation of instantial use with the aim of creating a visual narrative. In visual discourse, the phraseological image is evoked pictorially with or without a verbal text, and cohesion of phraseological meaning is retained.

3. Another interesting issue is whether the message of the verbal presentation of the phraseological image is influenced by quality and type of visual presentation. This aspect has received detailed attention in Burger's article (2008). Whether there exist more or less effective modifications from the point of view of the recipient is of great importance for the applied field of advertising. However, investigation of the recipient's viewpoint is not the aim of my research (see Burger 2008). 


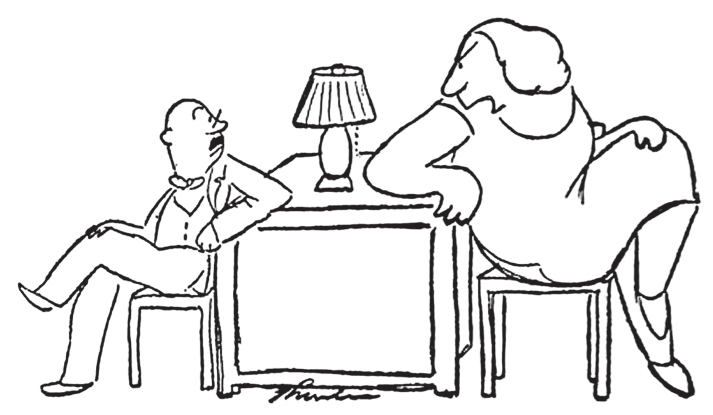

"I'm getting tired of you throwing your weight around."

Figure 6.2 Throwing your weight around

of human beings. Stylistically, it is a visual pun. The caption, coupled with the visual impact, brings out the literal meaning of the constituents of the PU to throw one's weight about/around, ${ }^{4}$ which is metaphorical in its base form. Metaphorical meaning is grounded in bodily experiences. ${ }^{5}$ Together with the visual impact of physical perception, the textual message creates a more powerful stylistic effect. In visual representation, the cognitive link between thought, language, and sight provides a significant insight as we turn from the sense of sight to abstract phraseological meaning. The shift from figurative to literal or from literal to figurative results in a pun. This pattern demonstrates the function of the sense of sight ${ }^{6}$ in mental and visual perception.

It is revealing to follow the ways in which visual and verbal representation can interact within a text, reinforcing the message or creating additional meanings (see Goodman 1996: 38). As a rule, a pictorial illustration follows a stretch of text or appears in the middle of it. Yet it may also precede the text, as is the case in “The Thurber Carnival", bringing the literal meaning to the fore (Figure 6.3):

an old bird

Question. After a severe storm we found this old male raven in the study of my father, the Hon. George Morton Bodwell, for many years head of the Latin

4. To throw one's weight around is an American variant of the PU.

5. "Metaphorical thought is grounded in nonmetaphorical aspects of recurring bodily experiences or experiential gestalts" (Gibbs [1994] 1999: 16). For more on people's everyday bodily and perceptual experiences as part of the fundamental grounding for human cognition and language, see Lakoff ([1987] 1990: xi-xvii); Gibbs (2006).

6. For the importance of a cognitive-linguistic view of the sense of sight in cognition of a literary text, see Popova (2003). 


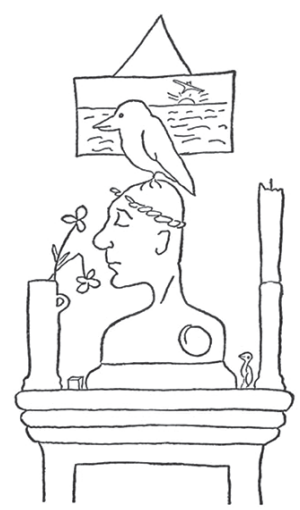

Figure 6.3 The old bird

Department at Tufts, sitting on a bust of Livy which was a gift to him from the class of '92. All the old bird will say is "Grawk!"

Answer. I_am handicapped by an uncertainty as to who s a y s " Grawk", the raven or your father. It just happens that "Arrk" is what ravens say. I have never known a raven that said anything but "Arrk."

J. Thurber, The Pet Department

An old bird is a metaphorical PU used to denote someone who is too experienced, too shrewd to be taken in. The picture of a bird and the question addressed to the Pet Department are non-figurative; they both feature an old raven sitting on a bust in the direct sense of the word. However, the answer involves parallel perception and the reader is simultaneously aware of figurative thought and literal meaning. Phraseological pun is one of the creative uses of PUs which stretches the imagination and conceptualises experiences in figurative terms (see Ch. 4.2). Moreover, the pun has turned visual: the pictorial representation becomes part of the process of change and development of thought in discourse.

The pun calls forth mental visualisation and demonstrates the importance of the sense of sight in mental and visual processing. With the help of the sense of vision, perception secures a link between understanding and sight. It is a perception that derives mainly from the sense of vision and "provides motivated explanation for certain aspects of language structure” (Popova 2003: 135). In cognitive psychology, sight is viewed as a primary sense in cognition; people rely on sight more than on other senses. Instantial use of the metaphorical PU turns into a metaphorical experience of understanding as seeing.

In literary discourse, the visual may be involved in meaning change and development, contributing to figurative networks in discourse. The new visualisation 


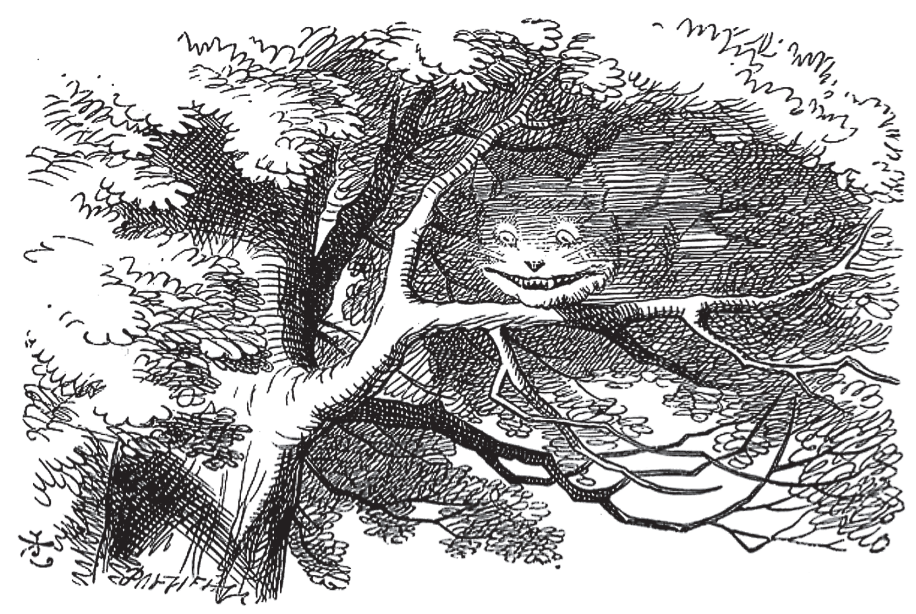

Figure 6.4 A grin without the Cat

becomes part of the mental world. ${ }^{7}$ In Alice's Adventures in Wonderland, Lewis Carroll reiterates the PU to grin like a Cheshire cat both verbally and visually (original illustrations by John Tenniel 1865). The image of the Cheshire Cat appears in three pictures over a stretch of three chapters, sustaining figurative thought. In the first picture, Alice is looking up at the Cat, who is sitting in a tree grinning from ear to ear. The second picture features the famous grin of the Cat (Figure 6.4), which lingers after the Cat has vanished. The third picture presents the Cat's head (Figure 6.5) above the Queen, who is ready to cut off everybody's head, including the Cat's. Her order does not really work as the executioner does not know how to cut off a head without a body to cut it off from. This presentation of an image is a breach of the traditional way of using illustrations in children's books, resulting in "uncommon nonsense" (Carroll 1928:142) typical of the genre of English Children's Nonsense Literature. Visual representation of instantial use is one of the ways of depicting a world of logical improbability.

The famous grin, metonymically standing for the Cheshire Cat, is a verbal and visual extension of a phraseological image (Carroll 1928:80-116), creating a sustained visual pun. In discourse, a phraseological pun frequently pervades a stretch of text and contributes to its coherence and cohesion, as is the case in this text. A dynamic reiterated visualisation of a phraseological image is a technique

7. According to Spiegel, traditional visualisation in literature starts only in the fiction of the 19th century when the "visual perspective moves to the centre of a coherent and fully articulated literary form” (Spiegel 1976:33). 


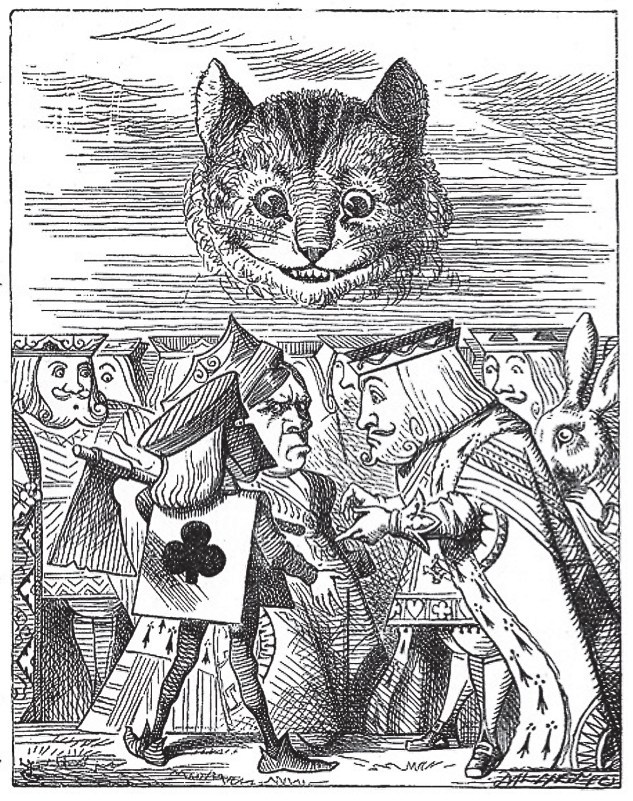

Figure 6.5 The Cat's head

of image development in text; it reveals the potential of visual and verbal sustainability of the PU.

Skilful multimodal use of PUs is common in book covers; for instance, the stylistic pattern of punning is used in the book cover of Reigning Cats and Dogs by Katharine Macdonogh (1999), which offers visual representation of pampered royal pets in paintings and photographs since the Renaissance on both front and back covers, hinting implicitly at the existence of an impressive array of them in royal history. The cover employs replacement of a constituent of the PU to rain cats and dogs, resulting in a homophonic pun: a common technique in book cover design.

Concurrent use of several stylistic patterns is also frequently used in graphic design of book covers. For instance, the cover of Nick Kochan's book The Washing Machine (2005) (Figure 6.6) featuring a washing machine at work, laundering bills, is sufficient to retrieve the base form of the PU money laundering from long-term memory. ${ }^{8}$ The subtitle How Money Laundering and Terrorist Financing Soils Us reinforces and explains the idea. It is clear that a washing machine presupposes laundering. The bills that are being laundered imply that this is dirty money: you do not wash clean things. This is another PU with metaphorical links

8. For stylistic use of the PU money laundering, see Naciscione (2003b, 2006a). 


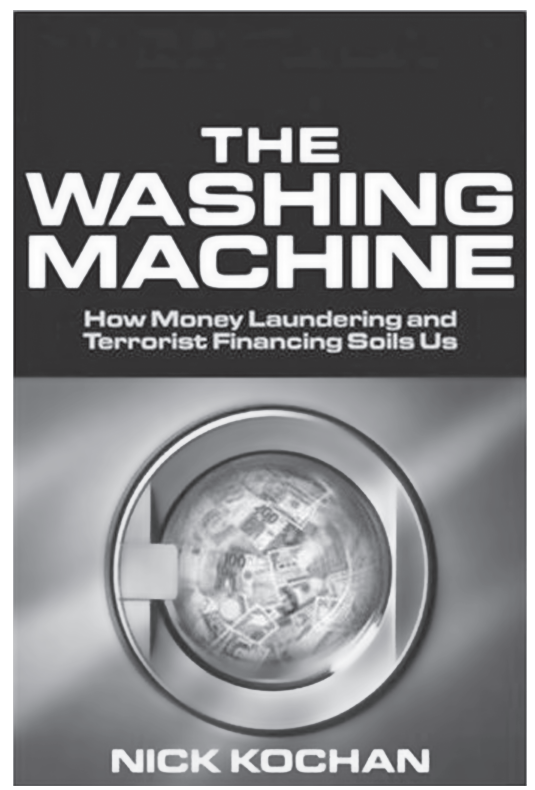

Figure 6.6 The Washing Machine

to the PU money laundering and an extension of the phraseological image: $\underline{\text { soils }}$. Thus, the cover of the book is a visual allusion to the image of money laundering, accompanied by extended metaphor. Concurrently it also resorts to punning, as both the figurative and direct meanings are clear to vision and understanding. Moreover, instantial use of the PU in the title performs an umbrella function, encompassing the whole text of the book (see Ch. 5.5.1).

\subsection{Visual representation in media discourse}

Change and development of phraseological meaning is not merely a feature of illustrations in a literary discourse, as we have seen from Thurber and from Lewis Carroll's Alice's Adventures in Wonderland (a sustained visual pun). Instantial stylistic use is a mode of figuration that is also common to various types of newspaper texts, which easily combine verbal and visual representation in creative thinking. Let me examine the PU to put one's best foot forward, which appears in the headline of a news item The Queen puts her best (bare) foot forward in The Times (22 April, 1999, p. 1). The headline is instantial use due to insertion of the epithet bare, which appears in brackets. This is highly unusual, as the base form never contains brackets. The brackets become a semantic technique. Moreover, the instantial constituent bare brings out the literal meaning of the 


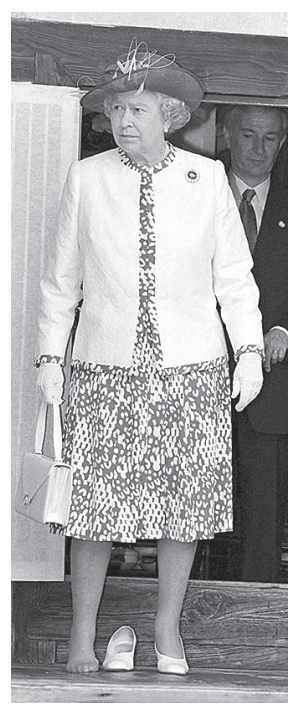

Figure 6.7 The Queen

constituent foot, which results in a phraseological pun as part of the process of semantic change in the instantiation of the phraseological metaphor. The pun is enhanced by a big photograph of Queen Elizabeth with one of her shoes off (with one bare foot) (Figure 6.7).

To put one's best foot forward is a polysemous PU. One of the meanings is "to make the best possible showing" ${ }^{9}$ When the Queen celebrated her 73rd birthday in Korea she had to observe local custom by removing her white court shoes to enter a traditional house in her stockinged feet. The literal meaning of shoes is spread throughout the news item: the Queen is kicking them off and wriggling her feet back into them again. The phraseological pun permeates the text, contributing to its coherence and cohesion.

The last paragraph mentions “the Queen's momentary scowl at being wrongfooted", that is, at being put in an unexpected or difficult situation (Collins Cobuild English Dictionary for Advanced Learners [1987] 2001: 1816). One aspect (having no shoes on) stands for the general feeling of the Queen on being put at a disadvantage. This is a metonymic link achieved by associations of contiguity. The successive change from one figurative mode to another - metaphor - pun - visual pun - metonymy - reveals a complex interaction of different tropes; it is a kind of "narrative strategy" (Gibbs [1994] 1999:454).

9. See Webster's New Universal Unabridged Dictionary ([1983] 1989:713). 


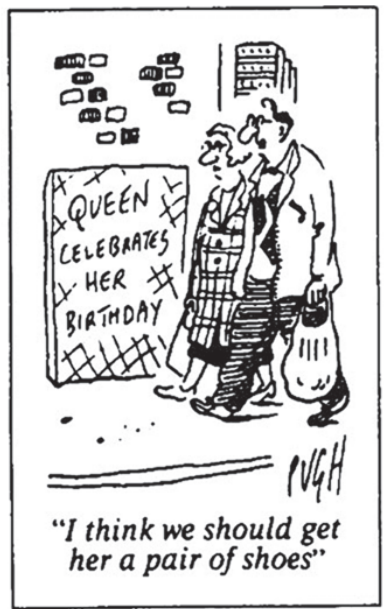

Figure 6.8 A new pair of shoes

The pun is further visualised in a cartoon placed at the end of the news item (Figure 6.8). However, the caption "I think we should get her a pair of shoes" is nonmetaphorical; in this context the cartoon reinforces the visual pun. The sequence constitutes a kind of narrative strategy, which reflects the development of figurative thought and a continual return to literal meanings in the realisation of a PU-based pun. The PU is sustained verbally and visually throughout the news item.

Phraseological metaphors may be visualised and sustained not only in news items and articles of a general type but also in serious specialist articles, as, for instance, the financial article Send Your Money Home in Time (29 September, 1997, p. 44) dealing with interest rates, stocks, and mortgages. The metaphorical focus of the article is the concept home. The idea of home as a desired place to live in is manifest in the use of three phraseological units that share the common constituent home, occurring within the limits of a short article. The first lines read as follows:

Your home has always been your castle, and it used to double as a piggy bank, until a classic late-' 80 s bust crushed the notion of housing as an investment.

Time, 29 September, 1997, p. 44

The article actually deals with the nonfigurative meaning of home, discussing existing homes and house prices and the idea of a house as an investment. The article ends with another PU with the constituent home, creating a frame construction and acting as a coda: 


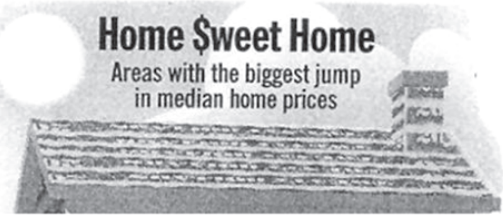

Figure 6.9 Time, 29 Sept., 1997, p. 44

A house as an investment is a pitch that hasn't opened many doors lately. But today, home isn't just where the heart is; it's where the smart money is too.

Time, 29 September, 1997, p. 44

The base form of the PU home is where the heart is has a positive meaning: your true home is in the place you love most. ${ }^{10}$ In the text the PU is used in the opposite meaning. The PU is extended by a parallel construction, which conveys the message of the article: a house is a good investment now. Usually phraseological puns have one or several constituents, which are used in their literal meaning(s). In this case the pun is created through an associative link between a home and a house.

The visual focus of the article is a graphic: a drawing of a house placed in the middle of the article, containing a chart with information on house prices in various states in the USA. As the article is financial, the house is drawn in austere lines, not like the dream house in home adverts. The chart gives the necessary financial information to persuade the reader of a sound investment. It reveals creative thinking as it has an unusual headline: Home $\$$ weet Home placed on top of a roof (Figure 6.9). This is a case of instantial use of a popular PU. The sweetness of home (the dream of a house of your own) is enhanced by a visual representation of the dollar sign $\$$, which is always seen as a symbol of wealth and money. The symbolic meaning is incorporated in the semantic structure of the PU: it becomes part of the meaning of the PU in the given instantiation.

Thus, this newspaper article has made use of three metaphorical PUs containing the constituent home and a symbolic visual representation to reflect semantic development of the concept home. Visual comprehension is facilitated by "metaphor networks" (Trim 2007).

Use of a symbol is one of the visualisation techniques. For identification of instantial graphic implications, it is important to know the cultural background: the use and symbolic meaning of the currency sign. Graphic properties are generally used to represent the extra-linguistic world in an accurate manner. The visual effect works together with the verbal in creation of a visual pun; it is a way in

10. See Cambridge International Dictionary of Idioms (1998: 195). 
which "words, typography and pictures are woven together to form multimodal texts" (Goodman and Graddol 1996:1). The graphic representation is inextricably linked with the content of the article. The symbol \$ performs a semantic function. The visual creation stretches the usual system of typography and affects the relation between the visual and the verbal. Use of the dollar symbol produces a special visual effect that adds a new visual and semantic dimension to the text, a dimension not available in core use. "How elements in visual and verbal modes interact on the page is a central issue in multimodal texts" (Goodman 1996:69), that is, in texts which employ features from more than one semiotic mode of communication simultaneously (Goodman 1996; Kress and Van Leeuwen 1996; Machin 2007; Forceville 2008; Forceville and Urios-Aparisi 2009b). Thus, a merger of verbal and nonverbal communication is a feature of discoursal use of PUs in newspaper texts.

Visual representation of instantial stylistic use is a mode of figuration that also forms part of various types of Internet texts, which easily combine verbal and visual representation in creative thinking, exploiting semantic, stylistic, semiotic, and psychological elements to achieve an economic, political, or social effect. This especially applies to advertising texts, which frequently resort to stylistic use in visual representation due to their persuasive power (see Ch. 7.5). The increasing need for new forms of expression has sought creative sophisticated pathways for representing a message. The visual offers endless opportunities on the Internet, lending a new dimension by further developing and reinforcing the image which the figurative meaning has evoked.

Multimodal metaphor is the most common technique of stylistic use of PUs on the Internet. Let me take one PU and examine a number of its visual representations. For instance, over the last decade the Internet has been teeming with various images featuring the PU money laundering. Though this term is informal as to its stylistic level, it is in standard use in criminal law; for example, the official name of the US law is the Money Laundering Statute. Thus, it is a terminological PU or a terminological phraseologism according to Nikulina (2005). The picture of laundered bills ${ }^{11}$ (Figure 6.10) contains no text or caption. This is a case of creative visualisation of an abstract concept constituted by metaphor. The picture is used to give visual shape to the concept of money laundering, to illustrate a "theory constitutive metaphor", and to help explicate it (Gibbs [1994] 1999: 169179). The visual representation enhances comprehension, which involves parallel perception: the reader is simultaneously aware of the figurative thought in legal language and of the literal meaning.

11. This picture has been taken from the site of St. Kitts-Nevis. See Money laundering is a global problem (2008). 


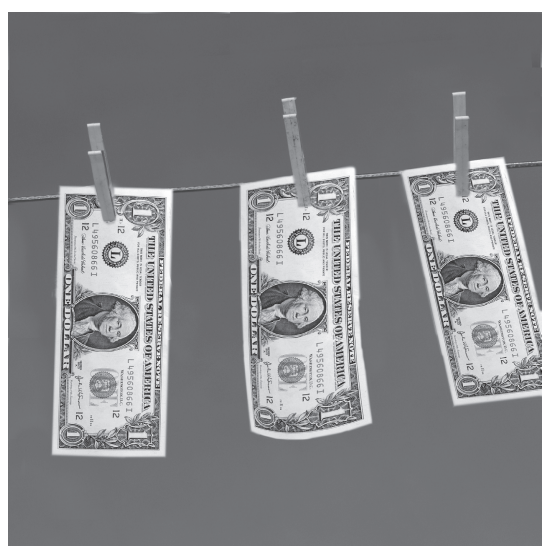

Figure 6.10 Laundered bills

The global culture of using both verbal and nonverbal techniques on the Internet has resulted in multimodal discourse, which resorts to several semiotic modes of expression. ${ }^{12}$ This development is also seen in numerous sites dealing with money laundering and conferences dedicated to it (Figures 6.11, 6.12, 6.13). Use of symbols is one visualisation technique that helps to depict the abstract in terms of the concrete in multimodal manifestations. In Figure 6.11 the dollar sign $\$$ has a special visual effect that adds a new visual and semantic dimension to the phraseological image that would not be available in a standard text.

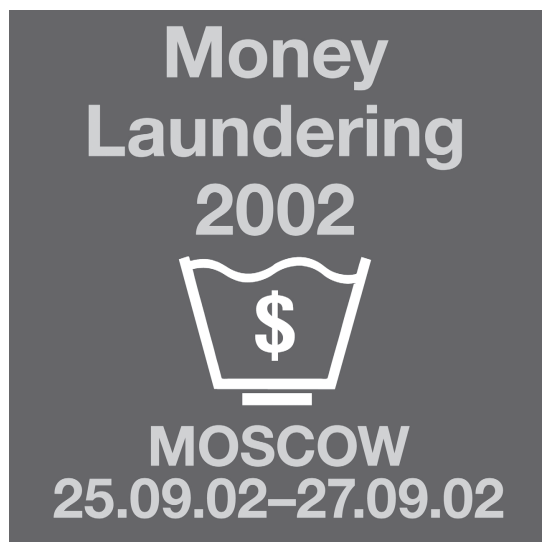

Figure 6.11 Conference on money laundering

12. For the semiotics of advertising see Beasley and Danesi (2002). 


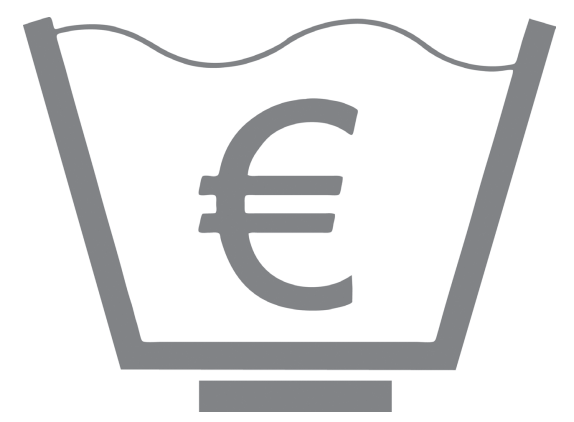

Figure 6.12 Logo of money laundering

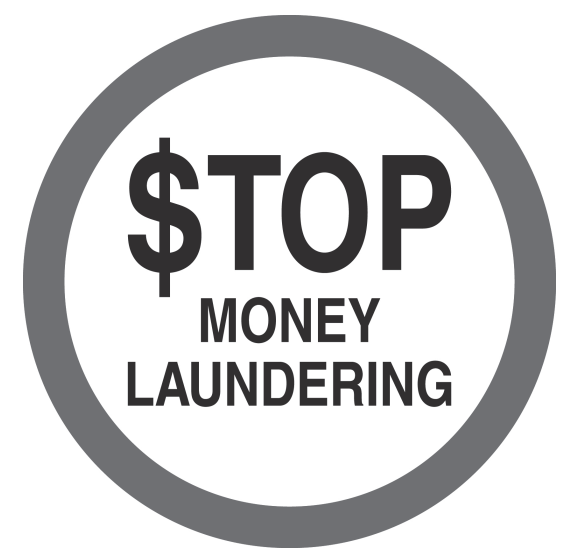

Figure 6.13 \$TOP!

A further development of the image of money laundering has resulted in a logo (Figures 6.11, 6.12), featuring a washtub with a currency sign in it. The graphic of the washtub provides a metonymic link to laundering; thus in this instantiation, metonymy is one of the aspects of "meaning construction" (Gibbs 2003:27-40; Panther 2005:353; Barcelona 2007; Gibbs 2007:20-28). Metonymy brings out the role of visual representation in the extension of the image of a metaphorical PU. This logo is frequently used for conferences and specialist websites devoted to money laundering. Numerous conferences have been held on money laundering in the EU, hence the euro $€$ symbol. For identifying instantial visual implications, knowledge of the social and cultural background, including the meaning of symbols, is essential.

Visual representation frequently resorts to use of semiotic elements due to their clear-cut graphic persuasive power. In Figure 6.13 the symbolic meaning 
is incorporated in a modified STOP sign, a command to terminate the activity. ${ }^{13}$ The graphic also contains the dollar sign $\$$, which is perceived as a symbol of money. Thus, multimodal enactment of phraseological image is another mode of presenting the message and visualising thought. Textual information is supported by pictorial perception. Semiotic elements help to retrieve and visualise the phraseological image. This determines the significance of multimodality in meaning construal and interpretation of a pictorial metaphor (Forceville 2008). The visual effect works together with the verbal in creating a visual pun.

\subsection{Implicit visual messages}

Visual representation of a phraseological image may convey implicit messages that are not directly expressed in text. This instantiation (Figure 6.14) is a case of concurrent visual and verbal allusion. Nonverbal representation beats the expected images of two well-known British political leaders: Tony Blair and Duncan Smith. If you take a look at the newspaper page, actually the first thing that strikes you is a black eye on each face in the literal sense of the word. "Perceiving is also thinking", Arnheim argues ([1954] 1974:5). The thought of an accident or a simultaneous personal assault is quickly discarded as you start reading the article. The two leaders have not been beaten physically but politically or rather metaphorically. The figurative meaning of a black eye (PU) comes to the fore: a defeat, rebuff, severe blow. ${ }^{14}$ The visual conveys the acute pain of failure: the pain of having been defeated. The first paragraph gives a verbal clue by way of extended metaphor: "Duncan Smith and Blair were b at te re d by Brent. Tom Baldwin and Greg Hurst ask whether this is a breakthrough, or just another by-election blip" (The Times, 20 September, 2003, SL, p. 4M). In fact, the two leaders metonymically stand for their political parties (Labour and Conservative) which had failed to win the by-election.

The instantiation reveals the interconnection of stylistic techniques: it shows how a phraseological metaphor turns into a visual pun. The base form of the metaphorical PU a black eye appears neither in the text of the article nor in the headline, nor indeed is a caption present. "PUs can be visualised without mentioning a single constituent" (Fiedler 2007: 104). However, we feel the absent presence of the PU. Interpretation of the text and of the picture heavily relies on knowledge of the PU a black eye, its figurative meaning, and the logical and indissoluble

\section{See Satcor Report on International Conference "Stop Money Laundering" (2002).}

14. Dictionaries give two meanings of a black eye - direct and figurative: (1) a discoloration of the skin around the eye; (2) (fig.) defeat, rebuff, heavy blow, failure (Kunin 1967a:294; Merriam-Webster's Online Dictionary 2009; Oxford English Dictionary 2009). 


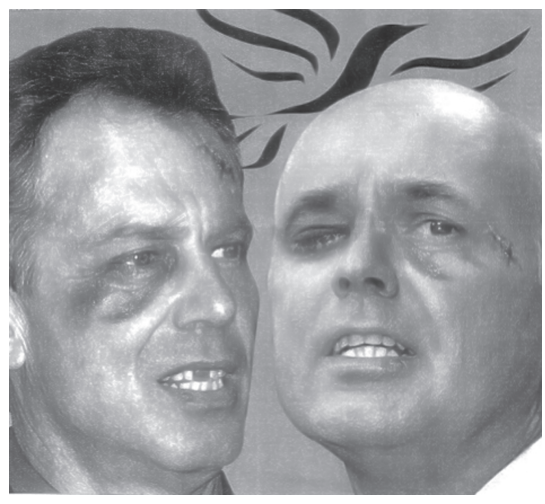

Figure 6.14 The Times, 20 Sept., 2003, SL 4M

link between the visual and the textual: it is implicitly present. Visual and verbal meanings are concurrently integrated in one phraseological metaphor: the physical black eye turns into a metaphorical black eye. Both the Labour and the Conservative leaders feel assaulted by the Liberal Democrats who won the by-election in Brent in 2003. The visual pun spans the whole of the article. The word at t a ck is reiterated throughout the lengthy article to uphold the battered effect in visual representation and provide further extension of the metaphorical thought. Metaphor permits a new and subtle understanding to emerge, hence the role of "perceptual experience and imagery" in metaphor comprehension (Paivio and Walsh [1979] 1998:312). The metaphorical experience reveals the importance of mental sight in the perception of abstract notions, while physical sight implies a perceptual awareness which aids comprehension of figurative language. In this case it is the instantial use of a metaphorical PU, in which visual pun is combined with extended metaphor, resulting in an allusion.

Use of photomontage involves a new medium to express figurative meaning in multimodal discourse. The technique creates a composite photograph: two photos combined in one picture, realised by image-editing software. Moreover, the technique of photo manipulation is also used: alterations are introduced to create a new modified image and develop the base metaphor of the PU.

Thus, visual representation is a technique of expressing an implicit message and sustaining figurative thought, provided the basic principle remains: cohesion and coherence of the verbal and the visual. Cases of multimodal use call for both imagination and a creative approach in their instantiation and for more advanced cognitive skills in inference and interpretation. 


\subsection{A discourse dimension}

Another interesting aspect of visual representation is the visual development of figurative meaning. Let me turn to an example of verbal and visual extension of phraseological meaning as represented in Mark Twain's humorous sketch $A$ Burlesque Biography. The meaning of the PU a family tree is based on a common metaphorical mapping. In its base form the PU is a conventional phraseological metaphor, available to users of English. First the PU appears in core use, that is, in its most common form and meaning. As the example shows, no change occurs in phraseological meaning in the text; the figurative thought is not developed, nor is it sustained:

\section{a family tree}

Then for the next two hundred years the family tree shows a succession of soldiers - noble, high-spirited fellows, who always went into battle singing, right behind the army, and always went out a-whooping, right ahead of it.

Mark Twain, A Burlesque Biography, p. 178

In cognitive psychology the image is generally viewed as a mental representation, as a picture in the head. As Steen points out, when processing metaphors, readers are able to construct at least three different kinds of mental representation: linguistic representation of the meaning of a metaphor, conceptual representation of the referential content, and communicative representation of the message it is attempting to convey (Steen 1994: 168).

In discourse, a phraseological image may be sustained over longer stretches of text (see Ch. 3.4), as it is in this sketch. The next paragraph contains instantial stylistic use. Creative expression of a new idea is achieved by instantiation of an extended metaphor. The metaphorical meaning is extended, creating sub-images which become part of the associative metaphorical network sustained on the basis of the image of the PU:

This is a scathing rebuke to old dead Froissart's poor witticism that our family treenever had but one limb to it, and that that one stuck out at right angles, and bore fruit winter and summer. Mark Twain, A Burlesque Biography, p. 178

If the PU a family tree is in core use, it has only one meaning - a scheme of one's genealogical succession of ancestry. The base metaphor stems from similarity and affinity of the two objects, i.e., both have a trunk and branches. In the given context only one branch or limb is singled out, the only one which stuck out at right angles, and bore fruit winter and summer. This metaphorical extension is actually 


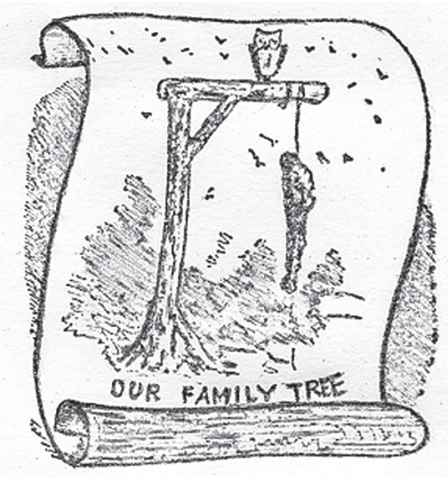

Figure 6.15 Mark Twain, A Burlesque Biography, p. 178

an allusion to another PU - a family (fruit) tree. ${ }^{15}$ The words poor witticism act as a cue, prompting and supporting the metaphorical network. Through instantial use, the PU a family tree acquires the meaning of "a gallows" and turns into a contextual euphemism, resulting in euphemisation of the text. This meaning becomes the semantic centre of the sketch. It practically covers the whole sketch (Twain 1961:178-182), thus sustaining metaphorical thought.

Discourse comprehension and analysis imply identification of instantial metaphorical meaning, determined by the thought expressed. Instantial use of phraseological metaphor is one of the ways to reflect a novel turn of thought in discourse. The image of the family tree has been extended and we see it in our mind's eye: we imagine it by forming a mental image. It is what I would call mental visualisation. Actually we have to visualise each time we perceive or think of an image. We visualise figurative meaning in our thoughts, as thought and imagination go together, creating a mental picture, even if the text contains no visual representation.

In the sketch the extended metaphor of the family tree is followed by a pictorial illustration. The visual lends a new dimension: it further develops and reinforces the image which the figurative meaning has evoked.

This is not an illustration of the base form of the PU as it can be found in a dictionary entry; it is a case of creative visualisation (Figure 6.15). The visual is, as it were, a continuation of the verbal text. The possibilities of novel extensions of metaphor in text have been pointed out by many pre-cognitive and cognitive linguists, usually illustrated by a sentence or two (Boldireva 1967; Shadrin 1969; Naciscione 1976; Lakoff 1986; Mena Martínez 2003; Arsentyeva 2005, to name

15. A family (fruit) tree - a fruit tree bearing different varieties of the same fruit grafted on to it (Chambers 20th Century Dictionary [1983] 1987:455). 
but a few). However, the visual offers new opportunities. Visual representation of instantial meaning enhances, develops, and sustains thought and language. Thus, visual representation is a means of sustaining a figurative thought.

The textual information is supported by the pictorial perception. The drawing helps to bring out one of the metaphorical meanings of the second constituent of the PU tree (which is a polysemous word), namely, "a gallows" (Webster's New Universal Unabridged Dictionary [1983] 1989: 1945). Another dictionary formulates this meaning as follows: "a device used to hang a person, has one upright post and a projecting crosspiece” (New Webster's Dictionary 1988: 1642). By punning on the two meanings of the constituent tree, Mark Twain extends the image of the base metaphor. The semantic role of visual representation lies in developing and extending figurative meaning. The illustration speaks a visual language of its own, accentuated by the caption OUR FAMILY TREE, which acquires the effect of a coda. The accent falls on our, emphasizing the uniqueness of the instantiation. Thus, understanding discoursal metaphors requires "extended and attentive focus processing" (Steen 1994:245). For full understanding of metaphor in use, both verbal and visual comprehension is important, together with conceptual knowledge.

The PU a family tree is further extended in the sketch, creating a metaphorical chain, which calls for a sustained mental vision in one's mind's eye:

I will remark here, in passing, that certain ancestors of mine are so thoroughly well-known in history by their aliases, that I have not felt it to be worth while to dwell upon them, or even mentioned them in the order of their birth. Among these may be mentioned Richard Brinsley Twain, alias Guy Fawkes; John Wentworth Twain, alias Sixteen-string Jack; William Hogarth Twain, alias Jack Sheppard; Ananias Twain, alias Baron Münchausen; John George Twain, alias Captain Kydd; and then there are George Francis Twain, Tom Pepper, Nebuchadnezzar, and Baalam's Ass - they all belong to our family, but to a branch of it somewhat distinctly removed from the honorable direct line - in fact a collateral branch, whose members chiefly differ from the ancient stock in that, in order to acquire the notoriety we have always yearned and hungered for, they have got into a low way of going to_jail instead of getting hanged.

Mark Twain, A Burlesque Biography, p. 182

With the sub-image of a collateral branch that is distinctly removed from the honourable direct line Mark Twain establishes a semantic and stylistic tie with the base metaphor of the PU. Semantic and stylistic cohesion and coherence are enabled because PUs are stable, cohesive word combinations with a figurative meaning. The extended phraseological metaphor is sustained across five pages. 
The sub-image conveys a new instantial euphemistic meaning. However, only at the very end of the paragraph does the non-euphemistic meaning "hanged" appear as a sudden revelation of the plain and bitter truth, underscoring the meaning of the instantial metaphor - a gallows, which remains at the centre of events described in the sketch. The final paragraph contains a reiteration of the non-euphemistic hanged:

My own history would really seem so tame contrasted with that of my ancestors, that it is simply wisdom to leave it unwritten until I am hanged.

Mark Twain, A Burlesque Biography, p. 182

The sketch reveals how the base metaphor of the PU a family tree undergoes instantial semantic and stylistic changes in discourse: it is extended across the whole sketch to sustain figurative thought. The extended metaphor is also linked with other stylistic features - pun and euphemism. In cognitive processes figures of thought are combined, they interact with each other. Individual tropes are "functionally related to each other to provide figurative coherence to the text that cannot be explained merely in logical or causal terms" (Gibbs [1994] 1999:454). They also provide semantic and stylistic cohesion. In discourse the language becomes alive, new meanings are created and sustained. It is essential to develop an understanding of the discoursal dimensions of phraseological metaphor, including visual discourse. Extended phraseological metaphor is enhanced and developed by a pictorial illustration of the instantial image to create a visual impact. This is a case of visual sustainability. The example shows that extended phraseological metaphor is used to reflect extended figurative thought.

Visual representation of stylistic use has not exhausted itself. Further development of media and multimodal possibilities offers interesting new turns in visual discourse. Identification and interpretation of stylistic use in multimodal texts is more challenging. Interaction between the visual and its verbal counterpart has "a perceptual immediacy" that is lacking in language alone (Forceville 2008:463). It is common for magazines to use a PU on their cover and pick it up again in the cover story, which may be pages away. The title of the cover page catches the eye. However, only the interrelation between the two modes of expression provides a full understanding of the multimodal text. For instance, the cover page of Time (Europe edition, 18 December, 1989) contains both visual and verbal allusion to the PU to hang by a thread (Figure 6.16).

The cover is in three colours: the top is black, the middle is red, and the lower part is yellow: these are the colours of the German flag.

Moreover, the picture also features the symbol of East Germany. As it is hanging by a thin tattered thread, instead of the thick rope, it happily transforms into the flag of the Federal Republic of Germany in case of a fall. As we know, it turned 
The cover page

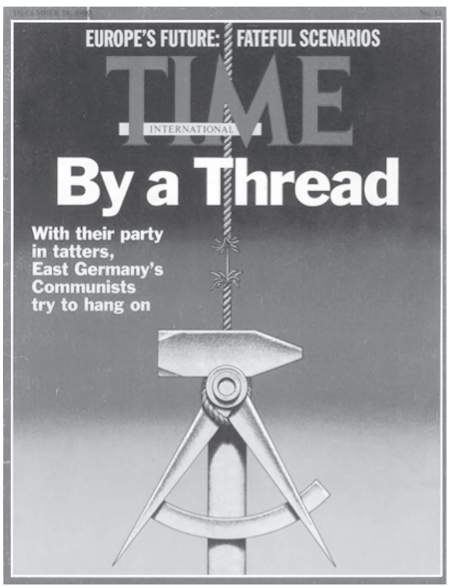

Text of the cover page

By a Thread

With their party

in tatters,

East Germany's

Communists

try to hang on

Figure 6.16 Time, Europe edition, 18 Dec., 1989

out to be the fatal thread for East Germany, and the symbol has luckily disappeared from the flag.

The fatal fall of East Germany is inevitable. The title of the cover page "By a Thread" is an allusion to the PU to hang by a thread. In its base form the PU is a conventional phraseological metaphor. However, in this instantiation the figurative thought is sustained further in the text, as we see from the subtitle and the cover story itself (pp. 10-14). The subtitle extends the metaphor: "With their party in tatters, East Germany's Communists try to hang on”. The first line at the top of the cover page "Europe's Future: Fateful Scenarios" acts as a cue to the precariousness of the situation. Thus, extended metaphor is linked with the pattern of allusion.

The cover story starts ten pages later. However, its headline Slender Thread, which is also an allusion to the PU to hang by a thread, establishes an immediate associative link with the phraseological image on the cover of the magazine. The article discusses the situation in 1989 when the power of East Germany was precariously hanging by a thread in a regime whose legitimacy was rapidly crumbling, despite the Communists trying to hang on. On page 12 appears a photo of Egon Krenz, the Head of State of East Germany. The caption underneath his photo reads: "Krenz after the fall: all efforts to hang on were doomed". He looks hopeless and crestfallen. "Despite his humiliation and loss of power, Egon Krenz hung on to the largely ceremonial office that traditionally went along with the party chairmanship. But his position there was also doomed" (p. 12). Extended phraseological ties sustain the visual impact. It is the phraseological image that 
bridges the distance and establishes the semantic and stylistic link between cover page and cover story. The text-forming function of metaphorical networks (see Ch. 3.2) is also manifest in the use of visual representation. The phraseological image is extended over the whole article, and the sub-images form part of the associative metaphorical network. Cohesion secures continuity of phraseological ties in discourse, including visual representation. Visualisation is an essential structure of narrative as we "think and feel through our eyes" (Spiegel 1976:25).

Metaphor, pun, and allusion do not work independently; they are functionally related to each other. ${ }^{16}$ This is concurrent use of several stylistic patterns within the context of one PU, providing semantic and stylistic cohesion (see Ch. 5.3). Visual comprehension is facilitated by the metaphorical context. Understanding the functional load of both visual image and language helps to bridge the cognitive gap between the textual and the visual, as they cannot be viewed separately. For instance, The Spectator often uses a phraseological image in the design of its cover. This visual representation goes back to 10 January, 1998 (Figure 6.17). Modern psychological research on perception has revealed the worth of pictures in communicating thought, which is enshrined in the well-known proverb a picture is worth a/ten thousand words (Mieder 1992:463) as part of popular wisdom in the modern age. ${ }^{17}$ A pictorial representation helps us to draw inferences as the eye is involved in active exploration. It is a visual experience in an attempt to establish the base form, which in this case does not appear anywhere - either on the cover of the magazine or in the text of the article or its title.

Visual perception, backed by semantic and stylistic analysis, allows us to draw the conclusion that the visual representation in Figures 6.17 and 6.18 is a case of concurrent visual and verbal allusion to the PU to skate on thin ice. The subimage spin, which is graphically presented on the ice, is a term in figure skating, while at the same time it is an extension of the base metaphor of the PU, creating a visual pun. Skating and spinning are linked metonymically, and they both constitute a single extended metaphorical image (see a verbal extended metaphor of the PU to skate on thin ice in Ch. 4.1). Concurrently, spin is also a direct allusion to another PU, a spin doctor, a PR professional who specialises in spin tactics to manipulate public opinion and provide a favourable bias. The meaning of the PU to skate on thin ice is enhanced by the ominous headline Heading for trouble on the front cover. The cover story

16. For more on use of several tropes working together in natural language, see Gibbs ([1994] 1999:449-454). For concurrent use of stylistic techniques in phraseological instantiations, see Naciscione (1976: 160-180); Ch. 5.3 of this book.

17. For a discussion of the verbal and visual potential of this proverb, see Mieder (1993: 133-149). 

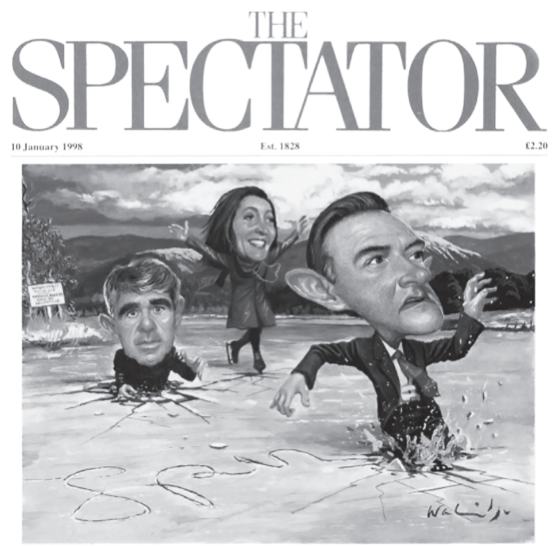

Jenny McCartney on the PR industry

Heading for trouble

Figure 6.17 The Spectator, 10 Jan., 1998

\section{SPINNING OUT OF CONTROL}

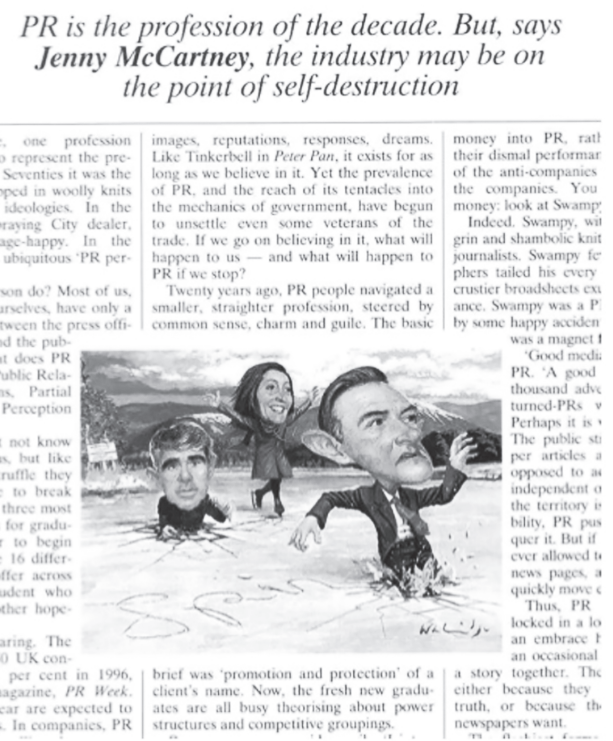

Figure 6.18 Spinning out of control, p. 8 
appears on Page 8; its title Spinning out of Control (Figure 6.18) forms part of the extended metaphor, creating a new meaning and reflecting further development of metaphorical thought. With the images of Alastair Campbell and Peter Mandelson in the foreground, spinning out of control illustrates the idea of the PR profession on course to self-destruct.

Creative expression of a new idea is achieved by an instantiation of extended metaphor, pun, and allusion in a process of meaning extension in one visual context. The visual implications of the pun help to shift from direct meaning to figurative meaning and back again. The sustained visual image becomes part and parcel of the meaning of the PU in the given instantiation. The abstract idea has been translated into visual form to render a hazardous situation. Thus, the visual representation becomes a genuine part of the concept of risk. The textual and visual representation of a thinking process is profoundly influenced by political, social, and cultural processes that lie behind the specific space and time, that is, the context.

The process of understanding and interpreting meaning requires "cognitive effort that takes place in real time, starting with the first moments when people move their eyes across the page" (Gibbs 1999a: 15). In this case it refers to both the visual representation and the headline, which attract the reader's attention. "Interpretation involves both conscious and unconscious mental processes" (Gibbs 1999a:331). I follow Arnheim in believing that "visual perception is an active concern of the mind" ([1969] 1997:37); hence, the importance of stylistic awareness and training the discerning eye.

\subsection{Visual literacy as a cognitive skill}

Stylistic use in multimodal texts is more demanding in identification and interpretation. It is important to understand figurative language and see its connection with visual representation. Let me have a look at another example of visual representation. This is a creative instantiation of visual allusion in a serious financial text. The allusion is to the base form of the PU to put all one's eggs in one basket (Figure 6.19). Importantly, with no textual presence of any of the base constituents the visual impact becomes the key to comprehension. Visual allusion is achieved as the PU is retrieved from long-term memory and we establish the base form. Eggs and basket are the implicit verbal elements of the PU, while at the same time they constitute the explicit visual presence of the phraseological image. Verbal absence turns into a presence due to visual representation. Emergence of the figurative meaning of the PU vis-à-vis visual representation of the literal meaning of eggs and basket results in a visual pun. The dual perception is 


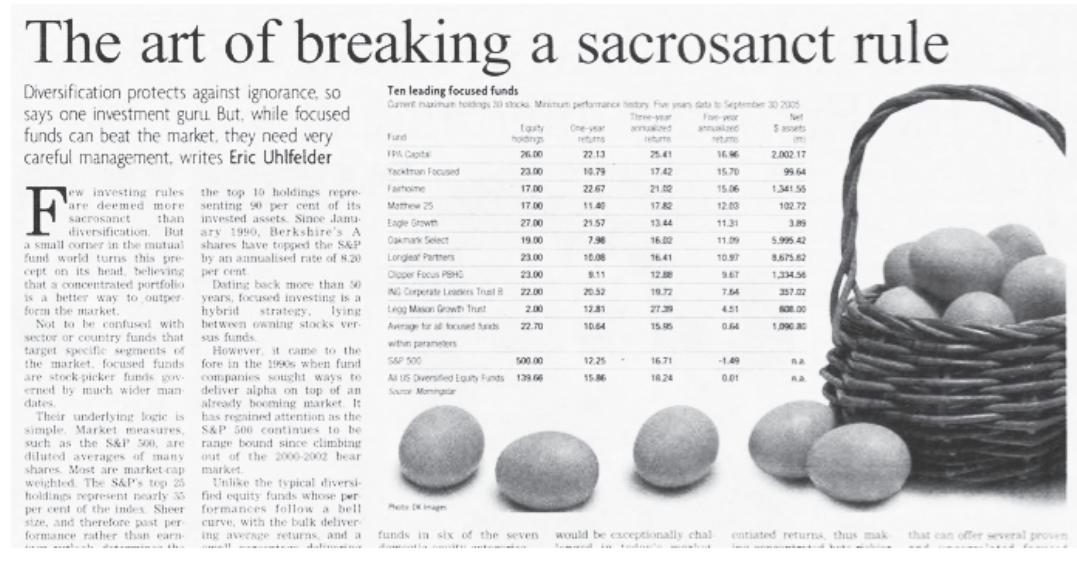

Figure 6.19 Financial Times, fm, 28 Nov., 2005, p. 3

enhanced as these constituents have been visually foregrounded ${ }^{18}$ in the article: you cannot miss the eggs and the basket when casting an eye on the page. The implicit presence of the invisible base form is indispensable to secure comprehension. Eggs and basket have also been psychologically foregrounded, turning into figurative constituents of the PU in our mind due to the natural perceptual link between sight and thought.

The headline The art of breaking a sacrosanct rule provides an important cue; it acts as a response-producing stimulus. Breaking plays a dual role: it is the explicit metaphorical break as part of to break a rule with insertion of the highly appropriate epithet sacrosanct, while at the same time it is also a subtle metaphorical sub-image in an allusion to the implicit PU. Breaking is the only textually visible link to the base form, providing associations of contiguity. As the article is devoted to the art of breaking the inviolable investment rule of diversification of equity funds versus focused funds, breaking is inevitably part of both breaking a sacrosanct rule and the danger of putting all one's eggs in one basket.

Although cognitive linguistics has it that "figurative language does not require special cognitive processes to be produced and understood" (Gibbs [1994] 1999: 17), in visual representation the process of perception and comprehension may be a pursuit of hidden connections and cohesion of the textual and the visual, which is especially important in language teaching. Recognition and interpretation of a creative representation may be cognitively challenging for L2 learners. Experience has it that understanding cohesive ties is crucial for comprehension,

18. For a detailed analysis of the theory of foregrounding and its stylistic and psychological aspects, see van Peer (1986). For features of prominence that differentiate the figure from the ground, making it more salient, see Stockwell (2002:14-15). 


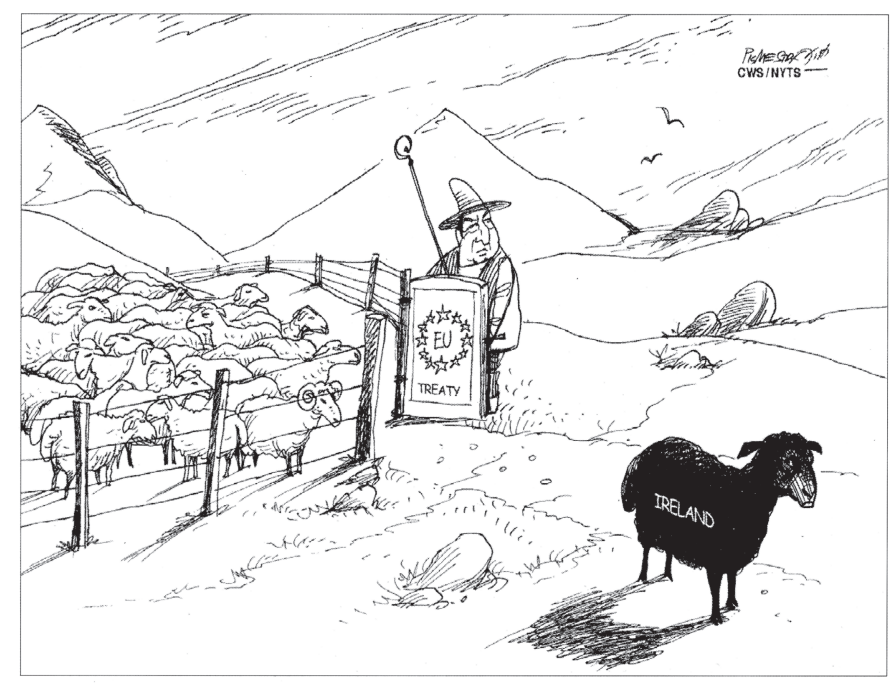

CARTOON BY PISMESTROVIC, KLEINE ZEITUNG, AUSTRIA @ CAI/NYT SYNDICATION

Figure 6.20 P. Pismestrovic, Kleine Zeitung, Austria, 20 June, 2008

while failure to recognise cohesion and insightful associative links leads to misinterpretation. The natural desire to understand leads to the link between the eggs and the basket, and breaking the sacrosanct rule of risk management. The link between the visible and the invisible is a dimension that allows us to gain an insight and draw inferences. The visible spurs our imagination and helps us to conceive the phraseological image, which is sustained throughout the text. It lingers at the back of our mind as the article explores the alternative of focused funds versus the traditional piece of financial wisdom not to put all your eggs in one basket.

Cognitive psychologists see visual perception as a cognitive activity. The human mind perceives and interprets the image with all its conscious and unconscious powers (Arnheim [1954] 1974:461) to establish the message and resolve the subtle complexity of the situation, using available linguistic and background knowledge. A semantic and stylistic tie is established with the base metaphor of the PU, although it does not appear in the text. Visual discourse is an interesting "perceptual experience" (Gibbs [1994] 1999:79) as we feel the invisible presence of the PU in the face of the visible absence of its base form.

To understand the following case of visual allusion (Figure 6.20), we need encyclopaedic knowledge of the political strife in the EU over the Lisbon Treaty. The second Irish Referendum (02.10.2009) reversed the decision of the first (12.06.2008), and the stray Irish sheep has returned to its flock. The available textual information is scanty: the name "Ireland" on the straying black sheep and "EU Treaty" on the pasture gate with twelve stars as a symbol of the EU. 
Visual perception supported by this information leads to identification of figurative meaning and the base form: there is a black sheep in every flock $>$ the black sheep of the family $>$ a black sheep. However, as Mieder points out, a decontextualised proverb is meaningless for all general purposes; it is the metaphor of the proverb that enables us to employ proverbs in so many different contexts, including advertisements and cartoons (Mieder 1989:20-21). ${ }^{19}$ The same applies to all PUs. In order to disambiguate the instantiation, it is essential to have a good knowledge of both the language stock and figurative means. Comprehension of the figurative links between the visual and the verbal is a cognitive act, as is creativity; hence the importance of visual literacy as a cognitive skill. ${ }^{20}$ Visual literacy is fundamental to understanding the coherence and cohesion of the visual and the textual.

On the other hand, a new instantiation is enabled due to use of the PU as a language unit and a pattern of instantial stylistic use, such as pun, extended metaphor, or allusion. To be creative implies going beyond standard form and meaning, and beyond conventional vision. When exploring creativity, Pope shows that creativity emerges every time some existing language material (words, images, sounds) is transformed into something judged to be fresh and valuable. Creativity does not come from nothing or from nowhere; it embraces "radical forms of recreation and includes actively engaged kinds of re-vision, re-membering and refamiliarisation" (Pope 2005:xvii). Moreover, visual discourse calls for new ways of both creation and interpretation. "Multimodal texts demonstrate linguistic and artistic creativity, and creative multimodality reveals how language functions" (Goodman 2006: 244).

In conclusion, this chapter takes a closer look at the creative aspects of verbal and visual representation of phraseological image in multimodal discourse. The image-bearing constituents of phraseological units lend themselves very well to creative textual and visual representation, including abstract qualities and implicit messages. The phraseological image is sustained as thought develops, contributing to creation of a visual narrative. The visual reflects experience beyond the possibilities offered by a text. The cognitive approach promotes comprehension and interpretation of phraseological metaphor in verbal and visual discourse and brings out its role in the communication of figurative thought. Mental visualisation of instantial stylistic use forms part of cognitive performance, enhanced by visual

19. Innovative stylistic alterations are common in use of traditional proverbs, as is also seen from the rich collection of Wolfgang Mieder's international archive of proverbs in Burlington, Vermont (Mieder and Litovkina 1999:3).

20. By visual literacy I understand the ability to perceive, comprehend, and interpret visual representation of language. 
representation of the extended image. Visualisation is a reflection of figurative thought. I would argue that phraseological metaphor occurs not only in thought, language, and visual representation; it also occurs in its perception. Visual representation of a phraseological image engages both the eye and the mind.

Comprehension and interpretation rely on cohesive ties between the visual and the verbal. Visual literacy is a cognitive skill which advances sociolinguistic competence: the ability to perceive, comprehend, and interpret the stylistic, social, and cultural message of a visualised phraseological image. Skills of visual literacy have become increasingly important as the nature of pictures has changed. Pictures do not merely illustrate the text or emerge as an afterthought; they frequently provide further development of thought. Training a discerning eye in stylistic awareness enhances our cognitive abilities for mental representation and processing.

Visual representation of PUs is a less examined mode of their stylistic use. Exploration of phraseological metaphor in nonverbal expression opens up new pathways and makes a good case for including studies in this field in general research on phraseology. 

PART II

Towards applied stylistics 



\section{CHAPTER 7}

\section{Applied stylistics and instantial stylistic use}

In the previous chapters the emphasis has been on the theoretical aspects of stylistic use of PUs in discourse. However, it is also important to explore the practical worth and application of this theory. I will attempt to demonstrate the usefulness of the concept of instantial use in various areas of applied stylistics.

\subsection{The rise of applied stylistics ${ }^{1}$}

The past decades have witnessed an increasing interest in stylistics and related areas, including different pragmatic aspects and implications. Innumerable publications and many international conferences have explored the interface of language and style in actual use.

Teaching literature in the classroom as part of language teaching is the area which has received most attention. Today literary texts are recognised as an important vehicle for raising language awareness and training. This applies not only to lexical and grammatical accuracy, but also to literary awareness ${ }^{2}$ and stylistic sensitivity. A stylistic insight helps to foster comprehension going beyond the surface meanings of words and reading between the lines of spoken and written discourse (McRae and Boardman [1984] 1989).

Several trends in the development of stylistics have emerged over recent decades. Contextualized stylistics has a special focus on the contextual aspect, exploring the relationship between language and context, and viewing contextual elements of literature as an aid to interpretation. This approach has created many valuable studies of individual works of literature (Fowler 1966, 1975, 1981;

1. The Oxford Handbook of Applied Linguistics (Kaplan 2002:3-515) sees applied linguistics as a new area of research; Grabe calls it "an emerging discipline for the twenty-first century" (2002:3-12). It is surprising that the handbook does not deal with application of the stylistic competence of the language user in any area at all, which means that applied linguistics does not include applied aspects of stylistic use in the understanding of the authors.

2. For literary awareness, see Zyngier (1994, 1999:35). She argues for the emergence of a new discipline - Literary Awareness - and shows how it can be beneficial to L2 students (Zyngier 1994: 95). 
Verdonk 1993, 2002; Verdonk and Weber 1995; Short and Verdonk 1998; Bex, Burke and Stockwell 2000). Discourse stylistics focuses on use of language and the stylistic features essential for understanding and appreciation of longer stretches of text (Carter and Simpson 1989; McRae [1987] 1990; Cook 1994; McCarthy and Carter [1994] 1995; Carter 1996: 1-15; Emmott [1997] 1999 et al.). Pedagogical stylistics has emerged to view the teaching of literature from the pedagogical standpoint (Bex 1988; Short [1988] 1992; Carter and Nash [1990] 1995; Carter and Long 1991; Widdowson 1992; Zyngier 1994, 1999, 2000; Carter 1997; Clark and Zyngier 2003 et al.). Cognitive stylistics is interested in the interaction between thought and language, figurative use of language, construction of new meanings and forms, and other cognitive aspects of language use (Lakoff and Turner 1989; Steen 1994, 2006; Semino and Culpeper 2002; Gavins and Steen 2003; Semino 2008 et al.). Steen argues for "emerging concerns with metaphor in applied linguistics" ([2007] 2009:402). Interest in stylistics and new developments in it persists, as is shown by publications and conferences of the 21 st century.

However, literary text analysis is not the only area for application of stylistic understanding, knowledge, and skills. A distinct need exists for applied stylistics, as stylistics may be applied for many purposes, not only in literary analysis, as has traditionally been thought. New possibilities for applying stylistics are being discovered in a number of areas, as this chapter reveals.

I would argue that applied stylistics is another field of special interest. This focus poses a new challenge as applied stylistics needs to be defined and developed as a distinct area. I would propose the following definition. Applied stylistics is an area which explores practical use of the principles, discoveries, and theories of language, literature, and stylistics, including cognitive stylistics. It is an umbrella term which denotes application of the stylistic competence of the language user in the fields of teaching, curriculum design, translation and interpreting, lexicography, glossography, compilation of notes and comments on literary texts, socio-cultural studies, ${ }^{3}$ visual representation, advertising, and marketing. Theoretical contributions of cognitive stylistics have provided cognitive insights in practical applications, especially the study of texts (literary, non-literary) and multimodal representations, and established a new way of thinking and viewing stylistic techniques as patterns of thought in language. Applied stylistics extends

3. The aim of socio-cultural studies is to enhance social, cultural, and linguistic understanding (Canale 1983; Bex 1988; McCarthy and Carter [1994] 1995; Carter 1996, 1997; Wierzbicka 1997; Skandera 2001; Pope 2005; Sabban 2006). Cognitive linguistics focuses on connections between language, mind, and culture (see, for instance, Kövecses, 2005, 2006; Gibbs 2008: 197 307) while phraseology explores PUs across languages and cultures (see, for instance, Granger and Meunier [2008] 2009b: 191-309; Szerszunowicz 2008). 
our understanding of the role of stylistic use, offering a wider perspective, creating awareness of the presence and operation of stylistic features, and modifying the views and principles underlying teaching and curriculum design. Emphasis on the applied value of a stylistic approach is of great importance when developing teaching materials based on the study of both literary and non-literary texts. A stylistic approach is also essential for skills training in various applied areas and developing stylistic awareness of creative instantiations of figurative language in general and PUs in particular.

In stylistic use of PUs, stylistic awareness implies a number of essential aspects; first and foremost it means an awareness of:

- $\quad$ significant changes in standard form and meaning;

- figurative meaning and creation of new meaning in discourse;

- associations, associative links, and figurative networks;

- cohesion and stylistic cohesive ties in the text.

Acquisition of stylistic skills and competence takes a great deal of time and needs to be sustained as an ongoing process. It starts with openness to discoursal use and figurative meaning with the aim of developing a feel for language use, including figurative meaning, the emergence of a new discourse form and an ability to comprehend associations and create new ones. To achieve this aim, teachers need to reflect more on the kind of materials they use and encourage learners "to develop their own thinking skills" (McRae 1996:30) and their creative skills in particular. My main concern is to examine ways in which instantial use of PUs is relevant to language teaching and learning, translation, advertising, and other areas of applied stylistics.

The importance of stylistic awareness lies in development of the learner's perception of language in use and his or her response to it. Stylistic literacy is a functional ability to use stylistic skills competently for applied purposes and activities. It is a skill that will help to apply language more purposefully and effectively. Stylistic analysis provides a deeper insight into language use and text organisation. This in turn leads to more efficient teaching and learning, which provides a basis for other areas of applied stylistics. Further development of both theory of cognitive stylistics and theory of phraseology will generate more awareness, which involves abilities and skills to perceive, comprehend, and infer. 


\subsection{Teaching and learning}

A discourse-based view has profoundly influenced the principles and practices of teaching and learning a language to both native students and L2 learners. Thinking of language as discourse has been a fundamental change. "The moment one starts to think of language as discourse, the entire landscape changes, usually, forever" (McCarthy and Carter [1994] 1995:201). Awareness of discourse features and its pedagogical implications have been brought up as an important issue. Teaching language awareness has become a necessary constituent in language teaching practices.

The 21 st century has witnessed a new development: a cognitive approach to teaching and learning in general and to teaching metaphor and developing metaphorical competence in particular (Petrie and Oshlag [1993] 1998; Littlemore 2001). Littlemore focuses on four aspects of metaphorical competence in learners' first and second languages: (1) originality of metaphor production, (2) ability to find meaning in metaphor, (3) speed in finding meaning in metaphor, and (4) fluency of metaphor interpretation. She argues for a cognitive approach to second language learning and teaching (Littlemore 2001:459-491, 2009).

All language teachers recognise the importance of teaching and learning phraseology, as PUs are a key problem for learners. The book Phraseology in Foreign Language Learning and Teaching, edited by Meunier and Granger ([2008] 2009), underscores the importance of learning PUs in second language acquisition and instruction: "an oft-neglected yet essential dimension of phraseology in a second/foreign language pedagogy: the learning aspect" (Granger and Meunier [2008] 2009a: 17). However, the volume has a very broad understanding of phraseology focusing on multi-word units and fixed non-figurative collocations. It does not deal with PUs as stable and figurative language formations, let alone their stylistic use, either in single sentences or in discourse.

The principles and practices of teaching and learning phraseology need to be reconsidered in view of a discourse-based approach to language use (Naciscione 2001c). Moreover, cognitive linguistics offers many insights which contribute to the comprehension and interpretation of stylistic use of PUs. The advantages of cognitive methodology when analysing creative changes of PUs have been pointed out by a number of researchers, for instance, Mena Martínez (2003); Ryzhkina (2003). My aim is to have a close look at the pedagogical implications of teaching and learning stylistic use of PUs in discourse from a cognitive perspective. 


\subsubsection{A discourse-based approach to phraseology in teaching}

When speaking about stylistic use, it is important to handle PUs at discourse level rather than at sentence level (the same applies to separate PUs as illustrations). It is also important to emphasise the cognitive and discoursal aspects. Sentence level studies do not account for the discoursal properties of PUs, which frequently may be used across larger stretches of text. Teaching instantial stylistic use is an essential strategy for raising stylistic awareness. By focusing on the discoursal qualities of use of phraseology, it is possible to develop an appreciation of and a creative approach to figurative meaning. "It takes imagination to learn a language" (McRae 1996: 18); and it takes imagination to teach figurative use.

\section{A. Foreign language teaching}

My aim is to look at ways in which analysis of stylistic discoursal use of PUs is relevant to language teaching and learning. Discourse-oriented teaching calls for reinterpretation of the role of PUs in texts and for rethinking of research findings over previous years with an eye to the entirety of text. Insufficient attention has been paid to the actual processes that PUs undergo in discourse. It is important to explore the "implications for the study of larger segments of the text and a creation of cohesion thus linking different discourse features" (McCarthy and Carter [1994] 1995: 88). A cognitive approach to discoursal use helps to answer many questions about L2 acquisition at a more advanced level, especially identification of figurative meaning across sentence boundaries and its comprehension, and to develop the ability to think outside the box.

Traditionally, PUs have been sparingly taught by language teachers and those that have been taught have been handled in traditional ways, dealing with the meaning and grammatical features of the base form and core use contained in one sentence. This attitude and practices of teaching phraseology both require review. A static, petrified view of PUs is not conducive to understanding discoursal use. Just as we come across decontextualised PUs or single sentence examples in theoretical works, the same approach is seen in teaching materials and dictionaries. ${ }^{4}$

4. The history of both linguistics and pedagogical approaches shows that the further we go back in time, the more we find a sentence-centred approach or even a word-centred approach. This is understandable in view of the development of linguistic thought. The sentence-centred approach was preceded by a word-centred approach (Nesfield 1924). Traditionally, issues of teaching phraseology have been mostly examined and illustrated in core use at sentence level. Howarth, for instance, is interested in the development of phraseological competence as a constituent of proficiency in a second language for advanced learners of English (as the title of his article shows). However, his understanding of phraseological competence does not include discoursal use (Howarth 1998). 
That is the main reason why exercises containing separate base forms and single sentences have been the traditional concern in teaching phraseology.

The two dominating approaches in teaching materials are as follows:

1. Out-of-context exercises, remaining at the level of the base form with tasks such as:

- match the definitions with the correct idiom (Watcyn-Jones 1990);

- match the idioms with the words associated with them (op. cit.);

- fill in the missing verbs (op. cit.);

- choose the correct meaning from the list (Cambridge International Dictionary of Idioms ${ }^{5}$ 1998: 456);

- give the American equivalent for British idioms (op. cit.: 457).

2. A single-sentence approach, which reflects sentence-bound thinking, remaining at the level of core use with tasks such as:

- fill in the blanks with the best idiom from the list above (McLay [1980] 1998);

- choose the word or phrase which best completes each sentence (WatcynJones 1990);

- say whether the idioms in the following sentences are used correctly (true) or incorrectly (false) (op. cit.);

- fill in the given missing words (op. cit.);

- complete the idioms with a suitable colour (choose from the box) (op. cit.);

- choose a suitable word from the lists on the right to fill in the gaps in the sentences (Cambridge International Dictionary of Idioms 1998).

Multiple choice exercises, gap exercises (filling in the missing words or phrases), "true or false" exercises, tick-box exercises and the like are basically intended to train a grammatical form or some lexical elements (such as prepositions, choice of synonyms). When applied to phraseology, such assignments often turn out to be mechanical, irrelevant, misleading, and unproductive. They are not designed to lead to a creative approach. Single sentence exercises confine all use to one sentence. This method prevents the language learner from shaping a discourse-based view of language use and does not facilitate proficiency in discoursal use of PUs.

This approach indicates that theoretically PUs are regarded as static and unchangeable or as dead clichés. They are seen as:

5. Cambridge International Dictionary of Idioms (1998) gives exercises on pages 456-469 to train the base form and core use with the correct answer supplied by the answer key. 
- something strictly confined to the limits of one sentence;

- incapable of responding to challenges that discourses present,

- incapable of conveying more in discourse than the meaning of the base form;

- unable to form semantic and stylistic interrelations with other discourse elements to play a role in cohesion and coherence of discourse.

McLay's book Idioms at Work (96 pages) offers only one task: Fill in the blanks with the best idiom from the list above. However, the title Idioms at Work claims a bit more than mere core use. In the Introduction to the book McLay says that the idiom has a different meaning and has nothing to do with the meaning of its constituents, and she gives the example to be fed up which "has nothing to do with feed" (McLay [1980] 1998:3). How is any instantial use possible if there is a failure to see the metaphorical link between the PU to be fed up (with something or someone $)^{6}$ and the corresponding free word combination? A contradiction seems to exist between the theoretical belief of the author and the methodology applied: although she considers that no link exists between the idiom and its separate parts, the book is provided with excellent humorous cartoons, which work as a pun and lay bare the semantic structure of the idiom, thus illustrating the base form.

McCallum's book More Idiom Drills: For Students of English as a Second Language (1978) offers a systematic approach to studying 180 useful idiomatic expressions. The book is divided into six units, each containing five short lessons. Each lesson starts with a short dialogue. The meaning of the idioms is given and exemplified. Oral and written exercises are designed for practice, followed by questions for discussion. At the end of each unit a specially written short play is supplied, providing a discourse environment. However, the book contains only core use, although it is designed for an upper intermediate or advanced class.

A discourse-based approach to PUs enables the teacher to shift the emphasis from the preoccupation of teaching separate PUs to the natural flow of language. PUs need to be looked at from the discourse point of view. In contrast to the orthodox teaching of static PUs as dead clichés and the concept that stylistic changes are violations of the language norm, a discourse-based approach allows emphasis on use of PUs in text. Merely indicating the change is not sufficient either. It is vital to present a dynamic view of phraseology, bringing out the role that PUs play in the web of discourse. It is crucial to establish their form and meaning in discourse and the instantial changes they undergo with an eye to the discoursal

6. To be fed up (with something or someone) means to be unhappy or bored and dissatisfied (Longman Dictionary of English Idioms 1979: 108). 
role of PUs and the message conveyed. This approach affords a shift of emphasis from teaching separate PUs in single sentences to PUs in actual use, the process of text creation, and phraseological choice.

It has been acknowledged that the old approach does not require "dynamic, interactive dimensions to the language" (McCarthy and Carter [1994] 1995:2) as it is a sentence-based approach. ${ }^{7}$ The discourse-based approach calls for new methodology as the old translation method or the subsequent cloze tests, multiple choice exercises, and box exercises do not foster understanding of the discourse environment, nor do they promote language learner ability to use PUs appropriately and creatively. The traditional approach does not take into account the potential of PUs to go beyond the framework of one sentence, the discoursal features of instantial use, the existence of particular patterns, or cohesive interrelationships in the web of discourse. These patterns have never been the concern of traditional teaching of phraseology. With the old approach "the emphasis is on a static, decontextualised view of language" (op. cit.).

In discourse, PUs are not fettered in their base forms or tied down to their core use. They are free to flow, shape, react, realise their cohesive potential, establish new cohesive ties, and create new meanings, depending on the thought and discourse environment. With instantial use, each case seems to be different, like a wave in the sea, which may differ greatly from or may be similar to others, but never quite the same. Yet some rhyme and reason exists in the variety; and it is important to understand how the similarities and differences come about.

Conventional exercises harness PUs in a strict unchangeable form, keeping them rigid and encased in their core use. Filling in the missing word presupposes a stencilled approach. These exercises should be reserved for beginner and lower intermediate levels, provided learners are introduced to:

1. the basic concepts of phraseology;

2. the fact that core use is not the only way PUs function in discourse; it is not the be-all and end-all of their existence;

3. the possibility of instantial use (even if only in a very simple way).

It is small wonder that after the traditional type of training learners feel nonplussed when faced with a real discourse situation where instantial use does not fit the prescribed form and meaning fixed in a dictionary entry.

7. For due criticism of this approach, including cloze exercises, see McCarthy and Carter ([1994] 1995). "Instead of targeting words at essential random intervals throughout the text and instead of deleting every nth word or instead of using the exercise to test grammatical knowledge, it will be more productive to draw attention to the specifically discourse properties of the text" (op. cit.: 76). 
In the case of phraseology, awareness is not merely a realisation that instantial use is present. Stylistic awareness also involves abilities to perceive, comprehend, and infer, assuming an adequate level of knowledge and skills. Raising stylistic awareness implies the need to foster student ability to observe and analyse instantial use in a particular text, to see beyond instantial realisations, and to discern patterns applied to achieve an instantial effect. It also means developing an ability to compare various instantial changes and identify patterns that repeat themselves, to notice successive elements that form an extended string of a PU and study the way the instantial elements are related, firstly, to the PU in the particular stretch of text; secondly, to the base form; and thirdly, to each other. Furthermore, it is essential to promote the ability to identify the explicit constituents that represent the PU in a particular application. This is especially true in the case of allusion, where it is vital to see the cognitive process whereby the meaning of the omitted implicit constituents is resurrected in the reader's mind.

Discourse analysis calls for skills which can unravel patterns encompassing larger stretches of text and bring out the cohesive relations between sentences. An efficient language user is able to recognise and identify typical patterns of instantial use, infer connections between base and instantial elements in discourse, and understand the implications of the instantial pattern used in text.

Learners need knowledge and skills to identify PUs and to handle both core and instantial use of PUs in discourse. Acquiring more knowledge of phraseology and its use will generate more awareness of language and style and will promote skills and competences that facilitate the process of learning L2 and using it more proficiently. Exposure to stylistically saturated language environments is essential to achieve language awareness at discourse level.

Another aspect also needs to be considered. Knowing how phraseology works in discourse is a significant step towards deciding what and how to teach. This goes together with the psychology of learning. Study of discourse stylistics requires insights from psycholinguistics and cognitive psychology. This approach widens the scope of language learner education and also of language teacher education and training. Discourse-based orientation promotes increased language awareness and facilitates conscious knowledge of the discoursal aspects of language. "A more reflective language learner is a more effective language learner" (McCarthy and Carter [1994] 1995: 165); the same applies to teachers and teaching.

The discoursal potential of phraseology lies in cohesion, as it is "the closeness of the relationship that determines the cohesive effect" (Halliday and Hasan 1976:289). For the learner it is important not only to realise that the base form of a PU is cohesive in its own right due to its stability and figurative meaning, but also to see in practice that in discourse the inherent cohesion of the base form is preserved and sustained, which accounts for instantial cohesive potential, in turn 
providing continuity and sustainability of phraseological meaning across sentence boundaries. Stylistic effect is created at the interface between the base form and instantial application in discourse. The clue to discourse analysis is the base form versus the instantial form as a semantic and stylistic relation. In discourse the cohesive effect is usually achieved by continuity of phraseological meaning beyond sentence level.

Enhanced stylistic awareness can be achieved in a number of ways, highlighting different aspects of discoursal use and targeting metaphorical ties, which show stylistic and semantic proximity, strings of sub-images, allusions, and associative links. Insight is also provided by phraseological signals and cues which prompt and guide. The best way of getting learners to focus on close and remote semantic and stylistic ties created in the web of discourse is through actual observation and interpretation of a stretch of text. This effort implies search, identification, and analysis of specific cases of use, taking into account all the implications of creative use with the aim of extending and stretching the mental vision and imaginative thinking of the language learner.

What are the specific pragmatic teaching concerns in securing a comprehensive discourse view of instantial use? A number of tasks need to be borne in mind and followed up as regular classroom practice. The teacher needs to focus on the following questions:

1. Are language learners able to see beyond the limits of a single sentence?

2. How efficient are they at identifying instantial use and recognising the various patterns in discourse?

3. Do they recognise the stylistic implications? How do they cope with patterns which are not immediately evident or discernible?

4. Can they resolve ambiguities, unravel associative ties, and provide missing cues?

5. Are they able to spot reiterated elements: reiteration of separate constituents, PUs or their image?

6. Are they in a position to interpret a stretch of text which contains concurrent use?

7. Can they cope with phraseological saturation and aspects of stylistic density and distribution?

8. Are they able to identify cohesion and coherence of instantial use over a stretch of discourse?

9. How well have they been introduced to the cognitive mystery of creation? Are they able to create an instantial form themselves? 
Both teachers and learners need to be aware not only of the cohesive potential of PUs and the discoursal role of instantial patterns as inherent features of the system of language, but also of dynamic instantial changes in discourse which involve creation of new discoursal forms and new meanings. Creative processes need to be taught, thus enabling learners to discern inventiveness and flexibility in creation of texts.

Discoursal phraseological competence is like a moving target, as discourse develops and changes constantly, each stretch presenting new wealth and new challenges. Only adequate training on a regular basis can counter the difficulties presented by creative use in various types of texts. The task the teacher faces in the classroom is to develop the necessary stylistic skills which can enable students to recognise instantial patterns, interpret their use, and comprehend the implications of phraseological choice. The ultimate goal is to foster a better understanding of the complexities and variety of instantial use, promote comprehension of discourse, and develop a feel for style. Language awareness involves conscious knowledge which may "act as a monitor or editor of language in use" (McCarthy and Carter [1994] 1995: 161).

Thus, the discourse-based approach to teaching phraseology makes a crucial contribution to understanding texts and adds value to discourse interpretation. It allows observation of the ways in which PUs are exploited and brings out the elaborate cohesive bonds achieved in discourse. It also allows exploration of patterns which extend beyond the limits of a PU and go across clauses, sentences, and stretches of text. Close study of the actual discoursal use of PUs provides a key not only to interpretation and analysis, but also leads to both accuracy and a sense of freedom in actual use. "Conscious awareness is not only valuable in itself but can also empower the learner to use the language with greater confidence" (op. cit.: 140). Many stylistic instantiations of PUs may present an incredible semantic challenge to the L2 learner, reader, or translator.

\section{B. Teaching language through literature}

Over recent decades, much linguistic effort has been devoted to style and the teaching of literature, that is, to the pragmatic aspects of stylistic research to raise sensitivity to the use of language in literature (Crystal and Davy [1969] 1995; Leech [1969] 1993; Widdowson [1975] 1991; Leech and Short [1981] 1994; Brumfit and Carter [1986] 1991; Carter and Long [1987] 1995; Short [1988] 1992, 1996; Carter and Nash [1990] 1995; Zyngier 1994, 1999, 2000; Mills 1995; Simpson 1997, 2004; Bex, Burke and Stockwell 2000, and others).

Literature has returned to the classroom and it is now taught again as part of language classroom activities. Increasingly, literary texts are recognised as being a medium for teaching language. The past few decades have witnessed many 
fruitful attempts to offer another pedagogical approach to language teaching and integrate language and literature teaching activities in the classroom, especially at an advanced level (Widdowson [1975] 1991; Carter [1986] 1991: 126-128; Bex 1988; Short [1988] 1992; Short and Candlin [1988] 1992; Carter and Simpson 1989: 11; Coulthard [1977] 1991; Carter and McRae 1996; Simpson 1997; Zyngier 2000; and many others). Integrated language and literature work is of great pedagogical benefit, as this approach helps to develop appreciation of the style, effects, and techniques of authentic literary resources (Carter and Long [1987] 1995:1). The integrated approach is designed to stimulate student language development and enhance sensitivity to use of language in literature (ibid.; Widdowson [1975] 1991:82).

Integration of language and literature work is for mutual benefit and synthesis at a range of pedagogical levels (see Carter [1988] 1992:176). One of the most obvious benefits is the raising of general language awareness. Carter argues that "the greater our detailed knowledge of the workings of the language system, the greater our capacity for insightful awareness of the effects produced by literary texts" (Carter [1982] 1995b:5). The focused and marked nature of these contexts makes literary texts ideal vehicles for this purpose (McCarthy and Carter [1994] 1995: 116-117). Drama texts can also be successfully used in language teaching (McRae 1985), as well as textual analysis of poetry (McRae 1998). Literary texts are commonly seen as examples of language in use, as instances of naturally occurring communication in real social contexts. Introducing more literary texts in the classroom fosters both processes of reflection and skills of analysis (McCarthy and Carter [1994] 1995: 135).

In literary texts, discourse analysis reveals meanings that are not brought out by traditional commentaries on separate grammatical, lexical, and phonological items. Discourse analysis is inextricably linked with style, which is an exceedingly complex issue. "Style is the most intangible quality of a text, yet is often one of the most immediately noticeable features of even the shortest text" (McRae [1987] 1990: 11). Working with a literary text sharpens perception of language and develops a person's capability of reading literature. Discourse analysis links together all the interrelated and interdependent elements, which join to lend a text "a stylistic identity" (op. cit.: 24).

Exposure to literary texts is a rich resource for drawing attention to essentially the same characteristic of language that is employed so effectively in literature - namely, its ability to construct meanings for us (Hasan 1989: 105; Cook 1994: 39). In discourse "meaning construction is an online process" (Radden et al. 2007:4). Understanding creative use of language forms part of literary awareness and competence, which serve as a basis for literary studies. Zyngier understands 
literary awareness as "the process by means of which students perceive the effects produced through the verbal patterning and the creative manipulation of language, before they can build substantiated readings of a text" (Zyngier 1999:31).

Literary texts are generally considered an effective means of training language awareness. However, it is the teaching of lexical and grammatical items in discourse that is usually pursued (James and Garrett [1991] 1995a) while discoursal use of PUs is paid no or little attention. It is important to learn to read with informed awareness and process a literary text. This would not be complete without interpretation of instantial stylistic use. Teaching and learning phraseology involves more than cognitive access to the meaning of the base form of the PU and introduction to core use in single sentences. It also calls for an understanding of the complexity of semantic structure and the stylistic effect of instantial use in discourse and the role of image-bearing constituents.

Many literary texts reveal linguistic complexity. These are texts which challenge or intrigue (such as Shakespeare's plays), texts which may be daunting for students. One reason for this is instantial use, which may be highly frustrating for foreign language students. Phraseological competence involves much more than isolated PUs or core use; it calls for a higher level of understanding of language in use with the aim of securing language proficiency. It goes without saying that the learner must be aware of the essential stability of the base form, the unique character of instantial use, and stylistic patterns of change.

Knowledge of phraseology implies language accuracy and its creative use in specific discourse environments. It entails appreciating figurative meaning and associations. In teaching the subtle workings of instantial use, the objective is to teach an understanding of figurative language, its creation and meaning.

In order to develop skills and insights which are part and parcel of a perceptive awareness of stylistic use of language, it is of paramount importance to comprehend coherent figurative development, secured by a PU in a number of successive segments of discourse, and follow the unfolding of the phraseological image sustained throughout the particular stretch of text and the stylistic effect it produces.

Teaching instantial use helps to disclose the cognitive processes of the mind in creative thinking: hence the importance of imagination as a mental concept in the process of teaching literary texts in the classroom. The mind performs not only common reasoning, but also perceptual and cognitive imaginative functions as mental experiences. It is important to secure an insight into the way imagination and creativity manifest themselves and how the mental processes of perception and cognition operate in discourse. 
This approach will help to concentrate on discourse processes, text-creating, choice of instantial use, the frequency of its occurrence, distribution, prevalence of a certain pattern in the works of one writer or poet, and bring out intradiscoursal and transdiscoursal links. Reiteration is another important item to focus on in discourse. It is also a good idea to look at titles, their implications and umbrella role for the whole text, as well as the opening and closing textual segments, and search for any significant anaphoric and cataphoric lexical or phraseological cues offered by the unfolding narrative.

Exploration of the discoursal potential of PUs is of immediate relevance to literary studies. It constitutes a vast field of inquiry. One of the most interesting aspects is the link between frequency and type of instantial use and various kinds of discourses, genres, or periods (for instance, instantial use and the genre of English Children's Nonsense Literature or the poetic and prose works of one author, such as Chaucer, Lewis Carroll, D. H. Lawrence, or works of an earlier and a later period by the same author). These features are relevant to the role of phraseology in conveying the overall stylistic message of the text. A comparison of differences in use of PUs and their presence or absence in various types of text should stimulate awareness and provide a good basis for stylistic analysis and interpretation.

Thus, integrated language and literary activities afford an opportunity to fuse linguistic and literary comprehension and develop a feel for the text. Stylistic and phraseological competence of the language user is a task that is not easy to deliver, but it is rewarding both for the teacher and the learner. However, a number of difficulties arise in teaching language through literature:

1. Inadequate training of teachers

As interest in classroom application of stylistics is still low, teachers have received little or no training in discourse and stylistic interpretation, while relatively few textbooks feature stylistics for practical use.

2. Challenges caused by use of figurative language

In order to maximise text interpretation and independent reading opportunities, it is essential to teach the meaning of figurative language and foster awareness of development of a figurative line of thought with the aim of enhancing comprehension of instantial use. Each instantial image represents a mental picture. ${ }^{8}$ Teaching of images enables the reader to discern the effects

8. In cognitive psychology the image is viewed as a mental representation, as a picture in the head. The "picture" is not a literal one, but rather a kind of "as if" picture. That is, imagery is a cognitive process that operates "as if" one had a mental picture that was an analogue of a realworld scene (Reber [1985] 1995:358). 
of discoursal figurativeness, create a mental image of instantial use, and establish the links provided to help to sustain it.

3. Teaching cohesive ties

Studies have shown that cohesion is an element which creates a major difficulty for L2 readers of literary texts in English. Cohesion is the network of explicit and implicit ties which makes a text a unified whole. Misunderstanding of cohesive signs can lead to misreading the entire passage (McRae [1987] 1990: 16). Failure to understand cohesion, rather than lack of lexical knowledge, is the most common cause of misreading (McRae 1996:35). Unresolved or false cohesion is only detrimental to interpreting or analysing a text.

4. Lack of training in the cognitive aspect

Teaching identification of instantial use goes together with insights from cognitive linguistics and cognitive psychology and training in cognitive skills, as well as psychology of learning and motivation. Learners become intrigued with the stylistic performance of PUs in discourse, which makes a qualitative difference to the level of acquisition.

5. The art of creation

This aim is hard to attain. A creative approach to language implies appreciation of new discoursal forms and meanings, and creation and development of an image in discourse. It also implies teaching how to create instantial use and networks, to extend and sustain an image, linking words and phrases together and providing meaningful associative ties. A focus on creativity requires greater language awareness on the part of language teachers and learners (McCarthy and Carter [1994] 1995). It also calls for enhanced awareness of style in various applied areas.

Cases of interpretation difficulties, or rather misinterpretation, often result from a misunderstanding of the discoursal dimensions of instantial use of PUs. Reading and interpreting of many literary texts becomes encumbered without an understanding of the subtleties of instantial use. Development of perception and stylistic literacy will help to overcome these difficulties.

The specific aims are to become style-conscious and develop an appreciation of the stylistic potential of PUs in discourse, to enhance perception and understanding of its nature, as well as to give an insight into the process of instantial use and help to capture the stylistic identity of a text in its entirety. There are psycholinguistic arguments for teaching discoursal use, as this facilitates development of associative and figurative networks. It can also help cognitive processes in teaching and learning. As McRae points out, learners should be encouraged to develop their own thinking skills (McRae 1996:30). 
It is equally important to teach creativity as manifest in literary texts, dispelling the image of phraseology as a set of rigid, almost fossilised language units incapable of discourse flexibility and sustainability, hence viewing use of PUs as a developing process rather than ready-made language material. The ultimate goal is learner ability to create instantial use in discourse by exploiting existing language patterns. Teachers and learners need to develop specific discourse skills to cope with all the relevant difficulties.

In conclusion, teaching PUs in discourse can lead to significant gains in stylistic awareness and competence: both language and literary competence. I would argue that the theory of instantial use of PUs applies to the study of literary texts, both prose and poetry, old and new writings, promoting sensitivity to language and literature. Competence in instantial use enhances reader or listener understanding of the text and stimulates motivation to further increase language skills.

\subsubsection{Language skills, learning difficulties, and identification errors}

Cases of instantial use may often seem to be vague, contradictory, and hard to grasp or analyse. Many types of instantial use may exert an inhibitory effect on the learner. L2 learners in particular may find it frustrating to deal with passages based on complicated patterns such as allusion or concurrent use, or working with more difficult newspaper texts, let alone sophisticated discourses such as Shakespeare's plays, or doing diachronic studies.

In order to resolve an ambiguity, the reader or listener needs adequate background knowledge. A mandatory requirement is the essential knowledge and insights that serve as a basis for skills development. For phraseology, this is first and foremost the contradistinction of language as a system versus language in use. Knowledge of phraseology as part of language stock comprises understanding of two categories: (1) the base form and its cohesive character due to figurative meaning and stability, and (2) instantial pattern as an abstract language element. These in their turn determine the need to:

- discover the significance of the base form, which is like a repository of semantic and stylistic potential to be used in instantial use within the stream of discourse;

- be aware of the role of PUs in the web of discourse.

Language in use also presupposes knowledge of cognitive skills, discoursal features, instantial use as a specific discourse phenomenon, application of an instantial pattern as a language element in a new discourse environment, as well as 
cognitive awareness of a novel discourse form and meaning. Teaching and learning of phraseology involves not only cognitive access to the meaning of the PU in discourse, the complexity of its semantic structure and stylistic effect, but also training and practice in discourse skills, which ideally should turn into intuitive skills of proficiency in use of PUs in discourse. It is not only PUs that need to be acquired: the foreign language learner also needs to be taught knowledge and skills of stylistic patterns and ways in which they manifest themselves.

Thus, the aim is to teach awareness and to show how instantial use works, to minimise errors in comprehension and interpretation, and to help the learner discover ways to cope independently with instantial use. This implies a sufficient level of knowledge of phraseology, discourse, and style and all the corresponding skills to apply the knowledge.

It is important to develop identification skills (see Ch. 2.4), which facilitate the process of drawing inferences. Learners need these skills to gain an understanding of contextual formations and the difference between core use and instantial use. Training in comprehension skills leads to enhanced awareness and an ability to understand discourse processes, including instantial use. "Language awareness assists in the development of interpreter and inferential skills" (McCarthy and Carter [1994] 1995: 165). Conscious effort improves perception of a stylistically changed PU in text and helps to see how a PU can acquire various contextual meanings and functions in different contexts. Identification skills are productive as they in their turn generate awareness of the functions of PUs in various types of contexts and texts. "What can be taught is the procedural ability, the ability to learn how to learn such things, the capacity of interpretation and inference in and through language" (ibid.).

Learning difficulties start with identification difficulties. Acquisition of phraseology implies learning various PUs, their form and meaning, together with exploration of the functioning of PUs in discourse with the aim of enhancing the ability to read, understand, and interpret discourse. Identification difficulties may lead to misinterpretation or breakdown in communication, creating difficulties in understanding the writer's or the speaker's message.

How to recognise PUs and their patterns of use, to perceive their impact and improve the level of comprehension, not in isolated examples but in discourse? Recognition is easy at very short intervals, whereas it becomes blurred or lost at longer intervals ${ }^{9}$ if learners are unable to see the figurative level sustained, identify sub-images and retain metaphorical ties, which have saturated the context, as in the case of extended metaphor, or vice versa, if they are unable to perceive the

9. For word recognition and priming, see Harley (1995: Ch. 3). 
abrupt shift from the figurative level to literal meaning which occurs in phraseological puns and phraseological zeugma. Links need to be reconstructed between parts of a PU or separate isolated constituents. In the case of stylistic use, it may be increasingly difficult to bridge the gap between sentences and find cues that may be spread over previous or subsequent paragraphs and chapters. Apart from knowledge of phraseology, discourse, and style, some essential skills are needed to secure comprehension and attain stylistic awareness:

\section{Cognitive skills}

Training in cognitive insights will lead towards ability to:

1. verify, evaluate, and monitor comprehension;

2. remedy miscomprehension;

3. perceive and respond to stylistic use;

4. recognise patterns of stylistic use;

5. understand the mental representation of an image;

6. perceive associations and develop associative thinking;

7. recognise continuity and cohesive ties;

8. understand the workings of creation of new meaning in discourse.

These skills imply the need to train the working memory of the learner with the aim of retaining phraseological information: ability to retain the base form of the PU in the working memory throughout instantiation, as well as ability to keep in mind instantial formations if reiterated or sustained. When encountering a new instantial element, the reader is able to perceive the link and recognise it as part of the stylistic use of the PU.

It is clear that sustained figurative use calls for additional identification efforts and enhanced cognitive skills of perception, comprehension, and interpretation in order to be able to follow an instantial development and to understand emerging turns of sustained figurative thought in discourse. To cope with the task, learners need what could be called sustained working memory so as not to lose the figurative thread. Sustained use also affords an insight into an interesting aspect of the figurative mode of human cognition: the ability to infer gradually, to understand increasingly in tune with the development of thought in an ongoing figurative environment. A PU is capable of delivering a greater degree of sustainability than a word by virtue of inherent cohesion of the base form of the PU and its figurative meaning.

Sustainability is an essential feature of stylistic use of PUs. Both reader and author exercise a considerable degree of stylistic awareness and cognitive skills: (a) a cognitive ability to perceive, recognise, and understand a sustained image 
in discourse; (b) cognitive skills to create instantial use and sustain the phraseological image across sentence boundaries, maintaining and developing the figurative image. Comprehension of sustained figurative use is a cognitive act, as is its creation. Experience of teaching L2 students shows that figurative thinking in a foreign language does not happen automatically: these cognitive skills need to be addressed and developed.

\section{Identification skills}

Identification includes basic skills of recognition, verification, comprehension, and interpretation (see Ch. 2.4). Improved identification strategies enhance reading comprehension and interpretation, which call for the need to:

1. establish the identity of the PU: identify the base form, access the meaning, and identify the base image;

2. establish the instantial pattern;

3. identify the discoursal form of the PU in full and follow up its development;

4. trace sub-images and cues;

5. identify cohesive elements: establish both base and instantial ties, and all the complexity of the figurative network;

6. explore continuity versus discontinuity;

7. establish reiterations to see whether they serve to convey novel turns or developments.

\section{Skills of visual literacy}

Visual representation calls for ability to identify and comprehend a non-verbal mode of expression to be perceived visually in multimodal discourse, and to establish ties between the visual and the verbal, helping to create coherent visual discourse. Visual literacy is increasingly considered an essential skill for coping with the world of work and social life (Goodman 1996:38).

Discourse analysis will be impaired if the learner fails to cope with instantial use. Identification skills are an essential part of phraseological competence. In less complicated cases the reader may be unaware of the difficulty and cope with it intuitively by understanding the general message. However, many discourse environments pose a challenge and call for enhanced awareness and conscious solutions when it is impossible to establish the precise semantic and stylistic value of the change without a special identification effort.

In the process of identification, it is easy to miss an important item, misread or misinterpret textual information, or misplace emphasis, as teaching practice shows. The identification procedure is fraught with danger. The most common hazards in identification are as follows: 
- failure to identify the PU, missing the whole PU, its parts or instantial elements; failure to identify the full context of the PU;

- failure to identify the base form accurately and hence inability to establish whether it is core or instantial use. This is usually due to absence of a verification process. Overreliance on prior knowledge may turn out to be a source of error, especially for L2 learners:

- overlooking phraseological variants and regarding them as instantial use;

- mixing up varieties of English: BrE vs AmE vs AustrE;

- disregarding dialectal variants;

- mixing up synonymous PUs;

- failure to identify instantial use (its form or meaning), grasp its significance, and appreciate the stylistic effect:

- failure to see the whole scope of instantial use and encompass the full extent of instantial application in cases of extended metaphor (all instantial constituents, sub-images, and cues);

- failure to identify instantial use in longer stretches of text or perceive the whole of the context when it exceeds the limits of several sentences;

- failure to spot obsolete PUs in diachronic studies;

- failure to identify an archaic instantial element in modern texts;

- failure to establish the type of instantial use or identify the pattern; failure to identify the stylistic potential or establish the stylistic effect to see what contribution is made by the particular case of instantial use to the discourse:

- failure to identify cleft use when part of the PU is carried over and used by another interlocutor in a dialogue;

- failure to identify all instantial changes in case of concurrent use;

- failure to identify several PUs used in one context in case of saturation or realise the importance of the density of PUs;

- failure to consider reiterations or the semantic and stylistic information they carry;

- failure to recognise small but significant changes because they look too small or seemingly unimportant, such as replacement or ellipsis of a single constituent;

- failure to identify the cohesive role of instantial use;

- failure to identify both core and instantial use in titles, recognise the umbrella role of the title whose context may be the whole work or link it up with core or instantial use, which may appear once or several times in the text;

- failure to identify changes in stylistic register due to instantial use;

- failure to show the link between instantial use and literary background, period, genre, type of narrative, or characters. 
To sum it up, the two basic types of identification errors for L2 learners are:

- the error of negligence (want of due diligence: missing, overlooking, not being aware);

- the error of assumption (overreliance: the "I assume" or "I know" approach). Both lead to incorrect conclusions.

Whatever the source, errors in identification lead to confusion, loss of information, misinterpretation, or a break in communication.

Careful identification procedure will at all its stages enhance awareness of the semantic and stylistic interrelationships encountered in the text. Training a style-conscious language user implies training in awareness with an eye to accuracy. McRae ([1987] 1990:27) recommends concentrating on "ways of looking for detail $^{10 "}$ to raise sensitivity to language. Here are some useful tips regarding what to focus on in the search for significant detail and instantial cues in discourse:

- use of phraseological constituents in their literal meanings or other metaphorical meanings;

- strings of connected figurative elements which constitute the web of an extended metaphor;

- new, unexpected elements which do not normally belong to the base form and which have appeared additionally;

- new, replaced elements instead of some of the base constituents;

- loss of constituents, disappearance of some base constituents;

- semantic ambiguities or unresolved figurative elements: presence of the inexplicable, the vague, and the ambiguous in discourse;

- implicit constituents and the way they tie up with explicit constituents in the text.

Significant detail lends more insight and offers an explanation of the presence of figurative items which cannot be fully understood and accounted for without knowledge of the base form of the PU and the whole web of interrelationships in the stretch of discourse.

Effective and appropriate instantial use in discourse calls for a good command of vocabulary, including phraseology, cognitive stylistic skills, and a certain element of creativity, potential for creative thinking, and a creative approach. It also implies ability to generalise and use language involving PUs in novel discourse environments, leading to an ability to employ patterns to recreate PUs in discourse. True proficiency is unthinkable without instantial use.

10. Italicised by McRae. 
Instantial use as an individualised discourse phenomenon proves difficult to handle as it calls for a profound understanding of the application of a PU and an instantial pattern as language elements in a new discourse environment. Following McRae ([1987] 1990:54-55), I offer A List of Dos and Don'ts, which includes some practical pieces of advice for L2 learners in identification to raise awareness in the process of working on texts:

\section{DO}

- always identify the base form;

- love your dictionary, use it each time to verify and validate a base form;

- double check, use several dictionaries and several types of dictionaries in your search if available;

- check both stability and figurative meaning to establish whether it is a PU or a free word combination;

- reread the context each time you have consulted a dictionary; while concentrating on the base form you may have lost the context; look at it with a fresh eye: the stretch may call for additional analysis;

- compare the discoursal form with the base form;

- identify instantial use to the full extent;

- establish the phraseological context in full;

- revisit the PU in order to detect sub-images and follow up the whole development of the PU;

- look out for cues or author's comments that prompt figurativeness or stability, words like proverb, saying, phraseology, saw, adage;

- read and reread the text, listen to it to hear what it says, read it out aloud, especially for onomatopoeic effects;

- be aware of reiterations and go back to the preceding stretch of text each time a figurative item reappears.

\section{DON'T}

- invent the base form of a PU: it has already been invented;

- forget that figurative meaning, stability, and cohesion are the three cornerstones of phraseology;

- study a phraseological dictionary separately from the context and then return to it: verification is part of identification in discourse;

- lose the metaphoric thread;

- miss some part of instantial use, the context may contain more than meets the eye;

- overlook sub-images;

- disregard cues or underestimate associations; 
- ignore reiterations: they are relevant in a good author;

- miss any visual representation of the PU (core use, instantial use or the literal meaning of its constituent(s);

- $\quad$ ever be too sure of yourself in analysis.

Learning and identification skills serve learners as a systematic resource, enabling them to discern the inherent qualities of use of PUs and to cope with the challenges of infinite textual variety and new inimitable discourses. To achieve the required skills level, a discourse-based approach to PUs needs to become normal teaching procedure during interpretation and analysis of texts. Reading with awareness, stylistic awareness included, is only possible with interpretation and appreciation of instantial stylistic use.

In conclusion, identification skills include ability to relate creative instantiation to the rules and patterns of language use. The language user must have sufficient background knowledge of and information on the base form and the instantial pattern, combined with stylistic awareness of the operation of language in discourse. Acquisition of the main patterns of instantial use and the respective cognitive and identification skills is central to discourse-based language learning and teaching. Phraseology is a useful classroom resource for training learner stylistic awareness, especially at advanced level, making learners aware of the roles of PUs in the web of discourse, their use in a particular type of discourse, linking it up with the style of a writer, a genre, or a period. Correct interpretation of instantial use in a multimodal text also depends on understanding the visual stimuli and the level of general visual literacy.

This section has looked at teaching and learning as an area of applied stylistics. For phraseology, stylistic awareness is a conscious heightened perception and understanding of the stylistic nature of PUs and their role in discourse. Comprehending the seamless web of semantic and stylistic interrelationships in discourse will deliver much better results in the classroom. The language awareness movement has spread not only in language teaching and learning and the cognitive domain of psycholinguistics but also in other areas of applied linguistics.

\subsection{Translation of phraseological units in discourse}

Translation is one field of activity where the stylistic competence of the language user is clearly seen. It also includes such a topical issue as translation of terminological PUs or, in other words, phraseological terms (mostly based on metaphor). An acute practical need exists for adequate translation of new figurative EU terminology, as my own experience as a translator and simultaneous interpreter has 
shown. Translation of phraseological terms reveals the role of cognitive theory in translation practice (Naciscione 2003b: 102-115, 2006a: 102-118). In the cognitive linguistic framework, metaphorical terms reflect a figurative mode of thinking, the same as all PUs. However, translation of phraseological terms is not the aim of this research as they usually do not reach a discourse dimension.

As to literary translation, existing explorations focus on various aspects of language and style, and their translation. In 2004, a special issue of Language and Literature 13(1) was dedicated to style and translation, revealing widely differing views and approaches. Malmkjær, for instance, argues the need for a special stylistics of translated texts to account for their relationship to a source text, which she calls translational stylistics (2004: 13-24). In translation studies the innovative line is mostly concerned with a stylistic dimension and a cognitive approach to both the translation process and translation theory (see, for instance, Oncins Martínez 2005; Boase-Beier 2006).

This section will focus on the discoursal properties of instantial stylistic use of PUs and the relevance of a cognitive approach to PUs in teaching and learning translation skills, and translation practice as an area of applied stylistics.

Traditionally, much attention has been paid to ways and techniques of translating idioms. Theory of translation has focused on the difficult features of PUs which have been dealt with at sentence level (Shadrin 1969, 1991; Levitskaya and Fiterman 1976; Kuzmin 1977; Vlahov and Florin 1980; Fernando and Flavell 1981; Gläser 1984; Veisbergs 1997b, 1999, 2006). However, a sentence or even a paragraph level account of the functioning of PUs frequently proves to be inadequate, as the isolated contexts in which they appear are insufficient to achieve an understanding of their discoursal properties. It is necessary to gain a broader view of stylistic capacity of PUs and the techniques used. A discourse-based view of language does not mean just looking at isolated, decontextualised language. This approach also involves examining how PUs contribute to the making of complete texts. A discourse-based methodology offers explanations and makes sense of those cases of stylistic use of PUs which on the surface seem to be vague, even incomprehensible, and hard to translate.

Thus, a cognitive approach is especially important when we deal with discourse phenomena that lie at the fringe of phraseology, stylistics, and translation studies. In order to develop skills in translating PUs in both literary and nonliterary texts it is necessary to be able to read them with comprehension and stylistic awareness, that is, with an eye to the stylistic features and meaning of PUs in the source text to avoid possible semantic and stylistic loss. Instantial use does not often lend itself to translation very well. The aim is to learn to process cases of instantial use and develop an ability to fuse literary, linguistic, and stylistic 
considerations. A better trained translator is more likely to have a subtle understanding of instantial meaning in the SL and use the TL appropriately.

Sometimes it is argued that PUs are less important for the translator than acquisition of words and set non-idiomatic phrases. But this is hardly the case. It is perfectly clear that PUs are semantically and structurally more complex and more flexible than words, especially in discoursal use, which may be a series of developments, a continuing process. A PU may function across large stretches of text, forming a figurative undercurrent running through all or part of an entire work. Double vision is created by a number of stylistic processes - such as use of extended metaphor, pun, allusion, irony - sustained by reiteration of the PU, constituting a web of unique interrelationships of figurative and literal meanings. In discourse, the PU retains its inherent cohesive links, which enables its retrieval even in highly complicated cases of use, such as phraseological allusion. These links also determine recall of the PU in cases of extended metaphor when the image is sustained over considerable parts of text, resulting in phraseological and stylistic saturation of discourse. Sustained discoursal use of PUs contributes to perception of the text as a cohesive and coherent entity. These discoursal properties only add to the challenges of translation.

Analysis of the stylistic use of PUs brings out and makes explicit what is normally felt intuitively. Psycholinguistics teaches how important it is to draw inferences and grasp not only what is being said, but far beyond that (Kess 1992: 189). A discourse-based view of stylistic use of PUs is also relevant for teaching and learning translation skills. It should be borne in mind that the translator needs careful training in all areas.

Preconditions for phraseological competence of the translator include knowledge of the phraseological system and the particular PUs underlying actual stylistic realisations of PUs in discourse, as well as discoursal use. Translation competence is closely related to linguistic, literary, and stylistic awareness, as it affords the translator an opportunity to gain control over language to meet translation needs. One step in this direction is to increase the translator's ability to reflect on and perceive the nature of discoursal use in order to increase the effectiveness of translation performance.

Training in awareness of the stylistic and semantic implications of discoursal use of PUs is an important step in overcoming some of the pragmatic difficulties in the process of translating PUs. McCarthy and Carter point out that it is crucial to learn how to produce and understand texts and their variation ([1994] 1995: 38). Awareness gains in the cognitive domain should not be underestimated as discourse analysis contributes to the meaning of text (James and Garrett [1991] 1995b: 14). In order to achieve improvements in translation performance it is necessary to enhance sensitivity to and heighten conscious perception of the 
nature of discourse and appreciation of style. Seeing across sentences as a conscious translation strategy will help to draw inferences and bring meaning out of the underlying discourse.

Awareness of difficulties must be a prime concern. A metaphorical network presents a major hurdle in comprehension and translation; this especially refers to translation of literary texts. Let me illustrate a process-oriented translation approach to extended metaphor in D. H. Lawrence's novel The Lost Girl. In portraying Albert Witham, D. H. Lawrence creates the image of a fish using the PU an odd/strange fish and extending the phraseological image over a large stretch of text, that is, over 25 pages (Lawrence 1920: 82-106). The PU first appears on p. 83, creating an effect of audible stillness:

\section{an odd/strange fish}

He spoke in a slightly mouthing way, not well bred in spite of Oxford. There was a distinct Woodhouse twang. He would never be a gentleman if he lived for ever. Yet he was not ordinary. Really an odd fish: quite interesting, if one could get over the feeling that one was looking at him through the glass wall of an aquarium: that was most horrifying of all boundaries between two worlds. In an aquarium fish seem to come smiling broadly to the doorway, and there to stand talking to one, in a mouthing fashion awful to behold. For one hears no sound from all their mouthing and staring conversation. Now although Albert Witham had a good strong voice, which rang like water among rocks in her ear, still she seemed never to hear a word he was saying. He smiled down at her and fixed her and swayed his head, and said quite original things, really. For he was a g e n u in e odd fish. And yet she seemed to hear no sound, no word from him: nothing came to her. Perhaps as a matter of fact fish do actually pronounce st re a m s of watery words, to which we, with our aerial-resonant ears, are deaf for ever.

D. H. Lawrence, The Lost Girl, p. 83

The whole page is saturated with an extended metaphor of a PU whose translation poses a number of difficulties for the translator. The major challenge is that there is no equivalent PU in Latvian. The translation savādnieks (a strange person) given in dictionaries for "an odd (strange) fish" is non-idiomatic and what is more it is in no way connected with fish or the underwater image which D. H. Lawrence employs across novels, creating transdiscoursal relationships, see Mr Noon (1984), The Plumed Serpent (1933). Replacement of the metaphor by a simile, like Viņš patiesi bija savādnieks, kā divvaina zivs... (he was truly a strange person, like an odd fish), would be a way out, as it would provide a basic 
image to be extended in this particular case of discoursal use, though it might raise an objection that no additional stylistic techniques should be introduced in the target text. Once translation of the PU itself is solved, care should be taken to encompass the whole web of complementary images or rather sub-images and metaphoric elements which all go back to the PU:

The odd thing was that this odd fish seemed from the very first to imagine she had accepted him as a follower. And he was quite prepared to follow. (...) If only she could have got into the right state of mind, she would really rather have liked him. He smiled at her, and said really interesting things between his big teeth. There was something rather nice about him. But, we must repeat, it was as if the glass wall of an aquarium divided them.

Even Albert's brother produces the same cool, fish-like impression:

Alvina looked at Arthur, Arthur was short and dark-haired and nicely coloured. But now, his brother was there, he too seemed to have a $\underline{\mathrm{du} \mathrm{mb}}$, aqueous silence, fish-like and aloof, about him. He seemed to swim like a fish in his own little element. Strange it all was, like Alice in Wonderland. Alvina understood now Lottie's strained sort of thinness, a haggard, sinewy, s e a - w e e dy look. The poor thing was all the time s w i m ming for her life.

The metaphoric extension of the image of the odd fish goes together with another PU to swim like a fish which is also based on an underwater image. The instantial replacement of running by swimming in the PU to run for one's life and the ironic insertion of own little in the PU to be in one's element all work to one end to create a figurative undercurrent. The sub-image of swimming is taken up again on page 86 :

But she did not feel at all comfortable. He seemed so pleased. Only he was not pleased with her. He was pleased with himself on her account: inordinately pleased with himself. In his world, as $\underline{\text { n a fish's }}$, there was but $\underline{h \text { is own }}$ swimming self: and if he chanced to have something swimming alongside and doing him credit, why, so much the more complacently he smiled.

As the metaphoric extension unfolds, a number of lexical items appear which are associated with the image of the PU and reiterated, achieving a cumulative effect. Let me examine the message of strangeness. On page 83 strange appears in a free 
word combination while on page 105 it is used as part of the base form (another variant of the same PU):

She might have married him. He would have been strange, a strange fish. But were it not better to take the strange leap, over into his element, than to condemn oneself to the routine of a job? He would have been curious and dishuman. But after all, it would have been an experience. In a way, she liked him. There was something odd and integral about him, which she liked.

Lawrence leads us further into the passionate flow of verbal consciousness (Spilka 1958). The synonym curious also appears later in the text. Though not part of the base form of the PU, it functions to uphold the notion of strangeness:

And perhaps she would have children. She shivered a little. No, not his children! He seemed so curiously cold-blooded. And yet, why not? Why not his curious, pale, half-cold-blooded children, like little fishes of her own? Why not? Everything was possible: and even desirable, once one could see the strangeness of it. Once she could plunge through the wall of the aquarium! Once she could kiss him!

On page 84 Albert is described as "an odd-looking creature" and he smiles broadly with his "odd, genuine gallantry". The translation options for the synonyms odd, strange, curious, uncanny and not ordinary have to be established not merely for the given examples, but for the whole discourse. Reiteration of these epithets creates semantic parallelism which is relevant to cohesion.

In order to establish all the cohesive ties in the text it is advisable to study the segments of text in which the PU is realised as well as to examine the text in anticipation for anaphoric references (Halliday and Hasan 1976:17-18). When going back it is easy to discover that the first appearance of the PU on page 83 is preceded by a description of Albert which directly leads up to the PU an odd fish and heralds it like a prelude:

Picture her disappointment when she found Albert quite unattractive. He was tall and thin and brittle, with a pale, rather dry, flattish face, and with curious pale eyes. His impression was one of unçanny flatnes lemon sole. Curiously flat and fish-like he was one might have imagined his backbone to be spread like the backbone of a sole or a plaice.e. His teeth were sound, but rather large and yellowish and flat. A most curious person. 
The phraseological image of an odd fish is not only sustained by a web of subsequent sub-images, but is also maintained by certain cues or prop-words which provide background information to support the image and impart a particular message to the reader, such as flat, flattish, flatness, flatly p. 82, p. 106, uncanny p. 82, curious, curiously p. 105, dishuman, dishumanness pp. 105-106. The meaning of the epithet uncanny - "odd, strange and hard to explain"11 - enhances the feeling of oddity. Reiteration of these prop-words is not accidental. They all act as recall cues. Care should be taken to retain this network in the TL as it not only contributes to the description of the fish, but also has a cohesive function, thus reinforcing the role of the PU in the discourse. Compare the previous example with the passage on pp. 104-105:

Albert Witham was distasteful to her - or rather, he was not exactly distasteful, he was chiefly incongruous. She could never get over the feeling the he was mouthing and smiling at her through the glass wall of an aquarium, he being on the watery side. Whether she would ever be able to take to his strange and dishuman element, who knows?

pp. 104-105

Page 106 contains paragraphs that round up the extended phraseological metaphor covering 25 pages. The extended metaphor develops, leading the reader onwards, as the story unfolds. Development of the phraseological image (little half-fishes) goes together with reiteration of the prop-words which reinforce perception of the fish world. The metaphorical network is further sustained by the PU to take the plunge. The link is also maintained by reiteration of plunge, which first appears on p. 105 as one of the sub-images (see above).

\section{to take the plunge}

None the less, as Christmas drew near Alvina worked up her feelings. Perhaps she would be reconciled to him. She would slip across and smile to him. She would take the plunge, once and for all - and kiss him and marry him and bear the little half-fishes, his children. She worked herself into quite a fever of anticipation.

But when she saw him, the first evening, sitting stiff and staring flatly in front of him in Chapel, staring away from everything in the world, at heaven knows what - just a s fis hes st a re - then his dishumannlike an arrest, and arrested all her flights of fancy. He stared flatly in front of him, and flatly set a wall of oblivion between him and her. She trembled and let be.

11. See Collins Cobuild English Language Dictionary ([1987] 1988: 1582). 
Taken separately, these prop-words are seemingly unambiguous and unrelated to the PU. However, in these contexts they are rendered salient. They cluster around the central image, they prompt and guide, acting as ties and performing a cohesive function.

Let me examine some of these translation aspects of discoursal phraseological use in Galsworthy's novel The Silver Spoon. The title is an allusion to the PU to be born with a silver spoon in one's mouth, which is umbrella use and encompasses the whole of the novel. All in all this PU is used eight times in the text; it is reiterated, extended, alluded to, and punned on across 242 pages (Galsworthy [1928] 1976). A comparison of Bauga's translation of this novel into Latvian (Golsverzijs 1962) with the original shows that the major translation challenge lies in extending the image in the face of absence of a Latvian equivalent, so that extension of the metaphor sounds at times artificial. Another difficulty is rendering the whole of the metaphorical web and preserving the double vision, including all the subimages which form part of the extended metaphor:

England with the silver spoon in her mouth and no longer the teeth to hold it there, or the will to part with it! And her very qualities - the latent "grit", the power to take things smiling, the lack of nerves and imagination! Almost vices, now, perpetuating the rash belief that England could still "muddle through" without special effort, although with every year there was less chance of recovering from shock, less time in which to exercise the British "virtues".

pp. $68-69$

Anglija ar sudraba karoti mutē! Zobu vinaivairs nav, lai karoti saturētu, bet nav gribas šḳirties no tās. Un Anglijas nacionālie tikumi - izturība, prasme uztvert visu ar smaidu, nezināšana, kas ir nervi un iztēle! Tie tagad neatškiras no netikumiem, jo noved pie vieglprātīgas pārliecības, ka Anglija “izkulsies” visam cauri bez sevišķas piepūles, lai gan ar katru gadu aizvien mazāk izredžu atlabt pēc satricinājuma, mazāk laika vingrināties angḷu "tikumos".

A comparison of the latent "grit" with nacionālie tikumi - izturība reveals no correspondence. The latter means "endurance". However, it is not part of the figurative flow and it provides no double vision, while the latent "grit" is part and parcel of the metaphoric continuum of the silver spoon in one's mouth. It has associations with the PU to grit one's teeth, which conveys determination to clench one's teeth and carry on in the face of hardship. Gritted teeth is a sign of resolution (though latent) and a stiff upper lip. Interestingly, Galsworthy has provided inverted commas for "grit" as a prompt and a lead. The metaphorical vision is 
lost in the Latvian translation. Preserving stylistic cohesion requires preserving all the ties, all the strands of the metaphorical web.

The effect of the metaphorical information of the extended PU is reinforced by the use of prop-words, which cluster around the metaphor and act as recurring cues in the creation of meaning. One of them is spoiled. However, the Latvian translation gives a different rendering in each of the following contexts, so that the line of thought is lost and the semantic network is not maintained. This is in line with the lingering prescriptive tradition in Latvian, where repetition is seen as undesirable and is to be replaced by a synonym. The English are spoiled (Latv. samaitāti) by past prosperity when England was in a position to hold the silver spoon in her mouth (Galsworthy [1928] 1976:68). Have the English got so spoiled (Latv. izlutinäti) that they get down from table when threatened with a spoon of bone? (p. 87). There is something dangerous about silver spoons as they spoil (Latv. saboja) men and women of property (p. 124). And finally the eleventh baronet is called a spoiled boy (Latv. palaidnis) when he is splashing and plopping his silver spoon (p. 242). In all these cases spoil could easily have been translated using one of its basic meanings izlutinatt. The reiteration of spoiled is not accidental. It is a recall cue which facilitates associative responses to the PU that is in the focus of this metaphorical network; therefore, it should not be disregarded. Each instantial pattern may create some difficulties in translation; however, some are more challenging than others. For instance, translation of phraseological allusion frequently presents considerable obstacles.

Failure to render phraseological allusion into Latvian may be illustrated by the PU when Adam delved and Eve span, who was then the gentleman? in Egle's Latvian translation of Shakespeare’s Hamlet (Šekspirrs 1964, see the English text of the example in Ch. 4.4):

Pirmais kapracis: Dārznieki, grāvrači un kaprači tomēr ir vissenākie augstmaņi; viņi turpina Ādama arodu.

Otrais kapracis: Vai tas bija augstas kārtas?

Pirmais kapracis: Tas bija pirmais, kas lietoja kādus kaujas rīkus.

Otrais kapracis: Kā - viņam taču nebija nekādu rīku.

Pirmais kapracis: Ko, vai tu esi pagāns? Kā tu tulko svētos rakstus? Svētos rakstos teikts, ka Ādams racis. Vai bez kāda rīka viṇš varēja rakt?

W. Shakespeare, Hamlet, Act V, Sc. 1

No equivalent for this PU exists in the Latvian language. The meaning of the whole passage is obscure. The effect is aggravated by the pun on the word arms, which is not achieved in Latvian either. 
Translation of phraseological allusion is usually a success if an equivalent exists of the given PU in the TL. For example, the PU the cat would eat fish but would not wet its feet has a Latvian equivalent kakis grib zivtinas èst, bet negrib kājinas slapināt. Obviously the origin of this PU goes back to Latin: Catus amat piscem, sed non vult tingere plantas (The Concise Oxford Dictionary of Proverbs [1982] 1992:38). This correspondence has enabled the translator, Adamovičs, to offer an adequate rendering of this instantial change in Macbeth (Šekspirs 1965, see the English example in Ch. 4.4):

Makbeta kundze: Tu baidies savos darbos būt tas pats,

Kas iegribā? Tu vēlētos gan iegūt,

Ko cienī pats kā dzìves dārgu rotu,

Bet paša acīs topi glēvulis,

Kam gribēt gribas, bet kas neuzdrìkstas,

Kā kakisis parunonāạ.

W. Shakespeare, Macbeth, Act 1, Sc. 7

Translation of instantial use of PUs is even more of a problem in verse that involves prosodic considerations. This also refers to modern translations of classical works into the same language. For instance, Coghill's translation of Chaucer's The Canterbury Tales [1951] 1955 into Modern English has disregarded instantial use in many places, replacing it by the literal meanings of words (see the original MiE example in Ch. 4.4):

Once, long ago, there dwelt a poor old widow

In a small cottage by a little meadow

Beside a grove and standing in a dale.

This widow-woman of whom I tell my tale

Since the sad day when last she was a wife

Had led a very patient, simple life.

Little she had in capital or rent,

But still by making do with what God sent

She kept herself and her two daughters going.

Three hefty sows - no more - were all her showing,

Three cows as well; there was a sheep called Molly,

Sooty her hall, her kitchen melancholy,

And there she ate full many a slender meal;

There was no sauce piquante to spice her veal,

No dainty morsel ever passed her throat,

According to her cloth she cut her coat,

Repletion never left her in disquiet 
And all her physic was a temperate diet,

Hard work for exercise and heart's content.

G. Chaucer, The Canterbury Tales, pp. 238-239

The allusion to the PU hunger is the best sauce is lost in the TL as sauce piquante (italicised by the translator, Coghill) fails to evoke any associations or develop a figurative line of thinking. Actually the literal meaning is reinforced by the use of the French word piquante. The reader remains in the realm of cooking. The second allusion is lost altogether, as the PU to cut one's coat according to one's cloth is given fully, so it is merely a case of core use. One reason why translations of Chaucer's works into MoE fall flat is that they fail to reveal creativity in use of Chaucer's language.

Failure to retain the image of the PU will result in failure to capture the semantic and stylistic message of the allusion, and hence a loss in translation. It is true that cases of instantial use do not lend themselves to translation very well; however, it would be incorrect to argue that they do not translate at all.

One way to achieve discourse competence is to perform contrastive analysis of discourse phenomena in the SL and the TL. Inability and failure to identify and comprehend the stylistic use of PUs means failure to recognise the cohesive elements that connect parts of the text and trace the semantic ties relevant for its comprehension. Indeed, failure to identify the complete network of relationships and associative links created by instantial stylistic use of PUs within the flow of discourse leads to inaccurate or false interpretation and hence to errors in translation. Inability to perceive the figurative web of the SL leads to loss or distortion of the semantic and stylistic impact of the PU in the TL. Stylistic awareness and a cognitive approach to translation may help to cope with some of these difficulties.

The translation skills needed to cope with this complicated task should be trained together with the ability to comprehend and feel figurative use, and acquire better identification skills. This would enable the translator to process stretches of text containing PUs changed to suit the stylistic discourse requirements and to interpret a whole range of instantial use. Translator competence is related to cognitive and linguistic awareness, thereby enabling the translator to gain control over language to meet translation needs. Translation is a cognitive operation of the mind.

In conclusion, the student of translation needs to be exposed to phraseology and its stylistic use. Unfortunately, most dictionaries do not help in training the translator in this respect (see Ch. 1.2), as they tend to avoid stylistic use of PUs in their entries. Even if dictionaries were improved, as they hopefully will be, they would never be able to reflect all the wealth and variety of instantial use. The main task is to train translator stylistic awareness to cope with discourse phenomena. 
A discourse-based approach enables the teacher of translation to shift emphasis from the preoccupation with teaching separate PUs and their translation options, but, rather, focus on discourse features, the choice, occurrence, and co-occurrence of the stylistic use of PUs and their distribution, as well as prevalence of a certain type of stylistic use in certain genres or parts of text.

\subsection{Lexicography, glossography, notes and comments}

Stylistic awareness of the discoursal properties of PUs is also important in such pragmatic areas as compilation of dictionaries and glossaries, as well as making notes and comments on literary texts. It is of crucial importance to reassess this area of applied stylistics in the light of a discourse-based stylistic approach to language. First I would like to explore a number of challenges in lexicography caused by instantial use.

\section{A. Lexicography}

Making dictionaries is hard and painstaking work; thus it is only natural that lexicographical errors occur even in well-researched and meticulous publications. Lexicographers have to identify the base form and differentiate not only between variants, synonyms, and homonyms, but also between core use and instantial use. A number of common errors may be looming in lexicographical practice:

1. Failure to identify the base form

Errors in establishing the base form and the true origin of the PU are frequently due to inaccurate identification of the base form, namely, confusion between core use and instantial use. ${ }^{12}$ For instance, Kunin (1967a: 149-150) registers the PU a cat with nine lives as an expression created by Shakespeare, quoting:

Tybalt: What wouldst thou have with me?

Mercutio: Good king of cats, nothing but one of your nine lives; that I mean to make bold withal, and as you shall use me hereafter, dry-beat the rest of the eight.

W. Shakespeare, Romeo and Juliet, Act III, Sc.1

On the same page Kunin gives another entry a cat has nine lives as a separate PU and gives the following example (op. cit.: 149):

12. For errors in differentiating between core use and instantial use, see Ch. 1. 
One of the most striking differences between a cat and a lie is that a cat has only nine lives.

Mark Twain, Pudd'nhead Wilson

The two forms a cat has nine lives and a cat with nine lives are both registered by Kunin as base forms, i.e., two different entries. However, all the other dictionaries of idioms give only one base form: a cat has nine lives, see Brewer's Dictionary of Phrase and Fable ([1959] 1968: 181), Longman Dictionary of English Idioms (1979:49), Pickering (1997:41) and others.

In point of fact, the PU a cat has nine lives was recorded before Shakespeare by John Heywood in A Dialogue Containing ... the Proverbs in the English Tongue 1546 (Pickering 1997:41) which was 18 years before Shakespeare was born (1564-1616)! Obviously a cat with nine lives is not a base form. Moreover, it is not a PU created by Shakespeare but a case of stylistic use of a PU well established in the language tradition of ENE. Kunin comes to the inaccurate conclusion that Shakespeare's play is the origin of this PU because The Oxford English Dictionary registers Romeo and Juliet as the source of the first recorded example. ${ }^{13}$

2. Failure to identify the etymology of the PU

The etymology of PUs may be one of the causes of lexicographical errors even in very good dictionaries. For instance, the PU to the world's end is given by Kunin's English-Russian Dictionary of Phraseology (Kunin 1967a:286) as a Shakespearean phrase. However, Chaucer used it five times in its core use in his works ${ }^{14}$ (MiE: $\underline{\text { un- }}$ to the worldes ende), which was 200 years before Shakespeare! The Oxford English Dictionary in XII Volumes ([1933] 1961:300 of vol. XII) proves that it was already used in the OE period with the preposition $o p: \underline{o p} s \bar{e}$ woruldes ende. It is crucial to distinguish between a free metaphorical combination of words created by an individual writer (in this case Shakespeare) and a PU - a stable word combination with a figurative meaning and well established in the language tradition.

Sometimes a specific meaning of a phrase is attributed to an author without recognising that the particular instantiation is a case of a well-known PU at the time. For example, Chambers 20th Century Dictionary [1983] 1987 gives the following meanings of colt's tooth: one of a horse's first set of teeth; love of youthful pleasures (Shak.); wantonness. It is imprecise to ascribe this phrase to Shakespeare as the PU to have a coltes tooth ${ }^{15}$ was used in Chaucer's day (and most probably

13. See the explanation in the Preface to Kunin's dictionary (1967b: 12).

14. See Chaucer CT, B, 3828; CT, D, 1455; TC, IV, 1580; TC, V, 894; TC, V, 1058 (Chaucer 1919).

15. For a detailed diachronic study of $a$ colt's tooth, see Whiting (1948). 
before him). In Chaucer's works it appears twice, once in core use: CT, A, 3888 and once as an extended metaphor, going beyond the limits of a single sentence:

He was, I trowe, a twenty winter old, And I was fourty, if I shal seye sooth, But yet I hadde alwey a coltes tooth. Gat-t o the d ${ }^{16}$ I was, and that bicam me weel.

G. Chaucer, The Canterbury Tales, D, 600-603

Establishing the origin of PUs may be a dangerous exercise. For instance, Simpson writes that "many of our common sayings and figures of speech originated from creative metaphors in literature". Among the examples we find in my mind's eye which he believes saw its first use in the plays of William Shakespeare (Simpson 2004: 94). However, lexicographical sources date the PU in one's mind's eye to the 15th century (Merriam-Webster's Online Dictionary 2009). Actually, I tend to think that people must have used it long before the first recorded case as the PU reflects a mental experience and a way people think.

3. Failure fully or partly to record instantial use

Many dictionaries fail to give instantial forms in their illustrations (see Ch. 1). Even those dictionaries that record instantial use in their examples frequently fail to take all the text of the example, leaving part of the instantiation behind, for example Brewer's Dictionary of Phrase and Fable ([1959] 1968: 181) gives the example "Good king of cats, nothing but one of your nine lives" from Shakespeare's Romeo and Juliet as an allusion to a cat has nine lives, leaving out the extension of the PU "dry-beat the rest of the eight". Thus it is an identification error (see Ch. 2.4): "eight of the nine lives" has been left out by the author of the dictionary:

Tybalt: What wouldst thou have with me?

Mercutio: Good king of cats, nothing but one of your nine lives.

W. Shakespeare, Romeo and Juliet, Act III, Sc.1

Likewise Kunin's example misses the previous line containing "Tybalt, you ratcatcher". Quoting only half of the instantiation does not bring out the full message. The humiliating rat-catcher is an anaphoric periphrastic extension of the image of the PU. Tybalt is an equally important item; it is part of the extended image, as it contains two meanings (a pun): it is used as a proper name, a nephew to Lady Capulet, and it also has the generic meaning of a common noun, that is, Tybalt was formerly a name commonly given to cats, hence it is linked with the allusion (see Brewer's Dictionary of Phrase and Fable [1959] 1968: 919). "Dry-beat

16. MiE gat-tothed - having the teeth far apart (Skeat 1919:47). 
the rest of the eight" is part of the associative network of the allusion, thus is part and parcel of the instantiation a cat has nine lives in Mercutio's retort. It is no use quoting bits and pieces: the instantiation needs to be treated as a semantic and stylistic whole, as a cohesive stretch of discourse:

\section{a cat has nine lives}

Mercutio: O calm, dishonourable, vile submission!

Alla stocata carries it away.

Tybalt, you r a t - c a t ch e r, will you walk?

Tybalt: What wouldst thou have with me?

Mercutio: Good king of cats, nothing but one of your nine lives; that I mean to make bold withal, and as you shall use me hereafter, dry-beat the rest of the eight.

W. Shakespeare, Romeo and Juliet, Act III, Sc.1

PUs do not occur in isolation; they are used in discourse. A discourse-based approach to dictionaries, including phraseological dictionaries (see Ch. 1), is most beneficial and indeed welcome. Stylistic awareness of instantial use is essential for both users and compilers of dictionaries.

\section{B. Glossaries}

Glossaries are designed to assist the reader with a specifically difficult text. In diachronic studies of English, an acute need exists for glossaries for OE, MiE, and ENE texts. Traditionally, glossaries are not discourse-oriented. With respect to phraseology, glosses do not reflect instantial use and hence do not single out the base form, which interferes with comprehension and interpretation of the text. Most glossaries deal only with separate words, leaving PUs out. For instance, Skeat's edition of The Complete Works of Geoffrey Chaucer (1919) contains an extensive glossary. However, most PUs are not included and instantial use is not identified in it. The reader may feel frustrated in many cases as dictionaries usually are not helpful in this respect either, especially in cases when the whole PU or some constituents have already become obsolete or diachronic variants exist. For example, the MiE PU a serpent under floures is not given by Skeat either under serpent or under floures (Skeat 1919). In Chaucer's works, the PU appears twice, both in an instantial form, see CT, D, 1992-1996; 2001-2003 in Ch. 5.4 and the example below:

Right as a serpent hit him under floures

Til he may seen his tyme for to byte,

Right so this god of love, this ypocryte,

Doth so his cerimonies and obeisaunces. 
Although Shakespeare's English is much closer to MoE than Chaucer's, it is by no means insignificant to have good glossaries of Shakespeare's works due to the complexity of thought and the subtle and intricate form of expression. All the glossaries of his complete works that I have read offer explanations of only a few PUs, all of them in their core use; see, for instance, Shakespeare's glossary by Crystal and Crystal (2002). This means that all the abundance of complicated instantial cases in Shakespeare's works remains outside the domain of the glossary. The few examples from Shakespeare's works quoted in this book clearly indicate that instantial use may cause serious difficulties for the uninitiated reader.

\section{Notes and comments on literary texts}

Notes and comments on literary texts appear either as literature guides or as special chapters at the end of books for both native students and foreign language learners.

Instantial use may turn out to be a stumbling block in reading and appreciating literature, especially in complicated and sophisticated discourses. I have chosen John Fowles' novel The French Lieutenant's Woman as it is a compulsory item for students of English Literature "A" level and GCSE in the United Kingdom, and English Literature at specialist English Departments in most universities, including the University of Latvia. The French Lieutenant's Woman has become part of the English-language canon. The first page of the novel contains an interesting piece of text:

The Cobb $^{17}$ has invited what familiarity breeds for at least seven hundred years, and the real Lymers will never see much more to it than a long claw of old grey wall that flexes itself against the sea.

J. Fowles, The French Lieutenant's Woman

Schools in the United Kingdom have access to excellent notes on English literature published by Longman: Longman Literature Guides. In this series, Spear's Notes on The French Lieutenant's Woman are of invaluable help to the reader and learner in coping with the innumerable allusions, references, and quotations; however, Fowles' imaginative and ingenious treatment of PUs has been disregarded. The quoted example is the only exception when Spear explains the meaning of what familiarity breeds, namely, contempt ([1988] 1992:11). However, this does not help to decipher the case. Merely mentioning "contempt" takes the reader halfway through the difficulties. Full comprehension and interpretation of this part of the discourse requires identification of the base form that this instantiation implicitly

17. The Cobb is a long harbour wall at Lyme in England. 
contains: familiarity breeds contempt. The allusion wh at familiarity breeds gives the meaning by way of periphrasis. What makes the process of identification more challenging is the absence of cues (either anaphoric or cataphoric) to prompt or lead the unaware reader to resolving the ambiguity.

Another series, Brodie's Notes, designed to aid GCSE and " $\mathrm{A}$ " level students in their coursework projects, sets an aim to increase understanding of English literature and provide imaginative responses. This series also includes Notes on John Fowles' The French Lieutenant's Woman by Handley ([1988] 1993), who gives no comment on what familiarity breeds in Notes on Chapter 1.

Handley focuses almost exclusively on separate words, proper names, and Latin or French phrases. For instance, to explain the phrase "you march away from the Rubicon", Handley gives the historical background: Caesar crossed the Rubicon and thus committed himself to war against the Senate and Pompey (Handley [1988] 1993:63). Handley adds that this implies decision while Fowles' phrase implies the reverse. However, Handley gives neither the PU nor any interpretation of its instantial meaning in discourse. Cf.:

\section{to cross the Rubicon}

'Then amen. Jacta alea est ${ }^{18}$ '. He picked up his hat and bag from the table and went to the door. But there he hesitated - then held out his hand. 'I wish you well on your march away from the Rubicon.

J. Fowles, The French Lieutenant's Woman

Interestingly, the same place in Spear's Notes receives a geographical and historical comment on just one word "Rubicon": the river which bounded Caesar's province; his crossing of it in $49 \mathrm{BC}$ marked the start of the war with Pompey (Spear [1988] 1992:43-44). The literary comment explains that it means that Charles had passed the point of no return. For the learner, however, it is essential to know the base form to cross the Rubicon and its meaning: to make a decision (Longman Dictionary of English Idioms 1979:280), as well as the pattern of allusion. This knowledge would help to appreciate the discoursal form, enhancing stylistic awareness and comprehension of figurative language, both in this particular case and other instantiations. If properly inculcated, these skills will eventually ensure stylistic awareness of language and turn into a tool for coping with difficult discourses in the future.

The older the text, the more the need for notes, including notes on use of PUs. Obviously PUs were not the focus of attention at the time when the notes were made. For example, Skeat's Notes on "The Prologue to the Canterbury Tales" in a

18. Italicised by Fowles. Jacta alea est (Latin) - the die is cast. 
school edition (1906:48-89) are extensive and profound; however, they deal only with grammatical, lexical, and versification matters.

It is interesting to explore literary and linguistic notes and comments on Shakespeare's works. His plays are a special type of discourse that call for detailed notes and comments to tackle the immensely complicated use of language, as well as the pitfalls presented by ENE. However, glossaries to Shakespeare's works tend to overlook PUs and their stylistic use, focusing on difficult lexical issues. For example, the Glossary for The Dramatic and Poetical Works of William Shakespeare (c1929), published by Thomas Nelson and Sons, gives only a few PUs, deciphering the meaning of the base form. To carry coals receives the explanation: "to submit to any humiliation - in allusion to the wretchedness of the menials employed in carrying coals to the halls and kitchens" (p. 544). Thus, the complex stylistic instantiation at the beginning of Romeo and Juliet remains unattended (see Ch. 5.4 and Appendix V).

Many teaching materials are designed to guide readers and help overcome these difficulties and prevent errors. For instance, Ilyish's notes on and glossary to Shakespeare's play Romeo and Juliet give a good historical insight into many difficult places; however, stylistic use of PUs is virtually overlooked. In some cases the notes are incomplete, giving only some of the semantic and stylistic information needed to perceive and comprehend the case. For example, the instantiation of "a cat with nine lives" 19 in the dialogue at the beginning of Act III, Scene 1 receives the explanation that according to a common belief "nine lives" means that cats usually survive because they are said to have nine lives. As the explanation is given in Russian, it does not establish any link with the English PU that serves to provide cohesion for these lines.

The famous dialogue at the beginning of Romeo and Juliet, Act I, Scene 1 (see Appendix V) containing phraseological saturation using a number of PUs with the image-bearing constituent wall $^{20}$ has been given a brief explanation: "take the wall - to take the upper hand" (Ilyish 1972:93). These notes and the glossary are designed for advanced studies in English linguistics in specialist departments.

In conclusion, among the reasons why instantial use of PUs is hard to master as a skill (both identification and actual use), one could cite theoretical obscurity or discoursal complexity, as well as insufficient support from dictionaries, glossaries, notes and comments. This is an area of applied stylistics that calls for further exploration, utilisation, and specialist training in stylistic awareness. Phraseological stylistic competence in lexicography will enhance the quality of

19. See the full text of this example earlier in this section.

2o. See the full text of this instantiation in Ch. 5.4. 
dictionaries, which would be of great benefit to all users, including native students and L2 learners.

\subsection{Advertising}

Applied stylistics does not confine itself to the objectives discussed above. It also has pragmatic and economic areas of application, such as advertising. Advertisements seem to have a ubiquitous presence. Advertising has evolved many types and modes of expression: commercial consumer advertising, wholesale advertising, prestige advertising (by government departments), classified advertising (want ads), amongst others, which may appear on radio and TV, in newspapers, street advertising (such as advertisements on buildings, billboards, buses, trams and other vehicles), specially designed printed promotion materials (brochures, flyers, posters, postcards, souvenirs), and globally on the Internet to be viewed by multimedia computer users.

It is common knowledge that the aim of advertising is to draw attention to a product or a service in order to sell it (Crystal [1987] 1995:390; Goddard [1998] 2003:9-21). Advertising needs both to inform and persuade (Crystal and Davy [1969] 1995:222), not in a straightforward way or by aggressive sales tactics, but in a more sophisticated manner. Use of figurative language, including visual puns and metaphors, has become a regular feature of contemporary advertising, which in turn has become a special type of discourse (Carter and Nash [1990] 1995; Cook [1992] 1994; Goddard [1998] 2003). In advertising, idioms and metaphorical lexical expressions may appear in an extended or altered form motivated by conceptual metaphorical mapping (Lundmark 2005: 104-129; Semino 2008: 168175; Forceville 2009).

Figurative language has become a powerful tool in marketing, where semantic, stylistic, social, and psychological criteria are at work to achieve an economic end. The advertiser expects the potential buyer to have some imagination and creativity to be able to conceive an advertising idea expressed by figurative means. Thus, as Leech (1966:175) observes, advertising extends the world of experience and opens up new pathways of communication.

Over recent decades, most of the research in advertising has focused on multimodal discourse, involving more than one mode of communication. The most prominent contributions to the research of metaphor in multimodal representations have been made by Charles Forceville (1991, 1994, 1996, 2008, 2009). Fruitful application of the theoretical tenets of cognitive linguistics to multimodal metaphor, including advertising, is systematically presented in Multimodal Metaphor, a volume edited by Forceville and Urios-Aparisi (2009b). 
Stylistic use in advertising has also attracted the attention of many phraseologists and paremiologists (for example, Mieder 1989:293-315, 1993: 135-172, 2005; Sabban 1998a; Litovkina 2000; Naciscione 2001a, 2001b:225-230; Bass 2003; Lundmark 2003, 2005, 2006; Omazić 2005; Džanić 2007; Fiedler 2007:75112; Burger 2008 et al.). Undoubtedly PUs, including proverbs, have found a "most vital stomping ground in the ever growing world of advertising" (Mieder 1989:298). Innovative ways have replaced core use in advertising, especially "in advertising slogans as they express the main message in advertisements" (Mieder 1993: 140-148).

It is revealing to look at the ways PUs are exploited in advertising and to explore how the phraseological image is used to construct meaning. A vast number of advertisements are based on PUs as the most suitable language vehicle to create a striking and memorable image. Memorability is an important function in advertising and creation of corporate identity (Goodman 1996:51). Figurative language makes the advertisement much easier to remember; therefore, figurative use of language is one of the most striking features of advertising style. Thus, it is of critical importance to explore the stylistic dimension of advertisements as they are built on a stylistic pattern, and, as a rule, on interaction of several stylistic patterns.

Strikingly, advertisements turn more to the visual than the verbal, which may be explained by human psychology: the sense of vision is frequently stronger than the sense of hearing. Cook points out the advertiser's faith in the superior power of pictures over words ([1992] 1994:55). People usually find it easier to believe what they see than what they hear.

In most cases it is the visual context and design of an advertisement that makes an immediate visual impact and causes the potential customer to notice it. Advertisements have become part of visual culture. However, in order to get people to identify a product or a service, remember its name, and persuade them that it is worth buying, advertisements basically rely on use of language. All the elements, the visual, the linguistic and the psychological, are essential: they combine to produce the brand image of a product or a service. Cognitive studies bring out the role of multimodal metaphor in the construction of meaning in advertisements (Forceville 2008, 2009).

PUs have a special role to play in advertising, not only due to their figurative meaning but also because they lend themselves easily to instantial use both in verbal and visual contexts. Usually the aim is to provide both narratives: textual realisation and visual representation, forming a multimodal text, for example: 


\section{to sit pretty}

Sell one of these and you could be sitting pretty.

Travel Weekly, 10 Feb., 1999, p. 24

The advertisement features a special comfortable armchair for air passengers (see Appendix IX). However, the product advertised is not a piece of furniture, but business class travel. The pun is created by visual representation. The linguistic and non-linguistic modes of expression are not independent of each other: verbal language is needed in order to interpret and amplify the meaning or use of nonverbal representations (Goodman 1996:381).

The following visual pun (Travel Weekly, 30 August, 1999, p. 12) contains no other text to introduce the PU but the unit itself: a show of hands (see Appendix X). The base form of the PU a show of hands denotes a form of voting which involves counting the hands raised by people to vote. However, the picture features a seated man with multiple hands like an Indian deity. The caption explains that a car rental company Holiday Autos thanks its customers for their support so that they have their hands full and hope that customers will continue to support the company with a real show of hands. The picture brings out the role of the phraseological image in advertising.

The next advertisement comes from fashion magazine Bella (12 March, 1997, p. 5) which presents a page with a headline Mum's the word! in an attempt to get mothers and daughters to go spring shopping together and find classic items to share without letting anybody know about it. A visual representation of the sales endeavour supports the play on words: famous mothers and daughters are photographed together. The advertisement is a pun based on two homonyms: Mum meaning mother and the PU Mum's the word! meaning let's keep this as a secret (Cowie, Mackin and McCaig [1993] 1994b:393).

In visual advertising the trend has been for the link between the advertised product and its visual representation to become more remote and indirect. It frequently exists only as a metaphorical and metonymic vision. For instance, an insurance advertisement for GE Travel Insurance Services is a picture of a welltended sheep in a lush green field. The caption reads: "We won't pull the wool over your eyes" (Travel Weekly, 19 July, 1999, p. 41) (see Appendix XI). This is a promise, implying that customers can trust the company; they won't be deceived or taken advantage of. They are expected to perceive the visual pun and comprehend and interpret the semantic link between the image of the PU and the wool on the sheep in the picture. The PU in the caption works like a coda both visually and verbally.

As social uses of language demand rapid response and interaction (Cook 1994: 255), advertisements, too, encourage a quick decision. They are designed to 
efficiently attract a potential buyer of a product or service, hence the role of stylistic pattern and phraseological imagery in assertive advertising. The skilful juxtaposition of figurative meaning and its instantial visual representation catch the eye and make the reader stop and ponder. For instance, the travel agency Cadogan Holidays advertises itself as a tour operator with a perfect history in short breaks (see Appendix XII) through a visual representation of an excellent specimen of a pedigree breed and the following text in the caption to create a visual discourse:

\section{It's n o shaggy dog story,}

we really do have an aw ard winning pedigree!

Travel Weekly, 30 August, 1999, p. 20

The extended image of the PU a shaggy dog story ${ }^{21}$ is used as a means of visual argumentation. The advertisement brings out the superior quality of the tour operator by drawing a parallel with the perfection of distinguished ancestry.

Advertising certainly works for marketing. It is marketing that decides the way a product or a service should be sold, such as the price, the place, and the time, including the way it should be promoted and advertised. Enhanced use of a combination of the visual and the verbal in advertising is in line with advertising psychology, more aggressive promotion, sophisticated marketing of products, and wider use of implicit advertising. Advertising tends to be more indirectly expressed, even encoded. It can also act more subtly, establishing "symbolic connections between the product and the ideals and emotive urges of the consumer" (Leech 1966: 176).

Although visual discourse is usually coupled with verbal text, working hand in glove with it, cases may arise when no verbal text exists: the visual narrative constitutes the whole discourse of the advertisement. However, the visual effects are tied with the verbal. Crystal believes that "linguistic and non-linguistic modes of expression are never totally independent of each other: verbal language is always needed in order to interpret and amplify the meaning or use of non-verbal representations" (Crystal [1987] 1995:381). From the cognitive viewpoint, both the visual and the verbal are manifestations of figurative thought.

Let me explore the visual representation of the PU there is a black sheep in every flock $>$ the black sheep of the family $>$ a black sheep on an apron (see Appendix XIII). This is a case when visual representation is not backed by the verbal, nor is it accompanied by any cues, close or remote; no base form is recorded on the apron, nor are any instantial elements explicit. However, to achieve comprehension the PU is retrieved from long-term memory and a tie is established

21. Note that the PU shaggy dog story and its metaphorical extension award winning pedigree are underlined in the advertisement! 
between the visual representation and the mental image of the PU. A complete absence of any text creates an effect that is purely visual. The visual communicates without words. It brings out the meaning due to its link with the mental picture. It stimulates the imagination of the potential customer, who stops and thinks and recreates the PU in the mind's eye.

This is not an advertisement in the traditional sense of the word. It does not advertise sheep-breeding, wool, the textile industry, or mutton. Nor is it directly linked with the image of the PU, which denotes a person who is in some way not up to the standards of the others in their family or group, and is considered bad or worthless by them (CCDI 1995:341). It would be far-fetched and unfounded to presume that a person working in the kitchen and wearing an apron is supposed to be the black sheep of the family. In this case the phraseological image has turned into a pure marketing tool, and the advertisement is a mere sales gimmick. It has a much broader purpose: to attract the customer, capture attention, make the customer stop, think, develop a liking, and buy the product. The ultimate aim of application of the phraseological image is a sale. The visual impact of the PU works and the sale is achieved. Interestingly, the aim of the advertiser in this case is not reinforcement of the brand image, either, but just a simple sale, as the name of the company is not even mentioned on the goods.

Thus, advertising is one of the types of multimodal use for pragmatic ends. The examples analysed reveal the potential of visual representation of instantial stylistic use to create a visual narrative. In an advertisement, the PU is usually represented by its image-bearing constituents in their literal meanings. However, it is implicitly present in visual discourse due to the stability, and the semantic and stylistic cohesion of phraseological meaning.

I understand that I have barely scratched the surface of stylistic use of PUs in the realm of advertising. However, the purpose of this section has been merely to give an insight, as this area of applied stylistics deserves a separate monographic investigation, especially as advertising is developing rapidly together with use of multimodal stylistic techniques. Moreover, each new piece of scholarly research expands the horizon of investigation in multimodal discourse, bringing out the great variety of metaphorical and metonymic conceptualisation in advertising (Forceville and Urios-Aparisi 2009a: 3-17).

In conclusion, instantial stylistic use of PUs is not only of great theoretical interest, but also a resource for applied stylistics: it has diverse practical applications in various spheres of life. In the cognitive linguistic view, figurative language structures not only thought but action, too (see op. cit.:3). The most common applied areas are: teaching and learning language and literature, teaching translation and translation practice, lexicography and glossography, social and cultural studies, advertising and marketing. The application of stylistic use is by no means 
exhausted by these spheres of human activity. The need for stylistic training is essential not only for would-be teachers, translators, and lexicographers, but also for specialists in any area dealing with applied stylistics. Training in stylistic use of PUs leads to substantial gains in cognitive skills and stylistic awareness: conscious perception and understanding of significant changes in base form and meaning, associative links and their networks, stylistic cohesive ties and construction of new meaning in discourse, including multimodal discourse presented in such modes of communication as pictures, film, music, sounds, and gestures. New ways and modes of stylistic use of PUs and their application is certainly one of the paths for further exploration. 


\section{Glossary}

access: retrieval (of the base form) from memory, used to denote both the process and the actual fact of recall. See also recall

applied stylistics: an area which explores practical utilisation of the principles, discoveries, and theories of language, literature, and stylistics, including cognitive stylistics. It is an umbrella term which denotes application of the stylistic competence of the language user in the fields of teaching, curriculum design, translation, lexicography, glossography, compilation of notes and comments on literary texts, socio-cultural studies, multimodal representation, advertising, and marketing

base form: the form to which other forms of the PU can be related and with which they can be compared, in practice the dictionary form and meaning, recorded as the headphrase. It is a form of the PU outside discourse, used as a base when assessing PUs used in discourse. The base form is stored in the long-term memory of the language user as a language unit which can be reproduced and which is accessed when a discourse situation calls for it. The base form is a cohesive entity per se which secures the existence and development of the $\mathrm{PU}$ in discourse

base metaphor: the metaphor which is part of the image of the PU in its base form

cleft use: one of the patterns of instantial use and phraseological cohesion across sentence boundaries. It splits up the PU, which is a stable figurative continuum in its base form. Instantial cleft use is made possible due to cohesion of the PU at language level. It is not only the syntactical flow of the PU which is discontinued; a cleft has strong semantic and stylistic implications in discourse

coda: a summary following resolution of an action at the end of a text, conveying a quintessential generalisation or a moral message

comprehension: a cognitive act which yields deep and thorough understanding of the principles, constructions, and interrelationships in a specific case of discoursal use. Comprehension of (phraseological) cohesion and coherence forms part of cognitive performance

comprehensive use: instantial use which encompasses a text, either appearing in titles and headlines or in codas. Comprehensive use applies simultaneously to the whole text. See also umbrella use

concurrent use: simultaneous occurrence of several instantial changes reinforcing the message and creating a focal point within the framework of one PU. Each instantial change exploited in concurrent use contributes to the combined stylistic effect of the whole instantiation. Concurrent use is characterised by a high degree of phraseological cohesion, which creates a powerful unified impact. The dense cluster of cohesive ties represents the complexity of human communication and cognitive processes

core use: use of the PU in its most common form and meaning. In its core use the PU does not acquire additional stylistic features in discourse and does not exceed the boundaries of one 
sentence, the same as the base form. Core use brings out the essential cohesive qualities of the base form

cue: a prompt that plays a supporting role in the metaphorical network, facilitates associative responses to the PU, and acts as a guide in the process of recall. As background information, cues support the image and impart a particular message to the reader. They are important at the level of textual organisation

cumulative use: incremental use of an instantial element gaining momentum achieved by successive reiterations of the same single pattern over a stretch of discourse, augmenting and increasing steadily in quantity, degree, or rate of development. It works consecutively as a technique of cohesion and enhancement. Cumulative use is based on the sequential principle when each successive item appears as part of a sequence, providing phraseological sustainability in discourse

diminutive: the diminutive in phraseology is a semantic stylistic category with diverse forms and means of expression. The diminutive may be part of the structure of phraseological meaning in the system of language. The diminutive constituent(s) of PUs may be formed by morphological means, lexical means, or in a combined lexical morphological way. Each of these is characterised by a varying degree of frequency, productivity, and diversity. PUs may also acquire instantial diminutive constituents in discourse

discoursal use: the ways in which PUs and other elements interact over a stretch of text which brings out their involvement in the interrelated web of semantic and stylistic interrelationships in discourse. PUs may play a considerable role in organisation of discourse, providing continuity across its various parts. The thread of phraseological meaning persists from one segment of discourse to another as the semantic process is continued and the discourse unfolds. The discoursal web is enabled by the very nature of the PU - cohesion of the base form. The PU, some part of it, or separate constituents cannot be interpreted without the complete extent of instantial use

extended phraseological metaphor: an instantial pattern involving a string of sub-images sustained and tied together by the base metaphor of the PU, creating a cohesive network of associative metaphorical bonds

identification: a procedure applied to a particular part of text in order to establish the identity of the PU, explore the type of its use, including instantial use, and the web of relationships with a view to discourse analysis of the instantiation. For L2 learners, identification starts as a memory exercise in recognition supported by verification of the base form from which the instantial form is devised. In the process of identification the steps - recognition > verification $>$ comprehension $>$ interpretation - are integral parts of a unified cognitive process

insertion: an instantial pattern where one or several instantial constituents are introduced into the base form of the PU. Insertion affects both structure and meaning of the PU in discourse

instantial stylistic use: a particular instance of a unique stylistic application of a PU in discourse resulting in significant changes in its form and meaning determined by the thought and the context. Instantial use explores experience far beyond the possibilities of core use, constituting a boundless resource for the writer's or speaker's creativity. The instantial form has been created for a particular purpose; however, the term instantial refers only to the textual manifestation. It does not refer to the base form exploited in the given context or to pattern, which are language means applied to achieve a novel stylistic effect in discourse 
instantiation: a specific case of instantial use, a stylistic realisation in discourse. See instantial stylistic use. Cf.: instantial premise (in logic) - a premise concerned with or arising from a particular case

interpretation: analysis of the discoursal features of instantial use and its stylistic message

memory search: a process where alternatives are considered until the target has been found or some piece of information has been located in memory. In instantial use, memory search refers to base forms and instantial patterns stored in long-term memory

multimodal discourse: a discourse that applies stylistic techniques from more than one semiotic mode of expression. The verbal works together with the non-verbal in construction of new meaning in metaphorical and metonymic conceptualisations which are patterns of both thought and action

pattern: a mental stylistic technique, a set of common rules of use in discourse. Each pattern is characterised by a number of formal and semantic features which are compulsory for new instantiations designed on the basis of the pattern. As typified techniques, patterns are elements of the language system which can be reproduced, the same as PUs in their base forms. Patterns are part of the mental lexicon, stored in the long-term memory of the language user. They are characterised by stability across centuries. New inimitable instantial forms are constantly generated in accordance with existing PUs and language patterns. Hence, pattern is the key to understanding the metamorphosis of a base form into instantial use

perception: part of the psychological process of cognition. Perception, implying recognition and understanding of the item, is the start of the identification process

phraseological allusion: a mental implicit verbal or visual reference to the image of a phraseological unit represented in discourse by one or more explicit image-bearing constituents, and their instantial ties, hinting at the image. Allusion shows the strength of cohesion inherent in the PU: one or more constituents are in a position to evoke associations with the whole PU. The explicit image-bearing constituents of the PU have a metonymic function; they act like a recall cue alluding to the PU, providing a web of associative links

phraseological cohesion: part of the meaning of the base form, the unity of phraseological meaning in instantial use, a semantic and stylistic relation, realised in discourse by virtue of ties with the base constituents. Phraseological cohesion is the degree to which all instantial elements belong together in a particular instantial application and cohere with the PU. Phraseological cohesion secures continuity of phraseological links in discourse, which is achieved by semantically and stylistically related items which are part of one instantiation of a PU in successive sentences or parts of text

phraseological meaning: the fully or partially figurative meaning of the base form of a PU, characterised by semantic stability and cohesion

phraseological pun: an instantial pattern where two interpretations can be assigned to the case of use: direct and figurative. The salient feature of this pattern is juxtaposition and contradistinction of the figurative meaning of the PU and the literal meaning of a constituent or constituents. As PUs are figurative, cohesive combinations of words, every figurative constituent invariably has a literal meaning at the same time. This is a technique of double exposure where two pictures appear on top of each other without coinciding. Dual perception results in dual reading of the lines

phraseological reiteration: a form of cohesion which may involve repetition of the whole PU, its parts, or isolated constituents which refer back to it. The pattern of phraseological 
reiteration creates close semantic and stylistic ties which promote textual cohesion and coherence. When involved in reiteration, the PU lends additional cohesive force across a given stretch of discourse. The closeness of the relationship between the PU and isolated phraseological constituents, including instantial constituents, determines cohesive effect. Reiteration reinforces the meaning and cohesive role of PUs in discourse

phraseological saturation: interfusion of several PUs which are instantiated in one stretch of text, blending and intermingling. The PUs and their instantial constituents pervade the text, resulting in a subtle network of phraseological ties that becomes a focal point where two or several phraseological images meet and a number of instantial changes are achieved. They become part of a phraseologically saturated segment of discourse: an instantial network in which a number of figurative strands are intertwined. Saturated stretches reveal how PUs may be realised in interaction as a polyphony of phraseological voices

phraseological unit (PU): a stable, cohesive combination of words with a fully or partially figurative meaning

phraseological zeugma: an instantial pattern relying on a phraseological constituent to function simultaneously as part of the structure of a PU and a free word combination

recall: the process of retrieving (phraseological) information from memory

recognition: awareness that an item has been previously seen, experienced, or learned

replacement: an instantial pattern involving substitution of a base constituent by one or several instantial constituents

reproducibility: the base forms of PUs and instantial patterns are reproducible elements of the language system due to their stability and cohesion. They form part of the mental lexicon of the language user, stored in long-term memory. Hence the instantial character of the discourse form is created by language means: new inimitable instantial forms of PUs are constantly generated, exploiting existing PUs and language patterns

stylistic awareness of instantial use: a conscious perception and understanding of significant changes in the base form and meaning, associative links and their networks, stylistic cohesive ties in the text, and creation of new meaning in discourse

stylistic literacy: functional ability to use stylistic skills competently for applied purposes and activities

sub-image: extension of the image of a PU in a direct way or through other sub-images. The sub-images become part of the associative metaphorical network created and sustained on the basis of the image of the PU

sustainability of a PU: the spread of its image over a length of text in sequential segments as part of the interrelated web of discourse

umbrella use: use of PUs in titles and headlines performing a sustainable cohesive text-embracing function. Umbrella use refers to and covers the whole of the text. See also comprehensive use

verification: establishment of the base form and meaning of a PU to ascertain its accuracy and determine its stability

visual discourse: a coherent visual representation of instantial use with the aim of creating a visual narrative. In visual discourse the phraseological image is evoked pictorially with or without a verbal text, and cohesion of phraseological meaning is retained

visual literacy: the ability to perceive, comprehend, and interpret visual representation of language 
visual representation: a non-verbal mode of expression to be perceived by sight. A visual expression of the text usually goes together with the verbal. Comprehension relies on the tie between the visual and the verbal 



\section{References}

A Dictionary of English Proverbs in Modern Use. 1985. Moskva: Russky yazyk.

Aitchison, J. 1978. Linguistics. London: Hodder and Stoughton.

Aitchison, J. 2003. Words in the Mind: An Introduction to the Mental Lexicon. Oxford: Blackwell.

Alexander, R. J. 1997. Aspects of Verbal Humour in English. Tübingen: Gunter Narr.

Amosova, N. N. 1961. Osnovi angl'iskoy frazeologii (Fundamentals of English Phraseology). Doctoral habilitation dissertation, Leningradskiy Universitet.

Apperson, G. L. 1969. Proverbs and Proverbial Phrases: A Historical Dictionary. Detroit IL: Gale Research.

Apperson, G. L. 1993. The Wordsworth Dictionary of Proverbs. Ware, Hertfordshire: Wordsworth Editions.

Aristotle. 1991. On Rhetoric: A Theory of Civil Discourse, translated by G. A. Kennedy. Oxford: OUP.

Arhangel'skij, V. L. 1964. O pon'atii ustoichivoy frazi i tipah fraz (On the Concept of the Stable Phrase and Types of Phrases). In Problemi frazeologii (Problems of Phraseology), A. M. Babkin (ed.), 102-125. Moskva: Nauka.

Arnheim, R. [1954] 1974. Art and Visual Perception: A Psychology of the Creative Eye. Berkeley CA: University of California Press.

Arnheim, R. [1969] 1997. Visual Thinking. Berkeley CA: University of California Press.

Arsentyeva, E. 2005. The role of extended metaphor and phraseological puns in producing a humorous effect. Internet-Zeitschrift für Kulturwissenschaften, 15 August, 2005, $<$ http://www.inst.at/trans/15Nr/04_09/arsentyeva15.htm> (30 October, 2008).

Baranov, A. \& Dobrovol'skij, D. 1999. Idioms from a cognitive perspective. Moscow State University Bulletin 19: 64-75.

Barcelona, A. 1998. The state of the art in the cognitive theory of metaphor and metonymy and its application to English studies. The European English Messenger VII(2): 45-48.

Barcelona, A. (ed.). 2000a. Metaphor and Metonymy at the Crossroads: A Cognitive Perspective. Berlin: Mouton de Gruyter.

Barcelona, A. 2000b. On the plausibility of claiming a metonymic motivation for conceptual metaphor. In Metaphor and Metonymy at the Crossroads: A Cognitive Perspective, A. Barcelona (ed.), 31-58. Berlin: Mouton de Gruyter.

Barcelona, A. 2007. The role of metonymy in meaning construction at discourse level. In Aspects of Meaning Construal, G. Radden, K.-M. Köpke, T. Berg \& P. Siemund (eds), 51-75. Amsterdam: John Benjamins.

Barta, P. 2006. Au pays des proverbes, les détournements sont rois: Contribution à létude des proverbes détournés du français, II. Paremia 15: 57-71. 
Bass, N. 2003. Phraseologismen und Modifikationen in der Deutschschweizer Anzeigenwerbung 1928-1998. In Flut von Texten: Vielfalt der Kulturen, H. Burger, A. Häcki Buhofer \& G. Gréciano (eds), 381-390. Baltmannsweiler: Schneider Verlag Hohengehren.

Baugh, A. C. \& Cable, T. [1951] 2001. A History of the English Language. London: Routledge. Beasley, R. \& Danesi, M. 2002. The Semiotics of Advertising. Berlin: Mouton de Gruyter.

Bex, T. 1988. Teaching literature across cultures: A linguistic approach. Parlance 1(2): 35-55.

Bex, T., Burke, M. \& Stockwell, P. (eds). 2000. Contextualized Stylistics. Amsterdam: Rodopi.

Boase-Beier, J. 2006. Stylistic Approaches to Translation: Translation Theories Explored. Manchester: St Jerome.

Boldireva, L. M. 1967. Stilisticheskiye osobennosti funktsionirovaniya frazeologizmov (Stylistic Features of Functioning of Phraseologisms). PhD dissertation, Moskovskiy pedagogicheskiy institut inostrannykh yazykov imeni M. Toreza.

Brewer's Dictionary of Phrase and Fable. [1959] 1968. London: Cassell \& Company.

Brumfit, C. J. \& Carter, R. A. (eds). [1986] 1991. Literature and Language Teaching. Oxford: OUP.

Bryan, J. 2001. An unfinished list of Anglo-American proverb songs. In Proverbium: Yearbook of International Proverb Scholarship, Vol. 18, W. Mieder (ed.), 16-56. Burlington VT: University of Vermont.

Bryan, J. 2002. Proverbial titles of dramas. In Proverbium: Yearbook of International Proverb Scholarship, Vol. 19, W. Mieder (ed.), 65-74. Burlington VT: University of Vermont.

Buchan, J. (ed.). 1935. A History of English Literature. London: Thomas Nelson \& Sons.

Burger, H. 1999. Phraseologie in der Presse. In Phraseme und typisierte Rede, N. Fernandez Bravo, I. Behr \& C. Rozier (eds), 77-89. Tübingen: Stauffenburg.

Burger, H. 2007. Semantic aspects of phrasemes. In Phraseology: An International Handbook of Contemporary Research, Vol. 1, H. Burger, D. Dobrovol'skij, P. Kuhn \& R. N. Norrick (eds), 90-109. Berlin: Mouton de Gruyter.

Burger, H. 2008. Das idiomatische 'Bild' und seine Modifikationen durch materielle Bilder theoretische und empirische Aspekte. In Beiträge zur Phraseologie aus textueller Sicht, C. Mellado Blanco (ed.), 89-113. Hamburg: Verlag Dr. Kovac.

Burke, M. 2003. Literature as parable. In Cognitive Poetics in Practice, J. Gavins \& G. Steen (eds), 115-128. London: Routledge.

Cairns, H. S. \& Cairns, C. E. 1976. Psycholinguistics: A Cognitive View of Language. New York NY: Holt, Rinehart and Winston.

Cambridge International Dictionary of Idioms. 1998. Cambridge: CUP.

Canale, M. 1983. From communicative competence to communicative language pedagogy. In Language and Communication, J. C. Richards \& R. Schmidt (eds), 2-27. London: Longman.

Carnes, P. 1991. The fable and the proverb: Intertexts and reception. In Proverbium: Yearbook of International Proverb Scholarship 8, W. Mieder (ed.), 55-76. Burlington VT: University of Vermont.

Carroll, L. 1928. Alice's Adventures in Wonderland. London: Macmillan.

Carter, R. (ed.). [1982] 1995a. Language and Literature: An Introductory Reader in Stylistics. London: Routledge.

Carter, R. [1982] 1995b. Introduction. In Language and Literature: An Introductory Reader in Stylistics, R. Carter (ed.), 1-17. London: Routledge. 
Carter, R. [1986] 1991. Linguistic models, language, and literariness: Study strategies in the teaching of literature to foreign students. In Literature and Language Teaching, C. J. Brumfit \& R. A. Carter (eds), 110-132. Oxford: OUP.

Carter, R. [1988] 1992. What is stylistics and why can we teach it in different ways? In Reading, Analysing and Teaching Literature, M. Short (ed.), 161-177. London: Longman.

Carter, R. 1995. Keywords in Language and Literacy. London: Routledge.

Carter, R. 1996. Look both ways before crossing: Developments in the language and literature classroom. In Language, Literature and the Learner: Creative Classroom Practice, R. Carter \& J. McRae (eds), 1-15. London: Longman.

Carter, R. 1997. Investigating English Discourse: Language, Literacy and Literature. London: Routledge.

Carter, R. A. \& Long, M. N. [1987] 1995. The Web of Words: Exploring Literature through Language. Cambridge: CUP.

Carter, R. \& Long, M. N. 1991. Teaching Literature. Harlow: Longman.

Carter, R. \& McRae, J. (eds). 1996. Language, Literature and the Learner: Creative Classroom Practice. London: Longman.

Carter, R. A. \& Nash, W. [1990] 1995. Seeing Through Language: A Guide to Styles of English Writing. Oxford: Blackwell.

Carter, R. A. \& Simpson, P. (eds). 1989. Language, Discourse and Literature: An Introductory Reader in Discourse Stylistics. London: Unwin Hyman/Routledge.

Chafe, W. 1990. Some things that narratives tell us about the mind. In Narrative Thought and Narrative Language, B. K. Britton \& A. D. Pellegrini (eds), 77-98. Hillsdale NJ: Lawrence Erlbaum Associates.

Chafe, W. [2001] 2004. The analysis of discourse flow. In The Handbook of Discourse Analysis, D. Schiffrin, D. Tannen \& H. E. Hamilton (eds), 673-687. Oxford: Blackwell.

Chambers Dictionary of Idioms. 1996. P. Hands (compiler). Edinburgh: Chambers.

Chambers Dictionary of Idioms and Catch Phrases. 1995. B. Kirkpatrick (ed.). Edinburgh: Chambers.

Chambers English Idioms. [1982] 1995. E. M. Kirkpatrick \& C. M. Schwarz (eds). Edinburgh: Chambers.

Chambers Etymological Dictionary of the English Language. 1882. A. Findlater (ed.). London: W. \& R. Chambers.

Chambers 20th Century Dictionary. [1983] 1987. E. M. Kirkpatrick (ed.). Edinburgh: Chambers.

Chaucer, G. [1951] 1955. The Canterbury Tales, translated by N. Coghill. London: Penguin Books.

Chernyshova, I. I. 1974. Tekstoobrazuyushchiye potentsii frazeologicheskikh yedinits (Textforming Potential of Phraseological Units). In Lingvistika Teksta (Text Linguistics), 159-166. Moskva: Moskovskiy pedagogicheskiy institut inostrannykh yazykov imeni M. Toreza.

Chiaro, D. [1992] 1996. The Language of Jokes: Analysing Verbal Play. London: Routledge.

Clark, U. \& Zyngier S. 2003. Towards a pedagogical stylistics. Language and Literature 12(4): 339-351.

Collins Cobuild Dictionary of Idioms. 1995. London: Harper Collins.

Collins Cobuild English Dictionary for Advanced Learners. [1987] 2001. Glasgow: Harper Collins. 
Collins Cobuild English Language Dictionary. [1987] 1988. London: Collins.

Cook, G. [1989] 1995. Discourse. Oxford: OUP.

Cook, G. [1992] 1994. The Discourse of Advertising. London: Routledge.

Cook, G. 1994. Discourse and Literature: The Interplay of Form and Mind. Oxford: OUP.

Cornoldi, C. \& Logie, R. H. 1996. Counterpoints in perception and mental imagery: Introduction. In Stretching the Imagination: Representation and Transformation in Mental Imagery, M. Marschark (ed.), 3-30. Oxford: OUP.

Coulthard, R. M. [1977] 1991. An Introduction to Discourse Analysis. London: Longman.

Cowie, A. P. 1981. The treatment of collocations and idioms in learners' dictionaries. Applied Linguistics 2(3): 223-235.

Cowie, A. P. 1992. Multiword lexical units and communicative language teaching. In Vocabulary and Applied Linguistics, P. J. L. Arnaud \& H. Béjoint (eds), 1-12. London: Macmillan.

Cowie, A. P. (ed.). [1998] 2001a. Phraseology: Theory, Analysis and Applications. Oxford: OUP.

Cowie, A. P. [1998] 2001b. Introduction. In Phraseology: Theory, Analysis and Applications, A. P. Cowie (ed.), 1-20. Oxford: OUP.

Cowie, A. P. [1998] 2001c. Phraseological dictionaries: Some East-West comparisons. In Phraseology: Theory, Analysis and Applications, A. P. Cowie (ed.), 209-228. Oxford: OUP.

Cowie, A. P., Mackin, R. \& McCaig, I. R. [1993] 1994a. General introduction. In Oxford Dictionary of English Idioms, A. P. Cowie, R. Mackin \& I. R. McCaig, x-lvii. Oxford: OUP.

Cowie, A. P., Mackin, R. \& McCaig, I. R. [1993] 1994b. Oxford Dictionary of English Idioms. Oxford: OUP.

Cresswell, J. 2000a. Introduction. In The Penguin Dictionary of Clichés, v-x. London: Penguin Books.

Cresswell, J. 2000b. The Penguin Dictionary of Clichés. London: Penguin Books.

Crystal, D. 1971. Linguistics. London: Penguin Books.

Crystal, D. [1987] 1995. The Cambridge Encyclopedia of Language. Cambridge: CUP.

Crystal, D. \& Davy, D. [1969] 1995. Investigating English Style. Harlow: Longman.

Crystal, D. \& Crystal, B. 2002. Shakespeare's Words: A Glossary and Language Companion. London: Penguin Books.

Cuddon, J. A. [1976] 1982. The Penguin Dictionary of Literary Terms and Literary Theory. London: Penguin Books.

Danchenko, N. N. 1977. Stilisticheskoye funktsionirovaniye frazeologitcheskikh edinits v poeticheskom tekste (na materiale stihotvornih proizvedeniy Dzh. G. Bairona) (Stylistic Functioning of Phraseological Units in Verse: Based on the Poetical Works of G. G. Byron). $\mathrm{PhD}$ dissertation, Moskovskiy pedagogicheskiy institut inostrannykh yazykov imeni $\mathrm{M}$. Toreza.

de Saussure, F. 1995. Cours de linguistique générale. Paris: Payot.

Dirven, R. 1993. Metonymy and metaphor: Different mental strategies of conceptualisation. Leuvense Bijdragen 82: 1-28.

Dobrovol'skij, D. 1980. Zur Dialektik des Begriffs der textbildenden Potenzen von Phraseologismen. In Zeitschrift für Phonetik, Sprachwissenschaft und Kommunikationsforschung 33: 690-700.

Dobrovol'skij, D. O. 1996. Obraznaya sostavlyayushchaya v semantike idiom (Image Constituent in Idiom Semantics). Voprosy yazykoznaniya (Issues of Linguistics) 1: 71-93.

Dobrovol'skij, D. O. 1998. Vnutrennyaya forma idiom i problema tolkovaniya (The Inner Form of Idioms and Issues of Understanding). Izvestiya AN. Seriya literatury i yazyka (Izvestia AN. Literary and Language Series) 57(1): 36-44. 
Dobrovol'skij, D. 2003. Cognitive theory of metaphor and idiom semantics. In Flut von Texten: Vielfalt der Kulturen, H. Burger, A. Häcki Buhofer \& G. Gréciano (eds), 143-153. Baltmannsweiler: Schneider Verlag Hohengehren.

Dorland's Pocket Medical Dictionary. 1995. Philadelphia PA: W.B. Saunders.

Dubinsky, E. M. 1985. Lingvostilisticheskiye osobennosti dvoinoy aktualizatsii frazeologicheskikh edinits (Linguo-stylistic Features of Dual Actualisation of Phraseological Units). PhD dissertation, Moskovskiy pedagogicheskiy institut inostrannykh yazykov imeni M. Toreza.

Džanić, M. 2007. Pragmatic properties of idiom modifications in the language of advertising. Jezikoslovlje (Linguistics) 8(1): 45-59.

Emmott, C. [1997] 1999. Narrative Comprehension: A Discourse Perspective. Oxford: OUP.

Encarta World English Dictionary. 1999. Microsoft Corporation/Bloomsbury Publishing.

Endzelīns, J. 1951. Latviešu valodas gramatika (Latvian Language Grammar). Rīga: LVI.

Enkvist, N. E. 1973. Linguistic Stylistics. The Hague: Mouton.

Eysenck, M. W. 1993. Principles of Cognitive Psychology. Hilsdale NJ: Lawrence Erlbaum Associates.

Fairley, I. R. 1973. Syntactic deviation and cohesion. Language and Style 6(3): 216-229.

Fedulenkova, T. 2003. A new approach to the clipping of communicative phraseological units. Ranam 36: 11-22.

Fernando, C. 1996. Idioms and Idiomaticity. Oxford: OUP.

Fernando, C. \& Flavell, R. 1981. On idiom: Critical views and perspectives. Exeter Linguistic Studies 5: 1-94.

Fiedler, S. 2007. English Phraseology: A Coursebook. Tübingen: Gunter Narr.

Field J. 2004. Psycholinguistics: A Resource Book for Students. London: Routledge.

Fill, A. 1992. Visions and revisions: A type of pun based on idiomatized complex words. In Language and Civilization: A Concerted Profusion of Essays and Studies in Honour of Otto Hietsch, Vol. 2, C. Blank, T. Kirschner, D. Gutch \& J. Gilbert (eds), 551-563. Frankfurt: Peter Lang.

Forceville, C. 1991. Verbo-pictorial metaphor in advertisements. Parlance 3: 7-20.

Forceville, C. 1994. Pictorial metaphor in advertisements. Metaphor and Symbolic Activity 9(1): $1-29$.

Forceville, C. 1996. Pictorial Metaphor in Advertising. London: Routledge.

Forceville, C. 2008. Metaphor in pictures and multimodal representations. In The Cambridge Handbook of Metaphor and Thought, R. W. Gibbs (ed.), 462-482. Cambridge: CUP.

Forceville, C. 2009. Non-verbal and multimodal metaphor in a cognitivist framework: Agendas for research. In Multimodal Metaphor, C. J. Forceville \& E. Urios-Aparisi (eds), 19-42. Berlin: Mouton de Gruyter.

Forceville, C. \& Urios-Aparisi, E. 2009a. Introduction. In Multimodal Metaphor, C. J. Forceville \& E. Urios-Aparisi (eds), 3-17. Berlin: Mouton de Gruyter.

Forceville, C. J. \& Urios-Aparisi, E. (eds). 2009b. Multimodal Metaphor. Berlin: Mouton de Gruyter.

Fowler, R. 1966. Essays on Style and Language. London: Routledge and Kegan Paul.

Fowler, R. (ed.). 1975. Style and Structure in Literature: Essays in the New Stylistics. Oxford: Blackwell.

Fowler, R. 1981. Literature as Social Discourse: The Practice of Linguistic Criticism. London: Batsford.

Fowles, J. [1974] 1975. The Ebony Tower. St. Albans: Panther. 
Freeman, M. 2000. Poetry and the scope of metaphor: Toward a cognitive theory of literature. In Metaphor and Metonymy at the Crossroads: A Cognitive Perspective, A. Barcelona (ed.), 253-281. Berlin: Mouton de Gruyter.

Galsworthy, J. [1928] 1976. The Silver Spoon. Moscow: Progress.

Galsworthy, J. [1928] 1978. The White Monkey. Moscow: Progress.

Garman, M. [1990] 1996. Psycholinguistics. Cambridge: CUP.

Gavins, J. \& Steen, G. (eds). 2003. Cognitive Poetics in Practice. London: Routledge.

Geeraerts, D. 2006. Introduction: A rough guide to cognitive linguistics. In Cognitive Linguistics: Basic Readings, D. Geeraerts (ed.), 1-28. Berlin: Mouton de Gruyter.

Gibbs, R. W. Jr. [1979] 1998. Process and products in making sense of tropes. In Metaphor and Thought, A. Ortony (ed.), 252-276. Cambridge: CUP.

Gibbs, R. W. Jr. 1990. The process of understanding literary metaphor. Journal of Literary Semantics XIX: 65-79.

Gibbs, R. W. Jr. 1993. Why idioms are not dead metaphors. In Idioms: Processing, Structure, and Interpretation, C. Cacciari \& P. Tabossi (eds), 57-78. Hillsdale NJ: Lawrence Erlbaum Associates.

Gibbs, R. W. [1994] 1999. The Poetics of Mind: Figurative Thought, Language and Understanding. Cambridge: CUP.

Gibbs, R. W. 1995. Idiomaticity and human cognition. In Idioms: Structural and Psychological Perspectives, M. Everaert, E. J. van der Linden, A. Schenk \& R. Schreuder (eds), 97-116. Hillsdale NJ: Lawrence Erlbaum Associates.

Gibbs, R. W. 1999a. Intentions in the Experience of Meaning. Cambridge: CUP.

Gibbs, R. W. 1999b. Researching metaphor. In Researching and Applying Metaphor, L. Cameron \& G. Low (eds), 29-47. Cambridge: CUP.

Gibbs, R. W. 2002. Psycholinguistic comments on metaphor identification. Language and Literature 11(1): 78-84.

Gibbs, R. W. 2003. Prototypes in dynamic meaning construal. In Cognitive Poetics in Practice, J. Gavins \& G. Steen (eds), 27-40. London: Routledge.

Gibbs, R. W. 2006. Embodiment and Cognitive Science. Cambridge: CUP.

Gibbs, R. W. 2007. Experimental tests of figurative meaning construction. In Aspects of Meaning Construal, G. Radden, K.-M. Köpke, T. Berg \& P. Siemund (eds), 19-32. Amsterdam: John Benjamins.

Gibbs, R. W. Jr. (ed.). 2008. The Cambridge Handbook of Metaphor and Thought. Cambridge: CUP.

Gibbs, R. W. \& Steen, G. (eds). 1999. Metaphor in Cognitive Linguistics. Amsterdam: John Benjamins.

Gläser, R. 1984. The translation aspect of phraseological units in English and German. Papers and Studies in Contrastive Linguistics 18: 123-134.

Gläser, R. 1986a. Phraseologie der englischen Sprache. Leipzig: Verlag Enzyklopädie.

Gläser, R. 1986b. A Plea for Phraseo-stylistics. In Linguistics across Historical and Geographical Boundaries, I: Linguistic Theory and Historical Linguistics, D. Kastovsky \& A. Szwedek (eds), 41-52. Berlin: Mouton de Gruyter.

Gläser, R. [1998] 2001. The stylistic potential of phraseological units in the light of genre analysis. In Phraseology: Theory, Analysis and Applications, A. P. Cowie (ed.), 125-143. Oxford: OUP.

Gläser, R. 2000. Phraseologismen als falsche Freunde. In English in the Modern World, M. Dakowska (ed.), 213-226. Frankfurt: Peter Lang. 
Glossary. 1929. In The Dramatic and Poetical Works of William Shakespeare 6, 539-582. London: Thomas Nelson \& Sons.

Goddard, A. [1998] 2003. The Language of Advertising. London: Routledge.

Golsverzijs, Dž. 1962. Sudraba karote (The Silver Spoon), translated by A. Bauga. Rīga: Latvijas Valsts izdevniecība.

Goodman, S. 1996. Visual English. In Redesigning English: New Texts, New Identities, S. Goodman \& D. Graddol (eds), 38-72. London: Routledge.

Goodman, S. 1997. One and the pun: How newspapers keep the monarchy in its place. Language and Literature 6(3): 197-209.

Goodman, S. 2006. Word and image. In The Art of English: Literary Creativity, S. Goodman \& K. O'Haloran (eds), 244-277. Basingstoke: Palgrave Macmillan.

Goodman, S. \& Graddol, D. 1996. Introduction. In Redesigning English: New Texts, New Identities, S. Goodman \& D. Graddol (eds), 1-2. London: Routledge.

Grabe, W. 2002. Applied linguistics: An emerging discipline for the twenty-first century. In The Oxford Handbook of Applied Linguistics, R. B. Kaplan (ed.), 3-12. Oxford: OUP.

Granger, S. \& Meunier, F. [2008] 2009. Introduction. In Phraseology in Foreign Language Learning and Teaching, F. Meunier \& S. Granger (eds), 15-18. Amsterdam: John Benjamins.

Granger, S. \& Meunier, F. (eds). [2008] 2009. Phraseology: An Interdisciplinary Perspective. Amsterdam: John Benjamins.

Gréciano, G. 1988. Affektbedingter Idiomgebrauch. Stilistisch-rhetorische Diskursanalyse, Forum angewandte Linguistik 14: 49-61.

Hackenberg, K. 1964. Englische idiomatische Redewendungen. Leipzig: VEB Verlag Enzyklopädie.

Halliday, M. A. K. 1985. An Introduction to Functional Grammar. London: Edward Arnold.

Halliday, M. A. K. \& Hasan, R. 1976. Cohesion in English. London: Longman.

Handley, G. [1988] 1993. Brodie's Notes on John Fowles's 'The French Lieutenant's Woman'. London: The Macmillan Press.

Harley, T. A. 1995. The Psychology of Language. Hillsdale NJ: Lawrence Erlbaum Associates.

Harrington, M. 2002. Cognitive perspectives on second language acquisition. In The Oxford Handbook of Applied Linguistics, R. Kaplan (ed.), 124-140. Oxford: OUP.

Harris, Z. 1952. Discourse analysis. Language 28(1): 1-30.

Hasan, R. 1984. Coherence and cohesive harmony. In Understanding Reading Comprehension, J. Flood (ed.), 181-219. Newark DE: International Reading Association.

Hasan, R. 1989. Linguistics, Language, and Verbal Art. Oxford: OUP.

Häusermann, J. 1977. Phraseologie: Hauptprobleme der deutschen Phraseologie auf der Basis sowjetischer Forschungsergebnisse. Tübingen: Max Niemeyer.

Hazlitt, W. C. [1869] 1882. English Proverbs and Proverbial Phrases. London: Smith \& Elder.

Hirst, G. 1987. Semantic Interpretation and the Resolution of Ambiguity. Cambridge: CUP.

Howarth, P. 1998. Phraseology and second language proficiency. Applied Linguistics 19(1): 24-45.

Hudson, D. 1958. Lewis Carroll. London: Longmans, Green \& Co.

Ilyish, B. 1972. Kommentariy (Comments). In Romeo and Juliet, W. Shakespeare, 93-126. Moscow: Higher School Publishing House.

Jakobson, R. 1960. Closing statement: Linguistics and poetics. In Style in Language, T. A. Sebeok (ed.), 350-377. Cambridge MA: The MIT Press.

Jamal, M. 2006. What is a Proverb? Theoretical Remarks. $<$ http://www.lingua-jip.de/pdf/What\% 20is\%20a\%20Proverb\%20\%28Translation\%29.pdf> (21 December, 2009). 
James, C. \& Garrett, P. (eds). [1991] 1995a. Language Awareness in the Classroom. London: Longman.

James, C. \& Garrett, P. [1991] 1995b. The scope of language awareness. In Language Awareness in the Classroom, C. James \& P. Garrett (eds), 3-20. London: Longman.

Jaworski, A. 1998. Talk and silence in the interrogation. Language and Literature 7(2): 99-122. Johnson, M. 1987. The Body in the Mind: The Bodily Basis of Meaning, Imagination and Reason. Chicago IL: The University of Chicago Press.

Jones, L. B. \& Jones, L. K. 1985. Discourse functions of five English sentence types. Word 6(1): $1-21$.

Kaplan, R. B. (ed.). 2002. The Oxford Handbook of Applied Linguistics. Oxford: OUP.

Katz, A. N. 1998. Figurative language and figurative thought: A review. In Figurative Language and Thought, A. N. Katz, C. Cacciari, R. W. Gibbs \& M. Turner (eds), 3-43. Oxford: OUP.

Kess, J. F. 1992. Psycholinguistics. Psychology, Linguistics and the Study of Natural Language. Amsterdam: John Benjamins.

Kirkpatrick, B. 1996a. Dictionary of Clichés. London: Bloomsbury.

Kirkpatrick, B. 1996b. Introduction. In Dictionary of Clichés, B. Kirkpatrick (ed.), v-xiv. London: Bloomsbury.

Kochan, N. 2005. The Washing Machine. Mason OH: Thomson South-Western.

Kövecses, Z. 2002. Metaphor. Oxford: OUP.

Kövecses, Z. 2005. Metaphor in Culture: Universality and Variation. Cambridge: CUP.

Kövecses, Z. 2006. Language, Mind, and Culture: A Practical Introduction. Oxford: OUP.

Kress, G. \& van Leeuwen, T. 1996. Reading Images: The Grammar of Visual Design. London: Routledge.

Kuiper, K. 2009. Formulaic Genres. Basingstoke: Palgrave Macmillan.

Kunin, A. V. 1964. Osnovniye ponyatiya angliyskoy frazeologii kak lingvisticheskoy discipliny i sozdaniye anglo-russkogo frazeologicheskogo slovarya (Basic Concepts of English Phraseology as a Linguistic Discipline and Creation of an English-Russian Dictionary of Phraseology). Doctoral habilitation dissertation, Moskovskiy pedagogicheskiy institut inostrannykh yazykov imeni M. Toreza.

Kunin, A. V. 1965. O frazeologicheskoy variantnosti i strukturnoy sinonimii v sovremennom angliyskom yazyke (On phraseological variants and structural synonyms in Modern English). In Problemy frazeologii i zadachi yeyo izucheniya $v$ visshey i sredney shkole (Problems of Phraseology and Its Study in Universities and Secondary Schools), 32-33. Cherepovets: Cherepovetskij gosudarstvenij pedagogicheskij institut.

Kunin, A. V. 1967a. Anglo-russkiy frazeologicheskiy slovar' (English-Russian Dictionary of Phraseology). Moskva: Sovetskaya entsiklopediya.

Kunin, A. V. 1967b. Predisloviye (Preface). In Anglo-russkiy frazeologicheskiy slovar' (EnglishRussian Dictionary of Phraseology), A. V. Kunin (ed.), 3-14. Moskva: Sovetskaya entsiklopediya.

Kunin, A. V. 1969. Osnovniye ponyatiya frazeologicheskoy stilitistiki (Basic concepts of phraseological stylistics). In Problemy lingvisticheskoy stilistiki (Problems of Linguistic Stylistics), 71-75. Moskva: Moskovskiy pedagogicheskiy institut inostrannykh yazykov imeni M. Toreza.

Kunin, A. V. 1970. Angliyskaya frazeologiya: teoreticheskiy kurss (English Phraselogy: A Theoretical Course). Moskva: Vysshaya shkola.

Kunin, A. V. 1973. Vklinivanie kak lingvisticheskoe yavlenie (Insertion as a linguistic phenomenon). Inostrannie yazyki v shkole (Foreign Languages at School) 2: 13-22. 
Kunin, A. V. 1974. Dvoynaya aktualizatsiya kak ponyatie frazeologicheskoy stilistiki (Dual actualisation as a concept of phraseological stylistics). Inostrannie yazyki v shkole (Foreign Languages at School) 6: 13-17.

Kunin, A. V. 1975. Inversiya kak yavlenie frazeologicheskoy stilistiki (Inversion as a phenomenon of phraseological stylistics). In Problemy leksiki i frazeologii (Problems of Lexis and Phraseology), 87-95. Leningrad.

Kunin, A. V. 1976. O stilisticheskom kontekste vo frazeologicheskom rakurse (A phraseological perspective of stylistic context). In Lingvistika teksta (Text Linguistics) 103, 155-162. Moskva: Moskovskiy pedagogicheskiy institut inostrannykh yazykov imeni M. Toreza.

Kunin, A. V. 1977. Zamena komponentov frazeologizmov kak stilisticheskiy priem (Replacement of phraseological components as a stylistic device). Inostrannie yazyki v shkole (Foreign Languages at School) 2: 3-12.

Kunin, A. V. 1980. Frazeologicheskaya derivatsiya v angliyskom yazyke (Phraseological derivation in English). In Voprosy slovoobrazovaniya i frazoobrazovaniya $v$ germanskikh yazykah (Issues of Word and Phrase Formation in Germanic Languages), 155-162. Moskva: Moskovskiy pedagogicheskiy institut inostrannykh yazykov imeni M. Toreza.

Kunin, A. V. 1983. Osnovniye ponyatiya stilistiki v oblasti frazeologii (Fundamental notions of stylistics in the realm of phraseology). In Struktura lingvo-stilistiki i ee osnovnye kategorii (Structure and Basic Categories of Linguo-stylistics), 44-49. Perm: Permskiy gosudarstvennyy universitet imeni A. M. Gor'kogo.

Kunin, A. V. 1986. Kurs frazeologii sovremennogo angliyskogo yazyka (A Course in Modern English Phraseology). Moskva: Vysshaya shkola.

Kurzon, D. 1997. Discourse of Silence. Amsterdam: John Benjamins.

Kuzmin, S. S. 1977. Translating Russian Idioms. Moscow: Higher School.

Lakoff, G. 1986. A figure of thought. Metaphor and Symbolic Activity 1: 215-225.

Lakoff, G. [1987] 1990. Women, Fire, and Dangerous Things: What Categories Reveal about the Mind. Chicago IL: The University of Chicago Press.

Lakoff, G. [1993] 1998. The contemporary theory of metaphor. In Metaphor and Thought, A. Ortony (ed.), 202-251. Cambridge: CUP.

Lakoff, G. \& Johnson, M. [1980] 2003. Metaphors We Live By. Chicago IL: The University of Chicago Press.

Lakoff, G. \& Johnson, M. 1999. Philosophy in the Flesh: The Embodied Mind and Its Challenge to Western Thought. New York NY: Basic Books.

Lakoff, G. \& Turner, M. 1989. More Than Cool Reason: A Field Guide to Poetic Metaphor. Chicago IL: The University of Chicago Press.

Language and Literature 13(1). 2004.

Language and Literature 16(2). 2007.

Lawrence, D. H. 1920. The Lost Girl. Harmondsworth: Penguin Books.

Lawrence, D. H. 1933. The Plumed Serpent. Hamburg: The Albatross.

Lawrence, D. H. 1978. Rawdon's Roof. In Love Among the Haystacks and Other Stories, 69-80. New York NY: Penguin Books.

Lawrence, D. H. 1984. Mr Noon. Cambridge: CUP.

Leech, G. N. 1966. English in Advertising: A Linguistic Study of Advertising in Great Britain. London: Longman.

Leech, G. N. [1969] 1993. A Linguistic Guide to English Poetry. London: Longman.

Leech, G. 1969. Towards a Semantic Description of English. London: Longman.

Leech, G. N. \& Short, M. H. [1981] 1994. Style in Fiction. London: Longman. 
Levitskaya, T. R. \& Fiterman, A. M. 1976. Problemy perevoda (Problems in Translation). Moskva: Mezhdunarodnye otnosheniya.

Litovkina, A. T. 2000. A Proverb a Day Keeps Boredom Away. Pécs-Szekzárd: IPF-Könyvek.

Litovkina, A. T. \& Mieder, W. 2006. Old Proverbs Never Die, They Just Diversify: A Collection of Anti-Proverbs. Burlington VT: University of Vermont.

Littlemore, J. 2001. Metaphoric competence: A possible language learning strength of students with a holistic cognitive style? TESOL Quarterly 35(3): 459-491.

Littlemore, J. 2009. Applying Cognitive Linguistics to Second Language Learning and Teaching. Basingstoke: Palgrave Macmillan.

Longman Dictionary of Contemporary English. 1978. Bath: Longman.

Longman Dictionary of English Idioms. 1979. Bath: Longman.

Lundmark, C. 2003. Puns and Blending: The Case of Print Advertisements. KU Leuven, ICLC8, $<$ http://wwwling.arts.kuleuven.ac.be/iclc/Papers/Lundmark.pdf> (18 November, 2009).

Lundmark, C. 2005. Metaphor and Creativity in British Magazine Advertising. PhD dissertation, Luleå University of Technology.

Lundmark, C. 2006. The creative use of idioms in advertising. Nordic Journal of English Studies 5(1): 71-98.

Lyons, J. 1981. Language, Meaning and Context. Bungay, Suffolk: Fontana Paperbacks.

MacDonogh, K. 1999. Reigning Cats and Dogs. New York NY: St. Martin's Press.

Machin, D. 2007. Introduction to Multimodal Analysis. London: Hodder Arnold.

Makkai, A. 1972. Idiom Structure in English. The Hague: Mouton.

Makkai, A. 1978. Idiomaticity as a language universal. Universals of Human Language 3: 401448.

Malmkjær, K. 2004. Translational stylistics: Dulcken's Translations of Hans Christian Andersen. Language and Literature 13(1): 13-24.

Martin J. R. [2001] 2004. Cohesion and texture. In The Handbook of Discourse Analysis, D. Schiffrin, D. Tannen \& H. E. Hamilton (eds), 35-53. Oxford: Blackwell.

McCallum, G. P. 1978. More Idiom Drills: For Students of English as a Second Language. New York NY: Harper \& Row.

McCarthy, M. [1991] 1996. Discourse Analysis for Language Teachers. Cambridge: CUP.

McCarthy, M. 1998. Spoken Language and Applied Linguistics. Cambridge: CUP.

McCarthy, M. \& Carter, R. [1994] 1995. Language as Discourse: Perspectives for Language Teaching. London: Longman.

McCarthy, M. \& O’ Dell, F. [1994] 1995. English Vocabulary in Use. Cambridge: CUP.

McLay, V. [1980] 1998. Idioms at Work. Ottawa: Language Teaching Publications.

McMordie, W. [1905] 1971. English Idioms and How to Use Them. Oxford: OUP.

McRae, J. 1985. Using Drama in Classroom. Oxford: Pergamon.

McRae, J. [1987] 1990. Words on Words: How to Write a Commentary on a Passage of Literary Prose. Napoli: Loffredo.

McRae, J. 1996. Representational language learning: From language awareness to text awareness. In Language, Literature and the Learner: Creative Classroom Practice, R. Carter \& J. McRae (eds), 16-40. London: Longman.

McRae, J. 1998. The Language of Poetry. London: Routledge.

McRae, J. \& Boardman, R. [1984] 1989. Reading Between the Lines: Integrated Language and Literature Activities. Teacher's Book. Cambridge: CUP. 
Melerovich, A. M. 1982. Semanticheskaya struktura frazeologicheskikh yedinic v sovremennom russkom yazyke kak lingvisticheskaya problema (Semantic Structure of Phraseological Units in Modern Russian as a Linguistic Issue). Doctoral habilitation dissertation, Leningradskiy universitet.

Mena Martínez, F. 2003. Creative modifications of phraseological units in English and Spanish. In Flut von Texten: Vielfalt der Kulturen, H. Burger, G. Gréciano \& A. Häcki-Buhofer (eds), 169-181. Baltmannsweiler: Schneidel Verlag Hohengehren.

Mena Martínez, F. 2006. Occasional phraseological synonymy. International Journal of English Studies: New Advances in Phraseological Research 6(1): 131-158.

Merriam Webster's Collegiate Dictionary for Windows 95. 1996. Dallas TX: Zane Publishing and Merriam Webster.

Merriam-Webster's Online Dictionary, 11th edn. 2009. <http://www.merriam-webster.com/ dictionary> (21 December, 2009).

Meunier, F. \& Granger, S. (eds). [2008] 2009. Phraseology in Foreign Language Learning and Teaching. Amsterdam: John Benjamins.

Mieder, W. 1982. Antisprichwörter. Wiesbaden: Verlag für deutsche Sprache.

Mieder, W. 1989. American Proverbs: A Study of Texts and Contexts. Bern: Peter Lang.

Mieder, W. (ed.) 1992. A Dictionary of American Proverbs. Oxford: OUP.

Mieder, W. 1993. Proverbs Are Never Out of Season: Popular Wisdom in the Modern Age. Oxford: OUP.

Mieder, W. 2003. Preface. In Cognition, Comprehension and Communication: A Decade of North American Proverb Studies (1990-2000), W. Mieder (ed.), 9-16. Hohengehren: SchneiderVerlag.

Mieder, W. 2004. Proverbs: A Handbook. London: Greenwood Press.

Mieder, W. 2005. A proverb is worth a thousand words: Folk wisdom in the modern mass media. In Proverbium: Yearbook of International Proverb Scholarship, W. Mieder (ed.), 167-233. Burlington VT: The University of Vermont.

Mieder, W. \& Litovkina, A. T. 1999. Twisted Wisdom: Modern Anti-proverbs. Burlington VT: The University of Vermont.

Mills, S. 1995. Feminist Stylistics. London: Routledge.

Money laundering is a global problem. St. Kitts - Nevis Financial Service Sector, 23 July 2008, <http://www.nevisblog.com/st-kitts-nevis-financial-service-sector-reviewed.html> September, 2009).

Moon, R. 1988. Time and idioms. In ZüriLEX'86 Proceedings, M. Snell-Hornby (ed.), 107-115. Tübingen: Francke.

Moon, R. 1992. Textual aspects of fixed expressions in learners' dictionaries. In Vocabulary and Applied Linguistics, P. J. L. Arnaud \& H. Béjoint (eds), 13-27. London: Macmillan.

Moon, R. 1996. Data, description, and idioms in corpus lexicography. In Euralex '96 Proceedings I-II. Papers submitted to the Seventh EURALEX International Congress on Lexicography in Göteborg, M. Gellerstam, J. Järborg, S.-G. Malmgren et al. (eds), 245-256. Göteborg: Göteborg University.

Moon, R. 1998. Fixed Expressions and Idioms in English. Oxford: Clarendon Press.

Moshiashvili, S. A. 1982. Tekstoobrazuyushchiye funktsii frazeologicheskoi konfiguratsii v sverhfrazovom yedinstve (Text-forming Functions of Phraseological Configuration in a Supra-phrasal Unit). PhD dissertation, Moskovskiy pedagogicheskiy institut inostrannykh yazykov imeni M. Toreza. 
Naciscione, A. 1973. Nekotorye okkazional'niye izmeneniya frazeologitcheskikh edinits v proizvedenyah Dzh. Chosera (Some occasional changes in phraseological units in the works of G. Chaucer. In Voprosi angliyskoy filologii (Issues of English Philology), A. Geniushas (ed.), 23-48. Riga: University of Latvia.

Naciscione, A. 1976. Okkazional'noye stilisticheskoye ispol'zovaniye frazeologitcheskikh edinits (na materiale proizvedeniy Chosera), Occasional Stylistic Changes of Phraseological Units: Based on the Complete Works of Chaucer. PhD dissertation, Moskovskiy pedagogicheskiy institut inostrannykh yazykov imeni M. Toreza.

Naciscione, A. 1982. Vosproizvodimost' priyemov okkazional'novo preobrazovaniya frazeologicheskikh yedinits $\mathrm{v}$ rechi (Reproducibility of patterns on occasional changes of phraseological units in speech. In Leksiskās un gramatiskās innovācijas (Lexical and Grammatical Innovation), L. Orlovska (ed.), 61-68. Rīga: Latvijas Valsts universitāte.

Naciscione, A. 1984. Rol' frazeologicheskikh yedinits v strukture stiha (na materiale angliyskovo yamba) (The role of phraseological units in the structure of verse: Based on English iambus). In Semanticheskaya integratsiya $v$ sintagmatike (Semantic Integration in Syntagmatics), V. I. Agamdzhanova (ed.), 106-112. Riga: University of Latvia.

Naciscione, A. 1986. Ritmoobrazuyushchie potentsii okazional'no preobrazovannyh frazeologicheskih edinits v stihotvornom tekste (na materiale angliyskovo yamba) (Rhythmforming potential of occasional changes of phraseological units in verse: Based on English iambus). In Yazykovye edinitsy i usloviya ih aktualizatsii (Language Units and Conditions for Their Actualisation), V. I. Agamdzhanova (ed.), 153-160. Riga: University of Latvia.

Naciscione, A. 1995. Ways of expressing the diminutive in English and Latvian phraseology. In Contrastive and Applied Linguistics 4(598), A. Veisbergs (ed.), 21-28. Riga: University of Latvia.

Naciscione, A. 1996. The diminutive in Lewis Carroll's poem The Little Man that Had a Little Gun: A study in practical stylistics. In Contrastive and Applied Linguistics 603, A. Veisbergs (ed.), 30-35. Riga: University of Latvia.

Naciscione, A. 1997a. Translation aspects of phraseological reiteration in discourse. In Contrastive and Applied Linguistics 607, A. Veisbergs (ed.), 31-35. Riga: University of Latvia.

Naciscione, A. 1997b. Translation of phraseological units in discourse. In Proceedings of the First Riga Symposium on Pragmatic Aspects of Translation, A. Veisbergs, I. Zauberga, \& B. Pernica (eds), 108-116. Riga: University of Latvia.

Naciscione, A. 1998. Phraseological puns in discourse. In Contrastive and Applied Linguistics VII, A. Veisbergs (ed.), 70-84. Riga: University of Latvia.

Naciscione, A. 2001a. Frazeoloğisko vienību stilistiskais lietojums reklāmā (Stylistic use of phraseological units in advertisements). In Linguistica Lettica 9, 169-177. Rìga: LU Latviešu valodas institūts.

Naciscione, A. 2001b. Phraseological Units in Discourse: Towards Applied Stylistics. Riga: Latvian Academy of Culture.

Naciscione, A. 2001c. Phraseological units in literary discourse: Implications for teaching and learning. In CAUCE, Revista de Filología y su Didáctica. Reading Beyond Text: Processes and Skills, 24, J. McRae (ed.), 53-67. Sevilla: Universidad de Sevilla.

Naciscione, A. 2002. Cohesion in phraseology. In Proceedings of the Tenth EURALEX International Congress, Vol. 2, A. Braasch \& C. Povlsen (eds), 533-539. Copenhagen: Center for Sprogteknologi.

Naciscione, A. 2003a. Phraseological metaphor: Dead or alive? In European Society for the Study of English, ESSE 6 - Strasbourg 2002, 2 - linguistics. Ranam 36: 23-30. 
Naciscione, A. 2003b. Translation of terminology: Why kill the metaphor? In Proceedings of the Third Riga Symposium on Pragmatic Aspects of Translation, A. Veisbergs (ed.), 102-115. Riga: University of Latvia \& Aarhus School of Business.

Naciscione, A. 2004. The pattern of instantial stylistic use of phraseological units as a mental technique. In Espace euro-méditerranéen: une idiomaticité partagée, Actes du colloque international, Tome 1: Rencontres Linguistiques Méditerranéennes \& Europhras, S. Mejri (ed.), 177-189. Tunis: Université de Tunis.

Naciscione, A. 2006a. Figurative language in translation: A cognitive approach to metaphorical terms. In Pragmatic Aspects of Translation, Proceedings of the Fourth Riga International Symposium, A. Veisbergs (ed.), 102-118. Riga: University of Latvia.

Naciscione, A. 2006b. Sustainability of phraseological image in discourse. International Journal of English Studies: New Advances in Phraseological Research 6(1): 43-56.

Nash, W. [1986] 1991. The possibilities of paraphrase in the teaching of literary idiom. In Literature and Language Teaching, C. J. Brumfit \& R. A. Carter (eds), 70-88. Oxford: OUP.

Nash, W. 1987. The Language of Humour: Style and Technique in Comic Discourse. London: Longman.

Nesfield, J. C. 1924. The Study and Composition of English. London: Macmillan \& Co.

New Webster's Dictionary. 1988. New Delhi: Allied Publishers.

Nikulina, E. A. 2005. Terminologizmy kak rezul'tat vzaimodeystviya i vzaimovliyaniya terminologii i frazeologii sovremennogo angliyskogo yazyka (Terminologisms as a Result of Interaction and Mutual Influence between Terminology and Phraseology in Modern English). Doctoral habilitation dissertation, Moskovskiy Pedagogicheskiy gosudarstvenniy universitet.

Norrick, N. R. 1986. Stock similes. Journal of Literary Semantics 15(1): 39-52.

Nowottny, W. 1962. The Language Poets Use. London: The Athlone Press.

Omazić, M. 2005. The pragmatic aspects of creative language use in advertising. In Pragmatics Today, C. Piotr (ed.), 277-285. Bern: Peter Lang.

Oncins Martínez, J. L. 2000. La funcion del 'malapropismo' en la obra de Shakespeare y Cervantes y problemas que plantea su traduccion. Cincinnati Romance Review 19: 128-137.

Oncins Martínez, J. L. 2005. Notas sobre la manipulacion creativa de fraseologismos en las comedias de Shakespeare y su traduccion al espanol. In Insights into Translation, A. L. Soto Vazquez (ed.), 27-48. Coruna: Universidade da Coruna.

Orr, L. 1986. Intertextuality and the cultural text in recent semiotics. College English 48(8): 811-823.

Orwell, G. 1946. Politics and the English Language. <http://www.panarchy.org/orwell/ language.1946.html> (18 April, 2000).

Oxford English Dictionary. 2009. Second edn on CD ROM, v. 4.0. Oxford: OUP.

Oxford Idioms: Dictionary for Learners of English. [2001] 2003. Oxford: OUP.

Paivio, A. \& Walsh, M. [1979] 1998. Psychological processes in metaphor comprehension and memory. In Metaphor and Thought, A. Ortony (ed.), 307-328. Cambridge: CUP.

Pankhurst, A. 1997. Interpreting unknown worlds: Functions of metonymic conceptualisation in William Golding's The Sea Trilogy. Language and Literature 6(2): 121-131.

Panther, K.-U. 2005. The role of conceptual metonymy in meaning construction. In Cognitive Linguistics: Internal Dynamics and Interdisciplinary Interaction, F. R. de Mendoza Ibáñez \& S. Peña Cervel (eds), 353-386. Berlin: Mouton de Gruyter.

Paprotté, W. \& Dirven, R. (eds). 1985. The Ubiquity of Metaphor: Metaphor in Language and Thought. Amsterdam: John Benjamins. 
Parsons, G. 1991. Cohesion and Coherence: Scientific Texts. Nottingham: University of Nottingham.

Pazos Bretaña, J.-M. \& Pamies Bertrán, A. [2008] 2009. Combined statistical and grammatical criteria for the retrieval of phraseological units in an electronic corpus. In Phraseology: An Interdisciplinary Perspective, S. Granger \& F. Meunier (eds). Amsterdam: John Benjamins.

Petrie, H. G. \& Oshlag R. S. [1993] 1998. Metaphor and learning. In Metaphor and Thought, A. Ortony (ed.), 579-609. Cambridge: CUP.

Pickering, D. 1997. Dictionary of Proverbs. London: Cassell.

Ponterotto, D. 2000. The cohesive role of cognitive metaphor in discourse and conversation. In Metaphor and Metonymy at the Crossroads: A Cognitive Perspective, A. Barcelona (ed.), 283-298. Berlin: Mouton de Gruyter.

Pope, R. 2005. Creativity: Theory, History, Practice. London: Routledge.

Popova, Y. 2003. The fool sees with his nose: Metaphoric mappings in the sense of smell in Patrick Süskind's perfume. Language and Literature 12(2): 135-151.

Pragglejaz Group. 2007. MIP: A method for indentifying metaphorically used words in discourse. In Metaphor and Symbol 22(1): 1-39.

Radden, G., Köpcke K.-M., Berg, T. \& Siemund, P. 2007. The construction of meaning in language. In Aspects of Meaning Construction, G. Radden, K.-M. Köpcke, T. Berg \& Peter Siemund (eds), 1-15. Amsterdam: John Benjamins.

Reber, A. S. [1985] 1995. The Penguin Dictionary of Psychology. London: Penguin Books.

Redfern, W. 1984. Puns. Oxford: Basil Blackwell.

Richards, I. A. 1936. The Philosophy of Rhetoric. London: OUP.

Ricoeur, P. [1975] 1994. The Rule of Metaphor: Multi-disciplinary Studies of the Creation of Meaning in Language. London: Routledge.

Riffaterre, M. 1959. Criteria for style analysis. Word 15: 154-174.

Ryzhkina, E. V. 2003. Frazeolocheskaya okkazional'nost' v angliskom yazyke: Kognitivno-kommunikativnye aspekti (Occasional Use of Phraseological Units in English: Cognitive and Communicative Aspects). PhD dissertation. Moskovskiy ordena Druzhby narodov gosudarstvenniy lingvisticheskiy universitet.

Rozenbergs, J. 1983. Latviešu valodas praktiskā stilistika, II Morfostilistika (Practical Stylistics of the Latvian Language, Part 2, Morphological Stylistics). Rìga: Zvaigzne.

Rūķe-Draviņa, V. 1959. Diminutive in Lettischen. Lund: Bokhandel.

Sabban, A. 1998a. Fühlen Sie sich nur nicht angesprochen! Inszenierte Negativität in der Werbung. In Phraseologismen in Text und Kontext, J. Wirrer (ed.), 73-95. Bielefeld: Aisthesis.

Sabban, A. 1998b. Okkasionelle Variationen sprachlicher Schematismen: eine Analyse französischer un deutcher Presse - und Werbetexte. Tübingen: Gunter Narr.

Sabban, A. 1999. Okkasionelle Variationen von Phrasemen in Spannungsfeld zwischen Zeichenbeschaffenheit und Kontextbezogenheit. Nouveaux Cahiers d'Allemand 99(3): 17: 541-554.

Sabban, A. 2004. Zur Rolle der Phraseme für die Konstitution und Funktion des Textes: Ein Beitrag zum Konzept der textbildenden Potenzen. In Wortverbindungen - mehr oder weniger fest, K. Steyer (ed.), 239-261. Berlin: Walter de Gruyter.

Sabban, A. 2006. Zur textbildenden Rolle von Phrasemen - mit einer Analyse von Musik-Moderationen und Kulturnachrichten im Hörfunk In Wörter-Verbindungen, Festschrift für Jarmo Korhonen, U. Breuer \& I. Hyvärinen (eds), 275-290. Frankfurt: Peter Lang. 
Sabban, A. 2007. Textbildende potenzen von phrasemen. In Phraseologie: Ein internationales Handbuch der zeitgenössischen Forschung, H. Burger, D. Dobrovol'skij, P. Kühn \& N. R. Norrick (eds), 237-253. Berlin: Walter de Gruyter.

Sabban, A. [2008] 2009. Critical observations on the culture-boundness of phraseology. In Phraseology: An Interdisciplinary Perspective, S. Granger \& F. Meunier (eds). Amsterdam: John Benjamins.

Satcor Report on International Conference 'Stop Money Laundering' 2002, <http://www. antimoneylaundering.ukf.net/stopimages/stopsmall.jpg> (19 September 2009).

Schiffrin, D., Tannen, D. \& Hamilton, H. I. (eds). [2001] 2004. The Handbook of Discourse Analysis. Oxford: Blackwell.

Semino, E. 2008. Metaphor in Discourse. Cambridge: CUP.

Semino, E. \& Culpeper, J. (eds). 2002. Cognitive Stylistics: Language and Cognition in Text Analysis. Amsterdam: John Benjamins.

Shadrin, N. L. 1969. Perevod kontekstual'no preobrazovannykh frazeologicheskikh yedinic kak semantiko-stilisticheskaya problema (Translation of Contextually Changed Phraseological Units as a Semantic and Stylistic Problem). PhD dissertation, Leningradskiy Universitet.

Shadrin, N. L. 1991. Frazeologizm kak obyekt sopostavitelnoy stilistiki (teoria i metod perevoda) (Phraseologism as an Issue of Contrastive Stylistics: Theory and Methodology of Translation). Doctoral habilitation dissertation, Summary, Leningradskiy Universitet.

Shakespeare, W. 1929. Romeo and Juliet. In The Dramatic Works of William Shakespeare 5, 1-88. London: Thomas Nelson \& Sons.

ShakespearePlaysPlus. 1996. Oxford WordSmith Tools 5.0. Oxford: OUP. <http://www.lexically. net/wordsmith/> (10 November, 2008).

Shaw, G. B. [1934] 1954. Preface to the Black Girl in Search of God. In The Black Girl in Search of God and Some Lesser Tales, 1-19. London: Constable and Company.

Short, M. (ed.). [1988] 1992. Reading, Analysing and Teaching Literature. London: Longman.

Short, M. 1995. Understanding conversational undercurrents in The Ebony Tower by John Fowles. In Twentieth-Century Fiction: From Text to Context, P. Verdonk \& J. J. Weber (eds), 45-62. London: Routledge.

Short, M. 1996. Stylistics 'upside down': Using stylistic analysis in the teaching of language and literature. In Language, Literature and the Learner: Creative Classroom Practice, R. Carter \& J. McRae (eds), 41-64. London: Longman.

Short, M. \& Candlin, C. [1988] 1992. Teaching study skills for English literature. In Reading, Analysing and Teaching Literature, M. Short (ed.), 178-203. London: Longman.

Short, M. \& Verdonk, P. (eds). 1998. Exploring the Language of Drama: From Text to Context. London: Routledge.

Simpson, P. 1997. Language through Literature: An Introduction. London: Routledge.

Simpson, P. 2004. Stylistics: A Resource Book for Students. London: Routledge.

Skandera, P. 2001. Cross-cultural ambiguity. Ranam 34: 29-42.

Skeat, W. W. 1906. Notes on The Prologue to the Canterbury Tales. In The Prologue to the Canterbury Tales, School edn, W. W. Skeat (ed.), 46-89. Oxford: Clarendon Press.

Skeat, W. W. 1910. Early English Proverbs Chiefly of the Thirteenth and Fourteenth Centuries with Illustrative Quotations. Oxford: OUP.

Skeat, W. W. 1919. Glossorial index. In The Complete Works of Geoffrey Chaucer, W. W. Skeat (ed.), 1-149. Oxford: Clarendon Press. 
Spear, H. [1988] 1992. York Notes on 'The French Lieutenant's Woman' by John Fowles, Longman Literature Guides. Beirut: Longman, York Press.

Spiegel, A. 1976. Fiction and the Camera Eye: Visual Consciousness in the Film and the Modern Novel. Charlottesville VA: University Press of Virginia.

Spilka, M. 1958. The Love Ethic of D. H. Lawrence. London: Dennis Dobson.

Steen, G. 1992. Literary and nonliterary aspect of metaphor. Poetics Today 13: 687-704.

Steen, G. 1994. Understanding Metaphor in Literature. London: Longman.

Steen, G. 1999. Analyzing metaphor in literature: With examples from William Wordsworth's 'I Wandered Lonely as a Cloud'. Poetics Today 20(3): 499-522.

Steen, G. 2002a. Identifying metaphor in language: A cognitive approach. Style 36(3): 386407.

Steen, G. 2002b. Towards a procedure for metaphor identification. Language and Literature 11(1): 17-33.

Steen, G. J. 2005. Metonymy goes cognitive-linguistic. Style 39(1): 1-11.

Steen, G. J. 2006. Metaphor: Stylistic approaches. In The Encyclopedia of Language and Linguistics, 8, 2nd edn, K. Brown (ed.), 51-58. Oxford: Elsevier.

Steen, J. G. [2007] 2009. Finding Metaphor in Grammar and Usage: A Methodological Analysis of Theory and Research. Amsterdam: John Benjamins.

Stockwell, P. 2002. Cognitive Poetics: An Introduction. London: Routledge.

Strässler, J. 1982. Idioms in English: A Pragmatic Analysis. Tübingen: Gunter Narr.

Straume, L. 1989. Stylistic use of occasionally changed phraseological units in English Children's Nonsense Literature. In Paradigmatical and Syntagmatic Investigations in Germanic Languages, E. Geniušienè (ed.), 96-97. Vilnius: University of Vilnius.

Svensson, M. H. 2008. A very complex criterion of fixedness: Non-compositionality. In Phraseology: An Interdisciplinary Perspective, S. Granger \& F. Meunier (eds), 81-93. Amsterdam: John Benjamins.

Sviridova, L. F. 1968. Obogashcheniye angliyskoy frazeologii shekspirizmami (Enrichment of English Phraseology by Shakespearisms). PhD dissertation, Moskovskiy pedagogicheskiy institut inostrannykh yazykov imeni M. Toreza.

Sweetser, E. 1990. From Etymology to Pragmatics: The Mind-as-Body Metaphor in Semantic Structure and Semantic Change. Cambridge: CUP.

Szerszunowicz, J. 2008. Decoding phraseological units as a socio-linguistic problem: On the example of onomastic idioms. National and Language Modern Aspects of Socio-linguistic Development, Third International Conference of KTU Panevėžys Institute Centre of Languages, 9-10 October 2008, <www.ppf.ktu.lt/25Szerszunowicz.doc> (25 September, 2009).

Šekspïrs, V. 1964. Hamlets, translated by K. Egle. In Viljams Šekspirs Kopoti raksti (The Complete Works of William Shakespeare), IV sēj., 235-392. Rīga: Liesma.

Šekspīrs, V. 1965. Makbets, translated by F. Adamovičs. In Viljams Šekspirrs Kopoti raksti (The Complete Works of William Shakespeare), V sēj., 5-114. Rīga: Liesma.

Tabossi, P. \& Johnson-Laird, P. N. 1980. Linguistic context and the priming of semantic information. Quarterly Journal of Experimental Psychology 32(4): 595-603.

Tannen, D. 1989. Talking Voices, Repetition, Dialogue and Imagery in Conversational Discourse. Cambridge: CUP.

Tarlinskaya, M.G. 1975. Struktura i evolyutsiya angliyskogo stiha (Structure and Evolution of English Verse). PhD dissertation, Moskovskiy pedagogicheskiy institut inostrannykh yazykov imeni M. Toreza. 
Taylor, A. [1931] 1985. The Proverb and An Index to 'The Proverb'. Bern: Peter Lang. Taylor, J. [1989] 1995. Linguistic Categorization: Prototypes in Linguistic Theory. Oxford: OUP. The American Heritage New Dictionary of Cultural Literacy, 3rd edn. 2009. <http://dictionary. reference.com/browse/> (15 August, 2009).

The Basic Works of Aristotle. 1941. R. McKeon (ed.). New York NY: Random House.

The Complete Works of Geoffrey Chaucer. 1919. W. W. Skeat (ed.). Oxford: Clarendon Press. The Concise Oxford Dictionary of Proverbs. [1982] 1992. J. Simpson (compiler). Oxford: OUP. The Oxford English Dictionary in XII Volumes. [1933] 1961. J. A. H. Murray, H. Bradley, W. A. Craigie \& C. T. Onions (eds). Oxford: Clarendon Press.

The Penguin Dictionary of English Idioms. [1986] 1994. D. M. Gulland \& D. Hinds-Howell (compilers). London: Penguin Books.

Thurber, J. [1928] 1973. The Beast in Me and Other Animals. San Diego CA: A Harvest/HBJ Book.

Thurber, J. [1939] 1983. Fables for Our Time and Famous Poems Illustrated. New York NY: Harper Colophon Books.

Toolan, M. 1997. What is critical discourse analysis and why are people saying such terrible things about it? Language and Literature 6(2): 83-103.

Trim, R. 2007. Metaphor Networks: The Comparative Evolution of Figurative Language. Basingstoke: Palgrave Macmillan.

Twain, M. 1961. The Complete Humorous Sketches and Tales of Mark Twain. New York NY: Hanover House.

Ullmann, S. 1957. Style in the French Novel. Oxford: Basil Blackwell.

van Peer, W. 1986. Stylistics and Psychology: Investigations of Foregrounding. London: Croom Helm.

van Peer, W. 2000. Hidden meanings. In Contextualized Stylistics, T. Bex, M. Burke \& P. Stockwell (eds), 39-47. Amsterdam: Rodopi.

Veisbergs, A. 1996. Idiom transformation, idiom translation and idiom dictionaries. In Symposium on Lexicography, VII: Proceedings of the Seventh Symposium on Lexicography, May 5-6, 1994 at the University of Copenhagen, A. Zettersten (ed.), 241-246. Tübingen: Max Niemeyer.

Veisbergs, A. 1997a. English and Latvian Word-Formation: Contrastive Analysis. Riga: University of Latvia.

Veisbergs, A. 1997b. The contextual use of idioms, wordplay, and translation. In Essays on Punning and Translation, D. Delabastita (ed.), 155-176. Manchester: St. Jerome Publishing.

Veisbergs, A. 1999. Idioms in Latvian. Riga: University of Latvia.

Veisbergs, A. 2006. East wind, west wind in translation: What the English tsunami has brought to Latvian. In Pragmatic Aspects of Translation, Proceedings of the Fourth Riga International Symposium, A. Veisbergs (ed.), 148-168. Riga: University of Latvia.

Verdonk, P. 1993. Twentieth-Century Poetry: From Text to Context. London: Routledge.

Verdonk, P. 1995. Words, words, words: A pragmatic and socio-cognitive view of lexical repetition. In Twentieth-Century Fiction: From Text to Context, P. Verdonk \& J. J. Weber (eds), 7-31. London: Routledge.

Verdonk, P. 2002. Stylistics. Oxford: OUP.

Verdonk, P. \& Weber, J. J. (eds). 1995. Twentieth-Century Fiction: From Text to Context. London: Routledge.

Verstraten, L. 1992. Fixed phrases in monolingual learners' dictionaries. In Vocabulary and Applied Linguistics, P. J. L. Arnaud \& H. Béjoint (eds), 28-40. London: Macmillan. 
Vinogradov, V. V. 1947. Ob osnovnih tipah frazeologtcheskih edinits v ruskom jazyke (The main types of phraseological units in the Russian language). In Akademik A. A. Shahmatov, 339-364. Moskva/Leningrad: Akademiya Nauk.

Vlahov, S. \& Florin, S. 1980. Neperevodimoye v perevode (The Untranslatable in Translation). Moskva: Mezhdunarodnyie otnosheniya.

Wales, K. [1989] 1995. A Dictionary of Stylistics. London: Longman.

Walter, H. \& Mokienko, V. 2005. Antiposlovitsi ruskovo naroda (Anti-proverbs of the Russian People). Sanktpeterburg: Neva.

Watcyn-Jones, P. 1990. Test Your English Idioms. London: Penguin Books.

Webster's New Universal Unabridged Dictionary. [1983] 1989. New York NY: Dorset \& Baber.

Werth, P. 1977. Linguistics of double vision. Journal of Literary Semantics 6(1): 3-28.

Werth, P. 1994. Extended metaphor - A text-world account. Language and Literature 3(2): 79-103.

West, D. 2005. Language, thought and reality: A comparison of Ferdinard de Saussure's Course in General Linguistics with C. K. Ogden and I. A. Richards' The Meaning of Meaning. Changing English 12(2): 327-336.

Widdowson, H. G. [1975] 1991. Stylistics and the Teaching of Literature. Harlow, Essex: Longman.

Widdowson, H. G. 1992. Practical Stylistics. Oxford: OUP.

Wierzbicka, A. 1997. Understanding Cultures through Their Key Words. Oxford: OUP.

Whiting, B. J. 1948. A colt's tooth. In Medieval Studies, U. T. Holmes \& A. J. Denomy (eds), 321-331. Cambridge MA: Harvard University Press.

Whiting, B. J. 1968. Proverbs, Sentences and Proverbial Phrases from English Writings Mainly Before 1500. Cambridge MA: Harvard University Press.

Winter, E. O. 1977. A clause-relational approach to English texts: A study of some predictive lexical items in written discourse. Instructional Science 6(1): 1-92.

Wykeham, R. 1936. 1000 idiomatische englische Redensarten. Berlin: Langenscheidtsche Verlagsbuchhandlung.

Zhantlesova, L. P. 1978. Tekstoobrazuyushchaya rol' frazeologicheskikh yedinits v sverhfrazovom yedinstve (Text-forming role of phraseological units in the supra-phrasal context). In Sbornik nauchnykh trudov Moskovskogo pedagogicheskogo instituta inostrannykh yazykov imeni M. Toreza (Collection of Research Work of Moscow M. Thorez Pedagogical Institute of Foreign Languages) 134, 228-244. Moskva: Moskovskiy pedagogicheskiy institut inostrannykh yazykov imeni M. Toreza.

Zyngier, S. 1994. Introducing literary awareness. Language Awareness 3(2): 95-108.

Zyngier, S. 1999. The unheard voices: A reader model for students. Language Awareness 9(1): 31-37.

Zyngier, S. 2000. Past, present and future in the teaching of language and literature. In Contrastive and Applied Linguistics IX, A. Veisbergs (ed.), 77-90. Riga: University of Latvia. 


\section{Appendixes}

\section{Appendix I}

For research and teaching purposes, highlighting instantial use helps to observe and focus on the relevant items (see Ch. 1 and Ch. 2.4). Compare the plain and highlighted texts of the following example (D. H. Lawrence, $\mathrm{Mr}$ Noon, Ch. 3):

Before Emmie arrived home, at a quarter to ten, he (Alf Bostock) had been in the back yard listening for her. He had heard her voice speaking to Mr Noon, though he had not caught what she said. But he had smelled a rat. And he was a very keen rat-catcher these days.

Therefore he did nothing that could betray his suspicions, and he set off to work a few minutes earlier than he need in order that he might turn back and do a bit of spying. When he passed a more-than-doubtful figure of Mr Noon in the field the smell of the rat was very hot in his nostrils. Like the wicked, he exulted, and said Ha-Ha!

I Before Emmie arrived home, at a quarter to ten, he (Alf Bostock) had been in the back yard listening for her. He had heard her voice speaking to Mr Noon, though he had not caught what she said. But he had smelled a rat. And he was a very keen rat-catcher these days.

Therefore he did nothing that could betray his suspicions, and he set off to work a few minutes earlier than he need in order that he might turn back and do a bit of spying. When he passed a more-than-doubtful figure of Mr Noon in the field the smell of the rat \& was very hot in his nostrils. Like the wicked, he exulted, and said Ha-Ha!

Before Emmie arrived home, at a quarter to ten, he (Alf Bostock) had been in the back yard listening for her. He had heard her voice speaking to Mr Noon, though he had not caught what she said. But he had smelled a rat. And he was a very keen ratcatch er these days.

Therefore he did nothing that could betray his suspicions, and he set off to work a few minutes earlier than he need in order that he might turn back and do a bit of spying. When he passed a more-than-doubtful figure of Mr Noon in the field the smell of the rat was very hot in his nostrils. Like the wicked, he exulted, and said $\mathrm{Ha}-\mathrm{Ha}$ ! 


\section{Appendix II}

Illustrations of the PU seo culfre is buton gellan in the OE and MiE periods (see Ch. 3.2):

c1000 Aelfric, Homilies II 144 [23-5]: We rædad on bocum be dære culfran gecynde, pæt heo is ... buton geallan.

c1000 Aelfric, Homilies II 46[3]: Seo culfre is buton geallan.

a1200 Ancrene 151.27: Habbe culvre cunde, that is with ute galle.

c1200 Orm I 41.1258-9: Forr cullfre iss milde, and meoc, and swet, And all withthutenn galle.

a1398 Bartholomaeus-Trevisa A8 [2.4-5]: A culuovre hathe no galle.

c1408 Lydgate, Reson 178.6796-7: They be so ful of pacience, And as a dowe they ha no galle.

1456 Hay, Law 30.17: Thai war symple as a dow but gall.

1483 Caxton, Golden Legende 31 [1-2]: The douve... hath noo galle.

1483 Caxton, Golden Legende 93 [2.14-5]: The douve ... is ... symple and wythout galle.

Whiting 1968: 142

\section{Appendix III}

A visual representation of the stylistic use of the PU a pretty kettle of fish in D. H. Lawrence, Mr Noon by the painter Ivars Poikāns (see Ch. 4.1):

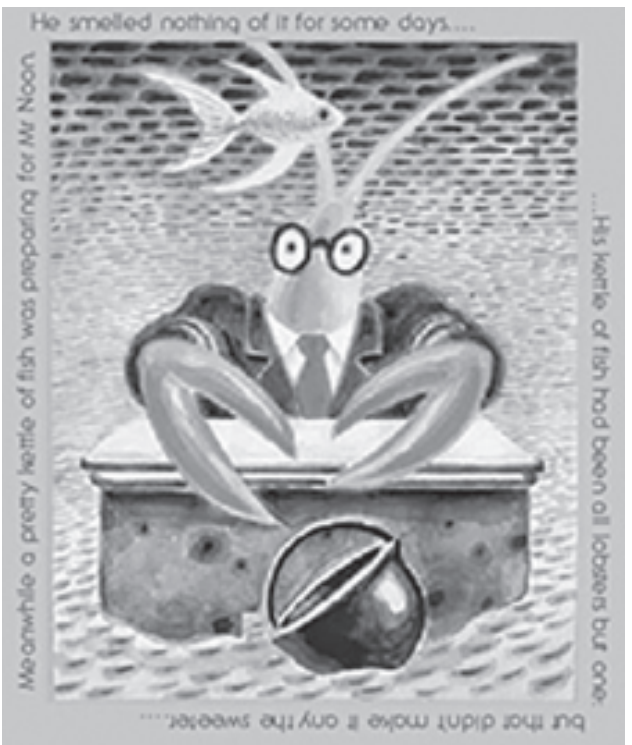




\section{Appendix IV}

Core use of the MiE PU to witen best wher ones shoo one wringeth in Chaucer's The Canterbury Tales (compare with concurrent use in Ch. 5.3):

\section{to witen best wher ones shoo one wringeth 1}

For god it woot, I have wept many a tere

Ful prively, sin I have had a wyf.

Preyse who-so wole a wedded mannes lyf,

Certein, I finde in it but cost and care,

And observances, of alle blisses bare.

And yet, god woot, my neighebores aboute,

And namely of women many a route,

Seyn that I have the moste stedefast wyf,

And eek the mekeste oon that bereth lyf,

But I wot best wher wringeth me my sho.

G. Chaucer, The Canterbury Tales, E, 1544-1553

\section{Appendix V}

The beginning of Act I, Sc. 1 of Romeo and Juliet (Shakespeare c1929:3-5) (see Ch. 5.4):

Enter Sampson and Gregory, armed with swords and bucklers.

Sam: Gregory, o'my word, we'll not carry coals.

Gre: No, for then we should be colliers.

Sam: I mean, an we be in choler, we'll draw.

Gre: Ay, while you live, draw your neck out o' the colla r.

Sam: I strike quickly, being moved.

Gre: But thou art not quickly moved to strike.

Sam: A dog of the house of Montague moves me.

Gre: To move is to stir, and to be valiant is to stand; therefore, if thou art moved, thou runnest away.

Sam: A dog of that house shall move me to stand: I will take the wall of any man or maid of Montague's.

Gre: That shows thee a weak slave; for the weakest goes to the wall.

Sam: 'Tis true; and therefore women, being the weaker vessels, are ever thrust to the wall. Therefore I will push Montague's men from the wall, and thrust his maids to the wall.

Gre: The quarrel is between our masters and us their men.

Sam: 'Tis all one, I will show myself a tyrant: when I have fought with the men, I will be cruel with the maids; and cut off their heads.

Gre: The heads of the maids?

1. MoE - to know best where the shoe pinches. 
Sam: Ay, the heads of the maids, or their maidenheads; take it in what sense thou wilt.

Gre: They must take it in sense that feel it.

Sam: Me they shall feel while I am able to stand; and 'tis known I am a pretty piece of flesh.

Gre: 'Tis well well thou art not fish; if thou hadst, thou hadst been poor John. Draw thy tool; here comes two of the house of Montagues.

Enter Abraham and Balthasar.

Sam: My naked weapon is out; quarrel, I will back thee.

Gre: How! turn thy back and run?

Sam: Fear me not.

Gre: No, marry; I fear thee!

Sam: Let us take the law of our sides; let them begin.

Gre: I will frown as I pass by, and let them take it as they list.

Sam: Nay, as they dare. I will bite my thumb at them: which is a disgrace to them if they bear it.

Abr: Do you bite your thumb at us, sir?

Sam: Ido bite my thumb, sir.

Abr: Do you bite your thumb at us, sir?

Sam: (aside to Gregory) Is the law on our side if I say ay?

Gre: (aside to Sampson) No.

Sam: No, sir. I do not bite my thumb at you, sir; but I bite my thu mb, sir.

Gre: Do you quarrel, sir?

Abr: Quarrel, sir! no, sir. 


\section{Appendix VI}

Main types of phraseological cohesion and sustainability in umbrella use (see Ch. 5.5.1):
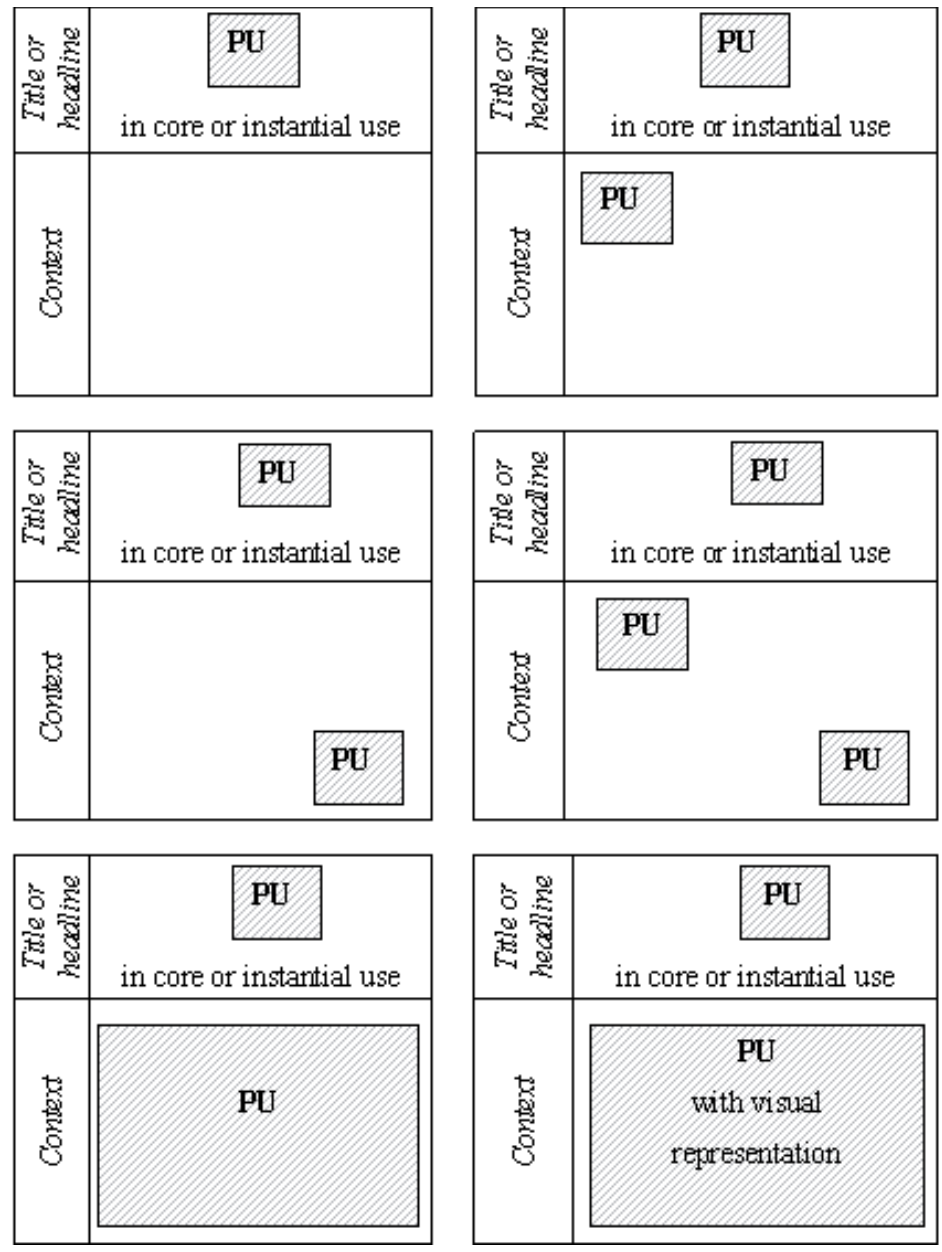


\section{Appendix VII}

Use of the PU a white elephant (instantial phraseological saturation, see Ch. 5.4) with Thurber's own pictorial interpretation:

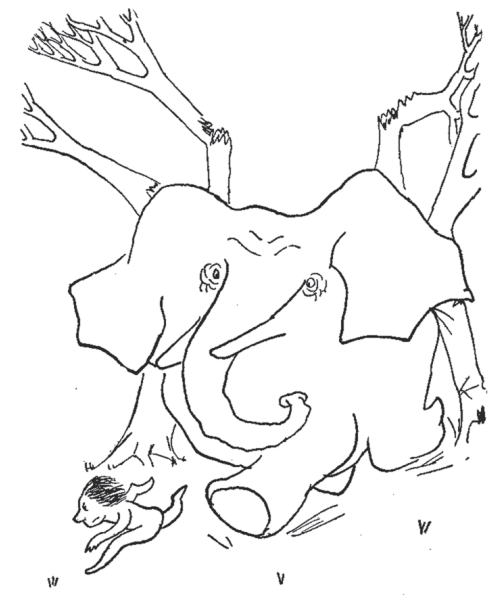

The Hunter and the Elephant

(Thurber [1939] 1983:26-27)

Once upon a time there was a hunter who spent the best years of his life looking for a pink elephant. He looked in Cathay and he looked in Africa; he looked in Zanzibar and he looked in India; but he couldn't find one. The longer he looked, the more he wanted a pink elephant. He would trample black orchids and he would walk right past purple cows, so intent was he on his quest. Then one day in a far corner of the world he came upon a pink elephant and he spent ten days digging a trap for it and he hired forty natives to help him drive the elephant into the trap. The pink elephant was finally captured and tied up and taken back to America.

When the hunter got home, he found that his farm was really no place for an elephant. It trampled his wife's dahlias and peonies, it broke his children's toys, it crushed the smaller animals around the place, and it smashed pianos and kitchen cabinets as if they were berry boxes. One day, when the hunter had had the elephant for about two years, he woke up to find that his wife had left his bed and his children had left his board and all the animals on the estate were dead except the elephant. The elephant was the same as ever except that it had faded. It wasn't pink any more. It was white.

Moral: A burden in the bush is worth two on your hands.

J. Thurber, The Hunter and the Elephant, Fables for Our Time 


\section{Appendix VIII}

Comprehensive use of the PU a wolf in sheep's clothing (see Ch. 5.5.2) with Thurber's own pictorial interpretation:

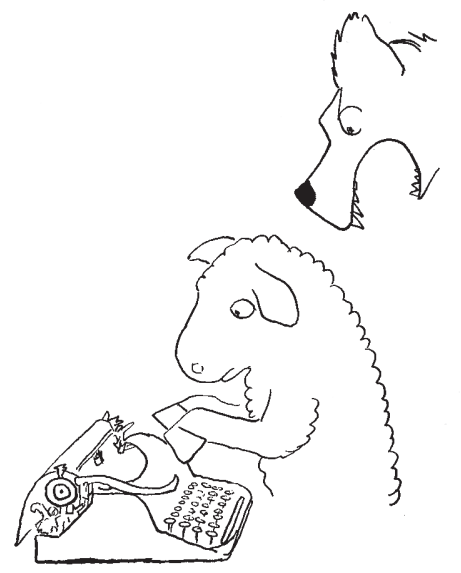

The Sheep in Wolf's Clothing

(Thurber [1939] 1983:38-39)

Not very long ago there were two sheep who put on wolf's clothing and went among the wolves as spies, to see what was going on. They arrived on a fete day, when all the wolves were singing in the taverns or dancing in the street. The first sheep said to his companion, "Wolves are just like us, for they gambol and frisk. Every day is fete day in Wolfland." He made some notes on a piece of paper (which a spy should never do) and he headed them "My Twenty-Four Hours in Wolfland," for he had decided not to be a spy any longer but to write a book on Wolfland and also some articles for the Sheep's Home Companion. The other sheep guessed what he was planning to do, so he slipped away and began to write a book called "My Ten Hours in Wolfland." The first sheep suspected what was up when he found his friend had gone, so he wired a book to his publisher called "My Five Hours in Wolfland," and it was announced for publication first. The other sheep immediately sold his manuscript to a newspaper syndicate for serialization.

Both sheep gave the same message to their fellows: wolves are just like sheep, for they gambolled and frisked, and every day was fete in Wolfland. The citizens of Sheepland were convinced by all this, so they drew in their sentinels and they let down their barriers. When the wolves descended on them one night, howling and slavering, the sheep were as easy to kill as flies on a windowpane.

Moral: Don't get it right, just get it written.

J. Thurber, The Sheep in Wolf's Clothing, Fables for Our Time 


\section{Appendix IX}

Use of the PU to sit pretty in a travel business advert in Travel Weekly, 10 February, 1999, p. 24 (see Ch. 7.5):

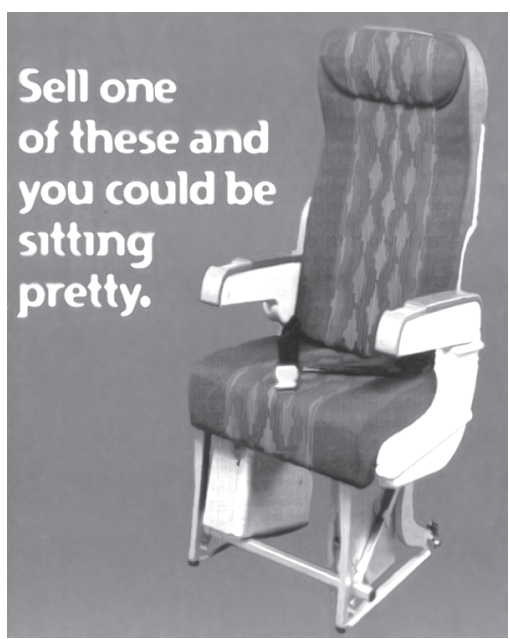

\section{Appendix X}

Use of the PU a show of hands in a travel business advert in Travel Weekly, 30 August, 1999, p. 12 (see Ch. 7.5):

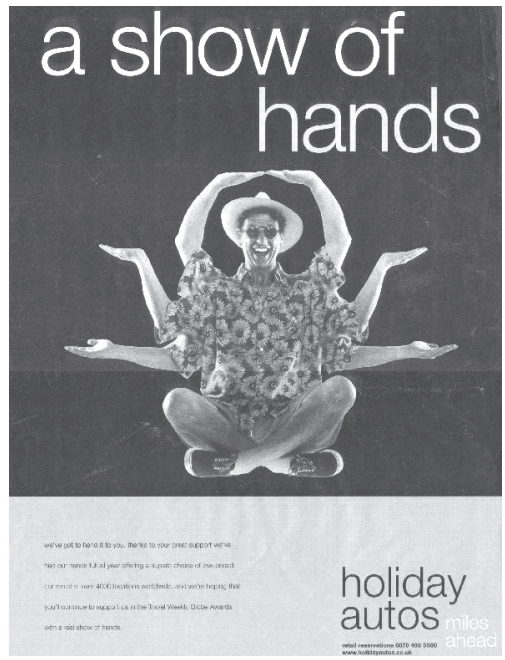




\section{Appendix XI}

Use of the PU to pull the wool over someone's eyes in a travel insurance advert in Travel Weekly, 19 July, 1999, p. 41 (see Ch. 7.5):

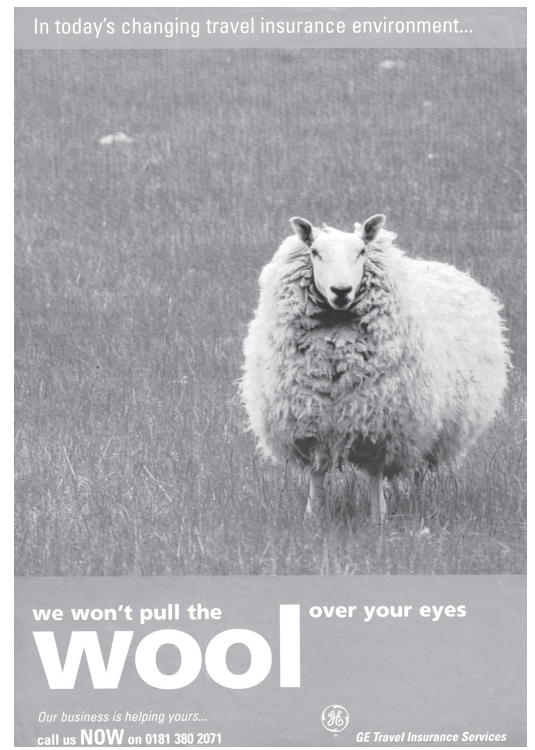

\section{Appendix XII}

Use of the PU a shaggy dog story in a travel business advert in Travel Weekly, 30 August, 1999, p. 20 (see Ch. 7.5):

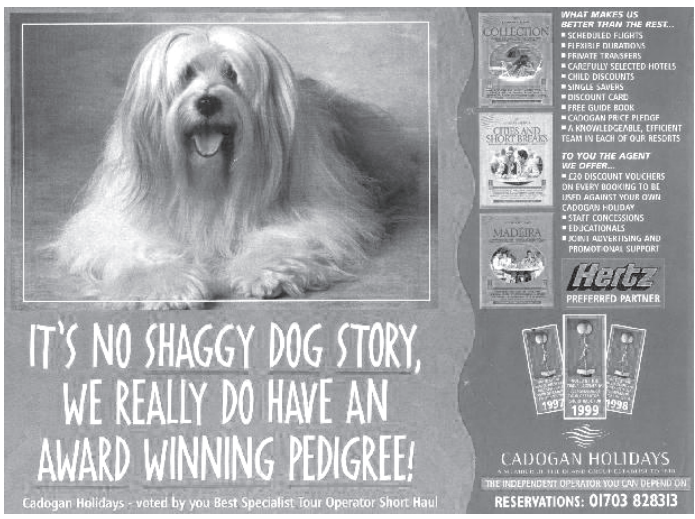




\section{Appendix XIII}

Use of the PU there is a black sheep in every flock > the black sheep of the family > a black sheep for advertising and marketing (see Ch. 7.5):

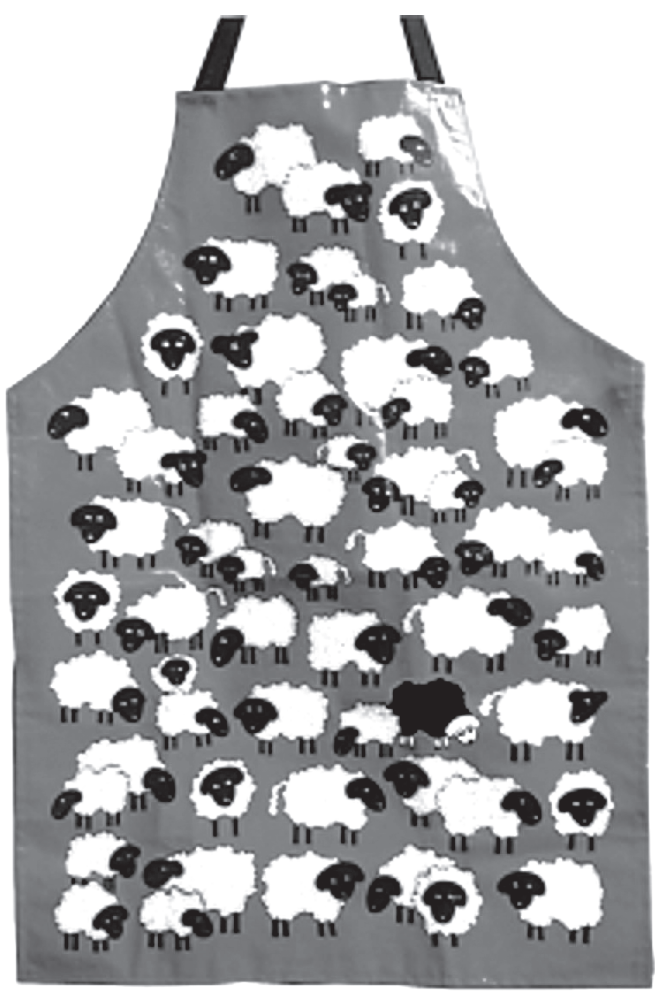




\section{Index of phraseological units}

A

Adam and Eve's togs 38

all is fair in love and war 127

apple of discord, an/the 107

art is long and life is short 105

at the end of the day 37

B

basket case, a 50

bear arms, to 117

beat about/around the bush, to 48

be born in the gutter, to 105

be born with a silver spoon in one's mouth, to

$165,234-235$

bed of roses, a/life is not a bed of roses 160

be economical with the truth, to 36

be fed up (with something or someone), to 211

be food for worms, to $118-119$

be home and dry/hosed, to 48

be in one's element, to 155,231

between Scylla and Charybdis 36

big fish/frog in a little/small pond, a 36, 48, 137

big head and little wit, a 137

bird in the hand (is worth two in the bush), a 161 , 172,174

birds in their little nests agree 92

bit by bit 136

bite one's thumb at someone, to $34,156-157$

bite the hand that feeds you, to 28

bit of all right, a 36,136

bit of blue sky, a 136

bit off, a 140

bit of skirt/stuff/fluff/crumpet/tail, a/someone's 136

bit on the side, a 136,138

bit thick, a 139

bittir swa wermod, (swa) (obs.) 83

black dog on one's shoulder, the 141

black eye, a $\quad$ 188-189

black sheep, a/the black sheep of the family/there is a black sheep in every flock $49,199-200$, 248-249, 284 blear someone's eyes, to 98-99

blood is thicker than water 95

bottom dog 126

break one's heart, to 36

break one's neck, to 152

break the camel's back, to/it is the last straw that

breaks the camel's back 49

bully for you! 38

burnt child dreads the fire, a 109

buy a pig in a poke, to 159

by hook or by crook 37

by small and small (obs.) $\quad 136$

by the skin of one's teeth 136,140

C

Caesar's wife must be above suspicion 149

call a spade a spade, to 160

can the leopard change its spots? 106

carry coals, to $95,156,244,277$

cast/fling an old shoe after someone, to 143

catch the eye, to $65,163,248$

cat has nine lives, a $37,114,238-241,244$

cat would eat fish, but would not wet its feet, the

$115-116,236$

chalk and cheese 36

change horses (in midstream), to 153

charley horse, a 135

chew the fat/rag, to 48

choose the lesser of two evils, to 111

clear as mud, (as) 36

coal-oil Johnny 135

cold comfort 36

come to pass, to $124-125$

course of true love never did run smooth, the 87

crash and burn, to 37

cross the Rubicon, to 243

cry out one's heart, to 101

culfre is buton geallan, seo (obs.) $\quad 70-71,276$

curses, like chickens, come home to roost 113

cut no ice with someone, to 126

cut one's coat according to one's cloth, to 115, 237 
D

daddy of them all, the 135

dark continent, the 36

devil's Paternoster, the (obs.) 53

die is cast, the 33,243

die with one's boots on, to 99

dirty money 180

doctors differ/when doctors differ, who is to decide? 49

don't count your chickens before they are hatched 171

don't swap the horses when crossing a/the stream 87

don't throw out your dirty old water until you get in your clean 89

do oneself a bit of no good, to 139

dove is without gall, the (obs.) 70

draw/drag a red herring across the path/track/trail,

to 49

drop in the ocean, a 136,139

drowning man will clutch at a straw, a 139,155

E

eager beaver, an 36

early to bed, early to rise makes a man healthy,

wealthy and wise 172

easy come, easy go 38

eleventh hour, the 36

every little makes a mickle $\quad 37,137$

eyeball to eyeball 163

eye for an eye (and a tooth for a tooth), an 38,159

$\mathrm{F}$

fall into the trap, to 33

familiarity breeds contempt $\quad 242-243$

family (fruit) tree, a 191

family tree, a $190-193$

feel like a million dollars, to 36

fiddle while Rome burns, to 38

fight like Kilkenny cats, to 107

fight tooth and nail/claw, to 48

finger/hand in every/the pie, (to have) a $\quad 28,49$

fit as a fiddle, (as) 124

fly in the ointment, a 152

food for thought 168,176

fools rush in where angels fear to tread 117

foot the bill, to 33

for better for worse 36

foul one's own nest, to 35

from top to toe 144
G

game of cat and mouse, a 37

gentleman who pays the rent, the 38

get one's arse in gear, to 38

get something right, to 173

get to first base, to 50

ghost of a chance, the/a 140

give someone a bit/a piece of one's mind, to 103

go easy on something, to 38

goodies and the baddies, the 139

good morning! 50, 97

go out like a candle, to 103

go out of one's senses, to 107

go red as a beetroot/beet, to 48

go to the devil, to 153

go West, to 96,106

great and small 137

grin from ear to ear, to 37

grin like a Cheshire cat, to 179

$\mathrm{H}$

handsome is as handsome does 37

hang by a thread, to $\quad 193-194$

hang in the air/be left hanging in the air, to 49

have a bee in one's bonnet, to 100,169

have a bird's-eye view, to 36

have a colt's tooth, to 239

have/get the drop on, to 138

have one's hand in the till, to 38

have something up one's sleeve, to 93

have/take a drop too much, to 140

have the last word, to 125

hear, hear! 38, 94-95

hear the last of someone, to $\quad 124$

hell hath no fury like a woman scorned 37

he should have a long spoon that sups with the devil 114

Hobson's choice 36

hold one's own, to 38

home is where the heart is 184

home sweet home 184

home truth 169

hunger is the best sauce $\quad 115,237$

\section{I}

in one's element 155,231

in one's mind's eye 240

in the soup 151

Iron Lady, the 36

it's an ill wind/it's an ill wind that blows nobody any good 49 
it's a small world 136

ivory tower, an 166-167

\section{J}

Job's news 107

Johnny Newcome/Johnny Raw $\quad 38,135,139$

Judas kiss 107

jump on/join the bandwagon, to 27,164

\section{K}

keep one's head, to 125

keep one's mouth shut, to 151

keep/show a stiff upper lip, to 164,234

keep the wolf from the door, to 87

kill two birds with one stone, to 93

king of the castle/hill 48

know best where one's shoe pinches, to 148,277

\section{L}

lead someone a merry dance/chase, to 48

leave no stone unturned, to 124

lend a hand, to 36

let the cat out of the bag, to $36,131,159,168,175$

like a child in a sweet shop/like a kid in a candy store 48

like a thousand of bricks 89

like looking for a needle in a haystack 28

like turkeys voting for Christmas 36

litmus test, a 38

little bird told me, a 136, 139-141

little by little 136

little chips light great fires 136

little green men 139

little knows the fat sow 136

little love lost between $\quad 38,139$

little mead, little need 137

little pot is soon hot 136

little Rhody 135

little/small frog in a big pond, a 136

little/small pitchers have great/long/wide ears 136

little strokes fell great oaks 136

little things please little minds 137

live and let live 36

loves daunce (obs.) 84

lyk an asse to the harpe (obs.) 83

\section{M}

make a mountain out of a molehill, to 38

meet one's Waterloo, to 36,107

mend one's ways, to 103 money laundering $\quad$ 180-181, 185-187

more than a bit/a little 136

move heaven and earth, to 36

much ado about nothing $\quad 38-39$

Mum's the word! 247

\section{$\mathrm{N}$}

neither fish nor flesh nor good red herring 37 never put off till tomorrow what you can do today 38

never the twain shall meet 37

new broom (sweeps clean), a 49, 82, 171

nine-day/nine days' wonder, a 36,149

nobody being the wiser 37

none of your business 37

no small feat 139

not for love or money 131

not to lift/raise a finger 48

not to see the wood for the trees/not to see the

forest for the trees 48

\section{$\mathrm{O}$}

odd/strange fish, an 24, 230-233

off the boil 49

old bird, an 177-178, Figure 6.3

old wives' tale, an/old wives' tales 160

olive branch, an 38

on the knees of the gods 37

on the rocks 94

out of sight, out of mind 38

out of the box 49

over the top 50

\section{P}

pay a call, to 36

people who live in glass houses shouldn't throw stones/those who live in glass houses should not throw stones 113

petty cash 136

picture is worth a/ten thousand words, a 195

pretty/fine kettle of fish, a 48, 84-86, 126, 276

promise the earth, to 153

promise the moon, to 153

proper/right Charlie/Charley, a 140

pull someone's leg, to 91

pull the wool over someone's eyes, to 247,283

purple cow, a 161

push/thrust someone to the wall, to $155-156$

put all one's eggs in one basket, to 197-199

put one's best foot forward, to $181-182$ 
Q

quote, unquote/quote, end quote 48

$\mathbf{R}$

rain cats and dogs, to 180

red herring, a 49

rift within the lute/little rift within the lute, a 136

right hand does not know what the left hand is

doing, the 33

ring in one's ears, to 103

rise to the occasion, to 103

road to hell is paved with good intentions, the 118

rock the boat, to 33

rote of all harmes, the (obs.) 71

run for one's life, to 231

run neck and neck, to 37

running battle, a 33

S

scarlet lady/whore/woman, a 48, 96

scratch my back and I'll scratch yours 37

serpent in one's bosom, a 154

serpent in the grass, a 109

serpent under flowers/grass, a (obs.) 109-110,

154,241

set the Thames on fire/set heather on fire, to 49

shaggy dog stry, a 248,283

shit and get off the pot 38

show of hands, a 247,282

shut up like a clam, to 151

silly billy, a 135

silver lining/every cloud has a silver lining, a 49

sing small, to 136

sit on the fence, to 166

sit pretty, to 247,282

skate on thin ice, to $88,160,195$, Figure 6.17 ,

Figure 6.18

skeleton in the cupboard, a 92

skin someone alive, to 49

slip on a banana skin/peel, to 27,48

small and great 137

small fry 136

small heart has small desires, a 137

small hours/wee hours, the 136

small rain lays great dust $\quad 136$

small talk 136

smell a rat, to $75,127-128,154$

snake in the grass, a 58,152

snug as a bug in a rug, (as) 37

someone's little joke 139

spill the beans, to 59 spin doctor, a 195

square peg in a round hole/round peg in a square

hole, a 119, 165

(straight) from the horse's mouth 163

stream of consciousness, the 168-169

strike/touch a cord, to 48

sugar daddy, a 135,138

swim like a fish, to 231

\section{$\mathrm{T}$}

tail-end Charlie, a 140

take a bit of doing, to 36,139

take care, to 127

take one's leave of someone, to 91

take the mickey, to 38

take the plunge, to 233

take the wall of someone, to $155-156,277$

talk the bark off a tree, to 49

talk the hind leg off a donkey/dog/horse, to 49

talk the legs off an iron pot, to 49

there's no fool like an old fool 37

there's no smoke without fire 36

thin excuse, a 136,140

thin/little/small edge of the wedge, the 136

thin on the ground 136

throw oneself on someone's mercy, to 152

throw one's weight about/around, to 48,177

tit for tat 159

too many chiefs/too many chiefs and not enough

Indians 49

top dog 126

to the world's end 239

Trojan horse, the 107

turn over a new leaf, to 104,147

two heads are better than one 38,111

$\mathrm{U}$

ugly duckling, an $\quad 135,139$

under one's/someone's roof $76,128-129,131-133$,

157

under the rose 160

up the spout 49

up to the neck 151

V

venture a small fish to catch a big one, to 137

W

Wailing Wall, the 36

walls have ears $\quad 157-158$

waste words, to 143 
watch the/a birdie 135,139

weakest goes to the wall, the $155-156,277$

wear one's heart upon one's sleeve, to 81

wear the stripes, to 36

well, I never (did)! 33

what does the moon care if the dogs bark at her?

38

what good wind brings you here? 33

what's sauce for the goose is sauce for the gander 141, 157-158

when Adam delved and Eve span who was then the gentleman? $69,117,160,235$

when pigs fly 36

when the cat's away, the mice will play 112,147

white elephant, a 161-162, 280

white feather, the $33,62,92$ white lie, a 165

Wild West, the 164

with a little/small A, B, C, etc. 136

with friends like these, who needs enemies? $\quad 38$

without rhyme or reason/neither rhyme or reason

94, 154

wolf in sheep's clothing, a 173,281

\section{$\mathrm{Y}$}

you can take a horse to the water but you cannot make him drink 33

you have made your bed and you must lie on it $53,105,126$

you have made your bed, now lie on it 105

your home is your castle 183 



\section{Subject index}

A

access 10, 66-67, 94, 99, 108, $113,119,217,221,223,251$

advertising 185, 206, 245-249 applied stylistics 10-11, 205207, 227-228, 245, 249, 251

B

base form $8-11,19,31-36$, $38-44,46-48,51-53,57-62$, 64-67, 76, 83-86, 89-90, 121, 133, 149-150, 181, 197-200, 209-211, 212-214, 220, 222$227,238-239,241-244,251$

base metaphor $80,86-87,90$, $113,132,175,199,251$

C

cleft use 102-107, 147, 150, 158, 224, 251

coda $162,167,170-174,183,251$ cognitive approach $7,11,17$, 21-22, 176, 200, 209

cognitive stylistics $15-17,21,30$, 206-207

cohesive ties $43,64,75,114$, 149-150, 158, 166, 198, 201, $207,212,219,222,232,250$ comprehensive use 162-174, 251

concurrent use 112,145-150, $160,180,189,195,214,224,251$ core use $8,35-36,38-44$,

$47-48,62,73,76,101-102,107$, 124-126, 129, 176, 209-212, $217,221,227,238-239,251$

cue $51-52,85,94-95,99$, $106-107,113-114,116,118,120$, $155,191,194,198,233,235,252$ cumulative use $134,142,146$, 252
D

dead metaphor 9, 22-23

diachronic stability $\quad 57-58,69$

diminutive in phraseology 134 , 140, 252

discoursal use 21, 29-30, 48, $89,123,133,167,185,207$, 209-210, 214-215, 219, 229, 252

discourse-based approach $\quad 15$, 17, 73, 208-209, 211-212, 215, $227,238,241$

E

extended phraseological metaphor 63, 70, 79-90, 192-193, 233, 252

F

figurative network $46,51,77$, 112, 116, 178, 207, 219, 223

I

identification $10,17,19,31$, $43-47,49-55,61,66-67,73$, $85,93,252$

insertion $73,99,103,147,150$, 181, 198, 252

instantial stylistic use $8-9,11$, $39-40,43-45,57,59-60,62$, $68-69,74,76,79,92,107,121$, $123,176,181,185,209,217$, 227-228, 237, 249, 252

\section{M}

metonymic personification 130, 164

metonymy $36,38,65,84,111$, 129-130, 132-133, 158, 164, 182,187 multimodal discourse $\quad 175,186$, 189, 200, 223, 245, 249-250, 253

multimodal metaphor $\quad 185$, 245-246

multimodal use 169-170, 180, 189,249

\section{$\mathbf{P}$}

pattern 9-10, 43, 51, 63, 65-73, 79-80, 84, 90, 101, 107-111, $113,119,128,131,133,145$, 147-150, 152-154, 194, 206, 212-215, 220-237, 253

phraseological allusion 20,46 , 70, 107-110, 112, 114, 117-119, 235-236, 253

phraseological cohesion 9, 32, 51-52, 60, 62-64, 67, 108, 112, $115,121,134,138,145,149-150$, 163, 170, 192, 253

phraseological image $7,9-10$, $52,57,63,68,73-74,76-77$, $80,83,90,93,102,109,119$, $123,128,131-134,156,158-159$, $166,175,179,181,186,188,190$, 194-195, 197, 199-201, 217, 223 , 230, 233, 246-247, 249

phraseological meaning 9-10, $17,21,32,36,38,46,49-50$, $58,62-64,74,84,87-88,90$, 107-108, 114, 121, 130, 132, 135, 137-139, 162, 175-177, 181, 214, 249, 253

phraseological pun 91-94, 100-101, 178-179, 182, 184, 253 phraseological reiteration $122-$ $123,125,133,253$

phraseological saturation 151, 153-154, 156-158, 160, 162, 214, 244, 254 


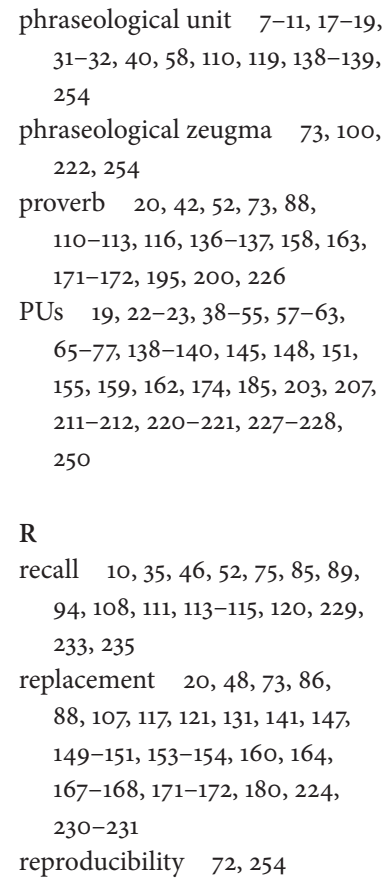

S

semantic and stylistic cohesion $7,57-58,74,77,79,90,133$, 192-193, 195, 249

stability of phraseological units 9, 57

stylistic awareness 10-11, 66, 73, 75, 119, 154, 197, 201, 207, 209, 213-214, 220, 222, 227229, 237-238, 241, 243-244, 250, 254

stylistic literacy $10,207,219$, 254

stylistic stability $\quad 57-58$

sub-image $17,80-82,88-89$,

$112,128,153,192-193,195,198$, 231, 254

sustainability $9-10,34,57$, 73-76, 90, 121, 123, 133-134, $145,163,166,170,180,193$, $214,220,222,254$
$\mathrm{T}$

translation of phraseological units 227

U

umbrella use $100,133,163,166$, $168,170,174,234,254$

V

visual allusion $\quad 181,197,199$

visual discourse $7,11,16$, 21, 176, 193, 199-200, 223, 248-249, 254

visual literacy $\quad 10,174,197$, 200-201, 223, 227, 254 visual pun $164,174,177,179$, 181-184, 188-189, 195, 197, 247 visual representation 10,68 , 110, 157-158, 169-170, 173-177, 179-185, 187-193, 195, 197-198, 200-201, 206, 223, 247-249, 255

visual sustainability $\quad 193$ 